being and becoming

a metaphysics of aesthetic experience

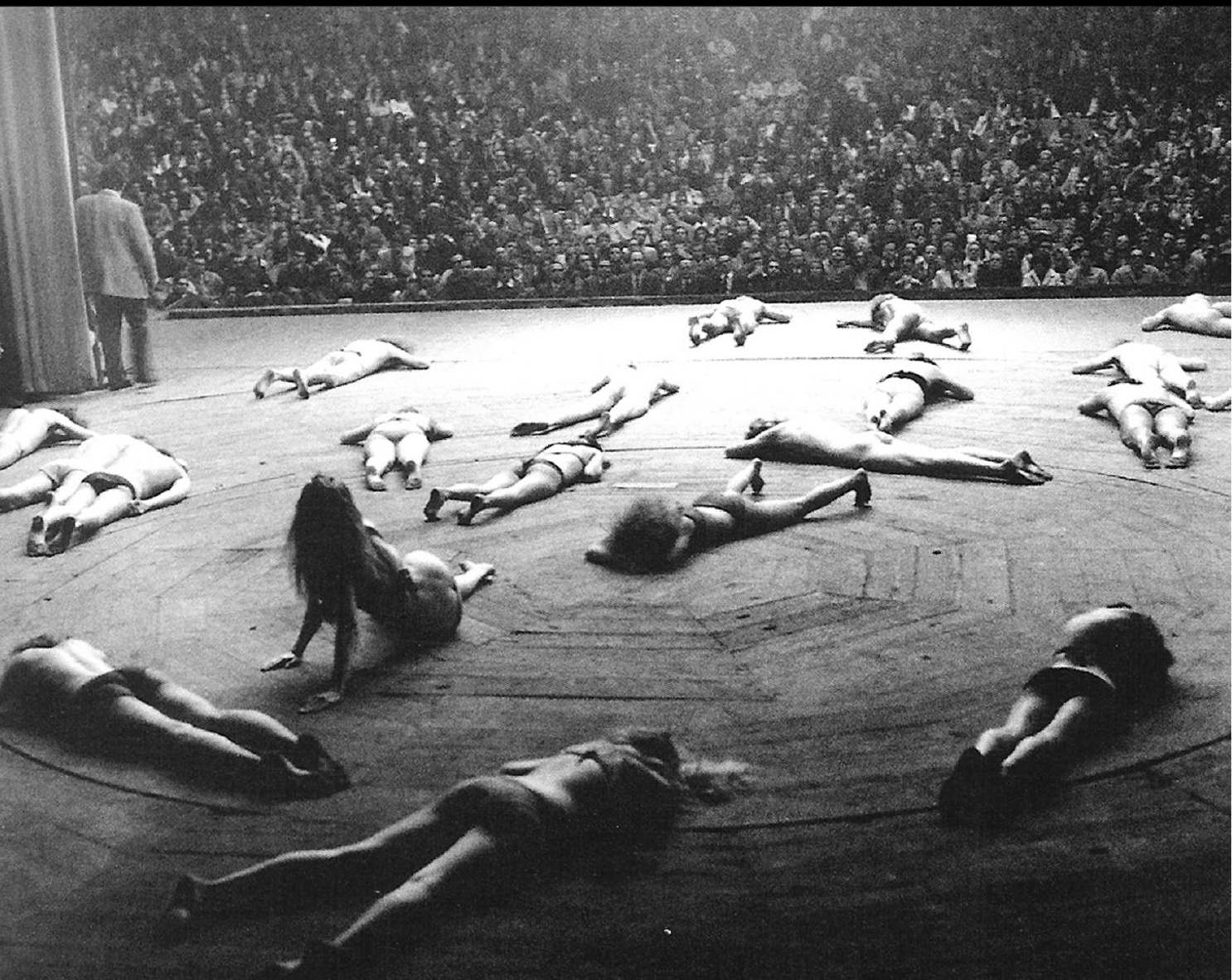





\title{
BEING AND BECOMING: A METAPHYSICS OF AESTHETIC EXPERIENCE
}

\author{
BY \\ CHRISTOPHER J. FIELD \\ Victoria University of Wellington, 2011 \\ SUPERVISOR: Dr. Peter Wood
}

\section{THESIS}

Submitted to Victoria University of Wellington in partial fulfilment of the requirements for the degree of Master of Architecture (Professional)

Wellington, New Zealand 
Thank you to the Indian family that accommodated me during that Autumn on Kashmir's Nigeen lake, where the impetus of the thesis first came.

Thank you to Ole Fischer whom introduced me to Renaissance architecture and the thought of Heindrich Wolfflin which made the thesis possible.

Thank you to my parents whom gave me a roof once finances had run out at the thesis' end. 


\section{Abstract}

In the tragedies of Greek antiquity occurred a rare phenomenological event that shaped its people, producing what the philosopher Friedrich Nietzsche argued as the highest culture and art of Occidental civilization. Distilling the tragic dramas to a metaphysic of time, the origins of a bed rock of aesthetic experience is exposed in the dual presence of what has commonly been referred to since antiquity as 'being' and 'becoming'. These two temporal phenomena are approached as qualitative experiences, which present two extreme polls of a basic spectrum of aesthetic experience. In understanding their underlying temporal origins, a direct and clear line of translation is found between these phenomenon and their aesthetic import through the mechanisms of physical, tangible architectural properties. In addressing how architecture mediates these phenomenon, two precedents are attended to which present pronounced ends of the œuvre of architectural conditions; Greek or 'classic' architecture, and that of the Brazilian slums or 'Favelas'. Through an in-depth study of the temporality of Greek architecture we are offered a raw reflection into both the nature of 'being' and the fundamental ways it finds a presence through architecture - it is a look into the built languages of our own aesthetic and architectural sensibility. The study of 'becoming' in the Favelas is of particular significance, in that it affords access to a more rare, and yet markedly important, spectrum of the built environment; in understanding its deeper aesthetic import, we inevitably approach persuasive grounds of a value that questions conventional practices of architecture. A design based project in the final section of the thesis attempts an amalgamation of architectures of both being and becoming, as a means to understand deeper relations and tensions between them through the more subtle language of visual representation. Approaching architecture through the theoretical and phenomenological lens of being and becoming, we gain a valuable insight into the less concrete aspects of the art; into what we feel within it, and consequently a deeper and more conscious understanding of why we make things as they are; and potentially, through such understanding, how they can be made better. 


\section{Contents}

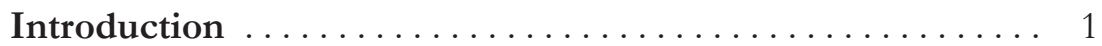

Chapter 1. Being, Becoming and Spatialised time - in theatre Section introduction ......................... 9

The Greek tragedies ........................ 14

Collapse of principium of individuation........... 17

Becoming of the Dionysiac .................. 19

Being, the present of the Dionysiac . . . . . . . . . . . . 21

Spatialised time......................... 25

Apolline being - of semblance and dream ........... 31

Chapter 2. Being - in Greek Architectures

Section introduction ............................ 39

Artistic volition ........................ 43

Draughstmanly Geometry .................. 47

The line ........................ 49

The surface $\ldots \ldots \ldots \ldots \ldots \ldots \ldots \ldots \ldots \ldots \ldots$



Closed Material Individuality . . . . . . . . . . . . . . . . 61

Symmetry and Clarity ..................... 64

Order and Clarity ......................... 69

Shape and Autonomy..................... 73

Permanence......................... 77

Reflections on temporality ................ 81

The Plane .......................... 87

Autonomy - and suppressing space ........... 89

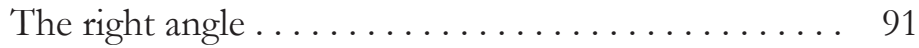

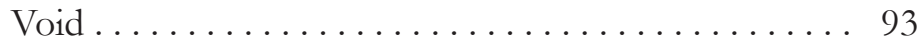

Atmospheres and Void. ....................... 96 
Clarity ....................... 107

Chapter conclusion ................... 109

Chapter 3. Becoming - in the labyrinthine slums

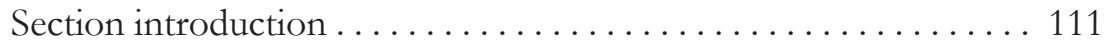

Open construction $\ldots \ldots \ldots \ldots \ldots \ldots \ldots \ldots \ldots$

The past that is $\ldots \ldots \ldots \ldots \ldots \ldots \ldots \ldots \ldots \ldots \ldots \ldots \ldots \ldots \ldots$

The labyrinthine Favela . . . . . . . . . . . . . . . . . . . . 129

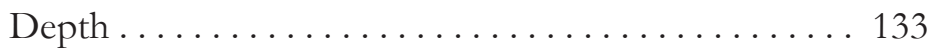

Fragmented unity . . . . . . . . . . . . . . 137

Immersive unclarity . . . . . . . . . . . . . . . 142

Tactile awareness .................. 148

Conclusion: Being, the fundamental character of art . . . . . 153

Chapter 4. Applied Design

Introduction ..................... 157

Catalogue of project.............. 167

List of Figures . . . . . . . . . . . . . . . . . 195

Select Bibliography ........................ $199-210$ 
"Tomorrow and tomorrow and tomorrow, Creeps in this petty pace from day to day To the last syllable of recorded time, And all our yesterdays have lighted fools The way to dusty death. Out, out, brief candle! Life's but a walking shadow, a poor player That struts and frets his hour upon the stage And then is heard no more: it is a tale Told by an idiot, full of sound and fury, Signifying nothing."

Act 5 , scene 5 of William Shakespeare's Macbeth. 
"Man spends his life struggling against time; and, acid like; time corrodes man, tears him from himself and keeps him from realizing his humanity. Everything becomes absurd." (Sartre, 1939/1963, p. 231).

Time, Jean Paul Sartre suggests, is the central theme - the metaphysic - within William Faulkner's novel 'The Sound and the Fury'. Where for Faulkner, in taking his title from Shakespeare's infamous soliloquy, "[Life] is a tale told by an idiot, full of sound and fury; signifying nothing", the 'idiot' represents humankind unable to grasp and accept its condition in time, making everything it does 'absurd'. We do not necessarily need to share Faulkner's pessimism to acknowledge the basic truth of his sentiment; 'time' erodes any construct of self, as it does the body, the physical and the cultural world; all is in a continuum of 'Becoming' - in both the sense of a creative coming-to-be, and declinative coming-not-to-be, but never, it seems, a static 'Being'. A truth that the individual, and humankind as a whole, indelibly struggles to acknowledge let alone find solace against.

Lawrence Kimmel (2007) in his 'notes on a poetics of time' suggests that arguably all human culture, its history and its practice, could be understood in some way or another as a reaction against this condition: either in an endeavour to find permanents, stability, immutability and stasis; a feeling of being within the perpetual becoming of the sensible world. Or conversely, in one to confront it, to apprehend its flow and decay without anxious restraint, to draw on it as a jolting, tragic impetus at the root of life's vitality - and poetic expression: "time held me green and dying", but yet "I sing in my chains like the sea" (Dylan Thomas).

This perhaps is never found more acutely than in art. In extending this reasoning, Kimmel, in sympathy with Yale's professor of philosophy Karsten Harries, suggests that art often finds its original impetus from these positions towards time. Regarding architecture Harries 
(1997) ventures as far to say that an entire history could be read with respects to its mediation of our relationships to 'time'. A history and capacity relatively unacknowledged within an art form which we too readily presuppose its raison d'etre to be in that of the 'domestication of space' (ibid).

This text is concerned with what has commonly been termed since the Greek writings of Perminides and Heraclitus as 'being' and 'becoming' respectively, and these two fundamentally temporal ${ }^{1}$ phenomena's basic mediation through architecture.

Most simply put, and in terms that hold true throughout the thesis, as 'Timaeus remarks in Plato's dialogues, 'becoming' pertains to "that which is always becoming and never is" and 'being' to "that which always is and has no becoming" (Timaeus, 27d-28a., trans. Jowett, B. 2009 , p. 16). As these phenomenon will be approached, 'being' and 'becoming' are not conceptual ideas, manifesting in architecture in the likes of literary statements appealing to the intellect alone, but present two antithetical, though interrelated, temporal-aesthetic experiences. Where becoming relates to an increased awareness of the perpetual flow of change and being to an expressed pause in that change. Both opposing qualitative experiences, or psychological states, are linked in difference to common temporality by a sense of the immediate present's continuity; its lack of fragmentation and division into a time sensed as linear and separated across the space of a past, historical present, and future. This quality of a continuous present forms an overaching state of 'Being' proper to both, presenting a concrete solace from a sense of time that, as Satre remarks, 'tears' one from themself. It is the presupposition

1 'Temporal' and 'temporality' as terms pertain to phenomenon related to time. The term 'time', for reasons that will become clear, is generally avoided except in particular application as it has a very set meaning here, while having ambiguous and ill defined connotations in general use. 
of the thesis that being and becoming constitute two extreme polls of a basic spectrum of aesthetics ${ }^{2}$ in architecture - in life generally -, in attempting to understand these polls we inevitably approach a metaphysic of what one feels at a deeper existential level in the built environment.

To explain these temporal notions further, however, in the short and inadequate space of this introduction, will only cause frustration and misleading over simplification. The proceeding chapter is dedicated to establishing a provisional theoretical and phenomenological understanding of not only being and becoming, but inevitably 'time' as we commonly conceive it; providing weight and meaning to terms that likely seem esoteric and cold. This takes the study away from architecture initially, as attention is turned to theatre. As an art form that has historically mediated these elements in a more pronounced manner, theatre provides greater accessibility for an initial raw and open reflection. This is undertaken primarily through the intriguing precedent of the Greek attic tragedies of 6th century B.C.E., and an interpretation of this event through the thought of 19th century philosopher 'poet' and classical philologist Friedrich Nietzsche; grounding the study in his conception of two fundamental aesthetic 'drives' that he hypothesised manifested in the dramas; that of the 'Apollonian' and 'Dionysian' - in short, modes of being and becoming respectively. The second major philosophical import at this stage is that of the highly influential ${ }^{3}$ late

2 Aesthetics is not used throughout the text in the restrictive lay sense of the term as something purely visual in nature, and to add, superficial, but in relation to a more holistic and total -background- mode of sensory and emotive feel-

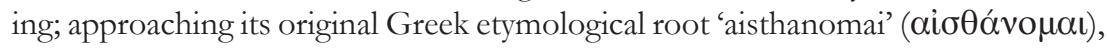
meaning, "to perceive, apprehend by the senses, to see, hear, feel." (Poteat \& Nickell, 1993, p. 24).

3 The interest in Bergson in the early 20th century was such that a public lecture he gave in 1913 in New York is reported to have caused the first traffic jam in the city's history (Bergson, 1983, p. xvii). While there is currently renewed interest in Bergson, as R. Lorand (1999) remarks, his philosophy was almost entirely 
19th, earlier 20th century French philosopher Henry-Louse Bergson the first philosopher, as S. Alexander remarks, to "take time seriously" (1966, p. 44). Bergson affords a deeper insight into the temporal workings of these experiential phenomena. ${ }^{4}$ Of the many theorists whom's thoughts are addressed, these two unconventional philosophers, -or the hybrid of them- provide the philosophical backbone of the text.

The remainder of the thesis is concerned with understanding being and becoming more concretely through their manifestation/mediation in architecture; through this, in tandem, coming to an understanding of architecture itself. The study's interest and scope is limited to establishing the fundamentals alone of these two temporal phenomena and their mediation, and therefore primarily only two precedents of the built environment are attended to that present pronounced ends of the aesthetic spectrum of being and becoming: Greek or 'classic' architectures, and that of the hill side slums of Reo de Janeiro, or 'Favelas' - respectively.

In Chapter two the basic properties of Greek form are systematically considered with respects to their temporal-spatial ${ }^{5}$ significance. Aspects as fundamental as the common line, geometric shape, and the right angle will be attended to. In the first instance the study will address and document how each formal element aspires to a quality of 'being', as a negation and cessation of change - of the becoming of 'things'. In the

forgotten after the 1940's; much like Nietzsche, Bergson's 'poetic style' and 'inclination towards intuitive knowledge' grated with the hard line of 'analytical trends' to follow in academia (p. 400).

4 Phenomena which are otherwise in Nietzsche's conception not specifically concerned with temporality - Nietzsche positions them as basic dichotomies that present opposing sides of two entire would views; order and chaos, intellect and intuition, beauty and the sublime etc. (1872/1999).

5 As to be expected, and as will become clear, a deeper consideration of matters of temporality can not be undertaken separated from space; their phenomenological relation gradually unfolds and exposes itself over the thesis. 
second, it will also be tentatively positioned that -indivisibly- this also equates to a negating of one's common linear sense of temporality as it re-presents/engenders the impression of a continuous present moment. Through Greek architecture's refinement to these ends, we are afforded a raw look into the underlying metaphysical significance of some of the most basic constituents of the main-line of contemporary and historical built environments.

Having a clear understanding of the built properties of 'being', in Chapter three we are in a position to grasp through point of difference the qualitative architectural significance of the Favelas. Beyond romantic clichés of the deeper virtues of the unprivileged at one end of common sentiment, and an environment that is incongruent with basic standards of dignity and social signification at the other, in the very built tapestry of these slums is accessible - once looked at through the necessary lens - a unique and vital corner of architecture's aesthetic capacity - and potential. The study of the Favelas' temporal-spatial qualities is approached incrementally, drawing out and reflecting on its most basic built conditions through the context of their efficacy to impart a qualitative sense of 'becoming'. As with the study of classic architecture, inseparably through this we also consider the mechanisms through which it engenders a sense of 'Being', as a continuity of the present moment. Final remarks on this common phenomenological link of 'Being' between both built conditions, serves to draw reflections to a close.

While the first chapter is philosophical in nature, and chapters two and three present a more pragmatically grounded theory as they deal with the tangibles of architecture, the fourth shifts to a design based application of theory. The design project - more subjective in nature - attends to a separate question, or an ideal, that arises naturally out of the study: how can being and becoming both co-presense in architecture? While linked at a deeper phenomenological level, without excep- 
tion these two elements are found to be mutually exclusive in terms of the physical architectural properties that mediate them; i.e, the physical treatment of an architecture that aspires to the quality of 'being' has fundamentally antithetical mechanism to that of an architecture that has its aesthetic grounded in 'becoming'. And yet, despite this conflict, there is much to suggest that their union is of immense existential and psychological value, if not necessity in order that they reach their total aesthetic import. Nietzsche, in his own terms, asserts both these points, as he found the Dionysian and Apollonian artistic drives to be in sharp opposition - where historically if one prevailed in a civilisation it was to the detriment of the other (Nietzsche, 1872/1999, p. 20). The tragedies, however, presented an exception to this, as for the first and last time in history they met in a rare union in which they became reciprocally beneficial to one another; compelling him to distinguish it as the highest art form of Occidental civilization (ibid, p. 104).

While such lofty ends might be outside the capacity of architecture, drawing these two temporal-aesthetics together in an applied project affords a complimentary understanding as to how these little understood phenomena can be mediated through the art's own subtle, reserved, yet omnipresent way as the background stage for the everyday poetics and prosaics of life.

In an academic and professional context where 'aesthetics' have come to occupy an almost strangely embarrassing and reductive place along side the 'serious' task of the Architect of conveying intellectual statements, social programing, or achieving functional efficiency, the quiet underlying value of the study is in its modest contribution of placing more weight in this less tangible, intuitive aspect of the art; what we feel in it. Understanding the deeper significance of aesthetics and having the ability to implement them knowledgeably, is a valid and serious task of the architect; it is a metaphysical responsibility. 


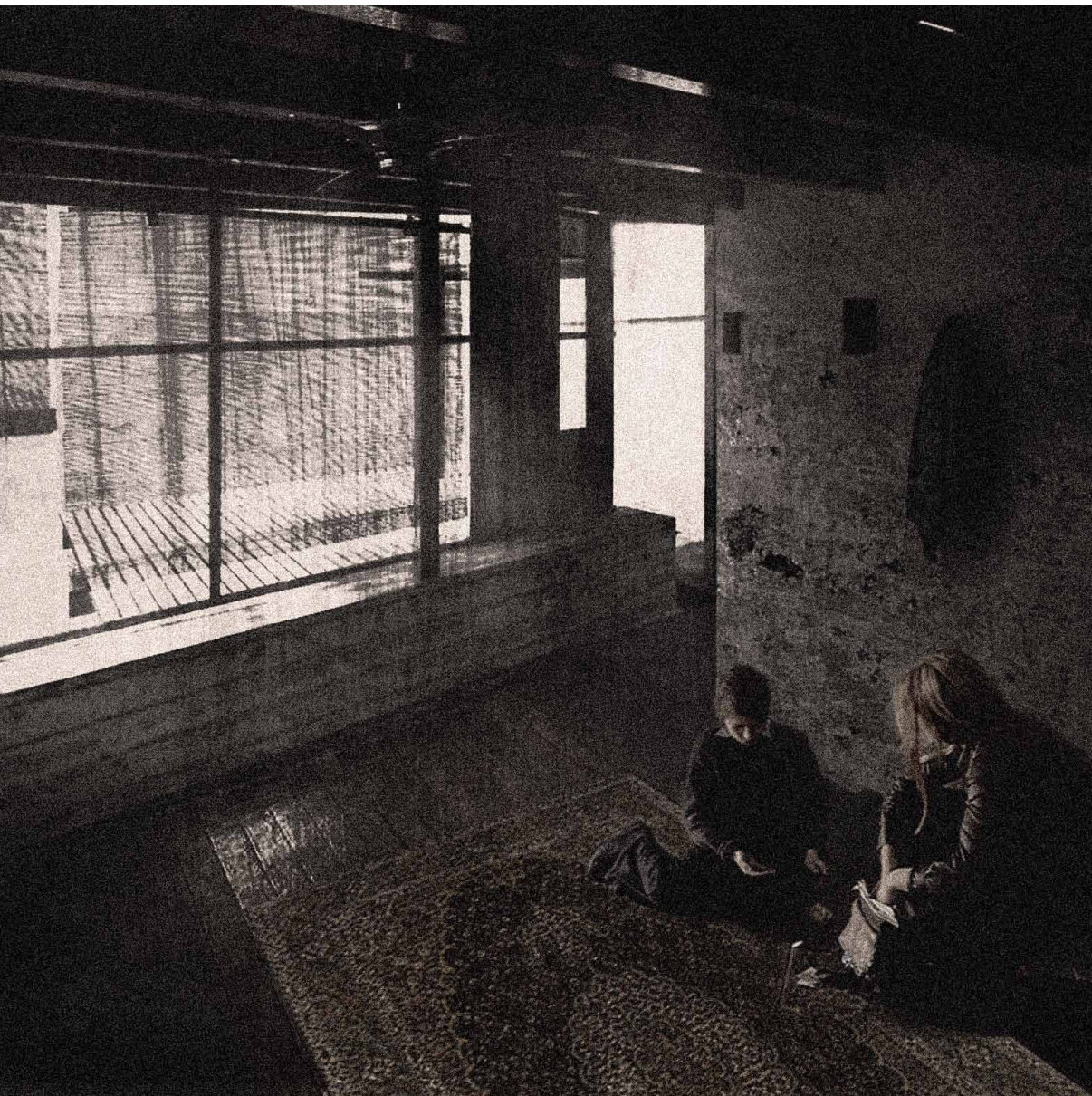

The background stage to the theatre of the everyday: image and architecture by author. 


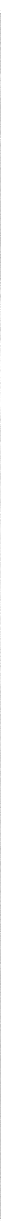

Figure 1: The living Theatre's 1968 Paradise Now production. Source: Courtesy of Beinecke Rare Book and Manuscript Library, Yale University; Living Theatre Records. 
The adjacent photograph was taken at a production entitled 'Paradise Now' by the Living Theatre in 1968, at Yale's Repertory Theatre in New York. Like many of their productions it holds little layered dialogue or planned structure. An ethos of the The Living Theatre's was, "Acting is not making believe, but living exquisitely in the moment" (Neff, 1970, p. 74). The temporal disposition of being in the 'moment' was a compelling and definitive instrument in their performance.

In this particular instance the matinee event progressed into an undefined protest. The boundaries between actor and their performance were blurred, and perhaps more apparent and significant to the outcome of the production that of the boundary between participator and spectator. This manifested most tangibly in the collapse of conventional spatial distinctions, as the audience were provoked to the stage and in equal measure the performance divulged to the space of the audience (Kostelanetz, 1989, p. 129). Actor and 'spectator' alike, with seemingly unreserved abandon, actively partook in the unfolding, nondescript event - a haphazard composition of spatial, social and legal transgressions - to the extent that, as C. Innes writes, "here naked spectators and actors embraced indiscriminately, even copulating" (1993, p. 187). This undefined protest eventually progressed to the street where it ended in the arrests of 10 performers and audience members for public indecency and disturbing the peace (Shank, 2005, p. 25).

Such a blurring of boundaries and the consequential possession of both performer and audience to the event was not only intended, but a central device of the Living Theatre's efficacy to affect (Kostelanetz, 1989). Through impromptu, spontaneous provocation an intentional collapse and transgression of the spectator's traditional objectifying distance was engendered, as they were pulled into the experiential immediacy, presence and engagement of the performers. The Living Theatre was not entertaining, but trying to bring the spectator to a lived mode; a liberated, ecstatic rapture, achieved in the immanence of 
the moment they occupied. ${ }^{1}$

In a study between acting and its relations with recognized so called 'altered states of consciousness', or 'ASC' within the field of Psychology of Consciousness, Eberhard Scheiffele documented the presence of these states within experiences reported by actors of such theatre. The characteristics of each are broad: departing from an extra-normal sense of attention and immediacy; to a sense of intimacy, arousal and emotional acuity; a heightened sense of reality with increased memory; and even encompassing the more esoteric, bastardised and clichéd phenomenon of a so-called ineffable 'unity' or 'oneness' (Scheiffele, 2001). Regardless of the diversity of distinguishable experiential characteristics, in the case of such theatre, as will become clear as we progress, what prefigures these 'states', or more singular 'state', is that act so important to the Living Theatre of achieving an immediacy, 'presence' or 'total absorption in the moment' (Scheiffele, 2001, p. 184), and more importantly for us, what this elicits: a disruption of one's common sense of temporality. An experience most overtly distinguished by what Scheiffele documents as a sense of "time standing still" or a "nonlinear experience of timelessness or eternal present” (Farthing, 1992, p. 211, Scheiffele, 2001, p. 184), but which is requisite of most, if not all, the above mentioned ASC. ${ }^{2}$

Curiously, this seemingly esoteric phenomenon is not particular

1 Importantly for the Living theatre's ends, one engendering a transfiguration of values and sensibilities that stand in clear distinction to the more subdued and prosaic reality of day-to-day life.

2 That time, linear time, sits at the core of a malaise of personal and social constraint, as the particular collapse in Paradise Now suggests, is perhaps not so un-obvious. Walter Benjamin argued in an analogous vain that the Communards in the 1871 Paris uprising shot with rifles at public clocks as signifiers of the 'unfreedom' of the social order they were attempting to overthrow (Marcuse, 1971, p. 177). 
to productions of the Living Theatre. We find evidence of its presence in that of Jerzy Godowsky's 'Poor theatre' of 1958, the Venetian 'Spontaneous theatre' of the early 1920's (Scheiffele, 2001, p. 181-190), and the Dada 'sound poems' enacted at the Cabaret Voltaire in 1916 (Ball, 1996). But perhaps its most profound manifestation in western history is in the remarkably similar event to that seen in Paradise Now of the Greek Attic tragedies of late 6th century B.C.E. Here however, the collapse of a common sense of time, and the resultant qualitative experience it engenders appears far more intentional, systematic, and overt.

The tragedies and the particular experience engendered within them present a platform on which to develop an understanding of this thesis' central concern: the phenomenological, qualitative states of 'being' and 'becoming'. It is an understanding both psychological and existential, and at times unfashionably within academic research, cosmological and metaphysical. The reflections in this chapter are essentially provisional. The intent is to afford the reader a point of theoretical and phenomenological reference, while developing the basic conceptual underpinning necessary for anything beyond purely cursory observations and reasoning, as the conceptual ground here is carried through to the study of architecture in subsequent chapters - it is the presupposition of the thesis that the aesthetic-temporal experience of the tragedies and Paradise Now alike, are equally present in architecture, though transfigured and mediated in its own more reserved and subtle way. As noted Nietzsche's conceptions of the Dionysian and Apollonian aesthetic states grounds the study, and as has been briefly viewed in the likes of Paradise Now, and Scheiffele's ASCs, the vital underpinnings of these phenomena are -as in Nietzsche's account- multi-faceted, dealing with many factors which at face value do not appear overtly concerned with matters of temporality; of being and becoming. Each factor is important however in their own right, presenting different angles through which to approach the same phenomenon - though temporal consider- 
ation always forms the common thread throughout the text as it is along the temporal axis of these wider phenomena that a direct line of translation from theatre -and philosophy- to architecture is found. As the temporally significant aspects of the tragedies were never fully worked out by Nietzsche, or at least not overtly so, it is necessary to supplement and advance on his position through the thought of Bergson and to a lesser extent that of Nietzsche's original philosophic source, Arthur Schopenhauer. While nothing here is clear cut and conclusive - the subject matter is often resistant to concrete formal comprehension ${ }^{3}$ - as much as the philosophy helps understand architecture, in turn the study of architecture in the subsequent chapters helps to more clearly understand the philosophy.

After an outline of the relevant aspects of the tragedies, Nietzsche's account of what is occurring with the Dionysian element of this event will be presented, followed by reflection on the thought of Bergson as means to further insight. This constitutes the provisional understanding of 'Becoming' as an aesthetic-temporal quality, while also introducing the notion of 'Being' as a sense of the present moment's continuity - both of which present the foundation for the study of the Brazilian slum in chapter three. The Apollonian as a particular conception of 'being' will be addressed as Nietzsche presents it and then briefly considered in light of its temporal relation with that of the Dionysian - the Apollonian quality of 'being' is foremost studied through, and in conjunction with, Greek architecture in the immediately proceeding chapter.

3 In Bergson's thought, as will be addressed later in passing, dealing with what he terms 'real time' by its very nature sits outside the conveniences of 'static' and clear conceptualisation; it is something 'intuitive' and felt over something intellectualised (1946/1934). St. Augustine, whom devoted his life to questions of temporality, captured the crux of the issue when he wrote: "What, then, is time? Who can give a quick and easy answer, who can find the proper words to make clear what it is? [...] I know well enough what it is, as long as nobody asks me (Augustine, 397 CE/1992, p. 154). 
In his evocative text The Birth of Tragedy, (first published in 1872) Nietzsche persuasively argued that the Greek tragic dramas developed out of the ritual worship of the Thracian god Dionysus - "not the god of time, but the god in time" (Kimmel, 2007, p. 263). The original Dionysian rituals took place during night festivals in the mountainsides of Thrace, in which worshipers, facilitated by narcotic drink and under torchlight and the beat of drum, progressively compelled themselves through frenzied dance and song to a 'maddened' state of 'ecstasy' (Rohde, 1920/1972, p. 256). At the climax of the 'sacred frenzy', at the point of exhaustion with every sense 'wrought to the highest pitch of excitement,' the revellers partook in animal sacrifice and 'orgiastic' sexual nonchalance (ibid). This was by no means arbitrary, it was an endeavour to achieve a 'union' with their god; to vicariously live out his own ritualised death in time and to enter into his then 'timeless' experiential reality. As Rohde writes, to see as the god sees: without "Time" and "things separated from it in time and space" (ibid, p. 256, \& 260-1). ${ }^{4}$

In this practice's development into the Greek tragic dramas the singing and dancing revellers or 'satyrs' later became the chorus positioned in front of the stage of the amphitheater[s] - "as reminiscent of a lonely mountain valley" (Nietzsche, 1872/1999, p. 42), while the 'mad, raving god' Dionysus re-manifested in the various protagonistheroes of the dramatic narrative. Despite the diverse myths and various protagonists portrayed, the dramas in essence for Nietzsche all enacted allegorically the countless forms of Dionysus' 'suffering' as a -time bound- corporal individual (ibid, p. 52). That is, the tribulations, dilem-

4 The above account of the early Dionysian rituals is from E. Rohde's text 'Psyche'. A friend and classmate of Nietzsche, he undertook a more thorough historical and psycho-theoretical study of the events based on Nietzsche's interpretation. See Rohde, E. (1972), Psyche: The cult of souls and belief in immortality among the Greeks (Hillis, W. B, Trans). pp. 253-267. Also see Guthrie, W. K. C. (1952).The Greeks and Theirs Gods, pp. 147-152. 


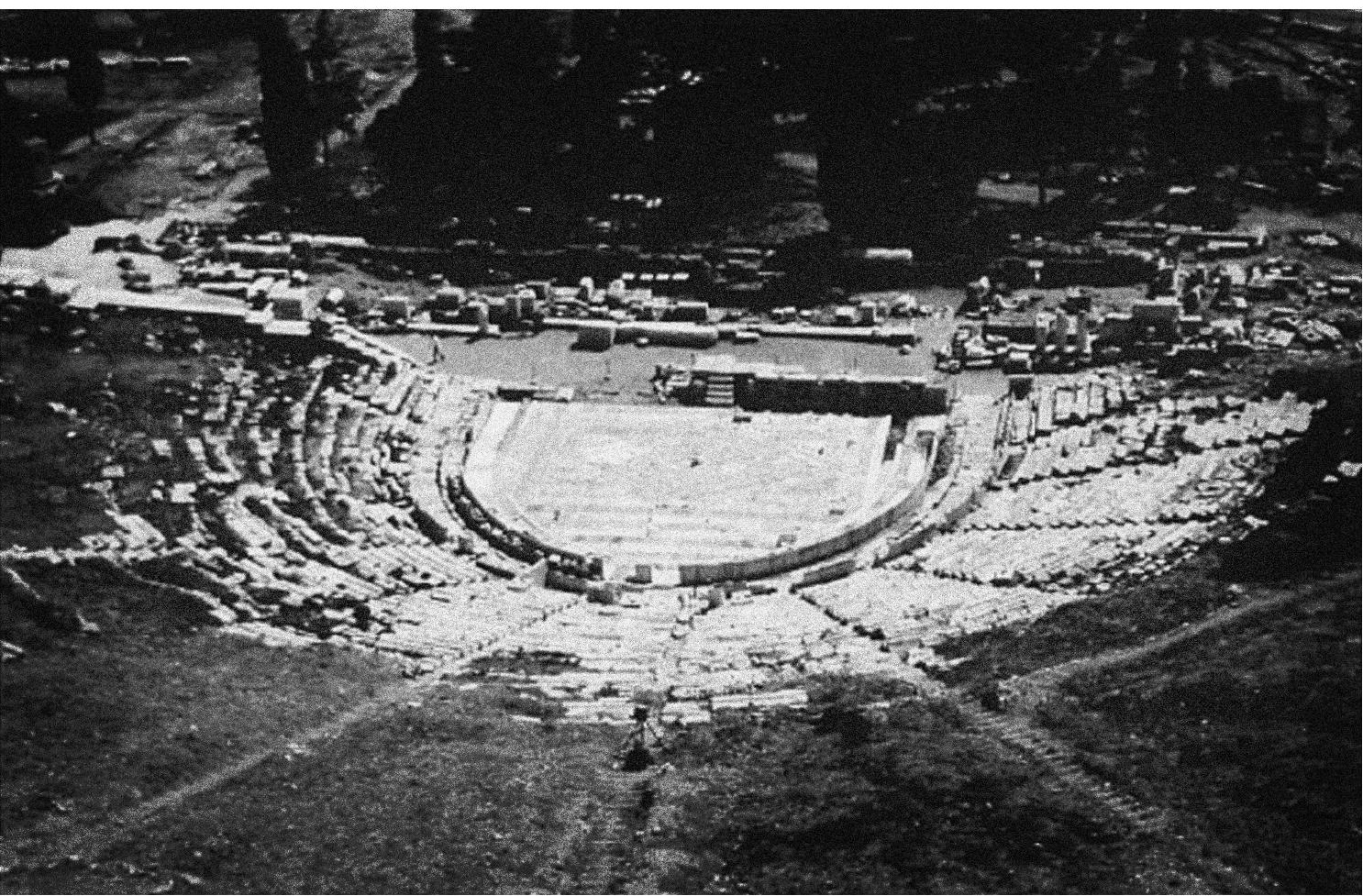

Figure 2: 'Theatre of Dionysus', Athens; viewed from the Acropolis, constructed 6th century BCE.

Sourse: Lawrence, A. W. (1957), p. 78. 
mas, 'the most painful, repeated overcoming of obstacles' (ibid, p. 113), which arise as a consequence of the individual's temporal existence; culminating in time's most certain pre-conviction - death by right of birth. But as in the original festivals the portrayal of Dionysus's death within the tragedies equally marks his, and by vicarious relation the audiences', transcendence of the time and space of the individual.

Beyond such metaphorical statements, a first indication as to what is occurring in this event in more concrete terms lies in the rigorous narrative-structure which, in difference to Paradise Now, is inevitably present due to elaborately storeyed myths performed in the dramas. As J. De Romilly in 'Le temps dans la tragédy grecque' observed, in the dramas of the play-writes Aeschylus and Sophocles these narratives were underlined by particular archetypal temporal structures. While acquiring an artful and nuance complexity, in their simplest form these were marked by a progression of portrayed events, from several years too generations past, leading in ever increasing tension and anxiety towards the protagonist hero's impending dilemma (De Romilly, 1968, p. 12) ${ }^{5}-$ Dionysus' tragic fate in time. In the dramas of Aeschylus early in the play the audience were made conscious of the nature of the impending dilemma, while Sophocles foretold not what was to take place but when (ibid, p. 16). Regardless of these deferences the conclusion -and affectwere the same: at the imminence of the crisis the story meets and unfolds in the present tense, it is at this point that the singing and dancing chorus standing before the stage with rapture and emotive acuity often began with the Greek word Tẃa, nu, or nun, that is now: "Now will new rules arise through revolution"; "Now I shall enter the palace..."; "Now the whole land of Asia is mourning"; "Now is the time when the gods could listen", or equivalent present tense statements such as,

5 As the reader is likely aware, and as Romilly notes, these are the basic mechanisms of dramatic narrative as we know it today in the likes of cinema and written narrative (1968). 
"The swift winged ships are here; there is no time left." (ibid, p. 1230). ${ }^{6}$

As occurred at Yale's Repertory theatre, in Nietzsche's argument, at the onset of the chorus we witness the same collapse of the psychological spectator/performer distinction. The 'contemplative' distance of the spectator is shattered as the chorus draws about itself "a living wall" in which it "shuts itself off" from the "real world" and its reality's "onslaught"; preserving an ideal and pure ground of "poetic freedom" (1999/1872, p 38). The audience, he writes, "identified itself with [the] chorus", as the those satyrs 'possessed' by and in union with Dionysus, to the extent that there was, "fundamentally no opposition between public and chorus the whole is just one sublime chorus, either of dancing and singing satyrs, or of those who allow themselves to be represented by these satyrs." (ibid, p. 42). In this intuit immersion audience and chorus alike experience a particular dislocation from the 'social sphere' becoming, as Nietzsche writes in his usual expressive manner, 'timeless servants of their god'; 'forgetting' there position and past reality in a collective civic order (ibid).

While a sense of 'timelessness' is presented with poetic prose at the edges and ends of Nietzsche's account of the tragedies' particular Dionysian state, this however is at face value not what dominantly figures with respects to both his psychological explanation of what occurs at this point, nor what he positions as its essential and defining aesthetic content. For Nietzsche, at the onset of the chorus, those entering into Dionysian 'ecstasy' experience a disruption of the 'principium of individuation' (ibid, p. 17). The notion of 'individuation', as Nietzsche acclimates

6 The other major, and later, play-write of the dramas was Euripides, though as De Rommilly observes he marks the first to abandon these temporal structures (1968, p. 24). Interestingly, it is Euripides that Nietzsche attributes -in his own terms - with the eventual 'violent death' of the deeper existential value of the 'old tragedy' (1872/1999, p. 87); the now contemplative spectator was presented with entertainment and logical dialogues appealing to the intellect alone. 
it from the 19th century German philosopher Arthur Schopenhauer, pertains to the mental predisposition or 'principle' of the mind to perceive the phenomenal world as persisting in distinct and individual empirical objects (ibid). That is, of perceiving distinguishable, isolated instances of form - 'things' - that endures with a degree of autonomy from a world that is in actuality -beyond common subjective apprehension- qualitatively more merged in a constant state of change. To add here, the tendency to apprehend phenomena as individuated 'things' is codependent on the 'principle of sufficient reason'. In the most basic and rough of terms, only if their are premises (sufficient reason) to apprehend something as distinctly isolated (individuated) from a more inclusive whole, then it is perceived as a completely detached/ distinct object (ibid, p. 17, \& Schopenhauer, 1969/1819). In this one does not apprehend phenomena directly, as it actually is - the 'thingin-itself' - but an individuated, superimposed representation (Ibid). Nietzsche positions this psychological activity in a deeper cosmological sense, wherein 'individuation' pertains to a basic principle or 'artistic drive' of the universe, as a 'primordial' consciousness or 'will', to separate from itself. That is, to 'individuate' itself, to tear consciousness away through isolating it to one point in space and time as a necessary condition to be able to 'look back' and 'reencounter' itself (Fink, 2003, p. 23). In this sense 'individuation' performs the function of creating an 'outside-itself' of a primordial 'will' that is the very living ether, or fabric of the ontological world (Stambaugh, 1987). While the 'artistic drive' of the 'will' manifests physically individuated forms, i.e. sentient creatures, individuated life, the perceptual activity of 'individuation' in a sense convinces one of form's distinction, affirming its isolation and inevitable autonomy from any connectedness with phenomena as a whole. For both Schopenhauer and Nietzsche this perceptual action of the mind constitutes our every-day experience of the world. It is, however, merely an 'appearance', or more, an 'illusion'; one which obscures a 
sense of reality 'as it is' (Nietzsche, 1872/1999, p. 16-8).

With this 'deceptive' veil of individuation 'torn apart' in the 'ecstasy' of the tragedies, audience and chorus alike come in contact with the 'ground' of matter; they are immersed in the true nature of phenomena as existing in a primordial 'unity'. One apprehends phenomena's condition of existing in an indivisible 'ocean' of restless, chaotic, both creative and destructive change; one which all is subject, as though to the 'innocent play of a child' making and destroying sand castles on the beach (ibid, p. xxiv). One does not intellectually grasp but intuitively experiences the sublimity of the phenomenal world's precarious condition in an immersed flux of entropic creation and declination; exposing all form's tendency to decay; all is finite; all is becoming.

While it is tempting to place the notion of 'unity' on an esoteric and grand metaphysical pedestal - Nietzsche certainly provisions such reading - we can also understand it in far more reserved and modest terms. As Speirs and Guess note, it is merely that without the appearance of a distinctness of an object, without the indelibley convincing impression of its isolation as a 'thing' which a native faculty of perception affords, as boundaries are blurred less lucid 'things' inevitably appear, or are felt to be, more unified, merged, 'one' with the matter and space around them (ibid, p. 17). ${ }^{7}$ This notion, placed in these more accessible terms, is also not limited to physical 'things', but to the diminishing of more overtly conceptual boundaries, such as the distinctions of spatial fields,

7 The perceptual tendency to individuate such a 'unity' is nowhere more apparent than in the manner in which most people draw. Consider the tendency of the unpracticed drawer -and certain stylistic methods such as that of early renaissance paintings -, to limit attention to and accentuate distinguished 'things' with a purely fictive exterior contour - in extreme cases depicting completely abstracted representation such as the stick figure of a child's drawing. The strong gestalt of the edge and line supersedes in emphasis the actual immense and visually integrated complexity of a depicted scene; only objects defined by the perceptual ends we make of them are rendered. 
"The works] re-present the world as I have intuitively sensed it to be - bebind the veil of appearances - as immaterial, interrelated and dynamic fux. Within this all-enveloping fux and flow, habitually perceived distinctions between things dissolve, and boundaries between interior self and exterior world become permeable and intermingled" (Davies, 2004: 74).

Figure 3: C. Davies' 'Blue World-Space'. 1985, Oil on canvas.

Source: Davies, (2004), p. 74. 
and habitual systems of social boundaries, behavioral codes etc - in short, of the very distinctness of subject/object relations on which these rely. A notion most overtly witnessed in the collapse of the spectator/ participator dynamic in Paradise Now - and the behavior elicited. The traditional mode of the 'spectator', affirmed by the spatial separation of stage and seating area, establishes an initial acute manifestation of the subject/object modality, only then to be consciously, actively transgressed. The isolated spectator is no longer watching from without as a removed subject apprehending exterior, distinct objects and events, but as a participator, in themselves less artificially isolated, experiencing from within a more immersing, un-abstractly dissected 'whole'.

While Nietzsche places emphasis on this 'destructive' quality of the collapse of the principium of individuation and the ontological reality it discloses, one that essentially constitutes the 'tragic' element of the dramas, he also asserts that the subject attains an unsurpassed 'metaphysical solace' through recognizing their union with the enduring, omnipotent 'will' underlying form - "despite the constant destruction of the phenomenal world" (ibid, p. 41). ${ }^{9}$ He writes, "For brief moments we are truly the primordial being itself", which exists as "the eternal life of that core of being" (ibid). As Fink notes, one recognizes Individuated existence as but "finite manifestation" or "temporal waves" of the greater unified surge of life of the 'will', allowing one to even take "delight" in the destruction of their individuated existence (Fink, 2003, p. 10). It is this union, and the 'solace' one attains within it,

8 This is certainly one of the more perplexing ideas presented, though by the end of the thesis it will become quite clear and less esoteric.

9 To add, a focus which most academic texts place attention on, ignoring the brief, yet significant, references Nietzsche makes on the particular solace also found in the Dionysian 'ecstasy'; a solace distinct from that of the Apollonian aesthetic experience considered latter. 
that the qualitative sense of a 'timeless present' is grounded, and while it is not attended to beyond a few cursory and poetic statements in The Birth, in the thought of Schopenhauer and Nietzsche's subsequent text 'The use and abuse of history' we gain a subversive insight into the relation - for us, a provisional one. At a purely theoretical level within Schopenhauer's thought, as M. Sanderson notes, "if the will is the thingin-itself, this means it exists outside of time, in what Schopenhauer understands as the timeless present." (Sanderson, 2007, p. 164-166). The present Schopenhauer writes, "is the only form in which the will manifests itself. It will not run away from the will, nor the will from it" (1969/1819, p. 280). The 'will' or raw consciousness is seen in his reasoning to be indivisible with the present moment, that is to say the 'endless present' is consciousness, or the 'form of life' (ibid). To attain a certain perceptually unmediated union with raw consciousness, as in the Dionysian 'ecstasies', is therefore to occupy as he terms it, "a point, an indivisible, ever-present present-moment" (1958/1818, p. 489). The supposed 'eternity' of the present is admittedly a difficult notion to grasp conceptually, by its very distinction it is beyond formal comprehension; ${ }^{10}$ its significance and apprehension lies in empirical experience, not its logical reasonableness. Logically however, Schopenhauer's reasoning implies nothing less than that the moment in which the tragedies were performed, all prior moments in history, and all moments that occurred up until the very moment, the very now, in which one is reading this text, are, or more $i$ s, the same present moment - it is just that much non-linear 'flux' and change has occurred within it.

It needs to be emphasised that while it is tempting given this supposed 'eternity' of 'will' and the present to infer that the particular 'solace' attained in the likes of the tragedies relates purely to a release from

10 Again, as is argued by Bergson, whom is addressed shortly, by its very nature the intellect can not grasp 'real' Time as it is, and is only attainable through the empirical experience of a direct 'intuition' (1946/1934). 
the corporal individuated self - in the sense of overcoming, or seeing beyond physical 'mortality' -, this is more a release from one's common sense of time generally and the complex emotional predisposition it engenders. ${ }^{11}$ As Nietzsche writes with regards to the value of such a qualitative experience, in the present moment one is unburdened by the "suffering and weariness" of the "dark invisible burden" of the past or the future (Nietzsche, 1873, p. 11). They are as a 'beast', he remarks, which always 'forgets' and "goes in the present", or a child whom 'plays' "between the walls of the past and the future" - that is a child yet to understand the phrase "once upon a time" (ibid). It is to be unburdened by the aggressive linear trajectory of 'time' through a certain autonomy, to not have one's self ever-break off and cascade into the past or pulled towards the future as though caught in an ever-present horizontal gravity and its accompanying temporal vertigo; to find calm and solace in the immutable, undivided, infinitely deep present: Schopenhauer writes, "Time is like an irresistible stream, and the present like a rock on which the stream breaks, but which it does not carry away" (1969/1819, p. 280). Nietzsche places considerable significance in this action and affect, asserting that any legitimate solace requires an element of such abandonment. It alludes anyone, he writes, "who cannot leave him[/her]self behind on the threshold of the moment and forget the past, who cannot stand on a single point, [...] without fear or giddiness," (ibid). The extreme case is one who has no ability to "forget"; always to be outside oneself, consumed by nostalgia towards the past, or anxiety or desire towards a predicted and envisioned future; one is lost to 'time'. Such as person becomes a "logical disciple of Heraclitus" - who "sees everything fly past in an eternal succession and loses himself in the stream of becoming" (ibid - my italics). It is to reason with pure intellect that all things are changing, ephemeral and finite, 'to stop

11 As Schopenhauer emphasises this is not to be confused with any 'doctrine of mortality' (1969/1819, p. 280). 


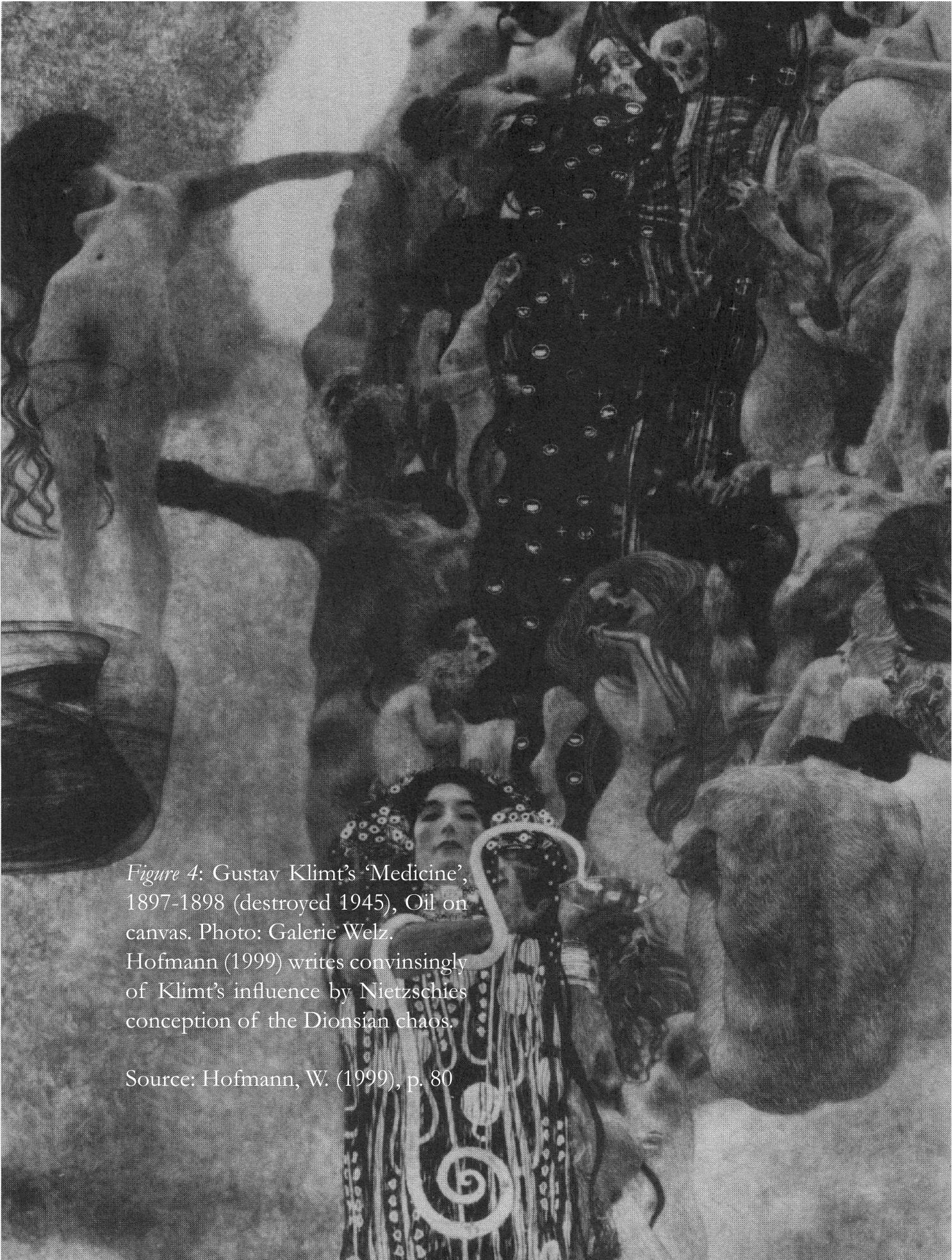


believing in one's existence' (ibid), but not to empirically experience the 'current' of phenomena braced in the continuity of the moment.

The apprehension of the perpetual decay of the phenomenal world - and we can add, apprehended within a continuous present moment - presents, as Nietzsche writes, the subject with a "truer, more real, more complete image of existence" (1871/1999, p. 41). In other words 'reality as it really is', beyond the placating illusion of the seeming stability of individuation and order more generally. The disclosure of this reality is met with an innate reverie and rapture, a fury and vitality. This is the liberated Dionysian state of 'ecstasy' that Nietzsche defines as the 'intoxicated' aesthetic experience.

In this aesthetic we have a tentative and provisional understanding of both the notions of 'Becoming' and 'Being' as a sense of the continuity of the present. However, with respects to the temporally significance aspects of this Dionysian state we are still left in want answers. How, for example, does the collapse of the 'principium of individuation' amount to a collapse of one's common sense of time? And why in such a collapse does one apprehend a fluidity of phenomena, while equally the continuity of the present? Indeed, what is our common sense of 'time', if time here is obviously distinct from 'Becoming'?

Although as J. Stambaugh suggests Nietzsche never explicitly worked out the temporal significance of his philosophy within The Birth and other texts, she writes that the principle of individuation is however for Nietzsche implicitly understood as 'time' (1987, p. 13-14). Time is that which separates the world, as the horizon or 'container' of our conventional sense of reality, with that of the 'ground', as the primordial unity of both matter and 'will' before individuation (ibid).

We find a supplementary understanding of the relationship between 'individuation' and 'time', 'time' and 'becoming', when we turn 
to the thought of Henry-Louse Bergson. ${ }^{12}$ In remarkable parallel to Nietzsche and Schopenhauer's conception of Individuation, Bergson placed our common sense of temporality as a consequence of the perceptual function of the 'mind' to distil from 'reality as a whole', categories of static, symbolic or abstract representations. This perceptual filtering in Bergson's argument is a necessary requirement for one to be able to function, as it takes from the immensity of all sensed phenomena only that which is sufficient for practical life, - reasoning, language etc; in essence, that required to 'act', cognitively and physically etc. (1946/1934, p. 222). Bergson writes, "life demands that we put on blinders, that we look neither to the right, nor to the left nor behind us, but straight ahead in the direction we have to go" (ibid, p. 161). It is for this reason, he continues, that perception "isolates that part of reality as a whole that interest us; it show us less the things themselves than the use we can make of them. It classifies, it labels them beforehand; we scarcely look at the object, it is enough for us to know to which category it belongs" (ibid, p. 162).

In contrast to Nietzsche's conception of Individuation with its focus on the spatial-material separateness of phenomena, in Bergson's account what is characteristic of these perceptual representations is that they are static and fixed, indeed their very value lies in the fact that they remove the most complex and un-quantifiable aspect of phe-

12 From the outset it is worth noting that by no means is it implied, or can it be, that Bergson's theories are in concord with Nietzsche's, there are many difference, though one of the most basic tensions is that which is of value. Nietzsche's concept of Individuation is essentially spatial in nature. That is, the collapse of individuation is defined as a loosening of perceived spatial boundaries of an object or construct; that this has any affect on one's sense of temporality, i.e. that one now apprehends a continuum of 'flux, is merely inferred but the reasoning not apparent. In Bergson's theory, in contrast, we are offered a more concrete understanding of the other side of the coin, of the temporal workings of this phenomenon. 
nomena - its lack of a fixed state, its perpetual condition of becoming (1946/1934). It translates that which is never persisting into something that is stable, as he writes, the mind "substitutes for the continuous the discontinuous, for mobility stability"; while in reality, "There do not exist things made, but only things in the making, not states that remain fixed, but only states in process of change." (ibid, p. 222-3). Change, both in our perception of it, and in the way it is conceived intellectually, becomes 'spatialised. An object is not grasped as perpetually becoming something ever-new at every instant, but is only distinguishable as holding a quality of change in any sense through a static but moving sequence of fixed states along an abstract line of a numerically, spatially divided time; the past or future measured by clock. Or, to approach it from another angle, the past and future, and the infinite spectrum between, as they are commonly constructed form a type of conceived space that separates and orders static 'things' spatially along a linear sequence. With no actual quality of change, as something seamless and stateless, occurring within an object being grasped or inferred, beyond its position in this linear-spatial sequence of time there is no qualitative state of its fluid becoming. Time as the ever-changing of things, writes Bergson, is reduced to a 'fourth dimension' of space; something essential qualitative, becomes quantifiable just as Euclidean space is, as it is perceived and/or treated as measurable, dividable and repeatable (1946/1934). ${ }^{13}$

Due to this perceptual predisposition, in common everyday reality within a linear or 'spatialised' sense of time, one is not only unable to see phenomena as it really is - the 'thing-in-itself' beyond static objects-, but by the same token is more generally unable to truly grasp and

13 The idea that time as it is commonly apprehended is not real, that it has no ontological substance outside of humane experience and that it is instead a perception, is not new. On a fragment found in Greece dating from the 5th century BCE, attributed to Antiphon the Sophist's text 'On Truth' is written: “Time is not a reality (hypostasis), but a concept (noêma) or a measure (metron).” (Sorabji, 2006/1983, p. 95). 


\section{Spatialised Time}

experience real change as 'real time' whatsoever, what he commonly terms 'Durée', or 'Duration'; that is, a seamless, ever-becoming continuum of change and movement. In 'spatialised' time the 'indivisible', 'continuous fluidity' of Durée, is fragmented into aggregates or segments, as it is perceived as a "discontinuity of moments replacing one another in a infinitely divided time" (ibid, p. 150). Bergson illustrates this by analogy of cinematographic film, wherein there is to the mind's eye a flow and succession in the moving image, but this flow as we know is mere appearance as it consists of static, individual film stills perception here performs the function of breaking the continuum of reality down into these more manageable quantifiable 'statics'. Continuing with this analogy, and inverting it with us now being the observer of the film, he writes, "the film could be run off ten, a hundred, even a thousand times faster without the slightest modification in what was being shown", this exposes a "weakness in our perception", one that lacks the subtlety to grasp the seamlessness of change and movement - we can not see the changeover from one film still to the next (ibid, p. 17-18). ${ }^{14}$ Regardless that we apprehend what appears to be 'flow' in things and in our own movement etc., we are actually quite removed from a "direct perception" of it (ibid). It is in this sense that 'time' as we commonly experience it is an "artificial scheme" which we "interpose unknowingly between reality and [ourselves]" (ibid, p. 167) - "movement is reality itself" (ibid, p. 169).

Now, a basic property of 'real time' -from now on referred to as Time -, and one that Bergson places much significance in, is that it

14 This notion was not foreign to Nietzsche, whom briefly writes of it in a latter text: "[...]: we are not finely tuned enough to see the supposed absolute flow of becoming; the perdurant is there only thanks to our unrefined organs which summarize and display that which really does not exist at all. The tree is something new at every moment: we assert form because we are incapable of perceiving the most precise absolute movement. (Nietzsche, 1881, as cited in Ansell, K. P., 2006, p. 61) 
"binders every thing from being given at once." (ibid, p. 110 my italics). In a more 'direct perception' one qualitatively grasps the 'continuous creation of unforeseeable novelty' (ibid, p. 107 my italics); the 'uniqueness' and 'moving originality' of every instant of experience as it unfolds at the ebb of the becoming of things. This qualitative sense is however removed by common perception, as the static objects it distinguishes from reality as a whole, are seen to be repeated instances of the same 'things' and occurrences, though 'rearranged' within a fixed number of possibilities - another Monday, another task with an envisioned number of variables within such systems; one of course composed of the many representative objects we make of the world. The future says Bergson is closed off, made essentially predictable and foreseeable; a deeper sense of the perpetual novelty and uniqueness of reality, the unrevealed and mysterious of every instant, is lost. Beyond one's common sense of temporality he advocates lies a genuine state of 'free will', of an open 'unlimited field' of 'possibility', not merely, he emphasises, a fixed set of possibilities within an order or system; in 'real Time' everything is no longer 'given at once' - as is the basic condition created by reality 'as it is' (ibid).

Such 'direct' perception for Bergson is only possible through the immediacy of 'intuition', while in contrast our native objectifying distance which manifests most explicitly in processes of the intellect analysis and abstract reasoning etc. -, though necessary for practical use, only serve to further remove one from it. In sympathy with Nietzsche 'art' is one bridge to such an awareness; he suggests that its very efficacy lies in its capacity to show us that which we commonly and essential do not see - Time ${ }^{15}$ (ibid, p. 170). This disclosure for Bergson being

15 In a somewhat contradictory statement Bergson (1946/1934) suggests that philosophy is that which is most capable of allowing one such an insight, whereas it is the artist's natural psychological predisposition, not the art they create, that affords them a more direct perception - not necessarily others through their work. However in the tragedies it is more a case of the individual becoming 
of profound metaphysical significance, just as it was for Nietzsche, as he believed 'real change' to be the very 'Elan vital' or essential creative vitality of life (1983/1907); whereas, "the world into which our sense and consciousness habitually introduce us is no more than the shadow of itself; and it is as cold as death" (1946/1935, p. 151). A sentiment captured by Faulkner: "Time is dead as long as it is being clicked off by little wheels; only when the clock stops does time come to life.” (1929, p. 104).

Bergson's conception of temporality not only affords an understanding of the distinction between 'Becoming' and 'time', but we also gain a tentative insight into the important relationship between 'Becoming' or Durée, and that of 'Being' as an unfragmented sense of the present. That one would apprehend a seamless 'fluidity' and continuity of change and movement as in the state of Dionsiac 'intoxication', while also grasping a sense of the presents' continuity, are here logically quite inseparable as qualitative experiences. As cited in Bergson's account through the native perceptual action to make the continuum of phenomena stable for cognitive and functional 'convenience', the actual flow of change is fragmented and made static at the very point of the moment, becoming a 'discontinuity of moments replacing one another' (p. 150). -These fragmented moments are then 'juxtaposed' against each other along a linear space, which is conceptually labeled past, present and future. It is this same division that explicates theoretically the qualitative sense of the moment's singularity and continuity, as the immediate present - the point in which consciousness unfolds; or more accurately, the very point of consciousness' presence - is no longer broken apart, fragmented, individualised, but remains intact; it persists, where all else changes. As Bergson writes, in a more 'direct perception' the present does not seem to be "constantly starting afresh", but is "thick", it has "depth", it is furthermore, he continues meta-

the 'art' as metaphysical insight; it is 'art' lived. 
phorically, "elastic" in the sense that it stretches back, encompassing the past (1946, p. 152). Within spatialised time, the remembered past is fragmented and separated spatially across time, in this it becomes as Bergson writes 'strange' and 'foreign', something sensed and concieved as 'done away with' (ibid, p. 151-152). In other words, it is separated by the construct of a superimposed linear distance, while in actuality, for him, the past is also contained in 'contracted form' within the present (1911/1896). ${ }^{16}$ Beyond perception's tendensy to make Time static and linear, Time - as past, present, and future - is more whole; compressed into a single, unfragmentment present tense experience, or a singular 'intuition' (ibid, p. 292).

It is important to note that this is by no means contradictory to Nietzsche's need to 'forget' as a requisite to 'stand within the moment'. He too theorized that within a more ontological sense of temporality -the 'super-historical' sense- 'the past and the present are one and the same' (1873, p. 11). 'Forgetting' here being not a negation of the past per say, but a letting go of a past conceived as severed as it irrevocably cascades back into the insurmountable, purely fictive space of time. ${ }^{17}$ In a more direct perception, a past lost is qualitatively brought into a certain intimacy of possession; 'forgetting' the past, we may understand, being analogous in affect to the manner in which one is released from a

16 Scheiffele also documents an altered and heightened capacity of memory in intense theaters, where 'vivid details' of sensory experience resurface and 'non-linear' conections are made between events (2001, p. 182-3).

17 In this explanation we more concretely understand theoretically that 'individuation' is not merely a spatial-material separation of 'things', but is equally a temporal separation. As was cited earlier, E. Rohde alludes to this when he writes that within the 'Dionysiac state' the individual's consciousness "free [s] itself from Time" and sees what only the god sees, "things separated from it in time and space" (1972, p. 260-1). The separation here being equally engendered by the abstractly conceived space of linear 'time', as opposed to been temporally unified in a singular and whole 'timeless present'. 
desire, once the object of that desire is attained.

In either Nietzsche's or Bergson's accounts a stronger sense of the present's continuity, its lack of linear fragmentation, is an inseparable qualitative experience with that of an increased sense of the flow of change. We see that 'Becoming' and 'Being' are phenomenological essentially two sides of the same coin; both are two conceptually distinguishable aspects of 'reality as it is', or at least 'reality' as it is apprehended once one's common sense of temporality is disrupted. This particular notion of the Dionysian state of becoming -inclusive of a state of Being - is primarily considered with regards to its mediation within architecture through the precedent of the Brazilian slum or 'Favela'. We will now turn to another type of 'being' as Nietzsche addresses it in the tragedies, one related though quite antithetical to that found in the Dionysian temporal experience. It is this particular 'being' which forms the bases of the study of Greek architectures.

Although Nietzsche acknowledges that in the intuitive grasping of the 'ground' or 'unity' of all things one attains a certain 'metaphysical solace', he regardless asserts that the apprehension of ceaseless 'decay in the infinite ground' (Fink, 2003, p. 10) becomes for the individual profoundly disturbing. As the Dionysiac ecstasy attained in the tragedies subsides and daily reality "re-enters consciousness", having "gazed into the true essence of things" the 'real' world inside the veil of time and individuation is experienced with a sense of "revulsion"; one can not help but see the cultured world and the human existential condition more generally as "absurd" (Nietzsche, 1999/1872, p. 40). One is consumed with an "ascetic, will-negating mood"; there is no desire to act, as action "requires one to be shrouded in a veil of illusion" (ibid). The finitude and destruction of the phenomenal world, which otherwise penetrates into waking reality as a subtle undercurrent, is laid raw in the psyche; the vanity and futility of humanity's endeavors become apparent. The only 'wisdom' that has validity, the wisdom that one now 
grasps in its entirety, is that of the wood-god Silenus: the best thing for the individual and human kind as a whole is, "not to have been born, not to be, to be nothing. However, the second best thing for you is: to die soon." (ibid, p. $23 \& 40)$.

The desire to overcome this 'tragic' reality of the human condition is for Nietzsche that which gives rise to the other half of humanity's 'artistic drive' and its accompanying aesthetic phenomena; not only in the context of the tragedies, but more generally to the existent that the above mentioned reality, and ones underlying anxiety towards it, is never far from awareness. This is the antithetical artistic drive and aesthetic of the Delphic god Apollo - the god of clarity, light, measure, shape and beautiful proportion (Fink, 2003, p. 15). As Dionysus is the deification of the aesthetic of intoxication and chaos, the 'shattering' of the world of appearance, of 'time' and individuation, Apollo is the deification of the 'principium individuationis'; the 'glorification' of the world of appearances and representation (Nietzsche, 1872/1999, p. 26). Apollo as Fink writes embodies the 'deceptive' beauty of a "seeming eternity of form, the firmness of appearance and the proportionate harmony of things" (2003, p. 18). While the Dionysian aesthetic of intoxication is comparable to one 'gazing' directly into the sun, the Apolline, Nietzsche explains, is like the dark patches before ones eyes after such a direct gaze, "as if there purpose were to heal them" (1872/1999, p. 46). In the quiet contemplation of an 'eternity of appearance', of a solidity of the placating illusion of Individuation braced against the destructive 'ground', one attains a certain reprieve and solace from the unease or 'suffering' of finite, ever-changing, corporal existence (ibid: 80). As L. Hatab remarks, drawing it back into the thought of Heraclitus, "separateness" achieves "a projected refuge from the reality of things essentially falling away into each other and the subsequent realization that the truth of things is an everpassing, i.e. ever-annihilating, form-destroing process." (1978, p. 23). It is a reprieve that obviously differs to that observed in the 'ecstasy' of Dionysian state as it is not a 'stepping outside' 
of the individual, but it is instead to respect the limits of the individual; that is, as Nietzsche commonly expresses it, to sit calmly and trustingly in a "rocking boat in the midst of the sea" (ibid, p. 26). ${ }^{18}$ One a reprieve attained through embracing Time the other, paradoxically, an irrational reprieve through further removing oneself from Time. The seeming continuity and stability of form found in this later solace is that which makes individuated existence bearable; laying way to one of Nietzsche's most noted assertions, "[...] only as an aesthetic phenomenon do existence and the world appear justified" (ibid, p. 113). Unlike Dionysian 'intoxication' which points to a certain 'truth' of reality, the Apolline is the illusionary aesthetic of 'beautiful semblance' and 'dream' (ibid, p. 19).

Within the tragedies the Apolline drive manifested in both the dialogue of the mythologies portrayed and their physical enactment by masked performers, these elements giving form and order to the formless Dionysian drive elicited through the song and dance of the satyrs. This union, which created in Nietzsche's view a rear balance and intensification of each drive, is of conceptual interest in the final applied chapter of the thesis, however the Apolline's particular manifestation in the dramas is not of immediate importance, both are distinguished by Nietzsche as 'plastic arts' of which this thesis central concern of architecture is quintessential $(1872 / 1999$, p. 76$)$. Architecture as a formative art, and more or less inevitably stable and ordered is - in theoryalways a resistance to the essentially destructive and chaotic drive of the Dionysiac; or to place it in other terms, its aesthetic value is derived from its requiting of a basic need for permanence and stability against

18 Nietzsche takes this description from Schopenhauer, the original is quite apt of the general sentiment he endeavours to convey: "Just as the boatman sits in his small boat, trusting his frail craft in a stormy sea that is boundless in every direction, rising and falling with the howling, mountainous waves, so in the midst of a world full of suffering and misery the individual man[/woman] calmly sits, supported by and trusting in the principiu individuationis [...]" (Schopenhauer, 1958/1818, p. 416). 


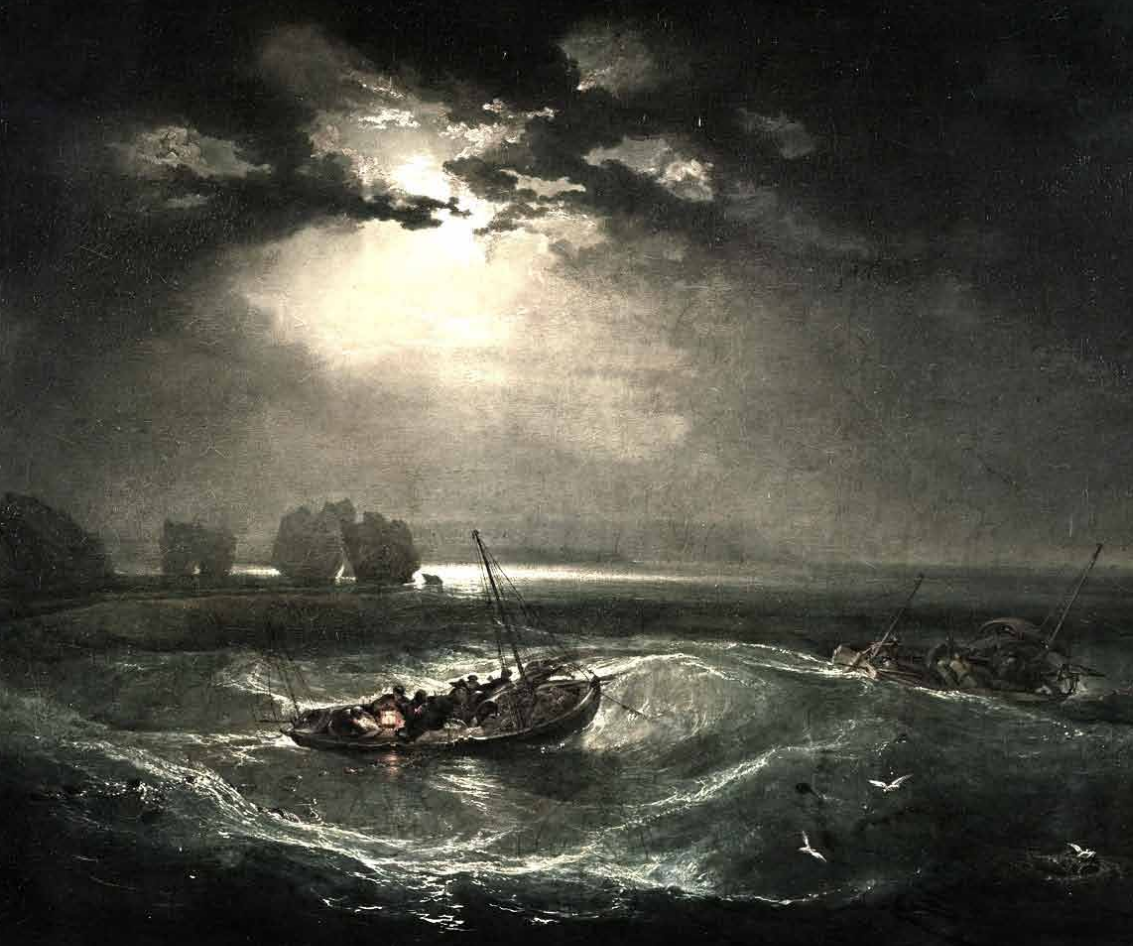

Figure 5: J. M.W Turner's 'sublime' painting 'Fishermen at Sea’. 1796, Oil on canvas, 91.5 x $122.4 \mathrm{~cm}$. London, The Tate Gallery.

Sourse: Bockemühl, M. (2000). p. 24. 
the ever present reality of entropic change, of Time, - not its disclosure and embracing as in the Dionysian. ${ }^{19} \mathrm{H}$. Wölfflin, whom figures predominantly in the proceeding chapters, writes in his own terms of such a drive as that underlying architecture: "What holds us upright and prevents a formless collapse? It is the opposing force that we may call will, life, or whatever. I call it force of form [fromkraft]. The opposition between matter and force of form, which sets the entire organic world in motion, is the principal theme of architecture [...] We assume that in everything there is a will that struggles to become form and has to overcome the resistance of a formless matter." (1886, p. 159). All built form, in Wölfflin's account here, at its core presents a resistance to the becoming of phenomena; an element of the Apolline drive to achieve its particular quality of 'being' through form that overcomes/suppresses the reality of 'becoming'.

In the proceeding chapter's study of the relationship between the architectural aspiration to achieve a state of Apolline 'being' and the physical properties of architectural form, the more pronounced and refined means and extents taken to achieve this end will be considered. In this effort Nietzsche's conception of the Apolline or 'being', as an acute form of illusionary 'individuation', is found to be remarkably accurate and instructive; in every regard the formal properties observed appear to aspire to this end. However to prefigure the study, on the face evidence, as accurate as it is, understanding 'being' in this respect alone proves incomplete. We will find a curious and paradoxical link between the 'being' of the Apollonian and that of the Dionysian's 'Being' as a continuity of the present; these to qualitative states are found to be inseparable within regards to architecture that aspires to a quality of 'being'. This relation can be roughly defined as follows: As linear 'spatialised time' is but a particular perception of 'real time', then if the

19 Though as will be found in the precedent of the Brazilian slum this limitation is challenged. 
former is removed - if a total impression of a cessation of becoming is achieved - the later is inevitably transcended as well; that is, if there is no Time given in the first instance, then there is none to be spatialised in the second. It is somewhat tedious to work this out at a philosophical level here, a more delicate conception and appropriate validation will be established as the thesis progress through the study of architecture.

Such a relation between the two is not inconsequential, with respects to their temporal value they are in theory fundamentally antithetical - and hold different philosophic significance in Nietzsche thought. In light of the relationship propositioned between 'spatialised time' and 'individuation', the aesthetic property of the Apollonian, in contrast to the Dionysian's 'Being', attains its effect and amounts not to the collapse or disruption of one's common sense of temporality, but its very affirmation and intensification. In other words, it is not engendered through 'timelessness' proper in the sense established as a complete transcendent undivided immutable present moment, but through the highest potency of spatialised time -the suppression of real Time as change; the everlasting of the static form/object. One the 'timelessness' of raw consciousness or present, the other a 'timelessness' or highest potency of 'time' of material, individuated, form.

Within the context of Nietzsche's thought, at a philosophical level one of the more significant implications of a qualitative relation between these two temporalities is that the 'deceptive' being of Apolline dream would also inevitably hold an element of metaphysical 'truth' that Nietzsche otherwise asserts the privilege of the Dionysiac state of intoxication; as it 'points' to, or collapses into, that 'inner core of Being'. This also leads to a further consideration with respects to aesthetic experience more generally. If we are to consider these two elements as constituting the ouvre of aesthetic gratification underlying all art, or at least all art that qualifies the term as Nietzsche implies, then one can tentatively say that all aesthetic experience of this metaphysical nature is fundamentally rooted in a disruption of a common sense of temporali- 
ty and the disclosure of 'real time', or at least that certain 'truth' of time as a continuity of the present moment; whether this disruption is absolute and transcendent as in the case of Dionysian 'Being', or whether, as will tentatively be reasoned in the subsequent chapter, it is a disruption engendered through an intensification and resultant collapsing-backinto timeless proper of the Apolline 'being'. While these later points are not the sole drive of the thesis to explore, they are important if not unavoidable considerations that help the study to reflect constructively on the aesthetic experience and architecture of 'being'.

As concluding remarks it is worth emphasising that each aspect addressed in this chapter forms a valuable premise to understanding the basic mediation of temporality in architecture - along the two polls of being and becoming. Nothing of what has been viewed here is superfluous to the following study; if points that have been raised are not drawn on directly, which they usually are, they form a valuable subtext which places consideration in a wider theoretical and phenomenological context. While temporality is always the common thread of consideration, from the notion of subject/object, spectator/participator spatial distinctions, to Nietzsche's conception of a spatial and temporal 'unity', - to note what may seem the more obscure - each present an integral and unavoidable part within a broader conceptual framework of experience. In many respects, each provides a different, and important, angle though which to understand the same phenomenon - one most holistically defined as the polls of being and becoming. As much as this larger philosophical picture provided by Nietzsche, and to add Bergson, helps in understanding the temporal significance of architectures, the study of architecture inevitably affords a valuable, clarifying - and often de-mystifying - insight into the philosophy. 


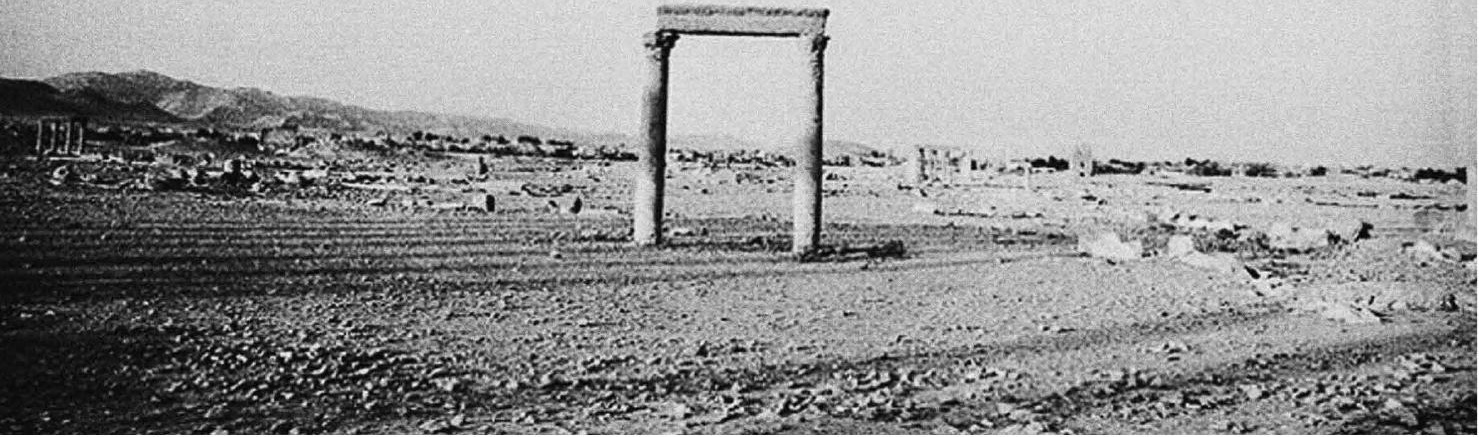

Figure 6: Segment from the Temple of Apollo, Antalya; constructed aprox, 540 B.C.E.

Sourse: R. Martin, (1998), p. 87. 
In his concluding remarks to The Birth', Nietzsche compels the reader to translate themselves back to Athens at the time of the dramas, to walk its streets and to view and appreciate the 'rows of high, Ionic columns' and 'pure and noble lines' of its architecture. Such harmony, tranquillity and beauty Nietzsche now asks the reader to reflect can be seen as manifesting in reciprocation, and equal measure, to the antithetical force that was drawn out in the Attic tragedies of the 'mad, raving god' Dionysus - as the deification of the all changing, all becoming of phenomena and the 'suffering' it causes; that is, the reality of the human condition (Nietzsche, 1999 p. 116). In the proceeding sections we will consider one side of this supposed dualism with respects to its place in what we feel temporally in architecture, and principally in relation to only one aspect of architecture; that of the relationship between the quality of being and the property of form. From this angle other properties of architecture are inevitably approached, however attention is always pivoted around considerations of form. This focused study presents a point of entry to understanding the interrelationship between architecture and temporal-aesthetic experience through the theoretical and phenomenological notions of being and becoming. In this endeavour it makes sense to depart where Nietzsche concludes; a reflection on the particular aesthetic quality of the formal properties of Greek architecture of antiquity, from its earliest carnations in the Doric order to its reappearance and transfiguration in the Renaissance. ${ }^{1}$ If Greek architecture truly was the reciprocal of the Apolline drive as Nietzsche attests, and this drive is above all one to find relief from the 'becoming' of reality as we

1 Unless otherwise stated 'Classic' form is considered in its ideal original state, not its ruined state, which of course, with its pronounced 'returning to matter' holds a remarkably different temporal value. The contrast between the intent of a 'timeless' form and its contemporary ruination, presents something of an implied poetic statement on the eventual primacy of 'real' Time - though not necessarily a suggestion of the vanity of the effort, as the form, as we will see, goes beyond merely negating the Becoming of phenomena. 
experience it, then we should expect to uncover physical, tangible architectural properties which directly meet and requite this need.

An entry argument for the presence of such properties of form can be read out of the art historian Wilhelm Worringer's doctoral dissertation Abstraction and Empathy, first published in 1907; and the works he positions his own arguments on, namely those of Alois Riegl, August Schmarsow, and Theodore Lipps. We may also compliment and advance Worringer's theoretical position with the more in-depth physical studies of form undertaken by the Swiss art historian of a similar period Heindrich Wölfflin. In the proceeding interrelated sections we will systematically uncover, examine and reflect on the relationship between form and being along three distinguishing formal categories, which for both Worringer and Wölfflin - in their own terms - constitute a number of early architectures of antiquity's fundamental makeup: that of, draughstmanly-geometry, closed material individuality, and the plane. After briefly establishing Worringer's overarching theoretical argument as an introduction, each formal category will be approached in its own subsequent section and in each case Worringer's arguments for their individual temporal-spatial significance are presented as a point of departure and first level of consideration. We will however inevitably progress beyond his reasoning proper in an effort to understand more fully the nature of the 'timelessness' such formal qualities aspire to and/or impart; principally grounding this in the reasoning propositioned earlier that within the Apolline 'being' there is also, paradoxically, aspects of the Dionysian 'Being' as a continuity of the present. Again to reiterate, answering this question is not the exclusive goal of these sections, but such considerations allow us to understand constructively and accurately 'being' as an aesthetic quality of architecture. To add, Worringer, nor Wölfflin, explicitly deal with temporality, it is therefor necessary to extract the temporally significant aspects from their observations and hypotheses; indeed Worringer's arguments are primarily concerned with 
space, with temporality often merely inferred.

It is worth expressing from the outset that this is by no means an esoteric study of what some may suppose historically removed architecture. It should become clear that the formal qualities and the aesthetic experience they engender that are presented are ubiquitous and foundational, albeit in transfigured form, to and throughout much of the historical and contemporary built environment. It is merely that in Greek architecture, and architecture of the same genealogy, we are afforded clear, unambiguous examples due to the relative focus of artistic intent.

Worringer offered a markedly different historical interpretation of the arts of antiquity in contrast to prevailing views of the time, views which the reader will likely recognise continue to dominate at a basic level as a common dogma. In the conventional Semperian view, ${ }^{2}$ the history of art is essentially a history of ability (Worringer, 1967/1907, p. 9). The supposed imputes of early art was to create copies of the natural phenomenal world with as much accuracy as possible, and this endeavour was only tempered by the skill and technical ability of the artist (ibid). In this reasoning the basic characteristic of artistic objects, and wider artistic 'styles' as a whole, are in the first instance a reflection of this limitation. When we consider the art of early cultures such as that of Egyptian antiquity, in this logic we interpret qualities such as simple regular lines and 'flat' 'inaccurate' representations -as found in the hieroglyphs- as a mark of the limited ability of the artist to render 'natural-models' - people, plants etc. - as they actually appear; in this we may be inclined to infer a certain 'primitiveness' in the lay sense of

2 The 'semparien' view refers to the theories established by the $19^{\text {th }}$ century Germane architect and art critic Gottfried Semper, or more, as Worringer suggests, the 'materialistic method' developed through a "petty misinterpretation of his book" - Der Stil. (Worringer, 1967, p. 9). 
the term - with all its attached presuppositions. Worringer's argument was however fundamentally different in that he considered technical ability as only secondary to the outcome of the art object. For him the characteristic quality of art is first and foremost the result of artistic volition; that is, the 'will' of the artist (ibid). In this reasoning the particular quality, the aesthetic, of art was quite intentional, as it was the 'will' of the artist to render the natural world not as it actually appeared to them, but in such a way that it gratified their basic 'psychic-need'. The quality of the art object always, he writes, "stand[s] in a causal relation to the psychic need which they satisfy" (1967. p. 12-3). In the case of the will to 'Abstraction', which Worringer argues - in sympathy with Nietzsche's views - was the pervading artistic volition from early Egyptian through to the Doric order of Greek architecture, this need was to escape both space and the 'flux' and 'happening', caprice and confusion of the existential condition of Time (1967) - or, more encompassingly, space-time. ${ }^{4}$ In other words, to find 'reprieve' from the basic constituents of the

3 To note in passing, the tendency to explain things away in terms of 'ability' over intended aesthetic quality, translates surprisingly clearly to the modernist sensibility to assume properties of architecture arise primarily out of requirements of 'function' and 'practicality' for which they were designed - over the aesthetic qualities attached to such 'purely' functional form. K. Harries addresses this very point when he writes: "Architecture is purposeless. What we build will find its utilization. Form does not follow function. Form does not arise out of its own accord. It is the great decision of man to make a building as a cube, a pyramid, or a sphere". That is, a deeper 'decision' to overcome the "terror of the infinite", of "time" (1997, p. 231). This point is raised as given our own tendencies and assumption, it is a thought of value to keep in mind; too easily the properties here discussed can be explained in 'functional terms', and arguments can potentially be lost to such ingrained reasoning.

4 We will gain an understanding of the relation between space and Time as the thesis progresses i.e how a negation of space equates to a negation of Time and visa-versa; due to the complexity of the relation it can not be attended to here. 
human condition - to negate one's actual being-in-the-world, to borrow a term from Hiedegger. ${ }^{5}$ This 'desire' was born out in, and causally gratified by the basic formal constituents - in his terming - of 'abstractgeometry', 'material individuality' and the 'plane'.

'Empathy' as a distinguished artistic 'will' marks a subtle shift in formal quality that gradually started to appear during the Doric order and following the same Greek tradition is most overtly expressed in Renaissance architecture (ibid, p. 80 \& 120). Such architecture still holds the basic above-mentioned formal properties, it is merely here that they are more 'relaxed', allowing in and 'expressing' a degree of organic movement or vitality as part of their affect, while in 'abstract' architecture the same properties are definitively more complete in removing all qualities of the organic's temporal nature from the representation. The empathetic will marks an increased sense and acceptance of "being at home in the world" (ibid, p. 45).

While these differences which define the two 'volitions' have interesting and obvious temporal significance they are however not the focus of the following sections. Both, as Worringer writes, meet "a common need which is revealed to us as the deepest and ultimate essence of all aesthetic experience: this is the need for self-alienation." (ibid, p. 23). It is the desire for reprieve from temporal-spatial existence through the 'eternalisation' (ibid, p. 83) of form basic to this 'self-alienation' that is of interest, and as we will see it is a desire met through the abovementioned basic formal constituents regardless of the formally nuance differences each 'will' elicits. -Both 'wills', and the formal properties as-

5 At the farthest, and most intriguing extent of this logic, it would not be to much to permit that the skilled early Egyptian artist could, had they desired, rendered through pigment or stone representations that equalled the realism of the likes of a $19^{\text {th }}$ century painting of Jean-Francois Millet, or a $17^{\text {th }}$ century Baroque sculpture of Bernini. However, what we commonly interpret as an interpretive simplicity, or abstraction, reflects nothing of inferiority, but in Worringer's reasoning a deep eversion to Time and space. 
sociated with them, are merely 'gradations' of varying 'intensity' of the fundamentally same 'urge' (ibid, p. 23). The study therefore focuses on the abstract volition, as the more total and 'intense' of the two to this end. In difference to Worringer, the position is held that a significant break from the fundamentals of the artistic intent to suppress Timespace did not take place until the 'baroque style', immediately succeeding Renaissance art and architecture - it is here that Wölfflin in his own terms observes an absolute inversion of both will and treatment of form; that is a transition from an architecture of 'Being' to one of 'Becoming'. To note however, even here we find argument that a definitive architecture of becoming, if such a phrase can be used, is only total in effect within the slums of Brazil; the Baroque still holds on to basic aspects of 'being' as a negation of 'becoming' ${ }^{6}$

Before elaborating on each formal property some of the ambiguity of Worringer's -and other's- own work can be shed with respect to these constituents' capacity to impart reprieve from Time, through teasing out two underlying qualities each possess; that which will here be termed Autonomy and Clarity. I only wish at this point to provide a brief acquaintance with these terms; the study will, and only can effectively, develop a thorough understanding of each as it progresses. In brief, Autonomy relates most closely to Nietzsche's conception of the Apolline, as it refers to qualities of form which project an articulated sense of its 'individuation'. That is, it projects a certain material 'closedness' / separation - an autonomy -, antithetical to any notion of a 'primordial unity'. The quality of Clarity in distinction transcends one's basic mode of apprehension and experience particular to existence in Time, that of

6 In this, while it may appear a misappropriation of Worringer's thoughts to apply the basics of the will to abstraction to 'Classic' architecture generally, and particularly latter Renaissance architecture -the 'empathetic art' - the level at which this text approaches the issue allows these architectures to be analysed under the same conceptual framework. 
gradual disclosure; as Bergson asserted Time is definitively that which "hinders everything from being given all at once." (1946/1934, p. 110). In difference, we perceive form with this attribute, to borrow Wölfflin's terms, as 'perfectly clear' and 'absolutely comprehensible' (1932, p. 224); that is, totally and instantaneously knowable. Time can reveal nothing more of the form than we perceive in the present moment from a single given point in Time and space; all is completely disclosed; Time is no longer a necessary condition of our experience of the object.

We will find argument that form appeals to both of these qualities, requiting the same 'psychic need' to overcome Time - and space - in each one's different but interrelated manner. Naturally both though distinct as cognitive processes, are merged in a far more complex and holistic experience of form, they are strictly speaking different sides of the same phenomena; their theoretical division here serves in the first instance as a convenience of study. Exposing these two qualities within each property of form will largely help structure the analysis. ${ }^{7}$

7 Worringer does not tacitly recognise these dual temporal implications, and consequently derives much of its rationale from the more convenient and established argument of form's implication for a projected autonomy; which alone does not go beyond Nietzsche's particular conception of Individuation. While qualities of clarity are presented in his argument they are not elaborated on for their own temporal significance; and are only considered with respects to their facilitating of autonomy in a purely spatial sense. 




Figure 7: Negative of an eclipse: static form of the geometric line juxtaposed against formless movement.

Source: F. W. Dyson, A.

S. Eddington, \& C. Davidson, (1920), p. 332. 
The geometry of interest in this section takes many names by various theorists, 'pure', 'regular', 'strict', 'crystalline' or 'abstract', and while each grasps something of its quility, discriptively it is most clearly captured -as it will be employed in this text- in Wölfflin's encompassing term 'draughstmanly' (1932/1915). It refers merely to the simple strict line derived from the precision of instruments such as compasses and rulers and the various regular forms and surfaces that this line can be configured into such as rectangular or circular planes; it is nothing more than the geometry that pervades much of the historical and contemporary built environment. It was for Worringer a first and basic step in the constitution of architecture for 'civilizations' of antiquity, such as Egyptian and early Greek, to placate an unease at their subjection to Time and space. In the following section concern will be primarily limited to that of the 'draughstmanly' line and surface, the particular temporal value of geometric shape, and three dimensional form generally, is more accurately a quality of 'closed material individuality' and will therefore be properly dealt with in the subsequent section.

Socraties, in Plato's dialogues, was one of the earliest to attribute a particular aesthetic value to instrumental geometry, one of 'truth' distinct from the relative 'pleasures' of the 'sensible world' of ever changing phenomenon, he writes:

"I do not mean by beauty of form such beauty as that of animals or pictures, which the many would suppose to be my meaning; but, says the argument, understand me to mean straight lines and circles, and the plane or solid figures, which are formed by turning lathes and rulers and measures of angles - for these I affirm to be not only relatively beautiful, like other things, but they are eternally or absolutely beautiful" (Plato, Phiebus 51c-d trans. Jowett, B. 2009, p. 232)

This basic point of difference between 'absolute' and 'relative' phe- 
nomenon that Socraties uses in discussion with Protarchus to convey what might be meant by 'higher' aesthetic sense, in many respect prefigures the basic underlying argument of Worringer - if not all debates. Positioned on the thought of Alois Riegl and August Schmarsow, Worringer argued that the capacity and efficacy of what he terms 'abstract' geometry to impart any aesthetic quality - that is a 'point of repose' from the changing sensible world, or 'beauty' - lies in the extent to which it projects a disconnection from the 'growth and withering' of the organic (Worringer, 1967, p. 20). A strict geometry, of abstract as opposed to natural quality, refutes at a basic tactile and visual level a relationship with the living organic world. In an appeal to our common sense such pure geometry is not, for the most part, present in the organic world we are a part of; and in this, with a certain simply logic, we mark its difference. The line of instrument, Worringer writes, was for the people of antiquity, "... seemingly purified of all dependence upon the things of the outer world, as well as from the contemplating subject himself." (1967, p. 36). In this quality of formal representation the, "last trace of connection with, and dependency on, life has been effaced", achieving the "highest absolute form, the purest abstraction [...] while everywhere else the caprice of the organic prevails." (ibid, p 20). Through this distinction abstract geometry is relinquished from one of the organic's most basic and certain natures; encompassing its inevitable declination, death by conviction of birth, but more broadly its temporal conditionallity as a whole. ${ }^{8}$ As Schmarsow suggest, any form alluding

8 This is a point worth emphasising: while a focus on the comparison between strict geometry and the organic tempts a reading that the gratification found in geometry rests in its overcoming of Time's most obvious, or more, preoccupying consequence for the organic - its mortality- , the quality of geometric abstraction is directed toward and achieves an overcoming of Time in far broader and complete sense. That is to say that mortality - which can, due to its existential bearing too easily take the pedestal - is merely a consequence of Time, but not the totality of what one find's disquieting within it. A focus on this significance lacks the immanence 
to the organic betrays its conditionallity and predisposition to growth and declination, which in turn discloses Time. Relaxation from strict geometry, Schmarsow writes, "caries the figures involved over into the conditions of growth and life, i.e. of temporality." (Schmarsow, 1905, as cited in Worringer, 1967, p. 87). This imparts to it its 'relativity in the world picture' (ibid).

This argument of difference is useful, pointing in the direction of the essential matter, yet better serves as a provisional analogy for something more ineffable. Strict geometry holds an obvious visual and tactile difference with the organic, but the feeling it imparts is arguably not simply in the fact of an arbitrary distinction alone with that which is subject to the condition of Time, but in the internal nature of its particular quality and what it holds for us. This is a quality we must know intuitively, as it evokes an aesthetic response, but our need here is to explicate that intuition, to make it effable. While in the course of Worringer's argument it is the mere fact of distinction alone that braces much of his logic, he does proposition 'necessity' as a characteristic quality we 'feel in it'; that is that we find 'crystalline' geometry necessary, or precise and efficient, in comparison to the 'arbitrariness' and 'caprice' of the organic (1967, p. 42). 'But here, as in the argument of difference,

of Time's impact on one's immediate experience, as it remains a removed idea. It is arguable, however, that it is a central part of the 'aesthetic' experience to the extent that an undercurrent of anxiety towards mortality is part of our immediate emotional constitution. -Such an argument is alluded to by Schopenhauer. Read, Schopenhauer, A. (1969). The world as will and representation. (E. F. J. Payne, Trans.). New York: Dover Publications. p. 280-283 (Original work published 1819). For an interesting and contemporary cross-section of this view and others read, Becker E, (1997). The denial of death. New York: Simon \& Schuster.

9 Worringer initially offers various rationalizations for what this extra quality of abstract geometry might be, however, self-admittedly he recognises these as "vague attempts at explanation" (1967, p. 36). It is consequently after this that he contents himself with the property of 'necessity' (ibid). This is not a term 
it is notable that there is not a direct relationship between the property of geometry and its projected relation to temporality; it has no bearing on our sense of Time directly, it merely mitigates phenomenon we find disquieting that are consequential to it, i.e. 'arbitrariness'. However, if we follow one of Worringer's central maxims more strictly than he himself does, that artistic manifestations directly "stand in a causal relation to the psychic need which they satisfy" (ibid, p. 13), we potentially expose a more intimate relationship between the 'will' or need -which is to overcome 'Becoming' - and the temporal property of 'abstract' geometry. As a point of entry to understanding what is a remarkably simple relationship we may adapt and supplement an observation made by Karstan Harries.

The common strict geometric line, Harries asks us to reflect, sits in a different relation to 'time' than say a line drawn by hand. In creating two lines, one without aid the other a circle braced by instrument, we would be obliged to recognise an obvious characteristic difference between the two; the former relatively clumsy - or "expressive"- in comparison to the latter's precision (Harries, 1997, p. 228). For Harries, in concord with Worringer, the latter as he writes, "comes as close as a

that he delves into in any depth, but in his brief referral to it the idea of necessity lies in an historical-evolutionary argument in which 'primitive' peoples, confronted with the uncertainty, caprice and confusion that Time engenders, found immense reprieve in the certainty, irrefutability and conclusiveness -that is, necessity- of regular geometry that was otherwise not present in the natural environment they were immersed - a notion harder to grasp considering our relative detachment from the natural environment. To add however, it is likely borrowed from the late $18^{\text {th }}$ century philosopher Friedrich Schiller, whom employed the term to denote a quality of the inner 'eternal self' - a raw consciousness or 'Absolute Being', as something altogether different from finite being. In this sense 'necessity' is fundamentally a description of 'timelessness'. Read Friedrich Schiller, (1967) On the Aesthetic Education of Man, in a Series of Letters, (Wilkinson, E. M. \& Willoughby, L. A., Trans). England, Oxford: Oxford University Press. p. 75. 
visual statement can to the timeless realm of the spirit, while the other has an organic look and seems to embrace time." (ibid). However, if we look more closely we can place this in more concrete terms. While indeed in this simple distinction we intuitively read two different representations of temporality, more precisely however, in the latter it is a case of a lack of representation. With all its deviation, its imperfection in traversing from one point and concluding at another, the mark made without aid of instrument is bound by the perpetual movement, uncertainty and instability that Time affords. The line of a rule, in comparison, discloses no evidence of such impairment. It does not convey any traversal as it becomes in Time, it merely is. Here we can recall Plato's/Timaeus's distinction where, 'becoming' is "that which is always becoming and never is" and 'being' is "that which always is and has no becoming" (Timaeus, 27d-28a). In this quality of 'being' crystalline geometry presents itself as 'absolute' and 'ultimate', to use Plato's terminology, in a consummate completeness within itself; its temporal boundaries are definite, it suggests no origins in Time while in the same measure suggests no further becoming to meet its own ends, ${ }^{10}$ in other words, it 'is' what it always will be.

To not have been, and only to be, is no unremarkable quality to project; one that we can infer has no place in the world-picture outside any 'need' of humankind. To the extent that all physical phenomena are in Time, all wear the mark of becoming - that is, the 'marks' of their past coming-to-be-as-they-are. Whether the organic leaf, or inanimate stone, imbedded in their form - and their matter - is their passage in Time. In the arcane lines of stone is impressed its original subjection to compression and heat and that of its weathering in a depth of Time incommensurable; while in the form of the leaf is a language of growth, which transposes seamlessly only to one of withering and decay. As sure

10 Why this equates to no future becoming either, and ambiguities around the argument, are more thoroughly dealt with the proceeding section. 
as the mass of physical objects demark their presence in space, their matter and form demark with equal tangibility their becoming in Time. While there is the trace of a constant change here, in the abstract geometric line there is nothing but a projection of pause and rest. That 'pure' geometry carries no such mark, is for it to impress that it is not subject to Time as one side of the most basic condition of all things -the other being space. ${ }^{11}$ It is in this affect that phenomenologically, we may entertain, Time is not given a presence, an import, through which to disclose it in the representation. As Jacques Derrida reflects, in sympathy with Bergson, Time is already that which we struggle to be aware of:

"Time... gives nothing to see. It is at the very least the element of invisibility itself. It withdraws whatever could be given to be seen. It itself withdraws from visibility. One can only be blind to time, to the essential disappearance of time even as, nevertheless, in a certain manner, nothing appears that does not require and take time." (1994/1991, p. 6)

We may adjust Derrida's statement however and say Time, as an opaque, but real and affecting force, gives much to see re-presentationaly as it moulds material phenomena, but denied this subsidiary trace, it regresses into its state of 'invisibility' and consequently is further pushed from awareness; in one's aesthetic apprehension of the strict line and the geometric form generally, the becoming of phenomena, and the very dimension itself, is not given disclosure.

It is this remarkable quality of simply 'being', both visually and tactiley, that we can speak of strict geometry and the form it demarks as not only mitigating the disclosure of the 'entropic' continuum of change, but as having a certain autonomy from it. To perpetually only be is to impress a certain detachment, to be of a condition separate

11 Space, we will find argument for in later sections, is also removed. 
and autonomous from our own corporeal temporal reality; the 'material would' is after all, as 'Timaeus remarks with a certain irrefutability, that which "comes to be and passes away, but never really is" (28a). It is to be removed and unaffected much like Nietzsche's boat in the sea, or at least one's indelible trust in it. Understanding the strict line at this level we may observe that complicitly it achieves its projected detachment in a spatial sense as well; this being perhaps its more obvious and intellectually accessible quality. In other words, it is an autonomy that is equally spatial in nature, and can be understood as such from this angle; just as Nietzsche's conception of 'Individuation' constitutes both a temporal and spatial distinction from what he conceives as an entropic 'unity'; 'reality as it is'.

While the strict geometric line embodies no quality of change, in the same measure the line as the visual and tactile edge of the form presents, to use Wölfflin's words, an 'articulated', 'clear-cut' crystalline division between itself and other material phenomena; that is, it imparts the appearance of a distinct, isolated individual 'object' (1932/1915). For Wölfflin, within Classic architectures the 'draughtsmanly' line was employed as a means to accentuate, and place visual attention on, the outline of the form, as it 'stresses the edges' (1932/1915, p. 18). ${ }^{12}$ This is a quality he presents in contrast to that aspired to in baroque architecture, wherein the 'sharp line' dissipates, becomes 'painterly' in affect. In the 'play' of intricate ornamentation across its surface all 'perfectly distinct' contours are obscured, details begin to 'entwine, fuse' and 'in-

12 To note as we begin to draw on Classic architecture as example, in Worringer's reasoning truly 'abstract' geometry gives way here to slightly more organic line treatment. As opposed to distinguishing itself completely from the organic through a point of difference, it becomes more a mater of reappropriation; as the strict line is grafted onto more natural models. For the purpose of this thesis, in a logical that inherently assets itself, the more 'vital', 'expressive' line in Classic architecture still impresses a state of 'being' as it has been established so far, and therefore this shift is of little significance. 
terflow' (ibid, p. 66). In this the rigid formal 'boundary' is supplanted by an overarching 'movement' that unifies and obscures the distinctiveness of the object; the eye is drawn to the intertwined mass, over formal outline; "linear style sees in lines, painterly in masses" (ibid p. 18). Wölfflin writes of the two approaches: "Classic taste works throughout with clear-cut, tangible boundaries; every surface has a definite edge, every solid speaks as a perfectly tangible form; there is nothing there that could no be perfectly apprehended as a body. The baroque neutralises line as boundary [...] form in itself grows intricate and the order more involved, it becomes increasingly difficult for the individual parts to assert their validity as plastic values; a (purely visual) movement is set going over the sum of the forms [...] The wall vibrates, the space quivers in every corner." (ibid, p. 65). In this we begin to grasp the dual affect of the line in achieving a certain complicit temporal and spatial autonomy; they are quite indivisible. Even when approaching the line with respects to its affect of a projected spatial autonomy, the consequence of it's 'blurring' is to impart a temporal quality of movement. As Wölfflin suggests, inevitably "by the depreciation of the clear, separate form the semblance of a mysterious general movement is produced." (ibid, p. 222, my italics). ${ }^{13}$ In this temporal-spatial autonomy of the geometric line we have a clear foundations of Nietzsche's Apolline aesthetic as the highest articulation of the 'principium of individuation'; the individual body both isolated in space and from the condition of becoming.

It is necessary to mention here quality of surface as a complicit property in this general affect - it is difficult to speak convincingly of a strict line lacking representation of Time, and projecting a spatiotem-

13 Analogous to the way a sharp and dense mark of charcoal on paper, when swept over and smudged, inseparably presents both a less defined edge and an impression of movement, or at least formal instability -latent movement-, regardless that the latter state is in actuality as static on the page as the first - Fig 7 conveys the point well. 
poral autonomy, if the surface between its points, the physical majority of the form, is considered indifferent in this affect. In the first instance, staying with Wölfflin's president of High Renaissance architecture as example, the common treatment of the immaculately polished, white stucco or marble surface finish common to it, can be understood as a continuation of the strict line with regard to temporal value. Qualitatively it imparts the same clear, rigid spatial-temporal articulation, analogous in property and affect to a line merely extruded out into a surface - equally unflawed, lacking the traces of temporal conditionallity, its coming-to-be-as-it-is in Time, while equally accentuating a distinct boundary. The affect is sufficiently captured in the common terming of architectural surface treatment as a 'finish'. The 'finish' presents, as Leatherbarrow and Mostafavie write, an expressed pause of the building's construction, an end to its 'life within Time' (1993).

This relation of the geometric line and surface runs deeper still in affect, in that both not only articulate the temporal-spatial separateness of the form, but arguably in inextricable measure depreciate the presence of the very matter the form is rendered in. - Raw matter being, as Mostafavie and Leatherbarrow suggest, that which has "implied in its constitution", and which "carries within its deepest layers", its "tendency towards its own destruction" (1993, p. 69); a notion equivalently expressed by Wölfflin's postulate that 'formless matter' is always that which the 'will' to form, and the properties of built form itself, 'struggles' to 'resist' and 'overcome' (1886, p. 159). In Classic architecture, as he alludes, the strict line not only defines and clearly 'separate' form as it 'stresses the edges', but draws the eye away from its substance, the 'matter' and 'mass' that it binds; classic sensibility 'sees in lines', over 'masses' (Wölfflin, 1932/1915, p. 18). This measure is supported further by surface treatment that conceals the richness of materials, with their own aesthetic import, under an immaculate and silent finish. Juhani Pallasmaa elucidates these points when he addresses the main 
line of modernist architecture's own "quest for the perfectly articulate autonomous artefact", he writes: "The aspiration for geometric purity and reductive aesthetics [...] weakens the presence of matter, in the same way that a strong figure and contour reading diminishes the interaction of colour in the art of painting" (2000, p. 79). Such surfaces, he reflects, "tend to remain mute, as shape and volume are given priority; form is vocal, whereas matter remains mute" (ibid). In this the surface, as with geometric line itself, projects an 'abstracted boundary or volume', which has a 'conceptual' and definitively 'immaterial' essence, over one which is physical, tactile and 'sensory' (ibid). The articulated form is, in intended affect, removed from the temporal conditionallity of physical matter, -of its inclination to return to 'formlessness' and placed in the static, un-physical and immaterial substance(lessness) of conceptual shapes: "Abstraction and perfection transport us into the world of ideas, whereas matter, weathering and decay strengthen the experience of time, causality and reality."(ibid). Form proper, as a composition of abstract relations -lines, angles, planes etc. - asserts its dominance over its very physicality, the 'stuff' these very relations are rendered in; matter's own aesthetic value, its physical corporality, becomes secondary if not mute to that of the form's abstractness. It is in this sense that such form's projected 'autonomy' is achieved not only as a spatiotemporal separation from material phenomenon as exterior conditions, but through denying, or inferring qualities that transcend, its own Time bound material constitution. In the most encompassing of terms it places itself, however subtly, outside what Nietzsche conceived as a more 'unified' material, spatiotemporal 'whole', through imparting the impression that it is not of the very substance that constitutes that 'whole'.

In the collective qualities of the 'abstract' geometric line and surface considered -merely the same qualities approached from different angles-, we have a first and tentative understanding of their place in 


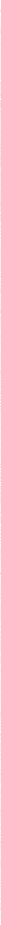

Figure 8: A section of the Doric Temple Propylaca, 5th century $\mathrm{BCE}$, Athens. Beyond its erosion and weathering still observable is the precision and fineness of the original line and surface treatment. As established by the likes of A. Q. Quincy, (1755-1849) and J. I. Hittorff, (1792-1867) the form would have been originally treated with a coloured finish; masking not only the stone's native 'marks' of Time, but to an extent that of the stone's particual materiality. Its intended temporal-aesthetic would have been remarkably different to that achieved in its contemporary condition.

Source: Lawrence, A. W. (1957) p. 383/plate, 63.

(Original photo by M. Picard) 
achieving Nietzsche's Apolline 'being'. Their value of autonomy forms a basis, and a remarkably simple one at that, from which the formal properties of 'material individuality' and the 'plane' precede, both in an effort to retain the abstract line and surfaces' original affect and were possible to extenuate it.

Autonomy is however only one side of such geometry's distinguishing quality with respects to what we apprehend within it. More intriguingly, with regards to the temporal aspects of 'being', the strict line not only impresses no origin or further becoming in Time, but through the same property, and arguably in complicit measure, in the ideal of its affect demands nothing of Time -and space- in its comprehension. This is a point that can only be put forward tentatively for now, as it only becomes more apparent when we consider the line's place in the other properties studied. This condition is inherent to what Wölfflin characterises as the overarching and definitive affect of an "absolute clarity" aspired to and imparted by Classic architectures; one arguably rooted in the strict line's native 'compressibility'. For Wölfflin through the manifest simplicity of the strict line and its demarking of a "perfectly clear and perfectly exhaustive silhouette"(ibid, p. 225) one is able to "assimilate at the first glance" form in its entirety. "Everything" he writes "is completely revealed" leaving no "mystery"; nothing unknown (ibid, p. 224). 'Visual perception' is 'exhausted' as one assimilates with 'perfect comprehensibility' all that the abstractly geometric line is without the need of the individual to actively participate in its revelation over Time (ibid). To borrow a term from the art critique Michael Fried, the strict line has a quality of "presentness": it is as though, he writes, "at every moment the work itself is wholly manifest"; 'instantaneously' apprehensible in the present moment. (Fried, 1998/1967, p. 145, his italics). Further apprehension through Time-space is unnecessary: i.e. no duration is required to apprehend the line in terms of immediacy of cognitive assimilation, while walking around it and engaging with or appreciating 
the art object etc., can disclose nothing more than is 'instantaneously' clear to sense perception in the present moment; there is nothing more to grasp, than the work is intended to impart, than what is directly before the observer. It is in this that we can speak more accurately and comprehensively of Worringer, Wölfflin and Plato's common descriptions of strict geometry as being 'absolute', 'ultimate' and 'finished'. Here we see it is not restricted to a physical, objective quality of form, but it is more overtly distinguishable as - intrinsically - a subjective condition of its apprehension: perceptually it is 'wholly manifest' in the present; in other words, our comprehension itself is 'absolute'; without the requirement of a past 'it was', or a future 'will be' of experience, to completely take in the object. As our own becoming in Time can disclose no more than what is already present, Time is therefore superfluous to our experience of the object.

Though this notion is simple, when we consider the strict line in isolation it is admittedly hard to grasp as something of efficacy, and is therefore unconvincing, if not seemingly insignificant. It is a quality that becomes more overt and holds more apparent bearing on experience when considered in its complicit relationship with the other formal mechanisms of Classic architectures. Indeed, this argument presupposes an ideal presentation of geometry, namely that it is viewed directly before us, from an ideal distance, and is restricted to the clear two-dimensionality of a plane surface; architecture's three-dimensionality posses a problem to such an ideal of clarity, if not to the validity of the argument itself. However as we will see, it is the very endeavour to retain this perceptual clarity -as an indivisible aspect of Autonomy -through insuring ideal presentation of abstract-geometry in the face of form's three-dimensionality that dictates a large part of the remaining properties of Classic architecture, and will be addressed in detail in the following reflections. 
From a developmental point of reference Worringer suggests that the property of 'abstract' geometry was not enough to placate peoples of antiquity's unease at their subjection to the condition of temporality -and space- and required further treatment of form to achieve a deeper repose. Their next endeavour was therefore to take form, based on 'natural models' of the 'exterior world', and, "tear it out of the flux of happening, to free it from all contingency and caprice, to raise it up into the realm of the necessary, in a word, to [further] eternalise it." (1967, p. 37). For Worringer, in conjunction with a reappropriation of 'abstract' geometry, ${ }^{1}$ such measure was achieved through two distinct yet interrelated treatments of form, that of closed 'material individuality' and the restriction of individual forms to the 'plane' (ibid, p. 38). Both are, in certain respects, methods to overcome problematics that arise once three-dimensionality is introduced into the artistic representation; namely as Worringer writes, the difficulty of freeing, "the sensuous object from the unclarity imposed upon it by its three-dimensionality" (ibid, p. 22).

In this chapter section the notion of material individuality will be as far as possible pried away from its dependency on the plane and considered in isolation; the plane will be addressed in detail latter. The idea of a form being 'material individual' presents more a defining conceptual quality of a wider formal treatment within Greek architectures. Anchored in this concept, the proceeding section will consider the broader and yet indivisible formal qualities addressed by Wölfflin of composition and proportion with respects to order, unity and perfec-

1 In terms of development within Classic style, up until the Renaissance, this reappropriation was characterised by a tension and compromise between an effort to render the 'natural object', or natural qualities, while 'wresting' it from its 'temporality' through the application of abstract geometry - as opposed, for example, to the likes of the 'absolute form' of a rigid, purely geometric Egyptian pyramid; there is obviously no 'natural' quality underlying such form whatsoever. (ibid, p. 37). 
tion that such a discussion presents. Also addressed is the quality of permanence. As in the previous section we are concerned solely with the temporal significance of this property, though spatial implications will be addressed where informative to this end. Structuring the study within the principles of Autonomy and Clarity each will be approach in turn.

At a basic level 'material individuality', or more simply 'closed' or 'tectonic' form in Wölfflin's distinction, pertains to the quality of Greek architecture in which each formal element that constitutes the building whole, and the whole itself, imparts the appearance of a distinctly independent 'self-contained' entity. It is the form Wölfflin tells us that "breathes independently" and always compositionally, "point[s] back to itself" (1932, p. 124). In one's immediate observation this is no more than the clear articulation of each member, structural or purely decorative; a column is clearly separate to the arch it supports, as is the arch from the architrave -though bound they do not merge, and clearly impart their difference as internally self composed formal elements (see figure 9). In Nietzsche and Schopenhauer's terms we are given 'sufficient reason' to distinguish the parts as parts, as 'Individuated' bodies. Of course this is nothing uncommon to the contemporary built environment, particularly in the case of architecture of modernist sensibility with its inclination towards exposed and clearly defined structure, details and functional components; here though the same sensibility self-consciously demands this treatment be justified in terms of a 'structural honesty', 'efficiency' or 'economy' of form; it has aesthetic appeal, but aesthetics is not its reason d'etre. ${ }^{2}$ In the Greek', with no mincing of intents, this quality takes on an extraordinary refinement in attaining what is quintessentially aesthetically gratifying within it, and

2 Fair enough, though in this obstinately rationalistic view arguable an important point is missed and the underlying metaphysical and existential significance is lost - in thought and in form. 
what arguably modernist taste both less consciously and/or admittedly aspire towards; that is, a quality of 'being' as formal beauty.

As a point of entry to understanding the temporal significance of 'material individuality' we will consider but one of the formal properties through which it is achieved, and in which its most basic temporal mechanism rests and for us is accessible; that of symmetry.

Symmetry's place in demarking a certain spatial autonomy or distinction is quite apparent. As Riegl attests, with simple reasoning, it is symmetry that "reveals to the exterior an uninterrupted tactile connection" (Riegl, 1985, p. 25). One is insured "in the most convincing of manners" that the form before them is self-contained, with its accented 'silhouette' presenting a "tactile impenetrability" to all sides (ibid); in other words, it demarks a spatially distinct, enclosed and isolated object. Little needs to be said here of symmetry's extension and reinforcement of the autonomy already aspired to through the strict line and surface; merely here it imparts that 'pronounced boundary' within the three dimensionality of form. While we will deal with its particular temporal autonomy later, to consider symmetry in more than purely spatially terms here we will approach it form the question of its particular temporal-spatial quality of clarity. In this we need to look more closely with respect to where it is used within Greek architecture, and state some very simple facts.

Taking the Doric temple of Hera (figure 10 - page over) as a visual reference we can observe that symmetry is orientated strictly about the vertical axis; that is, form mirrors or echo's itself in a horizontal direction from a vertical plane or point. As a simple example, if a column was dissected through cutting vertically directly down its middle, it would obviously produce to identical halves; from the shaft to the capital composed of the echinus and square abacus at its top, in any horizontal direction from its vertical centre form echoes a direct opposite. Likewise, if we marked a line down the centre of the building whole we 




Figure 10: The Doric Temple of Hera 1, (also know as 'The Basilica'), Paestum; constructed aprox 550 BCE.

Martin, R. (1998), p. 89

(my editing) 
would have two symmetrical opposites; it is a rule implemented from the smallest element to the whole. It is also observable that symmetry, with very few exceptions within individual elements, and no exceptions within the building as a whole, is not orientated about a horizontal axis, i.e. dissecting a column, or the building, half way up across its middle clearly does not produce two symmetrical opposites; there is proportion and order in this axis, but not symmetry. ${ }^{3}$ Now we may consider something perhaps less obvious, and in a way that will seem for now unwarrantedly abstract. Here we need to divide our axis further. If, for the moment, we block out all but one of the four planes of columns and imagine ourselves viewing it 'frontally', (the view it is designed for and that lies in the 'nature of the thing' as Wölfflin (1932) argues, - this will be dealt with in the next section) we see that from this position symmetry acts more directly and simply within space that most acutely recedes away from the ideal point of observation; the directly symmetrical shape of the column in contrast to repetition and less direct symmetry of parts spread out along the horizontal axis of the plane.

Positioned within planes, what symmetry operates within, with a gradual accompanying increase in directness, is space that most acutely recedes away from the spectator, a depth of field, or more strictly speaking what Worringer terms the 'depth dimension'. The reason for this is simple, it is recession and depth of form, and space, that obscures; it makes form, and the space that it demarks, unclear and un-prefigureable from a single point of view. Simply put, it is symmetry that shows us what we cannot see. Here we may supplement Riegl's essentially spatial notion of 'tactile impenetrability'. As Worringer adds the aim of the artistic volitions was not merely to perceive - in anyway common to us - form in its material individuality, as this would not necessarily require

3 I encourage the reader to observe the made objects around them; these rules of symmetry's place are still pervasive with respects to their aesthetic composition. 
symmetry, and suggests logically, "could have been made possible in practice by walking round it and touching it". But instead, he writes, "to gain out of the fragmentary structure and the temporal succession of perceptual moments and their amalgamation, as represented by the purely optical process, a whole for the imagination (Worringer, 1967, p. 40). That is, to 'reproduce it' as though our perception was unimpeded by the dis-clarity of our common mode of apprehension particular to the temporal existence of the individual.

We see this operate most directly within the thickness of form orientated within planes. In the cylindrical symmetry of the column, as the most unproblematic example, from any given horizontal vantage point we apprehend the visible portion of the column, exactly half, and with the regularity and certainty of its symmetry the imagination transposes what is visible to what is not; there is an exact echo of what we cannot perceive limited to one point of view; that is from one point in time-space. The same applies for more cubic geometries, or complex arrangements; such as the abacus in the former, the building whole in the later. However, although not affording a visible half in exact proportion to what is obscured, through a regularity of geometry the imagination is braced with certainty in prefiguring what is not immediately perceptible; naturally repetition of form as a type of symmetry is an extension of this, as in one element we find the completely revealed impression of similar elements, regardless that not all of a series of forms are immediately perceivable form one point of view. -These latter points where symmetry is not so direct we will deal with in more depth shortly.

For Worringer, the importance of this overcoming of the 'opticalperceptual' condition through symmetry and the faculty of imagination is in its insurance that the apprehension of form as closed in its materially individuality is not interrupted or impeded. He writes, "For only in the reproduction of this closed whole of the imagination could 


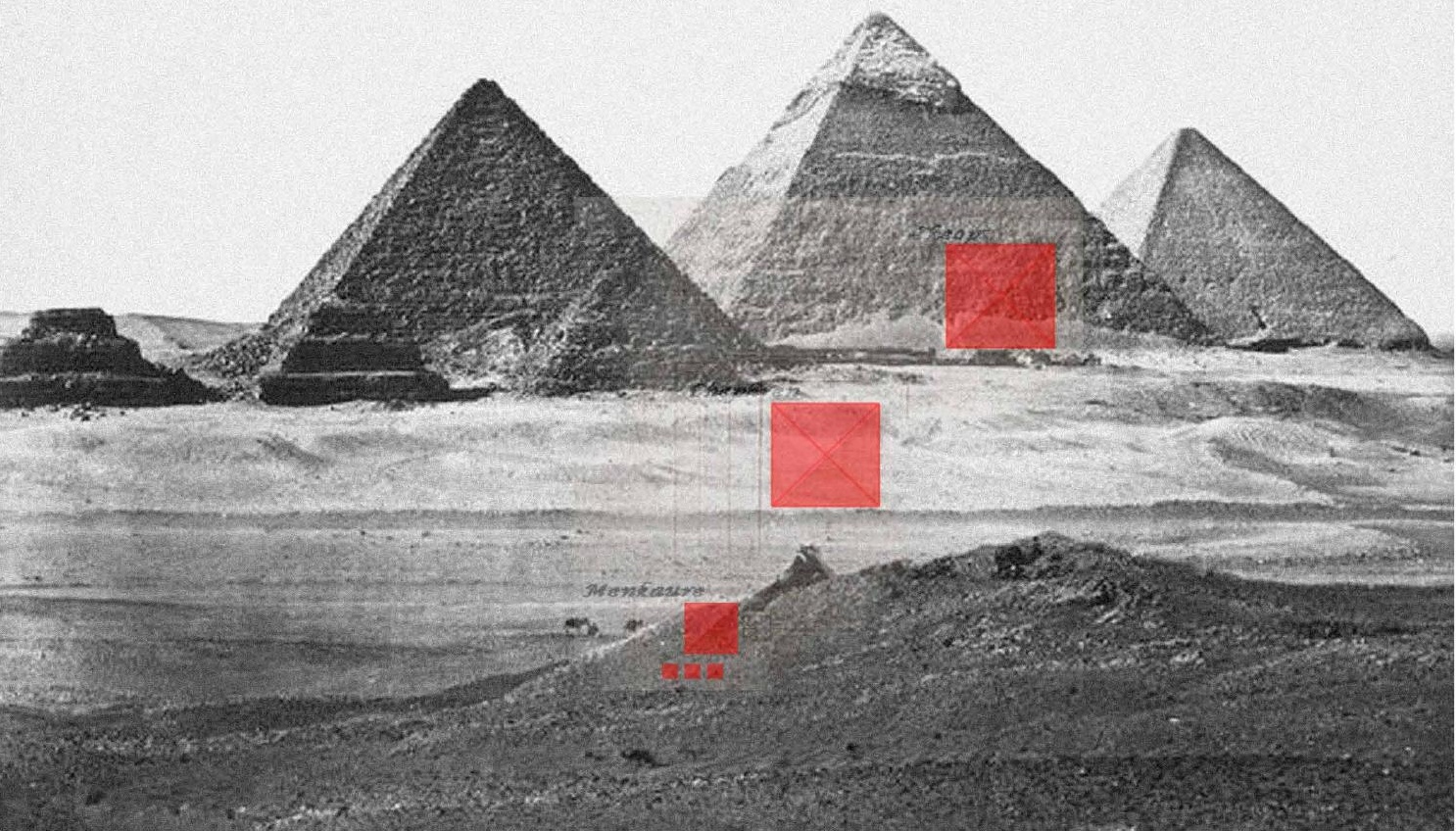

Figure 11: The Pyramids of el-Geezeh (Giza). Worringer argued that the pyramids represent the highest articulation of the will to abstraction. In terms of Clarity, a mental impression of the whole is provided from any one point of view. - Re-presenting a type of horizontal god's eye perspective of the plan view (indicated in red), Time is not a factor in the apprehension of thier form.

Sourse: Frith, F. (1862/1857), p. 117 (my editing). 
man find an approximate substitute for the absolute material individuality of the thing, which is forever beyond his reach." (ibid, p. 40), as it is, "in this succession of [perceptual] elements the individuality of the object melts away" (ibid, p. 22). Of course, we see that this quality of perceptual 'clarity' in its own right, without merely facilitating the impression of form as materially individual in a purely spatial sense, has significance with respects to its temporal implications alone.

What symmetry achieves is a facilitation and extension of the native temporal clarity of 'pure' geometry. That is, of the appearance of neither becoming in Time nor requiring duration in its contemplation; it simply is. However due to the three dimensionality of form, and the obscurity that depth imparts, this original, or ideal, quality of the abstract line is no longer possible. We are limited to perceiving it in Time, to walk around it, over Time and through space -that is, within 'timespace'-, in order to apprehend it. In this its ideal affect of absolute presence is devalued if not rendered useless; we, and the object, are pulled into the lived Time of the individual. It is symmetry that affords the reacquisition of pure geometries' presence as it reinstates it to the mind's eye - to the extent of the imagination's capacity -, as 'instantaneous', 'wholly manifest in the moment'; despite the actual perceptual immediacy lost as it recedes into the obscurity of depth. Perceptually - or more imaginatively ${ }^{4}$ - the form is 'absolute', 'finished' and 'complete' in our cognition of it. Becoming in Time is not a necessary condition in its contemplation; it not only adds nothing to its affect, and is therefore superfluous; it in fact deducts, and is therefore in its ideal, removed.

Symmetry is only one formal treatment within a wider order of composition and proportionality, it is through reflection on this order that we may further understand how temporal clarity is attained, particularly with respect to the building whole; which of course, one would

4 As Worringer suggests, "It is a question of imagination, not of perception.” (1967/1901, p. 40), though how much can we truly separate the two. 




Figure 12: Some of the basic proportional relations between elements of the Palazzo della Cancelleria's internal courtyard.

Sourse: Sklifas. S, (2008). (my editing) 
argue, can never be totally revealed and present to us from a single point in space-time. While in Classic architecture every element of form is clearly articulated in its closed individuality, Wölfflin suggests, in sympathy with common knowledge, that all including the whole adheres to a binding "strict arrangement" and "rule" (1932, p. 148). Through a "uniformity of proportions" and "oppositions clearly worked out and mutually supporting" the smallest element to the whole abides within a common order or an "underlying unity" (ibid, 1932, p. 221-222 \& 1967, p. 66).

Taking the internal courtyard of the Palazzo della Cancelleria in Rome as an example - figure 12, above - a basic sketch, rough as it is, within an elevation of a few bays of its arcade, begins to reveal a compositional and proportional interrelation of formal elements. Such a diagram however does little justice to the totality of this system or to the completeness of form's adherence to it. In the case of the Cancelleria this order is rooted in the ratio of phi/"golden section", in this Wölfflin asserts nothing is arbitrary, "not even the smallest detail is allowed to escape the basic ratio" (1967, p. 67). No element is without compositional relation to any other element, everything rest in perfect equipoise and balance in and between themselves. In the complete "unity' and the imparted "all-embracing harmony" between parts form takes on the appearance of what Wölfflin terms an absolute "inevitability" or "immutability" (1967, p. 66-67; \& 1932, p. 149). In other words, the spectator is convinced that "only this form was possible here and no other" (1932, p. 151). To quote what Wölfflin cites as the classic definition of L, B. Alberti, "the form must be of such a kind that we could change or remove no smallest part without destroying the whole" (ibid, p. 237); all is complete and 'finished' in an 'absolute' perfection.

If we could entertain the logic of this for the moment, one not only feels that a form should be as it is, and where it is, but through the clear articulated order in a certain regard one is able to prefigure what 
will be there - before its active revelation in Time. Not in an intellectually tangible respect - the ratio of phi for example is definitively irrational - but a deeper intuit sense of form's limit and inevitable bounds within a definitive order. It is as though, as Wölfflin writes, "the image of the whole is repeated in its parts", and visa versa (1967, p. 66). To add, while it is of course nonsense to imply one can completely take in a whole building from a single point of view, as Wölfflin suggests "we always know what we have to expect" (1932, p. 224). That is, we are afforded a knowledge that proceeds any immediate perception of the 'thing', a perception that otherwise requires one physically, actively, in the individuated corporal self, to engage with the object in Time and in space. P. Frankl puts this more concretely when he suggest that the imagination has no difficultly in "supplying what [is] temporarily hidden from view" (Frankl, 1968, p. 144), as it creates what he terms a "complete architectural image" - an equivalent notion to Worringer's, 'whole for the imagination'. This "architectural image" is a singular "mental image" of the building that one usually derives and constructs over time, -and never completely- as we "draw together into a single mental image the series of three-dimensionally interpreted images that are presented to us as we walk through interior spaces and round their exterior shell" (ibid, p. 143-4). In the case of early Renaissance architectures however, "The eye", he writes, "takes in the situation at a glance. The image -the architectural image- is complete from all viewpoints. There is no temptation for us to walk round the building because we realize at once that it can offer us no surprises."(ibid). In this we may understand that while in a literal sense the disclosure and revelation of the building whole through Time-space is inevitable, as of course it always is if we ever intend to occupy it, the form however in its ideal is bled of temporality's most disquieting, or invigorating, consequences for the spectator; its most essential aesthetic consequence for experience - for the temporal existential condition of individuation more generally. That is, 
depending on one's personal disposition, there is no 'surprise' and 'mystery', or confusion and fear in the face of the unknown. 'Time Bergson argued, "hinders everything from being given all at once" (1946/1934, p. 110), here Time is transcended in that the formal whole is given at once; all is "absolutely clear", prefigured and manifest in the present to the mind's eye. In the ideal of this affect the statements made with regard to symmetry's temporal significance, though arguable with less palpable efficacy, hold true here. One's contemplation of the form is complete, 'ultimate', or 'absolute', in the present moment. Actively Becoming through Time as a condition of one's 'knowing' or experience of the form in all that it is intended to be is reductive; in the form's ideal affect, it is removed.

We will now turn to the question of form's temporal-spatial autonomy, to both further consolidate how 'being' is achieved with respect to what we have considered, and to reach some new points. How though can we speak of autonomy, - of a separated, 'closed', material individuality of form - with such a deep "unifying" interconnectedness of parts? Autonomy and unity as qualities are after all antithetical; as terms, they are antonyms.

While definitively unified, Classic architectures Wölfflin tells us adhere to what he terms a "unity of multiplicity"; that is, while mutually supporting within compositional relations each part "breathes independently" (Wölfflin, 1932, p. 185). At an immediately obvious level, we read this independence in the articulated joints and seams between parts, i.e. an expressed point of difference through a moulding, extrusion or recession. An articulated window frame or a column's moulding

5 It is a reasonable presupposition that 'unknowingness' and the disquieting 'confusion' it can impart -or mystery and intrigue- are quintessential qualitative affects of experience that unfolds in Time, and of the human condition in Time more generally. 
at the base and capital of the Cancelleria suffice to make the point; all is 'clearly separated'. However this is more a theatrical touch dressing a deeper independence of elements, one that we have already viewed in passing but which we here need to attend to more directly. That is, the internally reflective composition within every element as it always 'point[s] back to itself' (ibid, p. 124). While every detail works harmoniously with the unity of the whole, each part within itself is complete in its internal resolution; proportionately and compositionally within itself it rests in a complete harmonious equilibrium through equipoise of its constituting geometries; it attains and impresses a consummate perfection within itself. For example if we were to remove a formal element, say again a window or capital of the Cancelleria, and observe it in isolation, while lacking in meeting its functional ends compositionally it is a 'self-contained' object in want of nothing. No imbalance is produced within the object through the removal of any immediately adjoining component; it still rests in perfect equilibrium within itself. In the horizontal and depth axis, which we have already observed symmetry operates within, this is nothing particularly complicated; for the most, in the aesthetic formal elements, we have regular symmetrically divisible shapes - circles, squares, rectangles, and combinations of these. Common to these geometries is the fact that they have equal, 'mutually supporting', reflective sides; they are internally in a very basic compositional equilibrium. In the vertical axis while there is not for the most part such basic symmetrically divisible composition of the form, there is, as observable in fig 12, more subtle harmonious relations of 'proportionality' at work -as noted in the Cancelleria, this is rooted in the ratio of phi. Across all axis each formal element is compositionally independent or 'closed'.

This brings us back to Wölfflin's notion of 'inevitability' or 'immutability' where both single part and building whole impart the appearance that nothing could be 'added or changed', that is we feel the form 
should be as it is. Inherent in this, Wölfflin remarks, are two basic principles of effect coined by Alberti as "finitio" and "concinnitas"(ibid, 1967 , p. 67). The former is a constituent of the later, which presents "the highest concept of all", both however Wölfflin notes mean essentially the same thing, or at least Alberti uses them interchangeably: the form in its 'proportionality' of height, breadth and depth relations projects itself as finished and in "complete Harmony"(ibid).

It is the quality of being "finished and ultimate", "perfect" and "harmonious" (Wölfflin, 1932, p. 151-152), which most overtly approaches the individual form and the building whole's temporal implications (with respects to its projected autonomy). In terms of temporality, these qualities are distinguished as a suspension or cessation of the becoming of the object; in other words, to be "perfect" / "finished", is to impress itself in a state of paused equilibrium, while the rest of the phenomenal world is in a restless, stateless process of transition. But to move beyond such a general statement, we need to consider this property with respect to its temporal value of 'being' in relation to that of the strict geometric line's; here we can make an interesting observation, one which allows us to speak more accurately of both.

In the previous section it was suggested that the geometrically abstract line is definitively that which has no mark of change; that is, of its ever having become in Time. Strictly speaking this is a relation it holds to its past, its quality of being lies in the impression that it never was perpetually and always. It was noted in passing that by extension this meant that it never will be as well. The fact being that which perpetually has no past can have no future. This is admittedly a perplexing statement that does not say much, though the logic and point becomes more reasonable when inverted: that which perpetually has no future clearly can have no past. In either account, if we remove either the 'was' or 'will $b e$ ' from the equation, the result is the same, something that always ' $i s^{\prime}$; that is, something appearing, whether we are conscious of it or not, as 
though it only occupies, or is of, the present alone - which in actuality, as Schopenhauer would argue, all things are.

Unfortunately this is a half-truth, or at least, in the case of artistic representation, it requires further measure to insure the impression. To illustrate the point, imagine a line, perfectly straight, receding away from you infinitely -for all you know- into the Horizon. For all its quality of having no mark of its ever having come-to-be, such a line still speaks of the continuum of change within Time, or more, of future participation within it. As Michael Fried suggests recession is almost a "natural metaphor" of "temporal experience" - "manifested, for example as expectation, dread, anxiety" (Fried, as seen in Harries, 1997, p. 216). Harries, reflecting on this statement, puts it eloquently when he writes that, "Our experience of recession, and more generally of distance, is inseparable from anticipations" (Harries, 1997, p. 218). That is, anticipations of a gradual unfolding of experience, or revelation and disclosure through Time; the undisclosed horizon references the unknown, of a comingto-be of experience. In terms of Clarity the line is not wholly present to us, while in complicit effect a sense of Autonomy, both spatial and temporal, is denied as we can not define its boundaries; it is not a spatially 'closed entity', while temporally we have not sufficient reason to conclude it is finite, finished and complete.

While bound by the abstract line and surface there is no mark of the form's ever having come-to-be as it is, more overtly here, as a form in perfect compositional equilibrium, there is a definitive impression that it will never come-to-be anything further. The line and surface therefore negate the 'it was' of the form, while the geometrically regular, proportionately balanced shape negates the 'will be'. It is in this regard that we can speak of it as temporally autonomous, in conjunction with its 'individuated' spatial autonomy; it is temporally-spatially 'closed'. 
Such temporal-spatial autonomy is significantly different to what we perhaps usually suppose of Greek architecture as we think of it as solid and 'plastic', and consequently, relatively 'permanent' and 'enduring' - as we do with most architecture. While of course projecting a degree of permanence in the sense of the edifice's capacity for a relative longevity within Time, this is strictly speaking a quality of its materials, not its form. The form of Greek architecture is definitively that which aspires to impress not duration in Time -that would require a past, an 'it was'-, but that it is without subjection to temporality whatsoever. Though, of course, the relationship between 'permanent' materials and 'timeless' form is not indifferent, and is of necessary consideration. Prima facie intuition suggests that there is an obvious and important connection; if the same form were constructed of timber or plastic it would have a remarkably different feel to it. The edifice, for all its represented autonomy from the temporal dimension, would materially impress a more pronounced susceptibility to the eventual primacy of entropy; a quite contradictory fragility and ephemerality would be introduced into the representation. Whereas, obviously, stone and the like's solidity and equally its weight, through a relatively slower metabolism of change in the former quality, and its physical immovability/stability in the later, in complicit affect project a native resistance to becoming; to the inclination of all phenomenon to fall into decay, and more generally to being caught up in and effected by exterior forces of movement and 'flux' respectively. This quality of permanence, however, presents a resistance to Becoming, not a transcendental autonomy from it. An important distinction as arguably permanence/resistance has a remarkably different qualitative affect; that is, while it is resistant to its own finitude, it does not necessarily suppress the presence of Becoming as a basic condition of all things, but potentially discloses it.

It is interesting here to note, as a means to elucidate the point, a latter idea of Nietzsche's, that of the 'eternal return'; or more, the mo- 




Figure 13: Nietzsche's 'mighty pyrimidal' stone, where the thought of 'eternal return' first came to him. Lake Silverplana, Sils-Maria, Switzeland.

Source: Young, J. (2010). p. 318 
ment of its conception. In 1881 while walking in a valley in Sils-Maria, Switzeland, Nietzsche came across what he described as a 'mighty pyramidal block of stone', (Figure 13, above) '6000 feet beyond man and time' (1888/1977, p. 12). ${ }^{6}$ The 'towering' stone for Nietzsche evoked a particular insight that extended his reasoning in The Birth: not only is everything in a state of becoming, but to the extent that all becomes continually in the infinite depth of Time, everything will eventually repeat or 'return' - exactly the same way and infinitely so (Nietzsche, 1883/2005). The point to be made here is not the idea itself, but of the affective capacity of something that has endured - and has potential to endure - within Time to disclose temporal depth through longevity of duration; that is, permanence. While one is unlikely to have been confronted with Nietzsche's notoriously perplexing if not suspicious 'revelation', the experience and force evoked by something extremely old, say a ruin or a mountain range, is perhaps not so unfamiliar: the opaque but sublime awe elicited as a narrow reality is stretched out to encompass events in a depth of Time incommensurable - and until such a point, a depth if occasioned in thought, conceptualised and reduced to the relatively emotionless dates of history; of 'mechanical time'. Of course architecture of Greek antiquity, in its ruined state, would stand to evoke the same affect; indeed arguably it is pronounced - the decay of something which aspires to the illusion of its total permanence, stands to accentuate the strength and eventual primacy of Time. But, if we were to draw on the logic already established, in its ideal temporal state - perpetually new, with immaculate finish and unweathered 'strict' edge - regardless that the edifice endures within Time, the marks, in a broad sense of the term, that would otherwise disclose its duration within the temporal dimension, and the dimension itself, are not both representationally and physically admitted into the form.

Permanence, however, as an affective, phenomenological quality, ar-

6 Sils-Maria is 6000 feet above sea level. 
guably has its own temporal value; prerequisite to, but not dependent on, the 'marks' that otherwise disclose an object's becoming in Time. Solidity, density, weight, 'massiveness' etc. of matter and the object more generally, - or more objectively, the 'mechanical' forces, the properties of attraction, that hold matter together and present the grounds for a sense of material 'permanence'/resistance - still potentially elicits a sense of temporal depth, even if the object that holds them has not necessarily endured within Time - for some time. Consider for example a newly constructed, large concrete object, say a damn; and consider too the haptic, empathetically embodied sense of its physical properties, density, weight etc: while even the material itself does not have a sense of past such as stone, it holds a latency in its deepest core of its future longevity and its future's past's longevity in Time; a temporal depth is projected and opened-up, so to speak, around the object. Analogous to the way in which a stone of size dropped into a lake creates larger, and further reaching ripples than a smaller, lighter stone; ${ }^{7}$ our attention within a narrow reality of our own historical-present, - if we are open to affect by it- is pushed out.

Now, turning our attention back to Classic architecture we can say that it of course has permanence, and yet it is permanence inferred on a form that is representationally without duration/becoming in Time; a form that in turn 'wrests' the matter it binds out of duration. In other words, permanence is isolated within the form, or as Theodore Lipps

7 While the focus here is concerned with permanence of matter proper, it is worth noting that it is also arguably a property of value and quality, that is of something that has a 'timelessness' in a more conventional use of the term as a longevity of appreciation - its capacity not to 'date' stylistically and functionally etc. Just as a classic painting, poem or text has a weight or gravity of permanence about it - they too seem to project outside of and open up one's narrow reality. It is in this sense that the Japanese architect Shigeru Ban once remarked, "Permanence is not a matter of the materials you use; permanence is whether people love your building." (Gorgolewski, 2005, p.10). 
writes in a similar and informative vain, "Mechanical forces are natural forces. In the geometric line, however, and in the geometrical forms as a whole, they have been taken out of the natural context and the ceaseless flux of the forces of nature, and have become visible on their own." (1903, p. 249). This observation merely draws explicit what is already implied in earlier reasoning, - it is permanence isolated and inferred onto what is represented alone; an edifice with no past coming-to-beas-it-is, or projected future coming-to-be anything further, but only an articulated state of 'being'. That is, a representation of the permanence of the 'presentness' of the form, its 'is-ing'; though, at the cost of the permanence of Becoming.

This last statement we may ratify through a summery and concluding reflection on the temporal significance of both 'abstract' geometry and material individuality, here drawing the observations made back into the thought of Nietzsche in The Birth' and Bergson.

Within the property and quality of Autonomy we have in every regard what appears Nietzsche's Apolline aesthetic as a 'glorified' formal articulation of the principium of individuation; the form both spatially and temporally isolated, without the impression of becoming or material connectedness with phenomena as a whole. To add, in every way this is achieved through appearance or illusion, sophisticated party tricks, dependent on the faculty of imagination, and one's capacity to have their perception inflected upon. It is a testimony to Nietzsche on the acuteness of his observation prior to any study undertaken by the likes Riegl, Worringer or Wölfflin. Even within this quality however we find grounds that this particular representation of 'being' is intimately, if not inseparably, related to the 'Being' of the Dionysian. Without excessive conjecture it is clear that this is not limited to the articulation of individuation, but also that of the 'timeless present' or the 'intact' moment; what we have is definitively the past and future - as spatialised constructs - removed, and an object impressing that it is perpetually 
and always of the present alone. This does not necessarily contradict Nietzsche, like many philosophers he is vague on the exact meaning of terms employed like the 'infinite' and the 'eternal' as to whether they pertain to an eternal endurance within Time, or are completely transcendental of it. In this respect, it is equally appropriate to say such a reflection has perhaps merely drawn more explicitly what Nietzsche, as an intuitive thinker, was grasping at in the first instance.

However in the quality of Clarity - as an intimate element of Autonomy - Nietzsche's limited conception of the Apolline becomes more problematic. As observed, Clarity operates through an articulated and experientially prefiguring order that provides a 'whole for the imagination'. Whether we interpret this order and the activity of the imagination as propositioning a transcendence of one's limitation to a single point in time or a single point in space makes little difference, -here we meet the particular unity that exists between the two - what is certain is that within one's aesthetic apprehension of the form there is a subjugation of 'individuated' consciousness. In other words, to the extent of the medium's capacity, we are provided a representation of consciousness/ awareness outside of the space-time of the individual; one is not limited to a single point in space-time and subject to the additional nature of experience being one of gradual sequential disclosure, but one occupies all points in space-time within the present. ${ }^{8}$ To add, this is not

8 This argument gains more validity in light of the well documented tendency within Greek architecture to taper the columns in-woulds - a treatment known as 'curvature' -, as to counter subjective, perceptual imperfection, i.e the natural curvature imposed on objects when viewed from a single point of perspective - that is, one point in space-Time. For a contemporary study of 'curvature' read, Haselberg. L (1999): Old Issues, New Research, Latest Discoveries: Curvature and Other Classical Refinements. In: Lothar Haselberger (ed.): Appearance and Essence. Refinements of Classical Architecture: Curvature. University of Pennsylvania Press, Philadelphia, pp. 1-68. Though to note, Worringer, in his drive to show that Greek architecture presents an altered 'volition' that begins to allow in organic elements, 
artistic representation in the conventional sense of the term, it is more a proposition or simulation of pre/un-individuated consciousness - before its isolation to one point in space-time. ${ }^{9}$ Arguably it is to simulate the Dionysian 'ecstasy', which as Heidegger writes with regards to both the word's etymology and Nietzsche's use of it, derives from the ancient

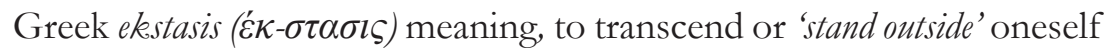
(1979, p. 154).

That the Apolline quality of 'being' amounts to this is far from an impossibility in Nietzsche's thought, but it is a possibility he limited to the 'profound' art of the tragedies. In the dramas the Dionysian drive for the first time 'spoke' through the 'image' of the Apolline embodied by the masked actors and dialogue - in this he writes "the vision represents not Apolline release and redemption in semblance, but rather the breaking-asunder of the individual and its becoming one with the primal being itself." (Nietzsche, 1999/1872, p. 44). This was however nothing he inferred on architecture - the Doric order, for example, was for Nietzsche a 'military encampment' against the Dionysian drive (ibid).

Of course this differs to the tragic experience in a key respect, it is achieved in the form through the cessation of its 'Becoming'. That is to say that while it represents the 'timeless present', it does so fundamentally through negating the form's and the individual's own becoming

suggests that such curvature was employed to make the building less rigid/abstract (p. 112). Observations here however suggest quite the opposite: though the Greek' becomes progressively more organic as a surface treatment, it is met by a more intense effort and refinement to exclude the temporal and spatial constraints of the individual.

9 As a side note, there does not necessarily need to be any validity to Nietzsche and Schopenhauer's cosmological speculation of the existence of such a pre-individuated state of consciousness. Regardless we see that there is historically and psychologically a deeply ingrained desire for such a state, one engendering and requited through the representation, whether founded in truth or not. 
within Time, and the conditionallity of both within the continuum of flux and change more generally. While the Dionysiac state held being and becoming in equal measure -and as was positioned, inevitably so ${ }^{10}$ here paradoxically only the 'Being' of the Dionysiac state is represented, and to the detriment of a sense of the object's becoming.

A paradox equally present when we put Bergson's challenging conception of temporality to task. At one level the form is definitively unlinear, or un-spatialised with respect to its temporal value. Within itself it lacks the capacity to be perceptually fragmented and organized as a succession of fixed states within a linear spatialised time, as there is no 'it was' or 'will be' of the form in the first instance- it is always impressing that it is of the present and therefor perceptually its fragmentation and dispersal across the artificial - separating - space of time can not occur. And while it can be reasoned that it has no actual past as a history of seamless duration, -and that it is therefore cut-off from its past- it is more tenable and accurate in terms of representation and the perception it impresses to reason that qualitatively its past is contracted within the present. That is that its past does not become 'foreign' or 'strange' to the present in which it is apprehended; the form representationaly is held in its entirety within the present in which one apprehends it. This manifests most explicitly in the quality of Clarity. As was addressed in the augment of Worringer the formal representation consolidates the 'fragmentary' 'succession of moments'. Within any one of the 'infinitely divided moments' of our conventional sense of temporality, the object is completely revealed in its totality; or to employ Fried's term, it is always 'wholly manifest' in the present. 'To place it other terms, in both cases of Autonomy and Clarity the function of mind to fragment and spatailise Time is mitigated within one's apprehension of the

10 To recall, we found tentative argument that once the moment ceased to be fragmented as static 'stills' it is logically inevitable that both moment and change retain undivided continuity. 
form itself, as the form is not subject to being temporally broken apart, - ever 'starting afresh' - and irrevocably separated from itself as each of its 'divided moments' cascade back into the abstractly constructed space of time; it instead remains temporally whole and unified within the present. But here we need to make a distinction: the present as it is represented is one immutable yet infinitely thin, as it denies its actual past - or more brings its infinitely thin past into the present -, as opposed to a present 'thick' and 'deep' as in Bergson's articulation of the phenomenon. ${ }^{11} \mathrm{~A}$ difference necessary to note as when we consider the architecture of the slum, which also invigorates a qualitative sense of the present's continuity, this present is found to be more overtly of the latter quality.

It is in this distinction that, paradoxically, we must also recognise that the object is the highest form of the 'spatialisation' of 'real Time' - just as it is the highest articulation of Nietzsche's 'individuation'. In the same action of form to negate its past and future as linear, separating, spatial constructs, the form definitively aspires to impress the cessation of its actual becoming with Time, as the matter the form binds is 'wrested from the world', it becomes mute; it is without mark of change. The formal representation presents a static object, indeed perfectly so, as is in Bergson's argument already the tendency of perception to create of all phenomena. As a static object, in theory, the only means to distinguish it temporally is not through grasping its seamless state of becoming as an immediate experience, but through its quantitative, measurable position within the linear and abstract space of 'mechani-

11 This is closer lying to Nietzsche's notion of a qualitative sense of the present as been locked "between the walls of the past and the future" (1873, p. 11), which in the tragedies seems more an action required to disrupt one's common sense of temporality, than the totality of the experience itself - or at least as Bergson conveys it. 
cal' time; that is, by the linear time that we measure with the cold hands of the clock. In short, the form - the object- to the mind's eye has no duration, movement, becoming; it is not qualitatively within 'real time' as the perpetual changing of phenomena.

Based on the conceptual ground of both Bergson's and Nietzsche's thought what we have is the present alone represented in a very particular way in its actuality, beyond aspects of 'spatialised time' or the 'principium of individuation', but at the cost of the reality that both philosophers place the utmost existential significance in - the materiel ever-becoming of phenomena. In this respect while such form points at or collapses-back-into that 'truth' of the immutable 'will' and present, it is a truth nested in a basic lie. It is still a negation as Nietzsche argued of the reality of the human condition, and the 'suffering' or unease this condition causes. 'being' as formal beauty then, is but heroin for the cultured. But we can add that it is a narcotic providing both escape in dream and equally within its deepest layers an element of metaphysical insight as it affords one side of a more holistic picture of the existential condition beyond the temporal horizon of the individual ${ }^{2}$ - the wholeness of the present (and consciousness), at least, beyond our linear, spatialised sense of temporality. Just as the satyrs of the Greek dramas screamed the spectator to the 'now', it would appear the voiceless form in its on manner draws our attention to the present.

12 Though it needs to be emphasised that it is not a complete picture within the horizon, as it negates the individual's reality of becoming. 




Figure 14: Columns and alcitrrave orientated within a plane. Temple 'C'. Early sixth century. Selinus.

Source: A. W. Lawrence, (1957). p. 348. (orginal photo by Alison France) 
The plane is broached by Wölfflin (1932/1967) as a defining and fundamental constituent of 'classic architectures', from Greek antiquity to High Italian Renaissance. Equally, Riegl and later Worringer place immense significance in this property, finding it similarly prevalent in Egyptian as well as in Greek representation. In all instances geometrically regular, materially individual forms were not arbitrarily positioned within a given space, all form was strictly orientated within purely vertical and horizontal, height and width, plane dimensions; the third dimension, which is then inevitably one of recession or depth, was deemed unnecessary and as far as possible omitted (Worringer, 1967, Riegl, 1985). In these planes form comes together to make the compositional whole of the architecture.

While the aim in this section is to understand the plane with respects to its temporal significance, and structuring this understanding within the two related temporal qualities of Autonomy and Clarity, in Worringer's argument the plane is interestingly more overtly related to space. Indeed, it is its spatial significance that for Worringer, and Riegl, distinguishes the plane. Though to note, in the proceeding elaboration it is clear that this is still fundamentally - equally - a question of temporality. This diversion is to some extent dependent on the angle of enquiry, as here we again confide that unity that exists both phenomenological and ontologically between space and time - a relationship that will be reflected on. While attention is placed on the plane initially, inherently this shift in perspective allows us to approach the properties of architecture already addressed from another angle and to consolidate early reflections.

The plane's significance in furthering a sense of form's autonomy is relatively easy to grasp, being ultimately an extension and reinforcement of the other constituents of strict geometry and closed form. However Worringer's arguments here are quite intriguing, and differ 
on a basic premise. While closed material individuality conveys form that 'points everywhere back to itself', to borrow Wölfflin's definition, expressing an indifference towards and disassociation with the 'becoming' of the sensible world, Worringer asserts that the use of the plane was in response to an intuit need to avoid the representation of space, as space is the one thing that envelops and unifies all things. This unifying quality of space inhibits closed form's projected detachment from the worldpicture, consequently drawing it into the 'flux' and 'happening' of phenomenon. In a certain sense the essence of the 'volition' to autonomy through the plane can be understood as more directed towards, and imparting a quality on, the space enclosed by the form than the form itself. Worringer writes, "It is precisely space which, filled with atmospheric air, linking things together and destroying their individual closedness, gives things their temporal value and draws them into the cosmic interplay of phenomena; most important of all in this connection is the fact that space as such is not susceptible of individualisation. Space is therefore the major enemy of all striving after abstraction, and hence is the first thing to be suppressed in the representation." (1967/1907, p. 38-39). He continues, "This postulate is inseparably interlocked with the further postulate of avoiding the third dimension, the dimension of depth, in the representation, because this is the authentic dimension of space." (ibid, p. 39) While height and width - vertical and horizontal - axis are of course spatial dimensions, for Worringer they are - somewhat obviously - necessarily permitted from the outset in order to render form 'whatsoever' in its closed 'material individuality' (ibid).

The reality and significance of Worringer's assertion on how the plane achieves this end is that through orientating form exclusively within the vertical and horizontal axis, essentially, what is read is a twodimensional object; that is, a surface, or at least something with the clarity of a surface. The third dimension of recession - the dimension that discloses space - is omitted. While the Greek of early antiquity, as 
with the Egyptian, required their architecture to demark space for utility, inhabitation, as all architecture must, its 'language' of form through restriction to the plane does not acknowledge the space it encloses or it is enclosed within. As far as it is within the capacity of formal quality to inflect on one's cognition of space, space is withdrawn as an actual condition in aesthetic contemplation of the form.

It is perhaps fair that our common sense should meet this notion with consternation. Neither the Doric temple of Hera nor the Renaissance Plazzzo della Cancelleria, all architectures for that matter, are merely contrived of flat two-dimensional planes, they are in distinction of form receding in depth and enclosing space; here indeed architecture demarks and shelters its utility, finding its functional raison d'etre. But for Worringer it is just this affect sort, of apprehending each facade as a plane in its own right, one that privileges its own vertical and horizontal orientation alone, which the artistic volitions sort to render. The temple of Hera in the ideal of its aesthetic contemplation is not intended to be apprehended and appreciated as a three-dimensional edifice, and indeed as we will see, it disrupts this very notion. Instead it invites a reading of the whole of the architecture as but a succession of planes purely of height and width alone, regardless of whether collectively they form and demark a three-dimensional space.

The common sense problem of why we should read a group of planes as only of the two-dimensions of the vertical and horizontal as opposed to some being of the vertical and depth dimensions, was acknowledged and yet somewhat avoided by Worringer. ${ }^{1}$ We can gather

1 Worringer instead invites us to read Riegl's elaboration of the plane, and while this is quite in-depth with regards to documenting the nuance differences of its applications historically, it still does not directly approach this particular elephant in the room. For Riegl's general descriptions of the plane read, Riegl, A. (1985). Late Roman art industry. (W, Rolf. \& Bretschneider, R. G. Trans). Italy, Roma: Archaeologica. (originally published 1901): For its philosophical and historical position in architecture, pp.19-31; with respects to the sculptural relief, read pp. 51 
an understanding of how such an affect is projected through approaching another complicit quality that accompanies the plane; that of the 90-degree angle. It is precisely this most ubiquitous of architectural conventions that affords a reading that one plane is not the continuation of another adjoining plane in the depth dimension and vis-à-vis; a reading not of rational deduction, but of a more immediate sense of things. If, for example, we were to entertain the un-Greek notion of a strait plane along its length suddenly receding at a softer oblique angle, say of 20-degrees, we may be inclined to read that second plane as a continuation of the first only with a new orientation. That is of it now vying off and projecting into the dimension of depth - 'the true dimension of space'. In this relationship the adjoining plane creates, or more discloses, a depth of field. While other angles of softer or more extreme degrees begin to merge planes -or walls-, collectively then giving the impression of a cohesive three-dimensional object, it is the 90-degree angle that disrupts this notion inviting us to read each plane as a new plane in its own right, privileging its own two dimensions of the vertical and horizontal. As Wölfflin writes in a similar vain, "if panels no longer lie in one plane, interest is at once diverted, they would no longer mean the same thing" (1932, p. 121). This quality of the right angle we may consider, within the limits of written language, is due to the equality of mutual difference it imparts on two or more conjoining planes; that is that they invariably read in equal measure as two distinctly separate entities/components to be apprehended. In other words, it employes and relies on the same measures as the 'closed', 'materially individual' form, as each plane while in a 'unity of multiplicity' with the whole, retains its independence as a 'closed' element. Neither plane demanding dominant ownership of the other as its continuation in recession; therefore each retaining its own limitation to height and width.

- 132; elaboration through the Constantine arch pp. -51-58; Egyptian relief and Greek composition pp. 58-69. 
Put simply, and grounded in a common-sense notion, we read each as a distinctly separated, individual, component of the architectural whole, much as we by inclination read common adjacent walls at 90-degree to one another as separate entities -entities of height and width alone. It is once 'vertical and horizontal elements appear at all sorts of angles' Wölfflin writes (1932, p. 120), that the 'frontality' of a plane is lost, and the 'underlying principle' changes - it begins to approach the likes of the Baroque where 'intensity' of perspectives of 'depth' are the 'salt of the work' (ibid, p. 115). In this impression of two-dimensionality, space as we define it with three dimensions is omitted in the language of form.

With respects to the other formal treatments considered, it is further the right angle that provides a certainty of the whole of its form for the imagination, as the form breaks off sharply perpendicular to a conjoining plane. Whether the plane of a row of Doric columns or simply the inner recession of a Renaissance arch, it is the clear crystalline edge of the line that dominates the necessity of a receding plane, in theory, as opposed to the recession itself; obscuring depth is replaced by the perfect clarity of the line. This imparts both crystalline geometry and demarks the bounds of its closed material individuality. As Worringer asserts, through the restriction of form to the plane occurs "the translation of depth relations into surface relations," (1967, p. 42), or as Riegl suggests even more aptly, the plane is principally directed towards a " $[. .$.$] transformation of spatial relations into plane relations."$ (1985/1901, p. 61).

Now, in this it still must be recognised that the plane was not an ideal solution, but a compromise with the requirements of inhabitation. To state the obvious, its capacity to truly omit the representation of space, to demark form without unnecessarily rendering depth of field, was limited by, and placed in balanced with, the fact that it was needed to enclose space. The most obvious limitation resulting from 
this compromise being that for the plane to achieve its desired affect most purely it requires apprehension from an ideal point of view; from an ideal distance, and strait on - if we were to stand directly beside a plane of columns and stare down its length what would it do but disclose depth? Wölfflin answers this reasoning when he writes, "Naturally, it was never possible to prohibit the eye from looking at a classical building more or less cornewise, but the building does not demand it. If this brings about an increase of interest, that is not prepared for from within, and the pure frontal aspect will always make itself felt as the one lying in the nature of the thing." (1932, p. 119). That is to say that its aesthetic appeal is always invested in its 'frontality', its 'singular image' captured in the flat, picture like plane. Still, the fact remains that a volume is demarked; which is all the more obvious when it comes to inhabitation and not ideal angles of appreciation.

Conceding this unavoidable reality, the question is raised as to what quality of space we are left with if - in following Worringer and Riegl's assertions - it is not strictly speaking spatial? There is as Wölfflin states a 'perfectly well-developed feeling for volume' (1932, p. 115) in the Classic, but such 'volume' is what Riegl refers to 'cubic space' as opposed to 'deep space' (1985/1901, p. 24). This is not a point Riegl elaborates on in length, though in the first instance of consideration the logic is relatively familiar given the study so far. It is merely a case of turning our attention from Autonomy -in spatial terms- as a quality of the physical, material form, to a quality equally of the space itself. Here we have a cubically enclosed space, demarked and separated in affect through the clear articulation of strict geometry rendered within the plane from space as a whole - or 'deep space', with no bounds or definable limits. ${ }^{2}$ Though most important in this enclosed volume is

2 Harries reflection on Fried cited earlier, that depth and distance - and the example of an infinite horizon- present a 'metaphor' for a latent temporal participation, are quite applicable here; though viewed from the angle of 'spa- 
not so much that it is isolated from 'deep space' as an exterior condition, - as noted by Worringer 'space as such is not susceptible of individualisation' - but that the space contained as far as is it can be is strictly speaking not represented, as we have seen, in its 'authentic' and vital dimension of depth; that is, space in itself is not given a presence within the building - as Riegl writes 'ancient art' endeavoured to 'negate' and 'suppress' the very 'existence of space' (1985/1901, p. 21). In other words, a subtle shift in spatial sensibility is aspired towards, or more affirmed, where a sense of space as something of substance, an actual thing - affecting and tangible - is supplanted as far as possible with, as Wölfflin remarks, a clear sense of 'volume'. The term 'volume', or 'cubic' for that mater, exposes much as an attempt at articulating an intuition of this imposed spatiality; both place space in terms of an abstract Euclidean or Cartesian quantifications of a void like medium; the numerical and metric measurement of something empty, as opposed to expressing a qualitative thing that confronts our sense perception. It is a conception quintessential of not only Classic, but as R. Jones writes, modern spatial sensibility:

"The modern notion of space is a compound metaphor that embodies all our concepts and experiences of separation, distinction, articulation, isolation, delimitation, division, differentiation and identity. The laws of perspective and of geometry for us are a codified summary of our normal experience of alienation, unique identity, and un-relatedness. It has all been abstracted, externalized, and synthesized into the cold, empty void we call space. This metaphor of space is our modern mechanism for avoiding the experience of oneness, of the chaos, of the ultimate state of unity to which the mystic seers and philosophers of all ages have referred."

tial participation' and spatial engagement/awareness the 'metaphor' becomes far more direct. 
(Jones, 1982 as cited in Davies, 2004, p. 71)

The crossing of an opaque sensibility or awareness of space as an absent void, as Jones articulates it, over a present substance is understandable as analogous in manner of difference to that between 'linear' or 'spatialised' time as both a perceptual and intellectual construct, contra 'real time' as Durée. Indeed, the sculptor Robert Morris suggests a relation that goes beyond analogy. In Bergsonian terms he writes, "Real space is not experienced except in real time." (1995, p. 176). That is, when "the body is in motion," in a space that demands an active engagement, a gradual unfolding, "location and point of view are constantly shifting at the apex of time's flow." (ibid). Such action he contends not only draws experience to the ebb of 'Time's flow -one's own unfolding/ becoming in Time- but in complicit affect invigorates a sense of one's embodied becoming in space; the two awareness's present an 'intimate inseparability' (ibid). Or, as C. Davies puts it simply, "In this perceptual state, rather than being mentally focused on the future and thus inattentive, even absent, to the present, one becomes acutely aware of one's own embodied presence inhabiting space" (2004, p. 75). Space, as with Time, becomes something substance like in the sense that it is apprehended as something we are within, conscious of and affected by.

The points raised by Morris and Davies on the 'present', admittedly potentially confusing left as they are, however concern us in the second half of the thesis, and will be elaborated on in that context - I raise them somewhat prematurely ${ }^{3}$ as a provisional means to understanding the current task. Here I want to stay with and attend more directly to the notions of space as substance or void, - as the spatial equivalent of

3 The notion of an experience felt to be in the present that Davies and Morris write of here is of course different, or more disclosed in a different way, to that which we have considered so far. This particular sense of the present, definitively that of the Dionysian experience and 'real time' proper and quite antithetical to the Classic's, is considered when we look at the Brazilian Favela. 
'real time' contra 'spatialised time' - as they are vital to understanding the temporal-spatial significance of 'being' of Classic architecture, and also later augments of the thesis more generally; not to mention that the reader is likely and fairly so suspicious of them. -The idea that we can be more or less aware of space through form, if at all, has a certain non-sense about it; it reeks of bloodless a-priori theoretical abstraction appealing to intellect alone, which, to commonly, is detached and removed from felt empirical experience.

To placate any such disconcertion, we may ground these notions as qualitative experiences through considering the familiar and more accessible notion of atmospheric density, as opposed to depth, as a particular instance in which space more tangibly takes on, or is sensed as, substance like in quality. Through contrast we are then able to establish a sense of 'cubic space' or void and more generally how it is achieved not only through the plane but, as will be tentatively seen, through the formal properties already considered.

Though not attended to by Worringer or Riegl, depth and density are somewhat interchangeable in terms of spatial quality, in that if 'deep space' is of significance to the extent that it is depth that discloses space, then in this regard density of space, as in atmospheric density, achieves the same ends. - Both not only inhibit the autonomy and clarity of objects - through 'linking' and 'obscuring' respectively - but potentially, in a quite inseparable measure, increase the spatial field's tangibility, making us aware of its presence and our, and all things, immersion within it. MerleauPonty expresses this phenomenon when he writes of the qualitative experience of night:

"When, for example, the world of clear and articulated objects finds itself abolished, our perceiving self cut off from its world imagines a spatiality without things. This is what occurs at night. It is not an object in front of me, it envelops me, it penetrates through all of my senses, it suffocates my memories, it almost erases my per- 
sonal identity. I am no longer protected within my perceiving post to watch from there the profiles of objects filing before me at a distance. Night is without profiles, it touches me itself and its unity is the mystical unity of mana. It is depth with planes, without surfaces, without distances from it to me.” (Merleau-Ponty, 1945, p. 328)

In this phenomenological account we have a peculiar and intimate link between qualities: a sense of density, depth and the abolition of clear 'objects' in reciprocal measure facilitating a space perceived as 'envelop[ing]', without producing an isolating 'distance' between things. The spectator, 'protected' within their 'perceiving post', is positioned not outside, 'watching', but within a qualitatively more immersing, unifying spatial-temparole field. ${ }^{4}$ Though of course a more palpable presence of space as atmospheric density presents itself in many other natural occurrences, of which all have a quite particular, quite ineffable, aesthetic mood and tenure. For example, a sea mist or a heavy fog blanketing an expansive landscape; dense to the extent that sound becomes absorbed and mute within it; or equivalently, recollect the humidity of a summer night, or the haze of a dust filled street of an Indian Bazaar, rendered vivid and thick as it is illuminated by hues of a setting sun. The visual aspects of these phenomena have been popular subject matter of many aesthetic works such as that of the $19^{\text {th }}$ century sublime paintings of J.M.W. Turner or C. D Friedrich - works which not only embrace

4 Night or darkness is particularly apt as one example of increased spatial presence, as both shadow and darkness are as Wölfflin suggests not treated indifferently within Classic representation: as he draws attention to, in painting as in architecture, uniformity of light and shadow were aspired towards - inevitably through the flatness of the plane - as a means to clearly define forms, accentuating difference and silhouette, whereas in contrast the Baroque with is painterly detailing and deeply receding enclaves, light falls on form in a dappled affect, where "darkness completely swallows up certain parts" - merging singular forms into a 'single motive' (1932, p. 225). 
6,5

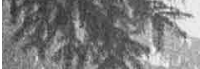

$17 x^{2}$

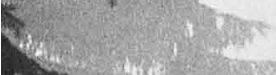

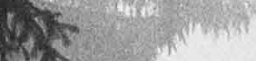

ny.

Whe 2.65 $x^{2}$



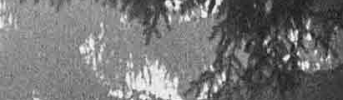

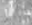

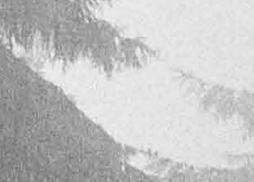

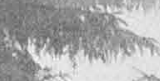

tat 7

3high
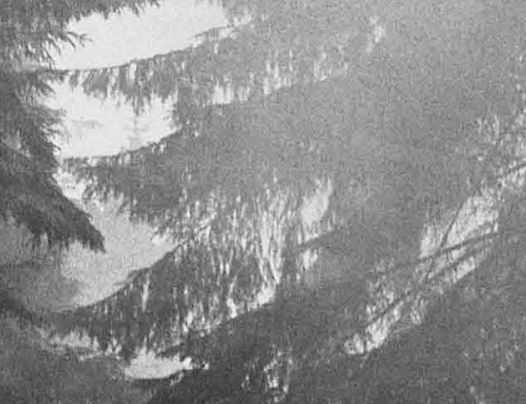

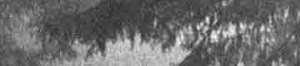

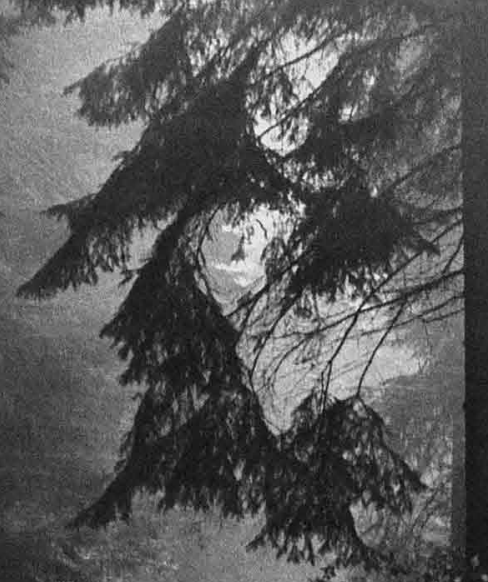

restictin

sis

ty.

+ resinges

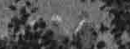

ativiv

(1):

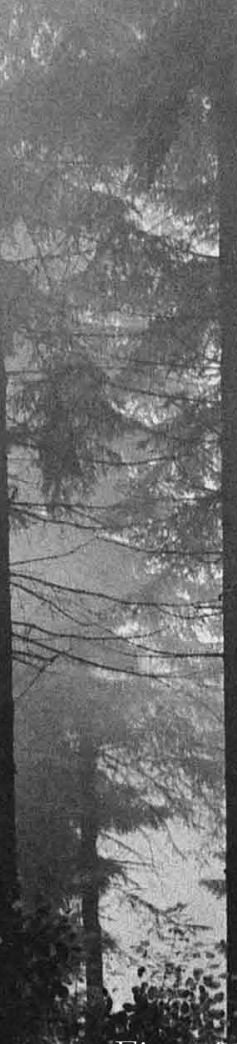

Figure 14: Ar example of spatial



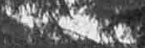

Q.

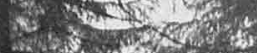
resta

te

Disting

Ang andinge

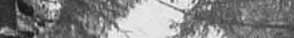

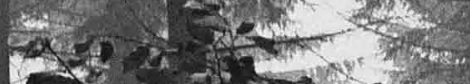

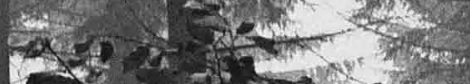

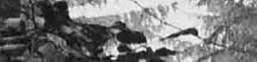
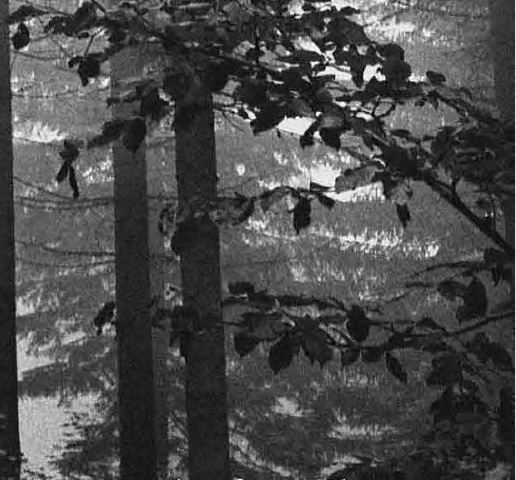
density and mmersion. Forest View' Source: Vaupel, H. (2008)-

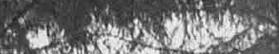

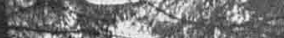

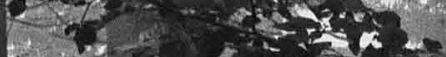




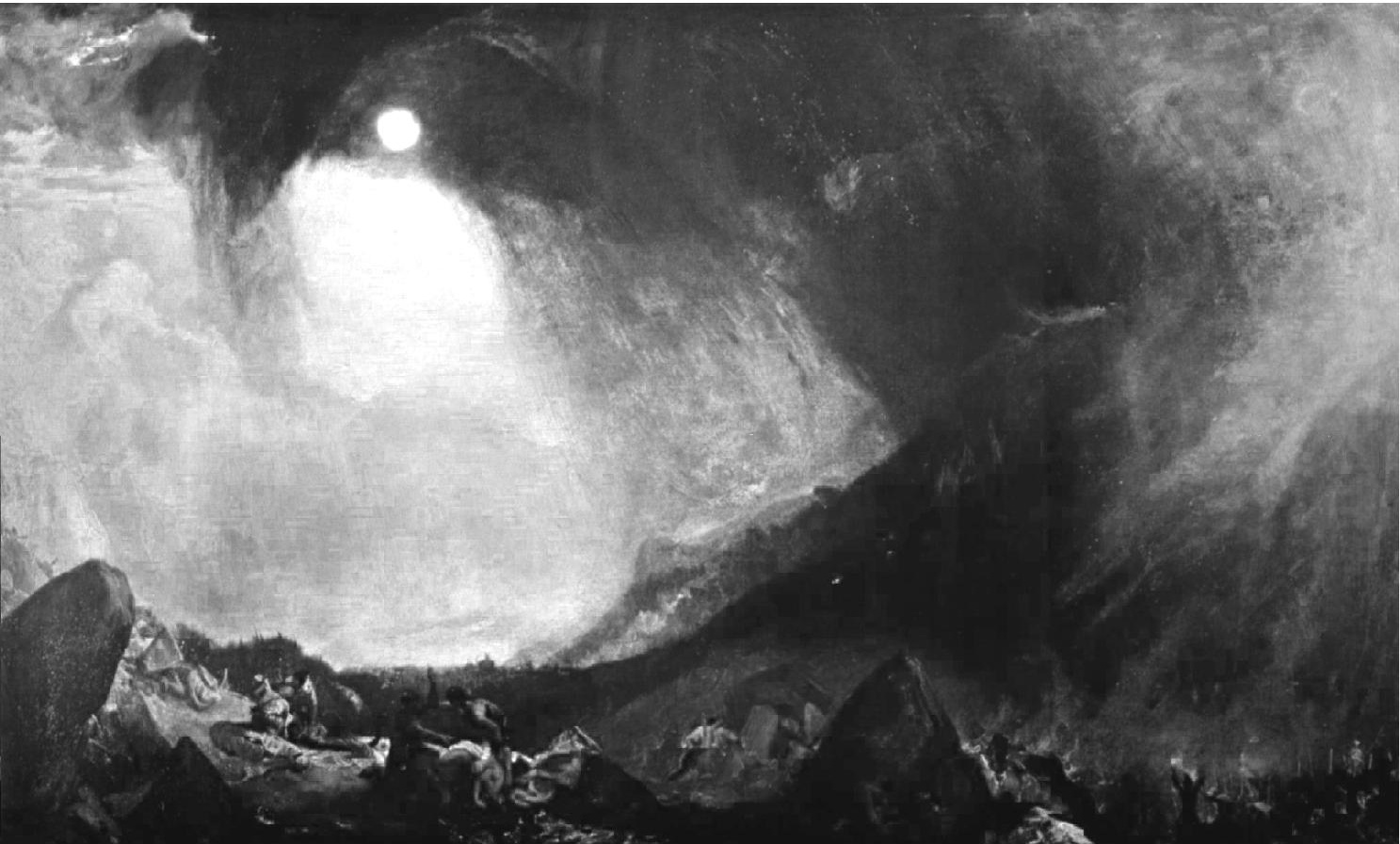

Figure 15: Turner, J. M.W, Snow storms. 1812, Oil on canvas, 146 × $237.5 \mathrm{~cm}$. London, The Tate Gallery.

Sourse: Bockemühl, M. (2000), p. 21. 
this quality as subject, but also in representational treatment; as Wölfflin would be inclined to refer to them, they are painterly in style in contrast to the contour defining representations of the linear Renaissance style.

In each case we witness a hindrance, or are denied 'sufficient reason', in the apprehension of clearly articulated and isolated forms as they, and one's self, dissolve into the obscuring and strangely intimate depth and density of space. As C. Davies expresses it, such phenomena -for her distinguished by a diminished 'visual acuity' of objects - "allows another way of sensing to come forward, one in which the body feels space very much like that of a body immersed in the sea" (2003, p. 323). In this respect, atmospheric density and/or depth while not the substance of space itself, potentially evokes or invites a subtly transfigured sensibility towards space as presence over void.

There is also much to suggest that such atmospheres are not only qualitatively extra-spatial in nature but also definitively and inseparably extra-temporal. B. Anderson distinguishes 'affective' atmospheres as disclosing 'intensive space-times' existing 'in-between subject/object distinctions' that exceed 'conceived space-time' (Anderson, 2009, p. 78-80). Of the spatial axis that constitute an atmosphere we have touched on above, though to note in passing Anderson adds and draws attention to collective emotive states or moods as atmospheric in nature - the heightened, collective emotional intensity of a 'revolutionary atmosphere' underlying sociopolitical change is one example he focuses on. Here too, through a phenomenon where space seems to take on a more tangible 'intensity' for the individual - seemingly imbued with an emotional tenure, whether in actuality or not ${ }^{5}-$ space is disclosed or at

5 I emphasis this point to placate the more skeptical of this notion. Though as Anderson alludes, it arguably presents a reality which the common psychological conception of 'subject/object' relations struggles to accommodate. The later section on the Brazilian slum and the past lends some validation to the curious idea that space literally takes on an emotional substance, as opposed to just seeming as such. 
least potentially perceived as something itself more thick or substance like; or as Anderson remarks, it imparts "a space of intensity that overflows a represented world organized into subject and objects or subjects and other subjects" (ibid, p. 80). The temporal axis of atmospheres manifests in what he reflects on as their common 'turbulent' or 'indeterminate' quality; in short they are, 'that which never quite achieves the stability of form' (ibid, p. 78, also see Tiffany, 2000). Whether a psycho-social mood or 'aura' which manifests from, and yet seemingly exists between a collective of people, or as in examples noted above of natural, relatively physical atmospheres, in all as he draws attention to there appear the common denominator of an un-finalised movement, an element of ephemeral, continuously flowing transition, or a perpetual coming-to-be which has not reached a definite stability or equilibrium; they are 'uncertain, disordered, shifting and contingent' (ibid). Nietzsche too writes in a similar vain of mood. It is, he muses, a condition engendered when two emotive states or forces lay in an unresolved duality, an unstable 'conflict' between the 'old and new' Nietzsche, 2006/1865, p. 21-3). Deleuze puts this same notion into Bergsonian terms when he speaks of "affecting" states and their atmospheric like quality, as they "go beyond the strength of those who undergo them" (Deleuze and Guattari, 1994, p. 164), they are "becomings", (ibid, 1987, p. 256) "experienced in a lived duration that involves the difference between two states" (Deleuze, 1988, p. 49, all quotes as seen in Anderson, 2009 , p. 78). Atmospheres as such, whether relatively physical or emotive, - the term ambience seems to acknowledge their indivisibility - present an overt rendering of the flow of change -and space -; one that is always there in actuality, but which eludes us within our linear and more 'static', spatialised sense of temporality.

Turning our attention back to Classic architecture, it is obviously outside the capacity of its form -and the medium of form more generally- to mitigate the relatively physical spatial aspect/axis of atmospheres 


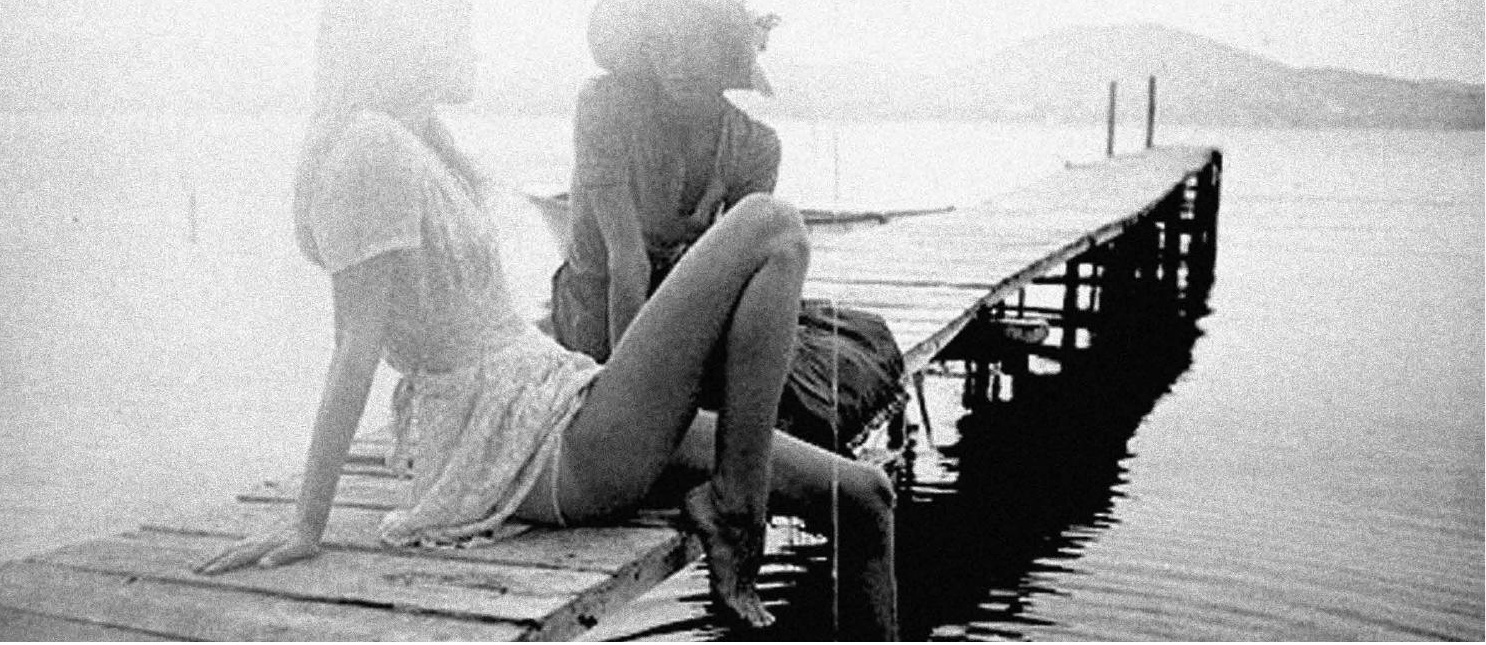

Figure 16: Les Demoiselles -colbot creek. Source: Hamelton, D. (1973). p. 155.

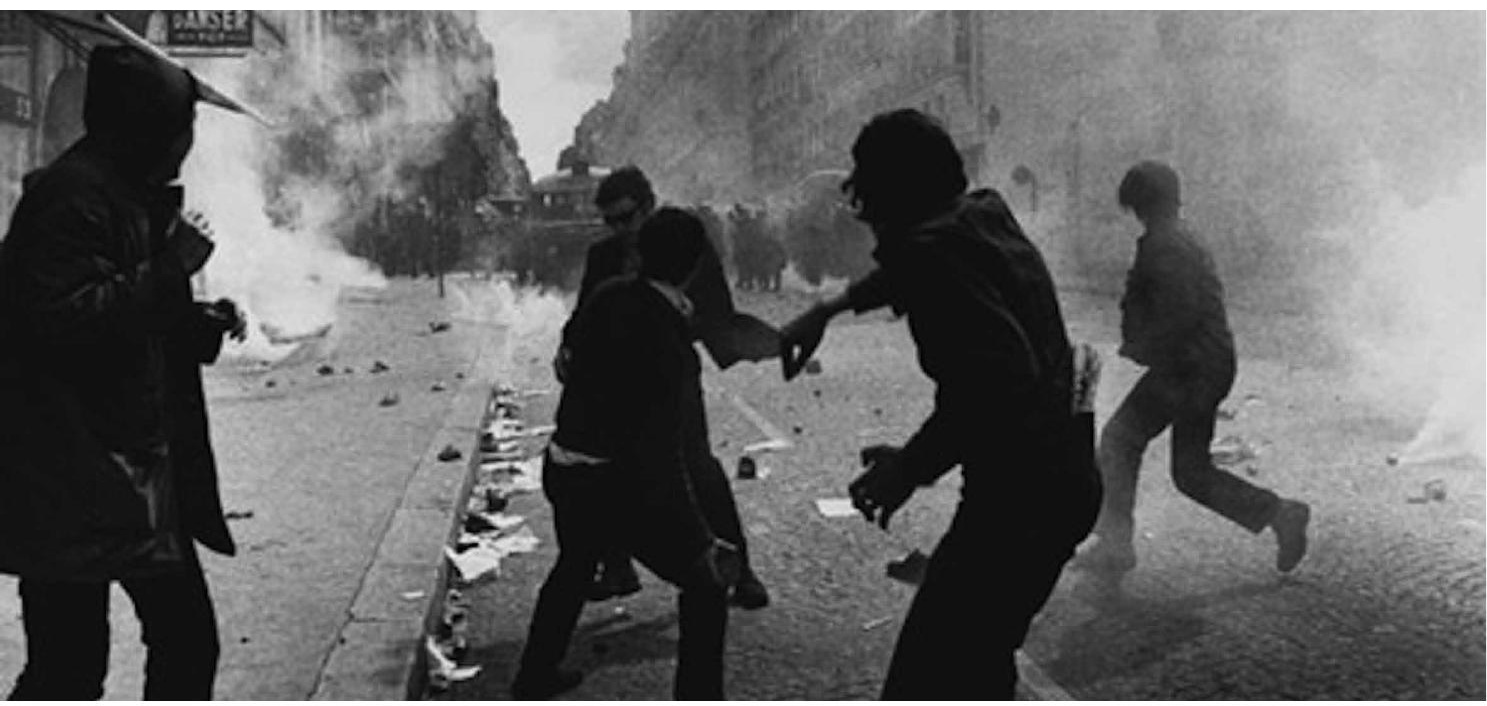

Figure 17: 1968 protests in Paris. Photo: (C) Hulton-Deutsch Collection/ CORBIS. Source: Ragovin, H. (2008). 
- of spatial density such as is engendered through atmospheric dust and the like. Instead, in the first instance, as is the drive of Worringer and Riegl's argument, it mitigates as far as possible spatial presence through the removal of depth, as one side of space's qualitative potential to be more or less 'deep' and dense. In this, as noted, the 'cubic space' in theory is principally without representation of space and in their reasoning is therefore 'suppressed'; a volume with a sense of spatial void is affirmed. In the apprehension of form space is here no longer the one thing that unifies - drawing all into the 'interplay of phenomenon' - it is the one thing which separates all. Also, in the likes of the thought of Merlue-Ponty, Davies and Morris, argument is given which suggests that the property of the plane and its removal of depth is deeply connected with the general 'visual acuity' (Davies, 2003, p. 323) of the rigidly geometric and closed autonomous objects considered in the previous sections: when the depth of field is not demarcated by a "clearly articulated [...] object in front of me" as Merlue-Ponty wrote, space then "envelops me". These properties too compounding the affect of a substanceless space, in complicity with a 'timeless' space that is composed of isolated 'objects', as opposed to a qualitatively denser spatial field of less visually acute, 'inter-linked' things. It is in this sense that Morris writes, "any time the object becomes specific, dense, articulated, and self-contained, it has already succeeded in removing itself from space." (1995, p. 176). Inverting this statement in concord with Merleau-Ponty and Davies reasoning, it is equally the object - the form - that in reciprocal measure removes 'real' space and vice versa. Space becomes the volume containing isolated objects, as opposed to objects that, losing their 'clossedness', diminish into a wider spatial-temporal 'whole'.

The brief reflection on atmospheres also lends credence to the idea that space as an atmospheric presence is suppressed in Classic architecture, so to speak, along its temporal axis - if the two can be separated theoretically. What appears intimately if not inseparably related in 
'affective' atmospheres as spatial densities is their temporal quality; they present holistically as Anderson notes 'intensive space-times'. -And if Morris's assertion that 'real space cannot be experienced but in real time' is taken prima facie, one could entertain that the removal of Time in the representation also plays its part in engendering a sense of spatial void, and visa versa. This gains some validity when the concept of Autonomy is applied to the space - based on the reasoning that form not only 'shapes' matter, but space. In principal, though harder to grasp, just as with the geometrically abstract, 'closed' form there is no representation of the space as something in a state of 'becoming'. Like the autonomous form it is bled of its temporality as it is rendered in a perpetual state of 'being' or 'is-ing'; with no past coming-to-be, or future coming-to-be anything further. In the first instance, the 'void' here is understandable as distinctly temporal in nature, as the space re-presents a perpetual temporal table-rasa. It is not just the initial clearing of the site for the placement of the building, but a space that is perpetually articulating its newness, its state of being a blank slate; a past-less and futureless vacuum locked in an infinitely thin present. That is to say that space retains an emptiness, or purity along its temporal axis, as the form that demarks it contains no 'marks' of any past that has occurred within it. $^{6}$

As a more general and obvious reflection, the 'volume' of Classic architecture presents a type of anti-spatial presence through its overt quality of projecting an articulated state of temporal pause attained by its proportional balance and 'harmonious' equanimity between parts; that is, its internal formal resolution as addressed earlier. 'Movement', 'turbulence' and 'indeterminacy' are placated. The space here is not charged with any mood as an expression of tension, of change between

6 The significance of this quality of the temporal void will be properly fleshed out and gain more weight and meaning when contrasted with the Favela's quality of retaining its past in the next section. 
two states, which arguably can as was addressed in Anderson's thought, impart the space - and Time - with a certain 'intensity' or palpability. To convey the point through contrast, Pol Bury's sculpture 'The Lectern' and the 'neoconcrete' artist Mira Schendel's 'Droghinas' present in two quite different ways a spatial-temporal field of increased presence through unresolved, 'open' form. 'The Lectern' as G. Brett remarks embodies a "repressed violence" or "lull-before-storm" quality (1968, p. 53). It is form in a latent state of movement, a tension between what it is and the impression of what it will be -collapsed, and the turbulence of collapsing-, jointly imparting the space with a mood-like tension - a qualitative substance - and a pent-up state of transition. In difference, Schendel's ambient 'Droghinas', although not expressing "any particular movement" as Brett suggests, "their fragility and energy indicate space as an active thing, a field of possibility" (ibid, p. 47). The 'Drogninas' do not present closed, internally resolved, isolated objects, but are ambient elements that merge into space and Time; they become receptive to it, part of it - mediums for it. In both examples space and Time are projected as more palpable affecting 'things' through providing them with a type of disclosing presence, ${ }^{7}$ a substance; the quality of space and Time being 'things' is the significant attribute, as it moves away from the perception of a spatio-temporal void that is definitively nothing - an empty,

7 Interestingly Brett places these works' capacity to disclose 'real space and real time' in difference with sculptures of the likes of Moholy-Nagy and Duchamp that had actual moving, vibrating elements. Duchamp writes on the reasoning behind his electrified, literally moving, sculptures: "To bring Time as a reality into our consciousness, to make it active and perceivable, we need the real movement of substantial masses removable in space." (Duchamp, 1937, as seen in Brett, 1968, p. 22). Schendel and Bury's works challenge such a notion by invigorating a sense of Time and space without actual physical movement, which equally [further] affirms the notion that form -which is generally a static medium - has the capacity through various treatments to not only increase, but further remove a qualitative grasp of Time-space in ones aesthetic apprehension of it. 


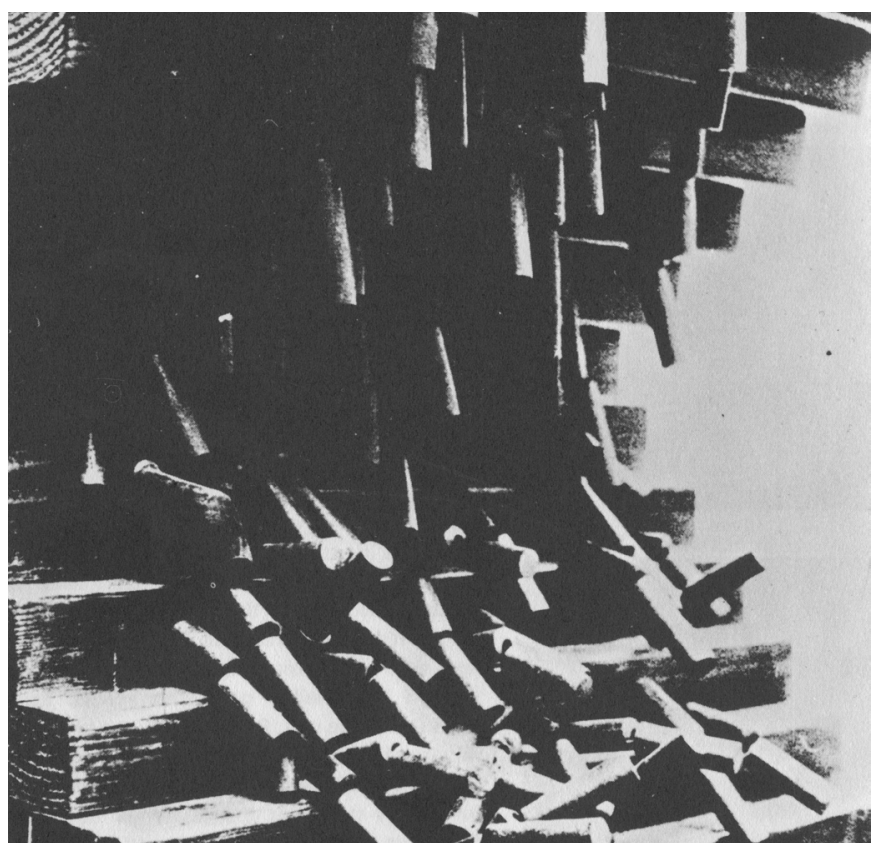

Figure 18: Pol bury: 'The Lectern'. 1963. Detail. Source: Guy Bret, (1968), p. 53.

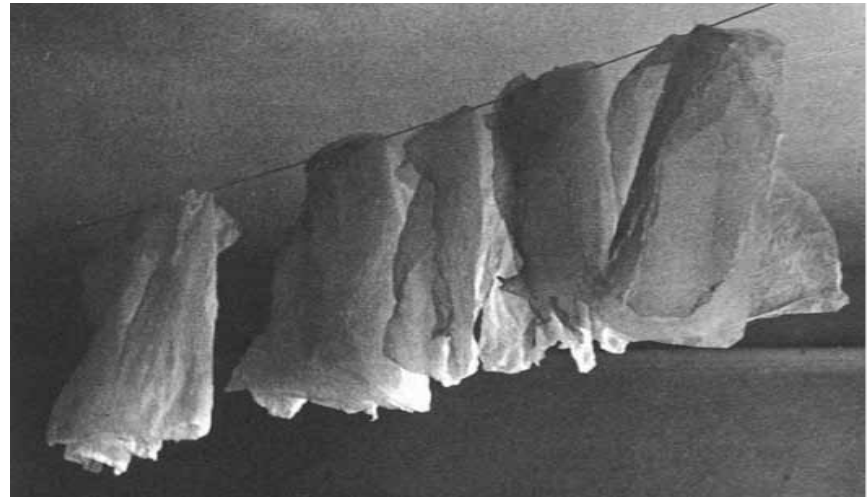

Figure 19: Mira Schendel : 'Another Droghinas'. 1966. Ricepaper. Source: Guy Brett, (1968), p. 47. 
static volume, occupied by isolated, individuated objects that are things.

To reiterate the central theme in conclusion: through the plane and the mutually supporting properties of closed form and geometric abstraction, space is further removed from awareness as a presence. Through a subtle inflection of perception, real space, much like Time, in its already opaque ethereality, is nudged further out of consciousness, and consequently a sense of void is affirmed. In apprehension of form space is here no longer the one thing that has the potential to 'inter-link' all things - imparting them their 'temporal value' -, it is the one thing which separates; the form projects an isolating autonomy from a more enmeshed, fluctuating, spatio-temporal 'whole' or, in Nietzsche's terming, 'unity'.

The principle and quality of Clarity has largely been implied in the study of the plane's Autonomy, but it is of value before moving on to the next chapter to briefly draw out its own particular import within the scheme of things. The point to be addressed is its complicity with the property of symmetry, and with systems of order generally.

We have already seen at length that the vital quality of the plane - in conjunction with the right-angle - is that of retaining a certain twodimensionality in the face of architecture's inevitable three-dimensionality. In this light what the plane achieves is an ideal 'all at once' presentation of form as a two-dimensional 'image': just as in the properties of closed material individuality, the plane also mitigates the obscurity that three-dimensionality inevitably causes, as it consolidates the 'fragmentary structure and the temporal succession of perceptual moments' into a 'whole' for the 'imagination'; a 'singular', immediately assimilable 'mental image' as addressed in Frankl's thought (1968). This ideal 'frontal', 'picturesque' re-presentation of form weakens the affect of reces-

8 Worringer uses this explanation in context of both the plane and symmetry $(1967$, p. 40$)$ 
sional depths which, as Wölfflin remarks, has the tendency to 'lead the eye on', as one is inclined in terms of aesthetic appreciation to reveal what is not immediately given (1932, p. 199). Instead, such an active engagement in Time - and space- is not required, as the plane obliges the more static appreciation of the frontal perspective; a singular frontal image which in turn, as considered earlier, through symmetry and its limitation within a strict order, pre-figures and reveals the building 'whole'. This property is inseparably tied with that of symmetry and order. We have seen that in Classic architecture any form that does not limit itself to the plane in its highest ideal -a completely flat two-dimensionality- requires the quite severe measure of direct symmetry; that is of directly symmetrical or mirrored forms such as the cylindrical column. Such symmetry is seen here to mitigate the relativity small amount of thickness -and the dis-clarity it causes- permitted within the plane as a necessity in order to render form in the first instance. It is the plane that insures that this quality of symmetry is not over extended, or more the imagination is not overly stretched, having only to bridge the limited depth of a plane's thickness. In a certain sense it is the plane that is the first order in achieving clarity through limiting, as far as possible, form to two dimensions, while symmetry picks up where the plane meets its limitation with the requirement of form and inhabitation. That is, of the requirement of conceding some depth to render form, and the problematic of when the plane is not viewed in its ideal - strait on from an appropriate distance. In the later, as mentioned in passing earlier, if we are to imagine ourselves standing inside or just outside a plane of columns and staring down its length, the plane's clarity is rendered

9 From the perspective of an active engagement in space, it is also this quality for Morris of having 'only various visual aspects: from this or that, close up or farther away', that 'removes' the object [and more clearly here the subject] from space (1995, p. 176). Space is no longer the essential medium through which to assimilate the work, it becomes mute and redundant as with Time. 
useless; we are at too acute an angle to apprehend its surface quality. Though even from such an oblique angle -which is not in the 'nature of the thing' in the first instance - we are still presented a degree of clarity through the direct symmetry and repetition down the entire length of the row of columns. This is a mutual relationship, as Riegl asserts, "Symmetry inherently belongs to the dimensions of the plane, it is limited, if not destroyed, by depth; for that reason in the visual arts of all of antiquity symmetry became the essential instrument of bestowing completeness on material entities on plane surfaces." (1985/1901 p. 25, my italics).

As has been addressed in each section, this 'completeness' we understand is not only, as in the quality of autonomy, attained through the form impressing that it never was, or will be, but only 'is' - 'finished' and 'inevitable' - as a physical thing, but in our perceptual assimilation of it. That is, it facilitates the 'instantaneousness', and perceptual immediacy of form through presenting it in its entirety; limiting the need to apprehend it over any duration of Time and through space. It is apprehended totally and completely within the present moment.

The study undertaking in these interrelated sections has endeavoured to draw out and understand architecture's formal capacity to elicit a qualitative sense of what in the most encompassing of terms can be defined as Apolline 'being'. With Classic architecture as the primary vehicle in this effort, a gradual picture has immerged through its refinement to these ends of the basic mechanisms that can be employed within the medium, and the sense of temporality or space-time these engender. As a phenomenology nothing here is clear cut, but in terms of aesthetic-temporal affect a few points are relatively certain: foremost, the properties considered collectively engender an articulated impression of a complete cessation of Time's flow. In the most general terms such form represents a pause or stillness, or an escape in the deceptive 'dream' of an 'eternity' of individuated appearances as Nietzsche refers 
to it, from the incessant becoming of the phenomenal world. To add, due to the totality of this affect -that has now been established- the formal edifice presents more than something simply 'static' and ongoing - or more, it presents a higher articulation of such a state. As Bergson reasoned, due to priorities of functional and cognitive action, perception has already reduced all movement and change to a linear sequence of static states; 'things' without change, and movement reduced to a collection of static points within space. In difference within such form, what is intuitively aspired towards and presented is an object with no temporal value whatsoever, whether time as linear - 'spatialised' -, or 'real' Time proper as a continuum of becoming. To draw it back into the simplest of terms, as linear time is but a mediation, a particular perception of real Time, to qualitatively express a pause in the later is to inevitable give no grounds to the former; no past, no future, and lacking any tension of change at the apex between these two points, no sense of the form's becoming - its state of transition - in the present in which we apprehend it. While it achieves an acute attainment of 'spatialised' time in the broad meaning Bergson gives the term, in the phenomenon's vital sense -as Bergson's naming of it suggest - as a space imposed on Time, it is disrupted. This space is removed, it is collapsed and compacted into an ongoing, continuous state of 'presentness'. The 'being' of the Apollonian, and the 'Being' of the Dionysian are given 're-presentation' through inseparable measures. 


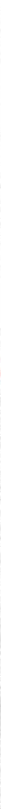

Figure 20: A view of the hillside 'Morro Favela' in 1920 overlooking the Classic architecture of Reo de Janeiro's central city district. After a program of urban reform initiated between 1902-1906 that sort to 'modernise' and 'beautify the city', the lower class were 'violently expelled' and subsequently forced to establish settlements on the surrounding hills (Vaz, L. F., Jacques, P. B., 2003, p. 263).

Source: Vaz, L. F, \& Jacques, P. B.

(2003), p. 263. Orginal photograph

by, Malta, 1920. A.G.C.R.J. 
In a journal entry dated 1967 the Brazilian avant-guard artist Hélio Oiticica, - a self proclaimed 'son' of Nietzsche in philosophical genealogy (Salomão, 1996, p. $96 \& 16)^{1}$ - professes to having found a certain "ground" in the "labyrinthine' streets and haphazard shelters of the hillside slums of Reo de Janeiro (Figueiredo, Pape, \& Salomão, 1986, p. 99). That is, as his friend and fellow artist of the 'neoconcrete' movement Lygia Pape recalls, a "Dionysian space" (Jacques, 2001, p. 27).

The Following sections reflect on the intriguing built environment of the Brazilian Favelas and the subtle yet omnipresent temporal affects this environment has the capacity to elicit. The study presents a shift in focus from the particular 'Apolline' temporal-spatial quality aspired to and imparted in Classic architecture, to that of the antithetical temporal-aesthetic of the Dionysian. As was positioned in chapter one, the Dionysian phenomenon was rooted in a more direct perception, a disclosure of sorts, of 'real time' - distinguished by a qualitative sense of the seamless, unforeseeable, becoming of phenomena within an undivided, continuous present moment; beyond the perceptual tendency in Nietzsche's account to 'individuate' phenomena, or to 'spatialise' Time in Bergson's. The aim of these reflections is to address some of the basic properties and conditions of architecture presented by the Favelas that mediate this temporal phenomenon, while complicity establishing the qualitative sense these properties impart.

The study will first present a brief overview of the Favelas' distinguishing 'unplanned' and 'permanently unfinished' mode of construction. As the theorist Paola Jacques $(2010,2003)$ argues this forms the origins of the built environment's unique character. It is an origin of particular importance to this study as it engenders a basic and fundamental departure from the properties that have been studied in Classic

1 Oiticica writes that he read Nietzsche from the age of 13; he was educated by his grandfather José Oiticica, the well known leader of the anarchist group 'Ação Direta' (direct action) (Salomão, 1996, p. 96 \& Oiticica 1992, p. 209). 
architecture, and which almost naturally manifest formal-spatial properties of an antithetical temporal nature. Following from this the study will attend first to the built environment's temporal significance with regards to the particular continuity it holds with its past. That is, simply, the dynamic in which earlier condition are retained through adaption and/or prefigure latter stages of its 'continual' development, creating a reciprocal relationship and continuity between old and new built form and materials. It will be positioned that this has the potential to impart a qualitative sense of 'real time' with regards - most directly- to Bergson's notion of a past more intimately connected within the 'thick' present. In the second section, Hélio Oiticica's art works and his underpinning theory are approached as a point of entry into a reflection on the temporal qualities of the Favelas' spatial-formal properties. For Oiticica - and most theorists that will be addressed - the Favelas' spatial conditions parallel those of the labyrinth of myth, in this regard both these environments are approached interchangeably - there are however differences which will be addressed. Departing from Oiticica this particular line of enquiry passes first through a comparison between the formal-spatial properties of the Favelas with that of Classic architecture; addressing its departure from the Classic's use of the 'plane' we then reflect on its shift from the quality of 'autonomy' to one of 'unity'. The third section considers the particular temporal mode of experience that the Favelas' Labyrinthine alleys engender; that of a gradual 'disclosing' of the environment, antithetical to the Classic's affect of 'Clarity' as an immediate revelation of its formal order. Following from this, section four looks more closely at the particular 'active', 'participatory' nature of this experience, expanding on its qualitative temporal significance, while introducing further distinguished formal properties that attribute to this affect. In conclusion the study considers the vital point at which Favela and Classic architecture are linked in terms of temporal quality, that of the 'aesthetic' sense of the continuity of the present moment. 
The slums of Reo de Janeiro's steeply inclined hillsides present a phenomenologically unique architectural occurrence with regards to temporal significance, if not architecture generally. Paola Jacques suggests that it is here, for once, that architecture no longer 'spatialises the time', but 'temporalises the space' (2003, p. 55). In the first regard this is in the quite literal sense of the slums' 'physical space' being in 'movement', as it shifts from what is a nearly unquestioned foundation of the traditional mode and conception of urban and architectural production: that of the 'planned', preconceived building (2003, \& 2010, p. 313). Jacques states the facts of the matter simply:

"The architecture done by architects has a conventional project and the project comes before the construction. It is the project that determines the end, the final stop. When a previous project does not exist, there is no predetermined form for the construction; therefore, it does not end, remaining in a constant constructive movement." (2010, p. 312).

Removed from the conventional plan, the Favela exists in state of 'permanent transformation', an open-ended process of construction that leaves the individual shelter and the wider urban environment 'continually unfinished' (ibid, p. 314). Jacques, in her extensive studies of the Favelas, observes this basic process as beginning out of necessity, as the builder - "usually the dweller with the help of friends and neighbours"(ibid) - establishes an initial shelter improvised out of found, brought and discarded materials. It is 'mostly precarious', but she asserts it forms the basis for 'future developments'. In a process of expansion, adaption and re-configuration in line with the economic means and immediate needs of the inhabitants (Lobosco, 2009), the shelter 'evolves continuously' with no 'pre-determined project' until it gradually solidifies into a 'cement and brick house' (Jacques, 2010, p. 
314). However, she writes, "even then the construction is not finished. Works [...] are constantly been undertaken [...] transformed day by day, continuously unfinished" (ibid, p. 312). T. Lobosco suggests that this process and the perpetual state of 'incompleteness' is by no means clearly seen as undesirable by the inhabitants: "as permanent ongoing project, they can see through the possibilities, the many forms it could have. This flexibility is more desirable than the tangible albeit rigid and fixed achieved stage of a house." This is as it relieves the pressure to achieve a finalised building, while in a peculiar inversion of modern sensibility, in the context of the Favelas the fixed building and the lack of open-ended development can also be seen as a sign of 'economic fragility' (Lobosco, 2009, p. 4). In Jacques account the changing, 'fragmented' aesthetic of the Favela is embraced by its inhabitants (2001). The architecture becomes less about the pre-conceived final vision, that momentary photographic ideal of the resolved object wholly complete and manifest at the end of construction, and more about a transitory activity. Construction is not contained within a designated and finite period between the conception of the project and its built realization, but is re-embedded into the temporal life of the building - into the life of its inhabitants. Architecture becomes a verb, as opposed to a noun; a temporal process over a fixed spatial arrangement; more the lived, unfolding activity, over the static, 'finished' object.

This shift from the 'finished' work in terms of both aesthetic sensibility and built reality, is something quite intriguing. It was the renaissance theorist Alberti whom placed the quality of 'finitio' as part of the 'highest concept of all' of Classic architecture; the affect that no 'smallest part' could be 'added or deducted', without impeding the harmony of the 'whole' (Wölfflin, p. 67). -To the mind's eye taking on the appearance of having reached an absolute equipoise within its proportionate composition; completely resolved and 'closed', 'inevitable' and 'finished' (ibid). It was an aesthetic ideal however, or more a 'law' or 
'rule' in Wölfflin's thought, that extended beyond Classic 'taste', it is just that here the law is 'revealed': Classic architecture, Wölfflin asserted, is the architecture of 'revealed law' (p.124). It was not only 'the vital nerve in every effect' of the Renaissance, but that of all 'art'. To qualify the term, art must form a finished "organism" in which one feels that, "nothing could be changed or moved from its place, but that all must be as it" (Wölfflin, 1932, p. 124). Even the baroque style, the supposed architecture of 'change', 'the becoming, the limitless,' of 'happening over being', with which he juxtaposed with the Renaissance, had to be constrained witbin it, it is merely that the 'rule' is 'concealed' within the painterly, seemingly animated, 'causal' affect of its ornate forms (ibid, p. 149). Each element, whether an organic detail or spatial arrangement, still sits within a proportional relations with other elements, it just that independently they do not stand on their own, but adhere and gain their 'sense and beauty' through a more absolute geometric interdependency within a completely resolved system of geometric order.

It is an imperative, or as Worringer would be inclined to term it, an underling 'artistic volition', that persists into the modern conception and built reality of architecture. Is it not the bighest appraisal, the very qualification of mastery, to say that a design is perfect, that 'no smallest part' could be changed without taking away from the 'whole? In difference of course, in the modern conception the imperative of a complete resolution, or a 'closed' system, is less aspired to through proportional resolution of form, whether in balance such as in classic or a controlled 'dissonance' as in the baroque, but more often superseded if not replaced by programmatic/functional resolution. That is, a 'finished' programmatic 'organism' or system that perfectly accommodates all aspects of the inhabitation/utility for which it is planned. The principle is the same, it is just that the law of 'inevitability', is re-appropriated to include not only form but the organisation of inhabitation itself. Though of course the two - form and program - are quite inseparable in the first instance; no more apparently so than in light that it is perhaps the most avid 
functionalists whom are against physical proportion for its own sake, and instead adhere to the dogma that 'form follows function' - the demands for the appearance of an 'inevitability' of form here are no less rigid. Program and form are linked in a complicit relationship in the demarcation of a complete 'organism'; a closed object, planned in its totality from the outset, constructed, then inhabited. ${ }^{2}$

In this logic regardless of the conventional architectural project's solidification in the legal and economic systems that regulate and legitimize it, it is clearly part of a more deeply ingrained need; an imperative that the architectural institution is built around and yet which equally holds it in place - what else is the architect's role constituted of but the meticulous rational planning and preparedness, whether pragmatic or poetic, required to implement such formal and programmatic finality? That is, it is underlain by this basic sensibility of what we expect, or feel that we require -one that in the mainstream is never seriously questioned- that architecture fundamentally needs to be complete in its resolution, or more simply, finished.

2 For a particular account of how program in 'modern' architecture engenders a 'spatialisation' of time through the 'utopian' ideal of deterministic planning, read: Grosz, E. A. (2002). The Time of Architecture. In Bingaman, A., Sanders, L. \& Zorach, R. Embodied Utopias: Gender, Social Change and the Modern Metropolis. London and New York: Routledge. pp. 265-278. To note, the 'spatialisation' of time in the main line of contemporary architecture addressed by Grosz, is, in this authors view, Spatialised time proper: not the higher refinement attained in the likes of Greek architectures. 
Of particular, and greater, interest to this study is that this shift from the fully resolved, finished building presents an almost natural genesis of formal-spatial conditions that have very particular and pronounced qualitative temporal properties - each of which will be considered over the remainder of the thesis. The first of which to be attended to, and which is the focus of the current section, is most immediately related to this process of construction: that of the continuity, the link, such open-endedness creates between the past and the present of the built environment, and the qualitative phenomenon of a more connected, non 'spatialised', sense of past this has the affective capacity to elicit. After establishing the ways in which the Favela retains a degree of continuity, this process will be briefly contrasted with that of the Classic and Baroque, before reflecting phenomenologically on its qualitative temporal affect.

The notion of continuity, a type of permanence, may seem problematic if not contradictory to infer on a built environment that is always 'changing'. The Favelas however differs from a purely transient slum such as a squatter camp, in that the settlements are not temporary, but established as permanent inhabitations. They endure as most architecture does albeit in a perpetually adapted manner. Of interest here, and with a most pronounced departure with Classic architecture, its continuity in Time is very sensitive to the impressions of its past having-come-to-be in Time.

Continuity of the built environment is retained in two primary ways. In the first and lesser instance, there is observable a literal formal retention, in that elements from the earliest 'shelter-dwellings' persevere in their original, though adapted, state into later more developed stages of the perpetual construction process. As Jacques (2003) notes, due to financial constraint more solid, and therefore costly fixtures such as initial walls etc., are retained and adapted while re-configuration and expansions orientate themselves around these; or, similarly, the for- 
mal element's raw material is recycled, repositioned or readapted into the ongoing construction. In the second instance, however, given the constant process of constructive transition, such literal continuity of form and materials is not always the case, as there are obviously breaks in such a retentive growth - a structure, wall, detail, raw material, is removed permanently, as an improvement and expansion takes place. But there is still here a temporal link, a continuity of sorts, between the new and the old that has been completely removed. That is in the sense that, as Jacques observes, even the first shelters, 'precarious' as they are, form the 'basis for future development'. As a quite literal example, a wall, balcony or walkway might gain its characteristic irregular shape as it fits about its immediate, often densely compacted environment at the Time it is built. -The conditions of that immediate environment may then change, whether physically or socially, and yet the form of the wall etc., may keep its 'shape' till a latter adaption; or vies-a-versa, the form is removed and yet aspects of its surrounding still hold peculiarities that arose form its originally adaption to the removed element - as observable in figure 26 (p. 135) where turns and small enclaves are impressed in the walkway from previous built conditions. The form itself, or its environment, then holds a latent imprint of these previous conditions; that is it impresses, however opaquely, the absent past condition - analogous, quite simply, to the way a negative imprint of a cast holds a presence of the object that came from it. Now of course there is not always literal imprints, but the point to be conveyed is that in a more holistic sense, a dynamic temporal relation between elements - spaces, programs, formal structures and paths, etc. - exists as they grow out of and follow on from past conditions; they are configured the way the are not only, if at all, through an ideal set of spatial arrangements - whether geometric or programmatic -, but also in relation to what was. In other words the built environment has its roots in its past; it is tangibly, and affectingly, connected with it as its past prefigures its current state. To 
the extent that this subtle temporal continuity exists, a 'comet-like' trail of is past coming-to-be is imbedded in its immediate state. Included in this general affect is the wearing and weathering of materials. That is of surfaces worn, chipped and marked from use, or the impressions left by previous fixtures or the weather stains on a component from a prior location etc. T. Lobosco describes the lack of material finishes in the Favelas as one of their most distinguishing features; interestingly she remarks that this is not exclusively due to the immediate lack of necessity for finishings - given the financially strained social context - but that the out-would appearance this imparts of a "transitory" project is embraced as it, again, plays its part in relieving the pressure of achieving a finalised building (2009, p. 5).

If this is compared with the qualitative properties of Classic architecture - and the Baroque - it is found to present more than a direct inversion of temporal impressions, as its departure occurs at a much more basic level. In Classic architecture it was positioned that there is a representational impression through both the strict geometric line and immaculate finish that the form has no 'marks' of it's past having cometo-be-as-it-is; one less a separation from its past than an impression that it ever had one. When contrasted with the Favelas, this representation is more clearly seen to present an artistic supplement or higher aesthetic articulation - a 'revealed law' - of a more basic, fundamental omission of Time in the representation, one also shared by the Baroque if not most traditions of architecture. That is, in both 'styles', of the more fundamental exclusion of the formal edifice's own actual process of creation; its conception and its construction. In the Baroque for example, while having a surface expression of an organic movement, it has no representation of its origins as an edifice that, starting from nothing, was constructed gradually through Time; that is, the impression of its actual 'becoming' in 'Time. -Impressions or 'marks' that in one way or another, and more or less, accompany all natural material phenomenon 
to the extent that all phenomenon occur within Time. Conceived and documented -spatially- in plan, its life within Time is designated to a finite period of construction, of which the final work shows no impressions, in fact it is at pains to deny - any exposed seams or particular formal relation that result from the inevitable fragmentation of an incremental build would only stand as a hindrance to its appearance of 'casual' organic movement. After this process the formal edifice abruptly ends its life within Time, albeit for the wear of its materials which fastidious maintenance then sets to overcome. ${ }^{3}$ It is 'finished', conveying a temporal vacuum before this point; its final form projects the quite difficultly attained and artificially imposed affect that it came to its 'complete' state of being without an incremental process of development. In this regard, its actual subjection to a past coming-to-be as such in Time is omitted; representationally it has no past, it is autonomous from the past - persisting continually paused in space, decoratively expressing a Time it has no concrete part in. ${ }^{4}$

These observations likely seem inconsequential, if not over embellished, however their significance with regards to their phenomenologi-

3 While it is purely speculative to infer what the architects of the baroque style intended -perhaps aging was a desired part of their affect? - D. Leatherburrows and M. Mostafavi (1993) provide an interesting reflection on the psychology behind buildings that are intended to have achieved an ideal finished states after construction. They remark on the "negative" sense that is often attributed to 'staining and erosion', as they become an "antithesis" to this finalised "ideality of the project": "Accordingly, the duration that is to follow the completion of the building -the life of the building- is conceived as a subtraction from the ideal condition of the project realized before inhabitation and weathering."'(1993, p. 82). In this removal of signs of age, they write, "will be seen as necessary as long as all stains are seen as signs of a deformation of an intended pure state." (ibid, p. 103).

4 In the case of the Baroque - Wölfflin's architecture of 'becoming' -, we again find that deeper, antithetical, desire or 'volition' manifests itself underhandedly and subversively in the artistic representation. 
cal affect gather weight when measured against the particular temporal quality of the Favelas. In the first instance, given that the Favelas depart from this constructive reality and inevitably the visual impression of been without a formal and material past, it would seem appropriate to invert the qualitative temporal affect it has: that is that is has the 'marks' of its past coming-to-be, disclosing Time as a basic condition of its constitution; and therefore, within the limits of the medium, Time itself. The statement however is somewhat empty, as it continues to treat the slums as purely representational in affect as in the Classic, and consequently does not account for the full shift that has taken place; a shift from a representation that only speaks of itself, conveying its own condition, to a 'non-representation" ${ }^{5}$ that is more concretely imbedded in the Time of its inhabitants. That is to say that it does not merely impress its own past - as a self-referential representational treatment -, but also, in a more direct way, that of its inhabitants. A point affirmed by the observation of both Jacques (2010) and Lobosco (2009) whom place much emphasis on the notion of the 'builder-dweller'; that is of the participation of the owner in the shelter's development, and also the lack of separation between inhabitation and the process of construction generally. In both these regards Lobosco writes, "sheltering and building become part of the same procedure" (2009, p. 5). The buildings' own history of change collates with, and is a more inseparable part of, that of its habitants; forming a collective past impression much like Aristotle's classic conception of memory as an 'imprint' of 'change' left in wax (Sorabji, 1972, p. 50). In this regard it presents a materialmemory as a physical omnipresent condition existing outside the indi-

5 Oiticica (1992), whom's thought will be attended to in the next section, uses the term 'non-representation' to mark the qualitative shift from art that isolates itself as something of 'contemplative' import, to something in which the individual is more actively and concretely a part of. 
vidual. ${ }^{6}$ As Leatherburrows and Mostafavi write of such architectures of change, it "age[s] with the family, changing as it does, yet sedimenting the past in the "present."' (1993, p. 82 - my italics). Such a 'temporal structure of building', they write further, is comparable to one's own experiences in [real time:

"At every moment in one's life earlier times of infancy, childhood, youth, and all other stages up to now are still present, increasing in number yet unchanged and familiar, and subject to redefinition and appropriation. Never is one's past not present, nor is the individual's past ever cut off from the tradition of one's culture and the time of the natural world.” (1993, p. 116).

What Leatherburrows and Mostafavi allude to in this statement, or at least position with some uncanny concordance, is that such architecture parallels - and therefore in a certain regard facilitates - a qualitative sense of Bergson's 'real' Time; that is, of a past that exists 'intact' without linear/spatial separation, within the present.

For Bergson, in one of his more perplexing ideas, the past -memory- in actuality is not located in the physical 'mind', but is outside of the individual. In this the past presents something quite tangible and real, as opposed to a figment of something 'done away with'; that is, as a mere phantom of a past reality 'localised in certain cells' of the brain while the actual past has cascaded irrevocably into the linear space of time (1911/1896, p. 153). Instead, beyond one's usual mode of temporal perception which suppress much of the past, filtering through only what is of immediate interest to action (ibid, p. 96), it exists in its entirety, ever growing within a contracted state in the 'thick' present; in

6 An impression, much like memory, that does not encroach into consciousness with a clear linear precision of events, but as vague yet affecting impressions of layered images and moods. 
this it is not 'cut off' from one's present and permanently dissolved in a temporal void, albeit for the gradually fading imprint left in memory - it is always retained - as Leatherburrows and Mostafavi write, 'still present', 'unchanged and familiar, and subject to redefinition and appropriation' (1993, p. 116, \& Bergson, 1911/1896). Now, there is not the need or the space here to expound on this at a theoretical level, ${ }^{7}$ instead we may grasp it phenomenologically as it manifests itself in the context of architecture. The Architect Peter Zumthore provides in an indirect way such an experiential account, one which interestingly approaches a sense of the past as an ambience/atmosphere - that peculiar phenomenon that places a wedge between 'subject/object distinctions' and invigorates a sense of Time-space's substance; here we understand that substance to equally consist of the past.

Reflecting on Ettore Scola's film Le Bal, Zumthore poses the question as to whether it is the stage, he writes, that "creates the film's dense, powerful atmosphere. Or is it the other way round? Is it the people who endow the room with its particular mood?" (1998, p. 24). He does not answer directly, but instead reflects, "I ask this question because I am convinced that a good building must be capable of absorbing the traces of buman life and thus of taking on a specific richness." (ibid - my italics). In this he subversively answers in the affirmative to both, exposing a quire intuition: the mood may be 'endowed' by the people, but the space retains this mood as an atmospheric quality, a particular subsidiary or residue that presences beyond the event that created it. Continuing, he draws this strange notion onto more tangible ground before throwing it back out into an ether beyond formal comprehension:

7 More space then is available is some what required to understand it at a theoretical level - Bergson devotes an entire book - 'Matter and Memory' $(1911 / 1896)$ - in an attempt to systematically articulate what he acknowledges as a profoundly perplexing idea; an attempt in this authors view that struggles to adequately ground it in empirical experience. 
"Naturally, in this context I think of the patina of age on materials, of innumerable small scratches on surfaces, of varnish that has grown dull and brittle, and of edges polished by use. But when I close my eyes and try to forge both these physical traces and my own first associations, what remains is a different impression, a deeper feeling - a consciousness of time passing and an awareness of the human lives that have acted out in these places and rooms and charged them with a special aura. [...] Architecture is exposed to life, if its body is sensitive enough, it can assume a quality that bears witness to the reality of past life" (ibid, p. 24-5).

Here for Zumthore the marks and impressions within a building made by past inhabitation stand as signifiers of those past events as such, and yet they themselves are not the essential impression but an initial more tangible bridge which, inciting awareness, lends itself to a 'deeper' 'different impression': traces of the past not as marks in the material thing, nor even in his own personal memory, but as an 'aura' or 'mood' as a particular aspect of the past, affecting and real, lodged within the space -and Time- itself and therefore perpetually encroaching into the present. A sentiment both perplexing and nonsensical and yet, one that is perfectly reasonable in Bergson's theoretical understanding of a more 'direct perception' of 'Durée réal'. Zumthore articulates an experience of a past that is not 'strange' and 'done away with', separated across the conceived space of a linear time, but one more intimately bound in the present tense of experience. Time is taken from a line across which things are spatially divided, and just as in the Favelas' built environment, compressed into a singular, flat 'whole' as the past is 'sedimented in the present'; or as Bergson writes of a more "concrete perception", it takes the divided moments of Time and "prolongs a plurality of moments into each other, contracting them into a single intuition." (1911/1896, p. 292). In sympathetic tone, Leatherburrows 
and Mostafavi, writing in parallel of both such a qualitative sense of temporality and the architectural properties engendering it, suggest that it, "perseveres the coherence of temporal continuity against it theoretical disintegration into separate parts: past, present, and future. Yet one's sense of the past or of the future involves a reach out of the present into some time within it (one's present) was not yet, or some time when it will be no longer." (1993, p. 116) That is to say that one 'reaches out' not to a past -and future - removed, but 'within it (one's present)', as an expansion of that (now) un-fragmented, and therefore continues 'thick' present to include in it the past: "architectural duration implies a past that is caught up in the present and anticipates the future" (ibid).

While in Classic architecture we found a representation of a continuos present, one engendered through a pronounce expression of its 'being' through a dislocation from the past and future, in the Favela - moving to the other temporal extreme - we find again properties that elicit a qualitative sense of the present's continuity; here though, in marked difference, a present that retains its continuity through 'contracting' the past into it; drawing a scattered Time into an immediate 'intuition'. It is curiously a past that in a certain sense 'is' -being- as opposed to 'was'. The temparol-spatial void of the Classic is replaced by the presensing of a more 'intense' substance like Time and space, and importantly, one that preserves a 'consciousness of time passing' as Zumthore expresses it. Both experiences of 'Being' and 'Becoming', or more generally 'real time', we may tentatively say finds import through such built conditions as they subtly erode through qualitative opposition one's common sense of temporality. Though with less potency than in the Greek tragedies, architecture through its own mode of mediation becomes conducive to a 'Dionysian' state, - closer, as Nietzsche argued, to 'reality as it is'. We will now turn our attention to further properties of the Favelas that through different mechanisms, and yet still arguably indebted to the open-ended build, stand to compound such an affect. 
In the following interrelated sections the temporal significance of the spatial-formal conditions of the Favelas will be attended to. Hélio Oiticica's art works present an interesting point of departure and reference in this endeavour, not only with regards to their stated influence by the environments of the Favelas (Jacques, 2003; Oiticica, 1992), but further in that their theoretical genealogy has its origins, among others, in a novel hybrid of Nietzsche, Bergson and Merleau-Ponty's thought (Braga, 2001; Figueiredo, Pape, \& Salomão, 1986; Asbury, 2005). As art, with a certain refinement in their intent, they present abstract distillation of some of the Favelas' basic formal-spatial properties. After a brief overview of Oiticica's thought behind his works, in this section we will draw his underlying reasoning into the more familiar ground of a comparison with Classic representation.

It was in 1959 that Oiticica produced and exhibited his 'Bilaterals' and 'Spatial Reliefs'. The first of a series of similar projects embodying a radical shift in theory and method from earlier works, ${ }^{1}$ culminating in the 'Nucleuses' of 1960 and the various Labyrinthine 'Penetrables' of 1961 through to the early 1970's (Oiticica, 1992/1960). Unlike his previous work -mostly paintings- dealing with pictorial affects restricted to flat rectilinear canvases, achieving what he would later term "state static par

1 Oiticica, originally a painter of De stiljl styled minimalist geometry, found his art up until this point as an "obsessive dissection of space [...] space without time", built on "mute planes" and the "rigorous objectivity" of the "Concrete movement'. "There is" he writes, "no reason to take seriously my pre-59 production" (1992, p. 27). It was in 1959 that the two sub-branches of the Concrete movement split -Grupo Frente and Grupo Rutura-. with the Brazilian poet Ferreira Gullar consolidating the latter's theoretical direction in the Neo-Concrete Manifesto based on the ideas of Merleau-Ponty (Oiticica, 1992, \& Zelevansky, L. Hillings, V. L., 2004) - with Oiticica's influence from his experiences in the slums placing interesting theoretical undertones in relation to the movement's general direction. 
excellence", the new works' distinguishing property was that they were spatial or "pluraldimensional" (Oiticica, 1992/1960, p. 35). In Oiticica's thought they no longer presented an object to be analytically contemplated in "mechanical-time" as it was unreceptive to such appreciation, instead the contemplative "spectator" was required to become a "participator", as their three-dimensionality obliged an "active" engagement (Oiticica, 1986, p. $77 \&$ Basbaum 2008, p. 115). That is, he propositioned, it obliged one to engage with it through Time and space; eliciting an experience as he terms it in "duration" (1992/1960, p. 35). Though they operated on a number of levels - employing colour and 'structure' as key aspects - it was this temporal experience engendered through an increased spatiality that was most basic to them. He writes:

"[...] the concept of time emerges as the primordial factor of the work. But time, here, is an active element: duration. In representation painting, the sense of space was contemplative, and that of time, mechanical. Space was of a kind which represented fictional space on the canvas, the canvas works as a window, a field of representation of real space. Time, then, was simply mechanical [... from the moment that the plane of the canvas began to function actively, the sense of time necessarily entered as the principal new factor of non-representation." (2003/1960, p. 36)

As 'non-representations' they become more installations or environments to participate in as opposed to art objects for contemplation. Michael Fried once wrote critically that, "the experience of literalist art is of an object in a situation - one that, virtually by definition, includes the beholder" (1998/1967, p. 125). This Oiticica was quite aware of, his installations most simply defined were a break from the 'static, analytical' nature of the fundamental object creating procedure of the main 
line of art, to that of the "non-object" as something "dynamic, temporal"; the experience in Time -and space- itself becoming their intent and value: "Faced with the non-object", he writes, "man no longer mediates through static contemplation, but finds his living time as he becomes involved, in a univocal relationship, with the time of the work." (2003/1960, p. 36). This experience of 'time', he positions, takes on particular meaning, "different from the meanings which it has in other branches of knowledge"; within the context of the 'work of art', he writes, "it has close ties with philosophy and the laws of perception, but what characterizes time in the work of art is its symbolic signification of man's inner relation to the world, an existential relation."(ibid). An 'existential relation' which he alludes to in later texts as an 'immanence' of one's self 'in the world' (Figueiredo, Pape, \& Salomão, 1986, p.74-5).

Beyond the stated significance, however, one may question as to whether Oiticica's thought and installations do not just re-present at a rudimentary level the accessible and academically tied surface distinction between the experiential nature of architecture and other plastic arts; spatial inhabitation contra the statically viewed picture. If it were simply a case of something being 'three-dimensional' for it to lend itself to a sense of 'duration', then this would lead us to the unlikely conclusion that all architecture, as the definitively spatial medium, holds such a capacity. The question that requires attention is how in more thorough terms is a sense of 'real time' attained?

Oiticica genuinely aspires to something in the Favelas, their spatiality; but, as he was aware, they, and his works, are not so much distin-

2 The term “not-object” was ‘invented' by Ferreira Gullar. (Oiticica, 1992, p. 36-37; Asbury, 2005). For Oiticica the term is somewhat interchangeable with "anti-art", the definition of which is: "understanding the artist and [his/her] reason for being not anymore a creator of contemplation but a motivator for creation. The creation as such is completed by the dynamic engagement of the "spectator," now considered a "participator." (Figueiredo, Pape, \& Salomão, 1987, p. 77). 
guished by the fact that they are spatial, as all architecture is, but by the degree to which they are spatial. This is of course not in a quantitative sense of volume, but a qualitative sense in that we are provoked or at least obliged to apprehend and experience space, to be more aware of its presence, more actively within in it within the Favelas in contrast to other architectural environments; it is qualitatively more 'spatial'. Given the earlier study of architectures of antiquity, this should seem less curious. It would be to suggest that the labyrinthine-favela is antithetical with respects to its spatial-temporal quality to that of the quality imparted by the likes of Greek and Egyptian formal properties shaped by the 'artistic volitions' to remove space and time - to elicit a sense of 'being'. Indeed, Oiticica was quite aware of this, and appears to have been familiar with Worringer's dissertation. He writes in a 1961 journal entry that for Worringer, Greek architecture is "fundamentally "plastic," meaning here non-spatial, or anti-spatial", where as in contrast, "The labyrinth [...] would be the bridge to a spatial architecture, active, or spatial-temporal." Within the labyrinth he continues, "architecture becomes non-objective, the space becomes more important"; to aspire to such an architecture "would be an attempt to confer on real space a time, an aesthetic life-experience (vivencia) [...] the first signs of this idea is the labyrinth." (Figueiredo, Pape, \& Salomão, 1986, p. 29).

In the first instance this may simply be drawn as an inversion of prior reasoning. If we recall, in Worringer's argument early Greek and Egyptian architectures were directed towards avoiding the representation of space, that is, of 'suppressing' space as an actual condition, a thing of substance in the art work and in our experience of it. This 'artistic volition' was due to the 'mere fact' that space is the one thing which 'links' and unifies all things, imparting them a 'temporal value', as they are drawn into the 'interplay of phenomena' (1908/ 1967, p. 22); in this regard it is a suppression of 'space-time' more generally. As studied, this was principally avoided within the representation of form through restricting it to purely height and width plane dimensions, as it is the depth- 


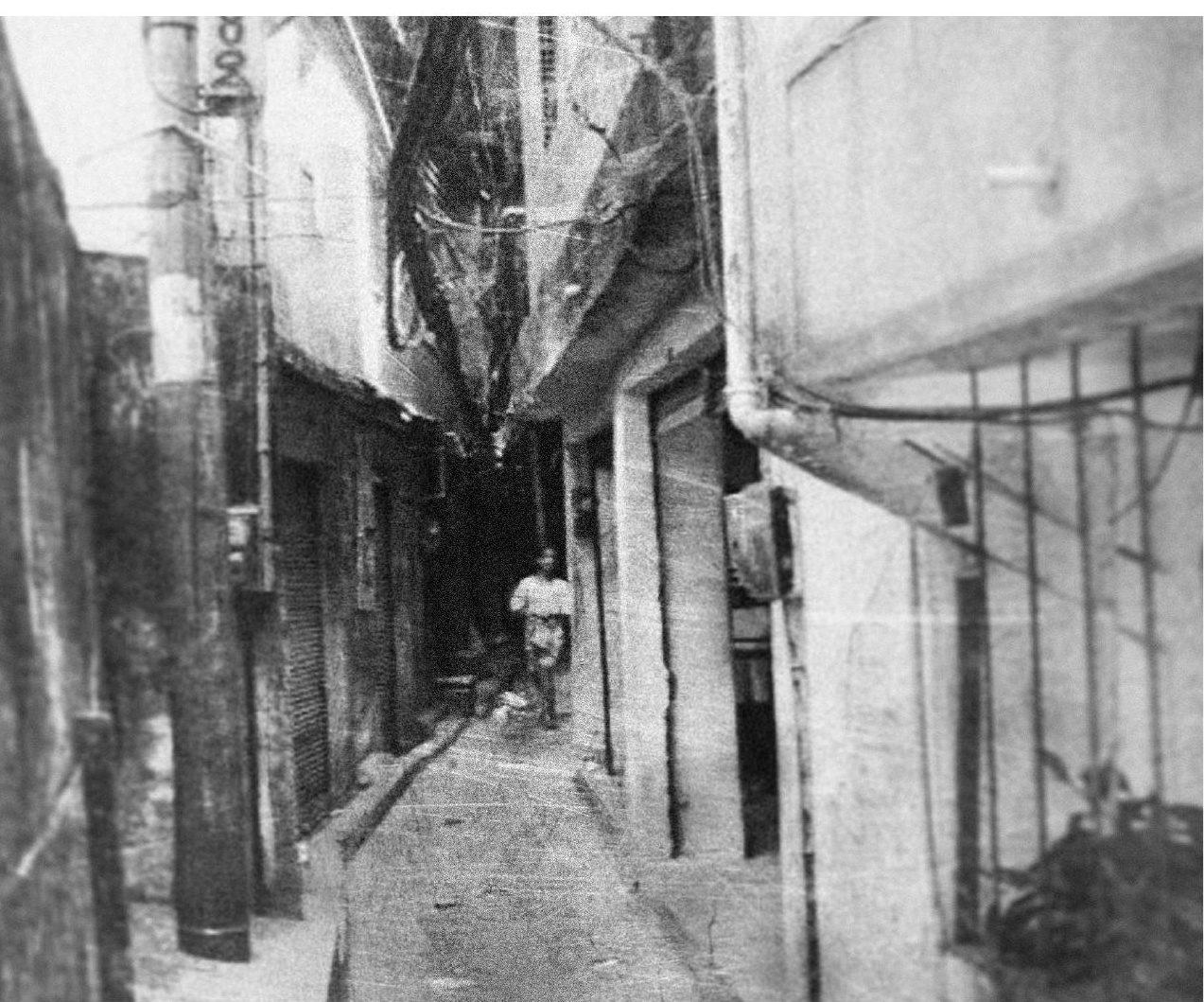

Figure 25: Alley in Rocinha

Favela. Source: C. Kelly, (2008).

"I ASPIRE TO THE GRAND LABYRINTH"

An isloated senstense in a journal entry by Oiticica, dated January 15, 1961. (Figueiredo, Pape, \& Salomão, 1986, p. 26). 


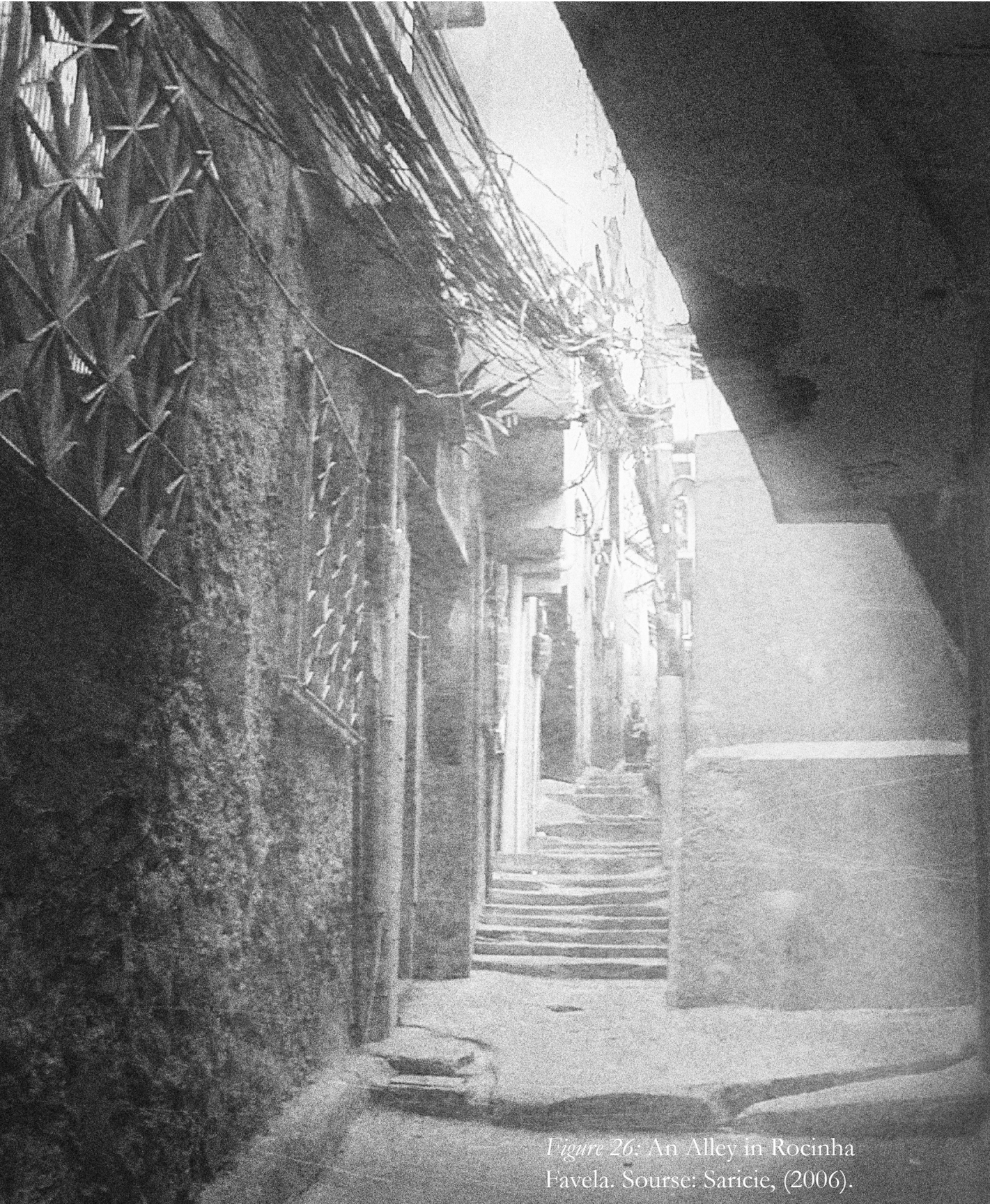


dimension for Worringer that discloses space. But what is the labyrinth but depth, and to add, density of space. To return to the president of the Favela, if we were to conceptually distinguish its many alleys, demarked by the fragmented and unruly interlaced shelter's that run its length, as being composed of planes - just as in Oiticica's abstracted works - they are arguably, in every respect, planes of depth. Perceptually they are planes operating in the height and depth dimensions, creating a depth of field which, given former reasoning, would amount to a disclosure of real space-time; making one aware, subtly and subconsciously, of its presence - or more, our presence within it. While 'classic' form's quality of suppressing space imparted a sense of a spatial 'void' - 'cubic space' that divided all, the labyrinthine-favela theoretically would re-invigorate one's sense of space as something of substance: space is no longer the one thing that separates all, but that which unifies all - drawing one into the flux of phenomenon. Oiticica too acknowledges this link, 'one depends on the other', he writes, resulting in something 'spacio-temporal'. Though for him the 'issue at stake' in such an increased spatiality is a sense of Time, 'not space': citing Bergson he writes, "if it were for space we would arrive again at the material, the rational. The notion of space is rational par excellence, it arises from the intellect and not from intuition." $(1986 / 1951$, p. 16). Therefore in his reasoning properties of spatiality - depth - gain their efficacy to erode one's conceived reality through the introduction of Time; but it may be added based on prior reasoning that this space itself in turn becomes 'real', as opposed to the 'rational' of elucidien/'cubic' abstraction, which is the 'intellectualized' space Oiticica is likely referring to. To move beyond mere reiteration of

3 Translated from the original Brazilian Portuguese: "O espaço existe nele mesmo, o artista temporaliza esse espaço nele mesmo e o resultado sera espaciotemporal. O problema, pois, é o tempo e não o espaço, dependendo um do outro. Se fosse o espaço chegaríamos, novamente, ao material, racionalizado. A noção de espaço é racional por excelência, provém da inteligência e não da intuição (Bergson)." (ibid). 
arguments we have already touched on, and to understand the Favelas' particular significance with respects to this phenomenon, we need to look more closely at its formal/material properties.

The quality of unity or interconnectedness, which is defining of spatiality's psychological significance in Worringer's view, and by extension we can entertain, a defining constituent within the aesthetic mood of the labyrinth proper as the spatial condition par excellence, takes on added aesthetic import in the particular case of the Favela as a labyrinthine environment unique in its own right. Here unity, as a qualitative experience of spatial-temporal presence elicited through 'depth', we may reason is overtly bound in a complicit relationship with formal unity/ interconnectedness. As Jacques notes a Favela, in comparison to more conventional conceptions of the labyrinth of myth, has a far more haphazard formal quality. She refers to this as one of "fragmentation", which arises naturally from its continuous, piecemeal construction from scavenged and recycled 'irregular material' (2010, p. 291). While to associate a 'fragmented' quality with one of 'unity' may seem a contradiction of terms, it is an appropriate description of the wider formal condition of the Favela as an intertwined and entangled mosaic of 'ad-hoc materials' and spaces; a chaotic unity of fragments. This becomes more clear when we recognize the sharp distinction it has with form that is 'self referential, internally resolved', and 'closed' in its 'material individuality' studied in chapter two. Compared to the 'clearly articulated' forms of Greek antiquity and the renaissance, there is here an overtly eroded sense of such individuality between fragments. That is, in the Favelas materials do not project a strong notion of object like autonomy, instead one is inclined to read each element as but an incomplete, imperfect, fragment of a wider 'whole'. No single element as Wölfflin would say 'breathes independently'. Indeed, his contrasting description with the Baroque has a certain validity: "No longer do beautiful element combine in a unity in which they continue to breathe independently, but the 
parts have submitted to a dominating total motive,"(Wölfflin, 1932, p. 185). Or, in a decidedly more Nietzschean tone, he writes further, "The imaginary barriers between figure and figure fall, and the total mass of created forms rolls on in a broad, unified stream" (ibid, p. 186).

However the similarities between the two in terms of 'unity' can only be taken so far; there is a vital differences between the 'absolute unity' as Wölfflin terms it of the baroque aesthetic, and the particular 'fragmentary' unity of the Favelas. Wölfflin's use of the term with respects to the baroque goes beyond describing a material interconnectedness of immediately conjoining forms, and addresses a wider order of geometric and proportionate relations under which all elements are linked holistically. As was addressed in passing earlier, each formal element in baroque, as in classic architecture, is in "co-operation with the whole" collectively forming a self contained, internally resolved 'organism', - that is, an 'object' -; this 'law' of the self contained object is merely 'concealed' (ibid, p. 185 \& 124). While in Renaissance architecture every element, perfectly balanced in themselves, combined to form a 'multiplicity of unity', the baroque equally forms a completely closed whole, however each individual element was not 'finished' within itself, -'breathing independently'- but gained its 'sense and beauty' though its cooperation with the building as a whole; forming an 'absolute unity' or a interdependent closed system of form (1932, p. 185). This overarching spatial order which connects elements within an abstract system is what Bergson terms, with a certain obviousness, a spatial "Geometric order", which creates autonomous systems or, "bodies [...] cut off from their homogeneous environment and separated by the intellect" (Lorand, 1999, p. 406). The Favelas clearly depart from this moving closer to what Bergson terms a 'vital' order, presenting temporally 'organized (living) bodies', which are no longer isolated and self contained by 'external principles' - i.e. abstract spatial measurements and proportions -, but organized from 'within', as they develop from a 'natural' 
non-linear internal 'growth' (ibid, p. 402 - \& Bergson 1946/1934, p. 35 - my italics). Of immediate relevance in the concept of a 'vital' order is that it includes, and engenders, difference. In a geometric order, or an order constituted by 'exterior' principles, all 'possibilities' are dictated and confined within its spatial (or temporal) patterns, arrangement, proportional relations etc.; anything that breaks from its continuity is, quite logically, then in dissonance with such a system and therefor excluded -detached and outside of it. In contrast a vital order, having no such overarching abstract system of relations - though having 'naturally closed boundaries' -, Bergson suggests engenders and includes difference, idiosyncrasy, 'multiplicity' and 'uniqueness' - not simply 'rearrangements' of the same elements within a set system (1946/1934). -Comparative to the common conception of order he notes, it is by all accounts what is considered 'chaos'; though it is really an order more nuance and un-intellectually tangible: 'where precise laws lead to apparently random behavior which is in fact minutely organized' (1946/1934, p. 217), through a 'complex non-linear dynamic systems with rich networks of interacting elements', which 'settle dynamically at the edge of chaos' (1983/1907, p. 22). 'The point to be conveyed is not a particularly complicated one. The Favelas, through departing from a closed 'geometric order', and a natural adherence to vital order, engender what may be called an open aesthetic, a 'fragmentation' of diverse and unique elements that cohere within a more nuance temporal unity, one that accommodates diversity and difference. At a visual level, it is an aesthetic order clearly seen to be embraced by its inhabitants through the use of a mosaic of diverse, vibrant and incongruent colours -sharply juxtaposed with the likes of the singular aesthetic tone of a baroque building, let alone that of the serial architecture common to a suburban development: any break, - difference - from this order would clearly be

4 As Bergson writes, "Disorder is simply the order we are not looking for." (1946/1934, p. 117). 
seen as in dissonance. ${ }^{5}$

From each individual, idiosyncratic and unique shelter to the slum collectively there is a comparatively diminished impression of autonomy as an articulated internal closedness, - and geometric unity as a system imparting the limits of the that closedness - the formal-spatial environment merges, or is more 'interlinked', not with things within its own detached order, but with the wider 'whole' - the greater unity of matter, space, and Time. In this sense it is a 'fragmented unity'. Julien Pallasmaa eloquently sums this up as a holistic experience -in spatial terms- and the architectural condition that engender it in a reflection on the thoughts of MerleauPonty. He writes:

"Maurice Merleau-Ponty described an "in-between" reality or "ground on which it is universally possible to bring things together." Beyond the physicality of architectural objects and practicalities of programmatic content, enmeshed experience is not merely a place of events, things, and activities, but something more intangible, which emerges from the continuous unfolding of overlapping spaces, materials, and detail. Merleau-Ponty's "in-between reality" is then perhaps, analogous to the moment in which individual elements begin to lose their clarity, the moment in which objects merge with the field. [...] Within the experiential continuum of enmeshed space, we understand distinct objects, distinct fields, as a “whole.””(Holl, Pallasmaa, \& Perez-Gomez, 2006, p. 45).

It is in this sense that one may entertain that both space and form within the Favela are complicit in projecting an overarching ambience of interconnectedness - or at least relative to the main-line of built environments. The out would appearance of the 'closed' clearly ar-

5 As is well known, many such suburbs have building regulations in place to prevent any such visual breach of their order. 


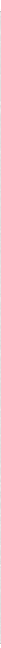

Figure: 27, 'the labrinth': I have been

generous... How have you been generous?

I have re-ordered time, I have turned the

world upside down.... all for you. (The

Goblin King).

Sourse: Lucas. G, Rattray. E, Laxer. D (Producers), Henson. J (Director). (1986) The Labyrinth [motion picture]. Quote, 1:31:33; Film still $00: 19: 25$. 
ticulated 'thing' is weakened; perceptually 'sufficient reason' to distinguish abstractly and acutely 'individuated' phenomenon is eroded - to the extent of this affect, qualitatively immersing one, in Nietzsche and Schopenhauer's logic, into the tumultuous 'unity' of matter -and also the 'ever-present' 'will' - that lies beyond this perceptual predisposition. Or as it has been developed in this thesis so far, an atmospheric like immersion in 'real' Space-Time. It is, as Merleau-Ponty writes of such space, "no longer [...] a network of relations between objects [...] It is, rather, a space reckoned starting from me as the zero point or degree zero of its spatiality. I do not see it according to its exterior envelope; I live it from the inside; I am immersed in it. After all, the world is all around me, not in front of me." (1964, p. 178). Davies expands on this when she writes, it is "essentially a spatiality without "things", in which the threshold between interior self and exterior world becomes porous, and the separation between "out there" and "in here" is transcended. Whereas visual acuity tends to keep attention focused on what lies in front or ahead [...] when it dissolves into a non-focused blur, one becomes aware of space as all around, bodily-enveloping as if one were immersed in the sensuous liquidity of the sea." (2004, p. 75). Space and Time, through crossing an opaque threshold of sensibility, become more the substance we are within, not the void, full of isolated objects, which leaves one always the spectator on the 'outside' - the objects and oneself separated, static and, comparative to a deeper sense of 'reality' writes Bergson, 'cold as death' (1946, p. 151).

Both notions of spatial and formal unity so far discussed are essentially visual in nature, or at least we have yet to move beyond the limited scope of treating them as 'aesthetic' in the restrictive sense of the term as something of purely visual quality. ${ }^{6}$ Though fundamentally re-

6 At this level, as Wölfflin would be inclined to express it, this is we may say the Favelas' 'painterly' quality. 
lated to this we have not yet touched on the 'active' participatory aspect of the environment that Oiticica emphasis as a vital contingent in drawing the 'spectator' into a more direct experience of 'duration'. -But, of course as already alluded to, considered in visual terms alone this is not to imply an inactive, un-participatory experience, of the 'spectator'. To speak of an aesthetic of such spatial-formal interconnectedness, is to articulate with the inadequacy of conceptualization a deep experiential immersion in the environment. We gain, however, a deeper understand of this notion of participatory immersion when we begin to consider a favela as obviously an environment in the first instance unfolded experientially through its passages and enclaves.

It is perhaps the notion of active immersion that articulates part of what is so compelling and aesthetically engrossing about the labyrinth of myth; albeit, as far as the imagination allows one to enter it. Here however, in contrast to the Favela, one might say that the immersion is more complete, the labyrinth constitutes a world in itself that one is bound. As was Lateralus's fate, they must wonder lost within its passages with no knowledge of what lays ahead, let alone how to reach its exit, or its 'centre', - if either of these at all exist. It is an experience, a journey -to employ a cliché term- that one is engrossed within; the world beyond this immediate reality falls away as the individual is lost to the time of the labyrinth. B. Tschumi addresses the matter at hand, and brings us to a point that is vital to the aesthetic mood of such a phenomenon: he writes, "a total revelation of the Labyrinth is historically impossible because no point of transcendence in time is available. [...] one's perception is only part of the labyrinth as it manifest itself. One can never see it in totality, nor can one express it. One is condemned to it and cannot go outside and see the whole." (Tschumi, 1975, p. 227).

While one may be able to leave the Favela, to step outside it in a literal sense, this is however a quality which in a certain sense it no less possesses. It is a quality that we may understand, in the first instance, 
through its particular ' 'un-clarity', which as we have so far found a certain antithesis to the quality of 'Autonomy' in the spatial-formal 'fragmented unity' of the Favelas, so to do we inevitably find an opposite to that of the perceptual 'Clarity' that was distinguished as operating as an inseparably element in the likes Greek and Egyptian architectures of antiquity. The switch from 'clarity' to 'un-clarity' marks a radically different mode of temporal experience; from the 'timeless' to Time 'condemned'.

To recall, the property of 'material individuality' in conjunction with the 'plane' negated the necessity of form's disclosure through time-space, as the perfect symmetry and order of the form as Worringer asserts consolidates the "temporal succession of perceptual moments" of the "purely optical process", affording a clear "whole for the imagination". In contrast, in the a-symmetrical composition of the Favelas, from the individual fragment to the whole, there is no order, no articulated logic through which to foresee and grasp more than is viewable from a single position in Time-space. To state the obvious, there is no 'artistic measure' taken whatsoever to 'free', 'the sensuous object from the unclarity imposed upon it by its three-dimensionality' (Worringer, 1967, p. 22). What is of aesthetic-experiential significance is that it is not only lacking order with a sort of passive un-clarity, but naturally achieves the opposite affect. As Jacques notes it is a lack of order that supersedes even the labyrinth of myth, let alone the modern "rationally built city", as in the Favelas "there is no plan" (2010, p. 316). 'Improvised and spontaneous', in a continuous state of evolution, it engenders a natural, relatively incommensurable formal-spatial 'complexity' (ibid). It presents in her view an experience which is the 'exact opposite of the modern urban experience', as it lacks the rationality of its 'strait lines', the logic of its grids and regular geometry (ibid). Apprehended from its alleys - as it only can be - as one traverses through a chaotic enmeshment of shelter's, even the most basic visual clarity is inhibited. As Jacques writes, the Favelas afford only "always-fragmented 
perspectives", lacking any "spatial reference" which imparts one a sense of "unfamiliarity"; it remains unknown, un-clear (ibid). One can only reveal the slum in Time, and never completely; its wider formal and spatial relationships are always obscured; it retains a certain rational impenetrability as, lacking the logic of a plan, it resists a holistic overview; that is, as Tshumi expressed it, there is no 'point of transcendence in time', no god's eye view. It is in this sense that experientially 'one is condemned to it', and cannot figuratively 'go outside and see the whole'. One is 'condemned' to experience such a built environment through Time and through space, these become the necessary mediums through which it must be actively engaged with; or more, inhabited.

In the first instance in terms of temporal significance, this particular mode of immersive spatial experience holds a clear and direct correlation with the qualitative affect of Bergson's 'real time', as, at a basic and concrete level, it re-asserts Time's original implication for consciousness, prior its 'spatialisation', through once again "hind[ering] every thing from being given at once." (1967, p. 110 - my italics). While the native predisposition of perception creates a 'limited amount' of static, repeatable, and therefor 'monotonous', 'objects' and occurrences from phenomenon as a whole, the labyrinthine-favela re-imposes qualitatively for the perceiver a relative degree of 'continuous creation of unforeseeable novelty' unfolding at the ebb of 'Time's flow; which is, as Bergson asserts, the actuality of 'Time once a more 'direct perception' of it is attained. That is to say while we are commonly removed from this quality of 'Time, -from phenomenon always becoming in a 'upsurge' of novelty- curiously here it is simulated if not reinvigorated - as is implied by Oiticica - as one's forced mode of traversal through the environment re-implements the impression of the gradual, relatively unforeseeable flow of phenomenon unravelling before them - prior its division into static 'objects' and 'habits' that prefigure experience into a limited number of predictable 'possibilities'. In this regard, the immersive alleys of 
the Favela engenders, to the extent of the built environments capacity to affect, a qualitative sense of phenomenon 'as it is' in its original and actual state of 'becoming'; in aesthetic terms re-imparting one with a deeper qualitative sense of novelty, awe and mystery, which our common 'spatialsed' sense of temporality denies - and affords what Bergson sugests as the 'grey and colouless' reality one commonly occupies.

A significant aspect in this unfolding quality of experience is that of the sense of immediacy it engenders; a notion that leads reflection to the other half of the experience of 'real time' - that of the qualitative sense of 'Being' within the present.

An immediacy of experience appears a common consensus among various theorists, regardless of the particulars of its terming: Oiticica writes with regards to his 'non-objective' works that the participator, 'no longer mediates through static contemplation' implying a more immediate contact with the experience of the installation; while Tshumi in similar tact suggests that through the inability to "step outside the labyrinth", to perceptually prefigure what experience it holds, it makes it "personal" eliciting an "immediate and concrete human activity." (1975, p. 224). "Perception in the labyrinth" Tschumi writes, "presupposes immediacy" (ibid). Elaborating he continues: "Unlike Hegel's classical distinction between the moment of perception and the moment of experience (when one's consciousness makes a new object out of a perceived one) the metaphorical labyrinth implies that the first moment of perception carries the experience itself." (ibid). Robert Morris places this in more concrete terms when he writes with respects to such environments that, "having no characteristic view, no singular profile to give $[\ldots]$ a definite gestalt, memory can't clearly imprint it." (1995, p. 187). That is that through both weakened visual clarity - as opposed to buildings and objects that have "clear gestalts as exterior and interior shapes" (ibid: 194) - and a spatial experience that gradually unfolds in depth, the formal-spatial environment is more resistant to being broken 
up and abstracted into a limited amount of stable 'images'/'object' by perception and 'imprinted in memory'; and therefore one is less likely to reduce experience to habitual repetition of a prior experience. What is significant in this, he writes, is that "Now images, the past tense of reality," - and, as Bergson would add, equally the future tense - "begin to give way to duration, the present tense of immediate spatial experience.", 7 or in other wording, the 'indivisible' experience of "physical space and that of an ongoing immediate present." (ibid, p. 176). To cite C. Davies again who places this in simple terms, "In this perceptual state, rather than being mentally focused on the future [or the 'past'] and thus inattentive, even absent, to the present, one becomes acutely aware of one's own embodied presence inhabiting space" (2004, p. 75). ${ }^{8}$ For Morris this state of "presentness" becomes the "primary dimension" of such space, -"overshadowing the static, rememberable image of the autono-

7 Morris uses the same analogy as Bergson in explaining this, memory images here are the statics of a film still; the imposed representation we put over phenomenon, and interpret it qualitatively as the same thing each time it is experienced (Morris, 1995, p. 177). It is important to note here that this is not in contradiction with the increased sense of past looked at in the first section. The 'memory' Morris speaks of differs from what Bergson calls 'pure memory' which "records every moment of duration, each unique, and not to be repeated"(1911/1896, p. 94). In contrast, the inclination of perception to create fixed, mediating, objects of 'things' and 'actions' -the 'memory' Morris refers to -, only stands to suppress 'pure memory'; as they are perceived as repetitions of the same thing, not totally unique and novel to sense perception as they unfold at the ebb of Time's flow (ibid). Such "recollection" writes Bergson, "passes out of time", they 'do not represent the past', but suppresses it through filtering through only what is required for functional action (Ibid, p. 92). In this functional action, he writes, experience actually becomes, "more and more impersonal, more and more foreign to our past life". (ibid, p. 95) - we will touch more on 'functional action' shortly.

8 It would be reasonable to infer here, given earlier logic, that this is a matter of taking attention from a past removed, 'spatialised', and not imbedded in the present. 
mous object." (1993, p. 187). Through "verb-type spaces", as opposed to a "noun" type space (ibid, p. 195 \& 204), one is brought to the "apex of time's flow" -the immediate present-, as "location and point of view are constantly shifting", "the body is in motion, the eyes make endless movements at varying focal distances"(ibid, p. 177-178), consequently imparting an experience less 'visual' and 'static', and more "temporalkinaesthetic" (ibid, p. 194). That is, a more 'direct' awareness of one's embodied presence in both 'real time' and 'real space' (ibid, p. 177).

This experiential quality arguably gains stronger efficacy within the Favelas through another spatial-formal property again unique to it as a labyrinth in its own right, the study of which gives us a deeper understanding of the notion of present tense temporal-spatial immediacy/ immersion through approaching it from another angle - one that more overtly presents it for what is: a tactile temporal-spatial awareness. In the likes of Oiticica, Morris, and Jacques accounts of the Favelas', or environments of similar spatial property, each place much emphasis on the physically 'active', and/or 'participatory' aspect that is obliged of the individual. That is of the shift from a space that requires but a visual passivity - a space of 'static images' in Morris's thought, or detached, purely visual 'contemplative' spaces for Oiticica (1992/1960) - to a more embodied "physical space", "requiring physical movement and duration" (Morris, 1995, p. 182). What is of vital importance, and what is implied in each of their accounts though not attended to directly, is that this is not common 'activity' or 'movement' of the every-day undertaken for practical and functional purposes, but a more consciously engaged or immersing participatory activity, which is of experiential value in its own right - beyond the future orientated ends for which it is undertaken. For Bergson 'detachment' from purely instrumental action is a necessary condition for the disclosure of 'real time'. He writes that it is through not perceiving "simply with a view to action", but instead to "perceive in order to perceive, -for nothing, for the pleasure of doing 


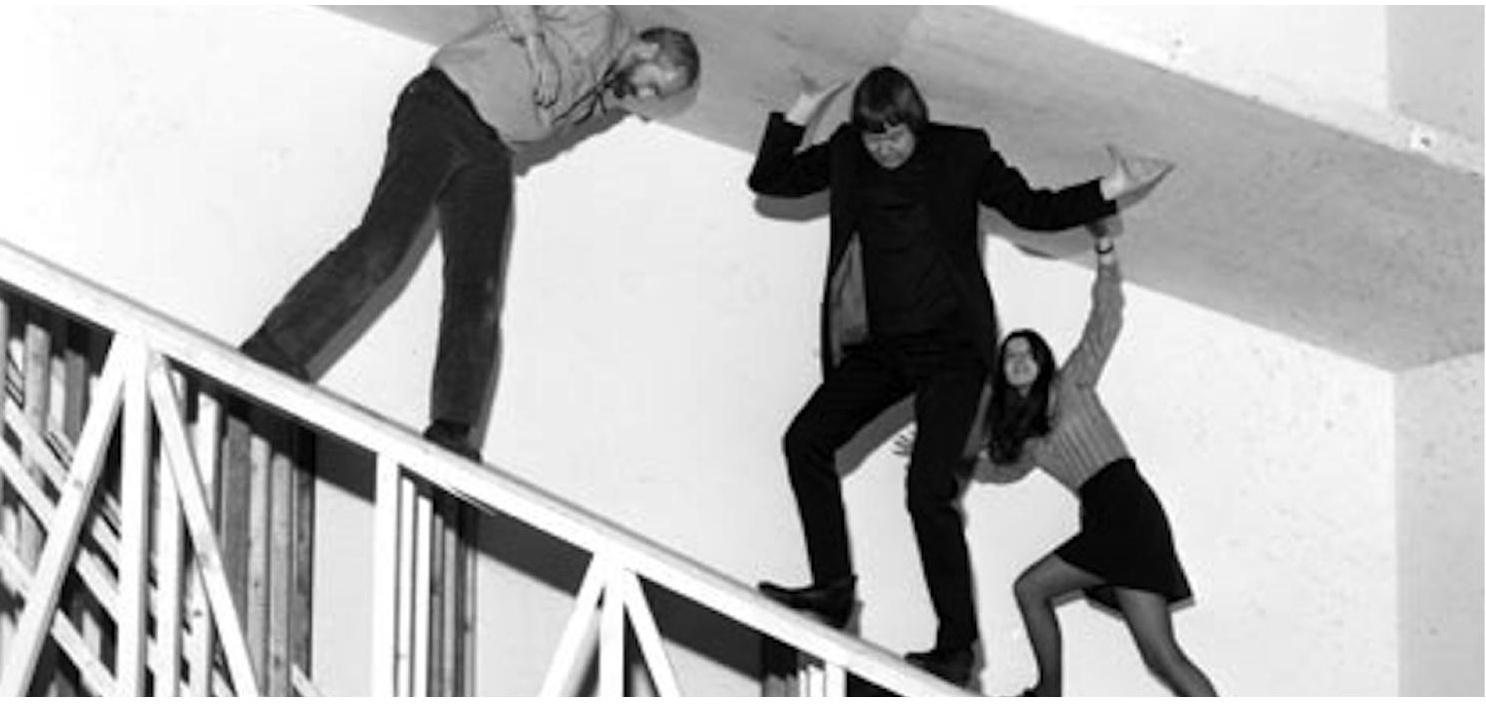

Figure 28: One of a number of "participartory" istallations of Robert Morris's "bodyspacemotionthings" exhibition at the Tate Gallery in 1971.

Source: Higgins, C., 2009. (Original photograph courtesy of the Tate Gallery, 1971.)

The exhibition was 'abruptly' closed after four days; as a curator at the time Kathy Noble remarked, 'people became very overexuberant'. A journalist reporting on the event noted: "Some of the 1,500 visitors became so intoxicated by [the] opportunities that they went around 'jumping and screaming', to quote the exhibition's keeper, Mr Michael Compton. They went berserk on the giant see-saws, and they loosened the boards on other exhibits by trampling on them. 'It was just a case of exceptionally exuberant or energetic participation'." (Higgins, 2009, par. 8). 
so," that affords a "much more direct vision of reality" (1946/1907, p. 162-3). To recall, it is the minds 'view to action', which limits one's 'horizons', showing us 'less the things themselves than the use we can make of them" (ibid); it is this perceptual predisposition which for one distils the sensible world into mediating static objects, stable simplified representations for 'convenience of use'. Objects which, Bergson writes, in turn as each is perceived "provokes on our part movements, at least nascent, whereby we adapt ourselves to it. These movements, as they recur, contrive a mechanism for themselves, grow into a habit, and determine in us attitudes, which automatically follow our perception of things." (1991/1896, p. 84). This inclination engenders, "a closed system of automatic movements which succeed each other in the same order and occupy the same time" (ibid, p. 90). In other words, such 'instrumental' movement mitigate a sense of 'real time', in the same manner as the static object, as there is no mark, no sense or awareness of experiences' absolute 'novelty' and 'uniqueness' occurring at the ebb of 'Time's flow. One qualitatively interprets a static unchanging worldpicture of habitual, 'monotonous' recurrences within a limited arrangement of possibilities.

Non-instrumental 'activity' is impressed in a very distinctive way within the Favelas: as Jacques writes, "To go up a favela on a hill is a unique experience in spatial perception. From the very first curves one discovers a different rhythm of walking, a swing that the circuit itself imposes. The best representation of this labyrinthine experience of walking", she writes, is "to dance" (2010, p. 316). It is this quality of 'dance' that distinguishes it from purely 'instrumental' activity, as it implies a certain awareness of the experience itself beyond habitual movement, an awareness of one's body acting in time-space. As S. H. Farleigh writes, in dance "or when instrumental movement is placed in a dance context", one is "released from the realities of instrumentally purposeful movement, since dance, as art, is movement that is aesthetically intended and valued." (1996, p. 183). Un-instrumental, 'aesthetic 
movement' in Fraleigh's account is distinguished in that it imparts one a "kinesthetic awareness" of "one's own motion in time-space" (ibid, p. 182). "Time-space" becomes a "lived ground embodied by the dancer", it is "lived" or mindfully experienced through the body (ibid, p. 184). In this for the subject space is "constituted aesthetically", (that is, felt). She continues, "Movement, space, and time are only abstractions until they are embodied" (ibid, p. 182) - "they go easily assumed and unnoticed (hidden in our everyday movement) until we give attention to them" (ibid, p. 185). Awareness of one's body, or a "kinaesthetically awakened, whole-body consciousness", inevitably equates to an awareness of space itself, as she reasons the body is space, it constitutes a "body-of-space" that we have an immediate sense of - "it is the origin for our perception and understanding of space in general" (ibid, p. 181). Equally it is one's "body-of-time", where "movement" within the "lived moment" is felt directly in its "unique and unrepeatable character" (ibid, p. 185). That is to say that beyond instrumental movement, their lies a more direct and 'immanent' sense through the body of the seamlessly unfolding nature of material phenomena at the ebb, the present, of Time's flow; or, as Oiticica terms it in a sympathetic fashion, one partakes 'actively' in 'duration' - not 'mechanical time' (1992/1960, p. 35-6). Directly quoting Bergson, she suggest that such movement is the 'execution' of the "mobility of the real" (ibid, p.182, \& Bergson, 1946, p. 222). It is to more consciously and attentively feel one's own embodied, and therefore immersed presence in the stream of Time-space.

Oiticica's art work further illustrate the importance of one's experience breaking form purely 'instrumental movement' to achieve such a temporal-spatial sense. It is here however not dependent on properties of the work itself per say, but on the mind-set of the art appreciator. While his works lacks the irregular and steep terrain of the Favelas, which has the capacity to impose on the participator a certain 'rhythm' as Jacques suggests, it instead makes use of the simple fact that it is 
presented as 'art'. What the subject brings to the work ideally is an attentive disposition: an intention to observe and consider the art object consciously, with the expectation that the artist has something to communicate. Oiticica's work however does not present an object for one to 'contemplate' -it does no gratify the intellect-, but a 'non-object' which is more accurately an experience; in this one's conscious attention is turned to the experience itself -not analytically so, but as tactile awareness. It is awareness of the experience of the spatial installation itself; that is of no more than movement through space and Time, as one reveals gradually the 'non-object'. Of course this is a banal activity in everyday experience, 'assumed and unnoticed', but here it is an activity done for it's on sake; it is not purely an instrumentally useful activity, but just as in 'dance' it has its own, internal, aesthetic ends. As Fraleigh writes "The movement of dance really accomplishes nothing (beyond being itself) and goes nowhere (outside of the dance)." (1996, p. 183).

It is the spatial-formal complexity of the Favelas that holds the capacity, however subtle, to erode habitual and purely functional action, and to engender a more bodily or tactile spatial-temporal awareness.

In each section this chapter has approached different properties of the Favelas, pulling apart for the conveniences of study what is a more unified formal-spatial character, which equally collectively imparts a more singular temporal-aesthetic experience. While perhaps unconvincing in themselves, a gradual picture has been rendered that suggests an environment with a remarkable and unique temporal-spatial aesthetic - one that challenges basic conventions of the main-line of contemporary architecture. As the 'dancing' revellers on the mountain sides of Thrace and before the stages of the Greek amphitheaters found their union with Dionysus, so to perhaps one is brought that bit more closer to a disruption of 'spatialised time' and 'individuation'; a more 'direct perception' of their embodied Being and Becoming in the world. 
Through the precidents of the Favelas and Classic architecture, this text has observed and presented argument for the relationship between properties of the built environment and what appear two fundamentally opposed temporal-aesthetic experiences - 'Becoming' and 'being' respectively. As a means to conclude the study of each we may address the remaining phenomenological question as to the apparent contradiction, or at least paradox, that lies in both: their link through both achieving an overarching 'Being' as a qualitative experience of the present moment's continuity; its lack of fragmentation across a linear, 'spatialised' time. Can we truly have two such similar experiences within two fundamentally counterpoised phenomenon, both built and perceived? In finding this quality in both, one may understandably suspect an error in argument - one perhaps subject to a bending of words for the convenience of theory. Morris and Fried would be the first to assert this, as they saw a mutual exclusivity in each notion of the present. Morris writes of his conception of a 'continuous present', engendered in a qualitatively more spatial environment, in direct rebuttal with that of Fried's 'presentness' of the articulated object 'wholly manifest' in the moment. The clear "all at once" gestalt of the autonomous object is, Morris writes, "not relevant and is probably antithetical to the behavioural, [present-tense] temporal nature of extended spatial experience." (1995/1978, p. 197). While Fried, with more pronounced certainty and destain, writes that Morris's 'theatrical'/'literalist' art and its conception, which 'corrupted or perverted', stands against the 'authentic art' of the 'instantaneous' object and its quality of impressing a 'continuous and perpetual present' (1998/1967, p. 147, his italics). For Fried we are already 'literalists', meaning here we are already in 'duration' in our daily lives, therefore, in his words, the 'presentness' of the distinct object is 'grace', and that which should be aspired towards in art (ibid). Fried gives no concession to Morris, and Morris any to Fried; one is authentic art, and correct reasoning, the other not. As in all dualistic arguments, 
they only speak of themselves, and no reconciliation or synthesis is considered let alone attained. In this they have missed a vital point: we are neither here nor there in terms of common temporal sense. Linear 'spatialised' time is experienced as a grey point outside of both 'being' and 'Becoming'. A 'moving image of eternity' as Timaeus describes a time 'measured by number' in Plato's dialogues (37c-39e). Neither 'eternity' proper, nor the true flow of becoming - a relatively lifeless point bled of the aesthetic-experiential richness of either - a 'shadow' wrote Bergson, a 'shadow' wrote Shakespeare, and a 'shadow' wrote Faulkner; as each philosopher and poet expressed something of the every-day of the human condition in 'time'. In the work of art and the considered built environments what one is potentially confronted with is an intensification of either poll, and the qualitative grasp of a certain 'truth' of Time. To draw it back into the simplest terms the thesis has employed, and in analogy if the pretence of a direct explanation cannot be stomached, in the refinement of the likes of certain Classic architectures, real Time, as change, in aesthetic apprehension is paused to the extent that common linear temporality (merely a perception of the first) is also overcome, if only for a time -all movement ceases, the 'image' begins to correspond with 'eternity'. While in the slum, in arguably a more holistic experience, the 'image' begins to altogether 'brake asunder' to borrow Nietzsche's words, as the individual apprehends in a more direct perception an immediate presentness of the current of real Timespace. It is Oiticica, though, that puts this in truly accessible terms and bridges the divide, when he writes of the 'fundamental character' of art in a journal entry dated 12th of November, 1965:

"The ancient position with respect to the work of art is no longer applicable - even works that do not require the participation of the spectator, what is proposed is not a transcendental contemplation but a state of 'being' in the world. Similarly, dance 
does not propose an 'escape' from this immanent world, but revels it in all its plenitude - what for Nietzsche would be the state of 'Dionysian inebriation' is in fact the 'expressive lucidity of the immanence of the act', an act that is not characterised by any form of partiality but by its totality as such [...] (Figueiredo, Pape, \& Salomão, 1986, p.74) ${ }^{9}$

What Oiticica suggests is intriguing in its simplicity, providing a complimentary layer of perspective. Whether the object par excellence of Classic architecture, eliciting an acute 'glorification' of the mode of reality of the 'principium of individuation', or conversely the experiential reality attained at the 'shattering' of that mode of perceiving, and an immersion into a more 'primordial unity', the work of art or built conditions considered invigorates these experiential realities, these modes of '[B]eing', in their 'totality as such', not their 'partiality'. Each is made more acute, 'lucid' and 'immanent' as has been the common condition throughout. It is the 'spatialisation' of time proper - as Time's fragmentation into many moments, or presents, across the linear space of a past and envisioned future - which prevents at a very basic level either state being apprehended in their totality, being imminently experienced. The collapse of this 'space' at a fundamental level, and the resultant spacelessness of the present, reveals each in all their 'plenitude': what is the present but the point at which we are conscious; and what is an acutely sustained present but an acutely sustained consciousness - an attentive,

9 Translated from the original Brazilian Portuguese: "A antiga posição frente à obra de arte já não procede mais - mesmo nas obras que hoje não exijam a participação do espectador, o que propõem não é uma contemplação transcendente mas um 'estar' no mundo. A dança também não propõe uma 'fuga' desse mundo imanente, mas o revela em toda sua plenitude - o que seria para Nietzsche a 'embriaguez dionisíaca' é na verdade uma lucidez expressiva da imanência do ato', ato esse que não se caracteriza por parcialidade alguma e sim por sua totalidade como tal [...]” (Figueiredo, Pape, \& Salomão, 1986, p.74). 
un-fragmented, uninterrupted, total and ongoing awareness of one's mode of perceiving, of one's immediate current reality - whether as an acutely individuated - and 'everlasting' - subject among objects or part of a greater fluctuating 'whole'. To be imminently conscious/present to either 'state of being in the world', is, as in the tragedies, inseparably connected to the 'now', the 'is-ing' or 'be-ing' of awareness, as is the vital act within both, consciousness is drawn back from the fictive temporal 'space' of linear time -one that engenders the distance of the true 'contemplative' and removed spectator -, and is grounded in an immanent, acutely present, state of awareness. An immanence to the world as appearance, or as a whole; apprehended for its own sake, as opposed for any ends we make of it. 

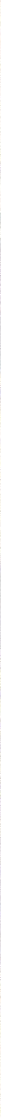
East facing view overlooking building rear and main entrance towards ocean.

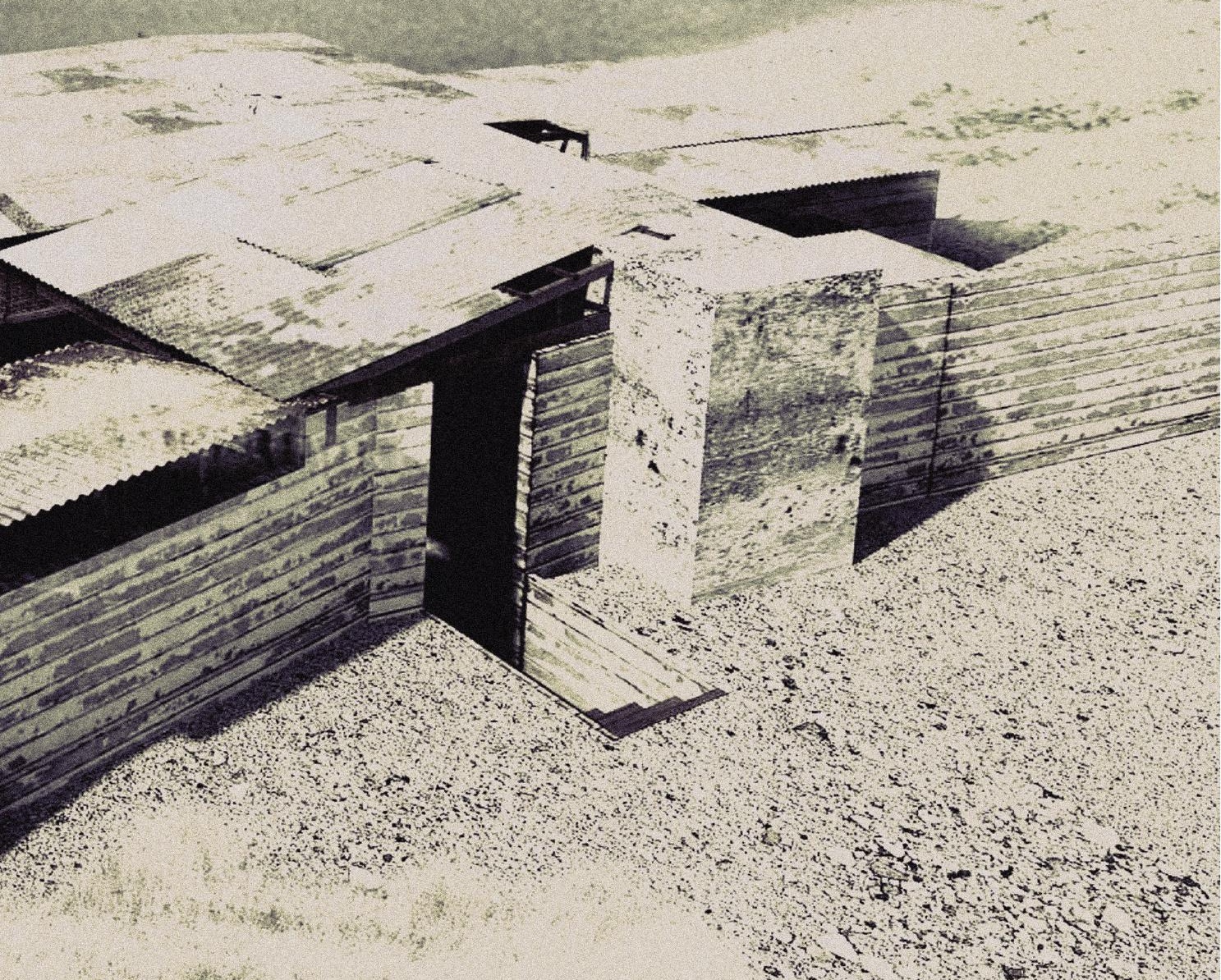


The tragedies in Nietzsche's view were an historically rear occurrence in humanity's history; the first and last artistic construct which reconciled the artistic drives of the Apollonian and the Dionysian, 'being' and 'Becoming', forming a union in which they reciprocally and mutually intensified one-another, compelling them to their most ideal states. Their manifest relation until this event had been dualistic, a reluctant countenance at best, in which one prevailed to the detriment of the other $(1872 / 1999$, p. 20). For Nietzsche this rear union elicited a more complete and balanced sensibility, in that it allowed one to both grasp the reality of the ever-changing nature of the world, while attaining solace in the semblance of Apolline dream, as the 'eternalistation' of individuated appearances. For this reason he positioned the tragedies as the highest form of art of occidental civilization (ibid, p. 104).

In understanding these aesthetic elements' temporal origins, we have also observed a curiouse native, intrinsic relation that exists between the two; one that conceptually allows us to grasp a further value of their co-existence within any given artistic medium. Both find a common axis in the immanence of the present, its continueity, and an inevitable disruption of the linear space of time. At this level, being and Becoming are not sharply opposed, but are complicit aesthetic experiences.

Both this native indivisible relation, and Nietzsche's own assertion of the existential value of the co-presence of each element in a kind of contrasting complicity, lends credence to the idea of an architecture embodying both being and Becoming. An architecture in which the formal properties of one aesthetic element would, in either indivisible or contrasting complicity, serve to heighten the aesthetic efficacy of the other; that is, co-dependently facilitate and intensifying each other's basic metaphysical quality of disrupting linear, spatialised time and disclosing a continuity of the present moment.

It goes without saying that such a union within architecture could 
never achieve the profound experience of the tragedies, compelling it to that 'highest of art forms'; arguably such a phenomena is the privilege of the medium of theatre with its complete immersive 'intensity'. And while we can speak of the lofty notion of disclosing ontological reality, it is more to aspire to a built environment, a stage, as the background to the every-day poetics and prosaics of inhabitation, which within architecture's limited capacity imparts a subtle yet omnipresent aesthetic value. One that just occasionally, in perhaps a moment of absent mindedness, affords an aesthetic reprieve from our common sense and relation to 'time' as a restless, aggressive linear trajectory ever 'tearing' us from the now; reprieve from, as Faulkner writes poeticaly "Constant speculation regarding the position of mechanical hands on an arbitrary dial which is a symptom of mind-function. Excrement Father said like sweating." (1929, p. 47). If it could make one just a little more aware of the 'ground', as a continuity of becoming and present, but yet also complicitly afforded 'escape' in Apolline dream of the ever-lasting of form, it would be a worth while aspiration; an aspiration to a space that in the most modest of ways would allow one to be and become.

Despite the ideal of their union, architecturally this is not a straightforward task. In the thesis we have reflected on the most overt properties of architecture that mediate each element, and in this we have seen their mutual exclusivity; the formal properties of Apollonian being are directly opposed to those of Dionsyion Becoming and vise-versa. While we can speak of a complicity in metaphysical affect, and that certain intensity that contrast always elicits; physically however - architectonically - it is a true opposition - not a contrasting opposition, but a detrimental one. Amalgamating the plane with its aesthetic quality of clarity, for example, with that of the labyrinth and its quality of unclarity, could only be achieved to the detriment of the purity of each other's aesthetic import. How then, if they compliment each other psychologically/metaphysically, yet deduct formally, can they reach a 
reciprocal union architecturally? This formal incompatibility presents an architectural problematic, or, as the contemporary fashion of rhetorical swagger will have it, a challenge.

This is not, however, to deal with anything new. What has hopeful become clear is that the text has been concerned with those aspects of architecture which are commonly left to intuition; aspects that are 'aesthetic' and related to the feeling of the work. It would be reasonable given the study to conclude that they are part of those elements that are grappled with in every design in order that it satisfies a certain requirement, beyond programmatic decisions - one which usually lacks immediate logical comprehension and articulation, but which seems second nature in moments of 'creativity' - to use a dated platitude. Here though the aesthetics of being and Becoming while foremost always intuitive in there application, can also be complimented by a reasoned understanding as to what is occurring when we usual say, 'it just seems to work aesthetically', or 'it feels right'. With that said, the following design does not necessarily attempt to appeal to perhaps more moderate aesthetic sense; which understandably uses these two elements with more subtlety. As in the text, the design is concerned with the extremes of these two aesthetic poles; where the representation of Apolline 'being' is implemented without reservation as in the Doric order, and 'Becoming' is as pronounced as in the Favelas. In this respect the intent is to attain a co-presence of each pole while attempting to retain their particular intensity as they inevitably counteract each other - an endeavour that often ends in moments of ambiguous compromise, but which provides grounds for reflection. It is these grounds which form the value - in an overtly intellectual sense - of the project. 
While foremost - inevitably - an intuitive project, and one that therefore lends itself more to intuitive appreciation, there are reasoned, intellectualized decisions that form its basis. While the more nuance intuitive aspects are better left to the ineffable and rich subtlety of communication afforded by visual representation, these conceptual underpinnings can be sufficiently addressed - as a means to compliment with the more logical and narrow medium of formal written language. The major reasoned decisions of the project take the form of basic, and initial, points of separation between elements of being and becoming within the building whole; separations that are then either inevitably or intentionally integrated and merged as the design progresses in Time - both separation and integration are of equal importance. The hard line of these decision are outlined below, while more subtle and specific details, and deviation from these - the crux of the work in many respects - are addressed in observations attached to specific images.

The first and most basic of these to be addressed is that of the separation of fixed, permanent and acutely Apolline forms from the inhabitation proper. The large in-situ concrete elements (observable from various angles in most figures) implement an initial and permanent appropriation of the site - which a more open-ended, continuous process of construction then orientates itself about. Their design follows a strict re-appropriation of the 'rules' of forms of Apollonian 'being' - inclusive of 'Being'. In the first instance, as they are not structural between themselves, they a granted an excess that Classic architecture could not afford: each concrete element is truly separated, as opposed to needing the extra measure of articulated mouldings to differentiate each element as they connect structurally to form the building whole. This basic 'Individuation' then attains an accentuated impression - 'revealed law' - of 'closed' temporal-spatial autonomy through each element's internal resolution. They are compositionally in a very basic equilibrium: symmetrically divisible forms grounded in the proportion- 
al relations of the ratio of phi. Collectively each 'closed' form then rests in an overaching relation as a whole through a basic compositional and proportional connection; again this is achieved through the more subtle - and irrational - ratio of phi across both vertical and horizontal axis, which is, importantly, worked out as a matter of balance between elements. While collectively forming a less regular arrangement than in Classic or Egyptian representation, -one that offsets the simplicity of the forms used and creates more visual interest - the vital impression in both of a collectively 'closed' formal edifice complete in itself is nonetheless attained; that is, a finished formal 'organism', in which no smallest element can be 'changed or deducted'.

Isolating these Apollonian elements as fixed sculptural forms - as the naturally demand to be - the remainder of the inhabitation proper is opened up to the potential of 'constructive movement' to borrow Jacques' words. In the scheme of things the conventional planning of the architect ends at this point, as the inhabitation is not prefigured in a set project, but evolves over Time. Design, building and inhabitation collate, as they are re-integrated into Time. The architect takes a back seat as design and development is gradual and ideally undertaken by the owner, beginning with, and progressing from, initial vital spaces in line with immediate limitations, needs and wants; building not from plans but immediately into existing structure - adjusting, appropriating or expanding. The architect, however, has a role, albeit relatively limited to the conventional (arrogant?) ownership, in the form of outlining flexible parameters, which inform nuance design details in order with the building's 'metaphysical' ends. The most basic of these are listed roughly as follows:

The underlying formal composition of the inhabitation proper breaks with the strictly regular geometry of the sculptural in-situ elements. These breaks are very subtle: while an overt departure from regular geometry to more embellished organic or dynamic 'expressive' 
forms might be expected, this would lead to a stronger fixtivity of form requiring more deterministic pre-planning; that is, form built to the ends of an impression, but which is less open to possibilities of adaption and re-appropriation in a practical sense - better for token statements appealing to removed intellectual discourse. Instead, employing more accessible conventions of building, subtle imperfection are introduced into collective arrangements and individual elements of form. Angles in the horizontal - and mainly depth - axis are slightly off a perfect 90 degrees, usually within 6 to 2 degrees difference, -an intentionally small amount, degrees of natural imperfection without instruments - while rough, less processed materials erode a more strict abstraction of the forms - there are intentional exception to this that are addressed later. These extremely nuance treatments are not a matter of poor compromise. The intent is not to abandon distinct 'objects' completely - but to draw them into Time. Subtly eroding the right angle, form - and the space it demarks - losses the acuteness of perfect geometric abstraction. The conceptual -conceived boundary - begins to collate with the material thing; that is, matter and real space begin to assert themselves over pronounced abstract relations; understandable also as a merging within a more connected spatial field through the lack of 'mutual difference' between elements imparted by the right angle (addressed, p. 90).

While the many fragments of the building integrate and merge structurally, - relations affirmed by visually more integrating lap joints connection to the Apolline elements is offset by negative detailing. As observable in the likes of figure 33 floors have a recessed gap where they structurally merge with the forms, while an offset timber trim accentuates a point of difference in ceiling connections (figures 39-41). This is a compromise that allows the Apolline elements to retain a degree of autonomy as permanent and 'timeless' forms as they become more integrated with the ever-adapting inhabitation.

The formal language of a 'fragmented unity' that naturally results 
from continual and open-ended construction is complimented by the treatment of materials, or more the lack of. Leatherburrows and Mostafavie place the affect of this in a simple equation; "Finishing ends construction, weathering constructs finishes." (1993, p. 5). Materials are left raw and open to weathering, while imperfections, marks and excess through re-appropriation and use, are equally unconcealed. Lacking the tedious effort of retaining appearances of a perpetually new and resolved state, imbedded in the building's language is its past havingcome-to-be-as-it-is, while the ever-shifting patina of weathered materials disclose a more subtle state of perpetual change at the ebb of Time's flow. The allowance - and accentuation, see below - of weathering and wear in the Apolline elements present a simple amalgamation of qualities of being and becoming. While form proper as a composition of abstract geometric relations of the line is retained, the surface is left to erosion and wear. The 'being' of the abstract form - the 'object' -, is drawn into the Becoming of corporeal, physical matter.

Important in the building's language is the juxtapositions between materials in terms of their different metabolisms of change/erosion - their relative properties of permanence more generally. Within the inhabitation proper, a certain formal and material lightness is aspired towards through the use of more delicate and age prone materials and structural elements. The relative ephemerality here gains clarity through juxtaposition with the exaggerated physical mass and stability of the concrete elements - and visa versa, these elements achieve a more expressed permanence around which the inhabitation evolves. While the inhabitation may look markedly different over Time, adapted or expanded, the forms will be as they are, with the age of a Greek ruin; demarking, strangely, not only timeless immutability - an 'eternal' present -, but an intense sense of the past reality of the many lives that take place here - a past brought into the present.

Touched on are more overt and basic properties. Comments and reflections associated with images deal with - equally important - particulars of the building, as opposed to blanket statements. 
A note on representation: a project that evolves over Time should capture stages of that progression - a view expressed by a number of critiques. To an extent this is valid, but only if the intent were to document a pre-determined vision of a sequence of finished states 'realized before the project'; a documentation with the ends of selling the idea and/or cataloguing the details of how it would be built. A difficult presupposition to depart from given this is what the architects roll amounts to. This would however be but a 'spatialised' representation of the building's life in Time; a linear sequence which prefigures and abstractly divides its phases (there would hardly be a better metaphor for the term 'spatialised time'). The images do not spatialise the Time of the building, but capture a temporalized space. The building is presented at a particular stage in its evolution, with the building itself presenting its temporal quality as it would in actuality - (their are exceptions to this as the computer model (in Revit) was rendered incremental before completion, though a point is not made of the slight stages that are inevitably present). While the 'time' of being is captured in the Apolline forms, a particular aspiration in the treatment of images was to develop a sense of mood or atmosphere; that is to impart an 'intensive spacetime'. While in visual terms an atmospheric presence results naturally from the very temporal-spatial properties inherent in the building - tension between form, old and new, imperfection - geometric, material and functional -, age and wear - measures have been taken to accentuate temporal-spatial presence through surface treatments of images. The images themselves are intended to have a sense of Time - reality - about them, a thickened space-time; as apposed to the perhaps more conventional abstract plan and clean render which appeal to the aesthetic of the new. 


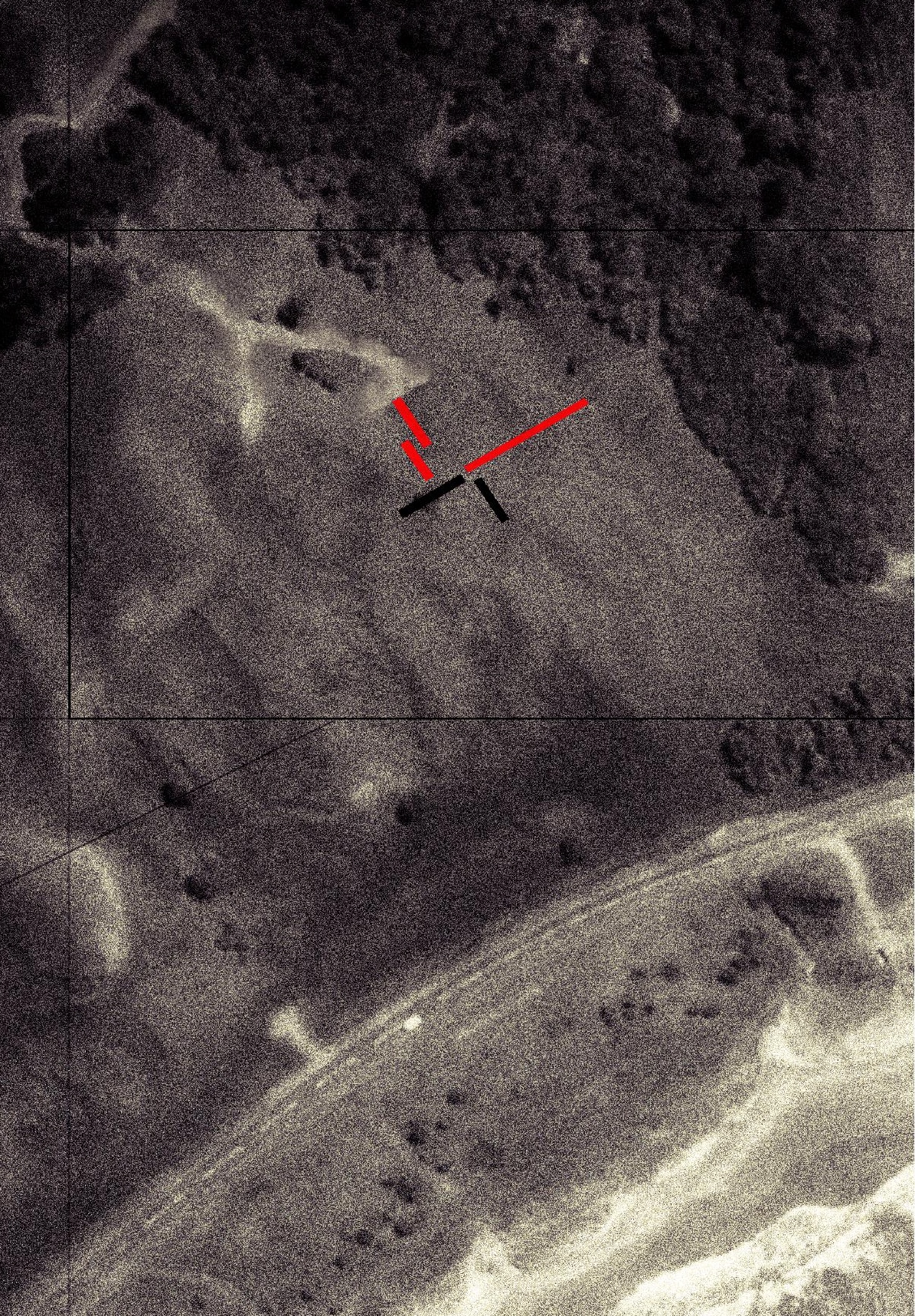


The building site is located on a rugged and steep easterly facing costal section; Makarori beach, Gisborne, New Zealand. 


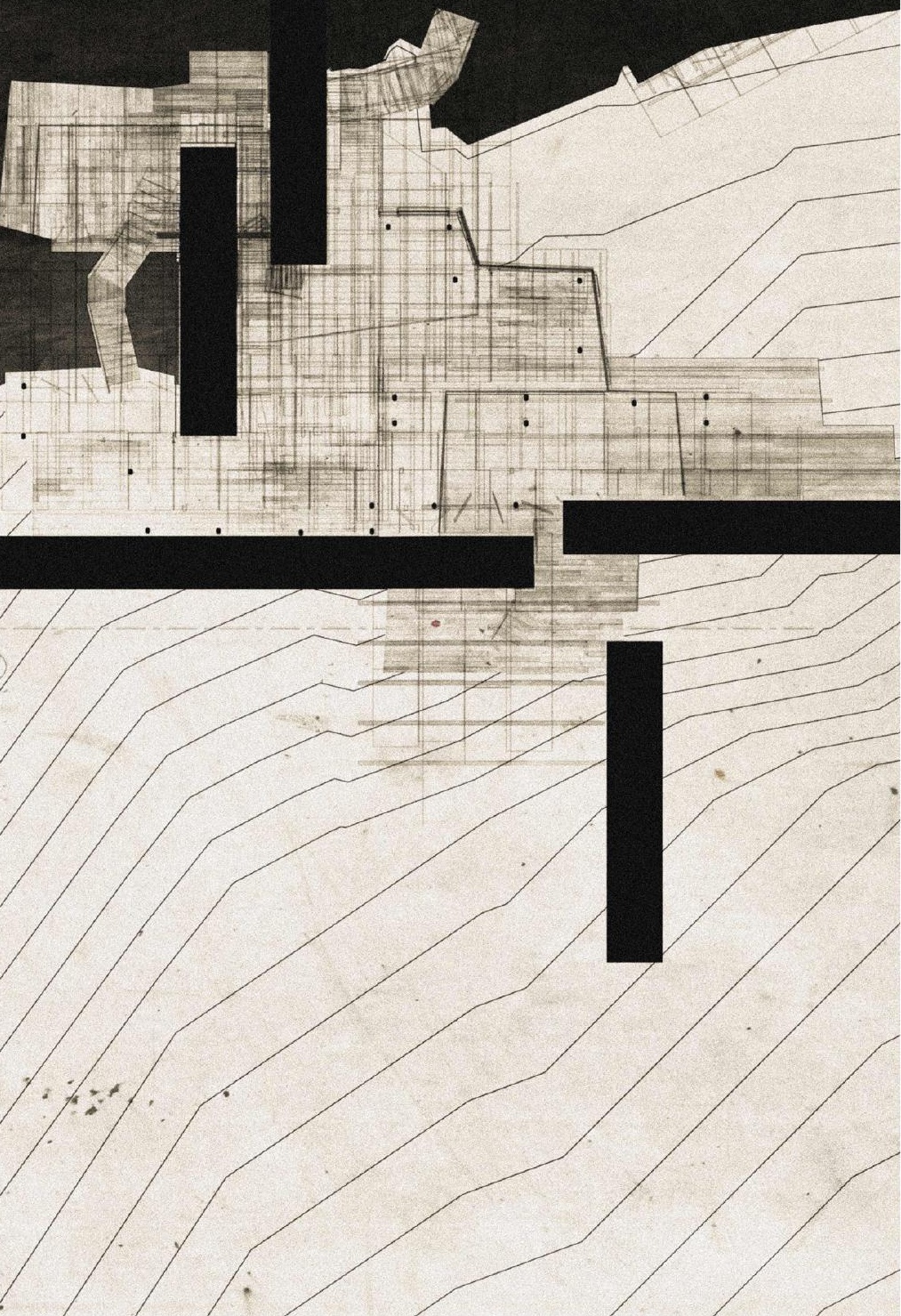


The building is approached over a rugged, steep rural farm track; little is exposed, but a bleak, sunken single level monolithic rear, with few indications of its presence encroaching over the hill slope (fig 29 \& 30). A dilapidated and unpretentious main entrance steps down awkwardly into an immersively disassociated, ambiguous, and idiosyncratic space (fig 32 - opposite). Imbedded in the language of this space is a history, a development. One is confronted with another entrance, or entrances - creating something strangely interior and exterior. The lower room presents an early structure, the original front; leading into an initial space of necessity, comprised of the main living area (fig 36). The cantilevered space above this is a latter adaption, providing an alternative entrance, among other nondescript uses (internal view fig 43), with a wing of even later bedrooms also connected to this mid-entrance expanding horizontally along the hill ridge.

It is uneconomical, inefficient and imperfect: the excess of a redundant roof of the lower room; the room above, no longer finds a defined function; the entrance space leaves one exposed as they move between - it may form an enclosed room, though this has not yet been 'resolved', and may not be, as it, and the other elements, have achieved something else. It has an aesthetic import - Time and its imperfection - that the perfectly planned and realized building struggles to accommodate. Things are as they are, as they adjust to a past, not an ideal geometric or programmatic arrangement which demands a blank slate: function follows form, and form follows from past conditions; it finds its 'sense and beauty' through the relative chaos of a 'vital' temporal order.

It is a space of depth and unclarity, as the Apolline plane is drawn into, and accentuates, the height and depth dimensions, while it is resistant to an immediate formal - and functional - comprehensibility. It lacks a plan. As in the Favelas, it is also a space of physical movement. It works with the irregularities of the site, and irregularity formed by the construction itself - equally grounded in the principle of developing from previous conditions. Steps and paths terrace awkwardly across the uneven surface. 

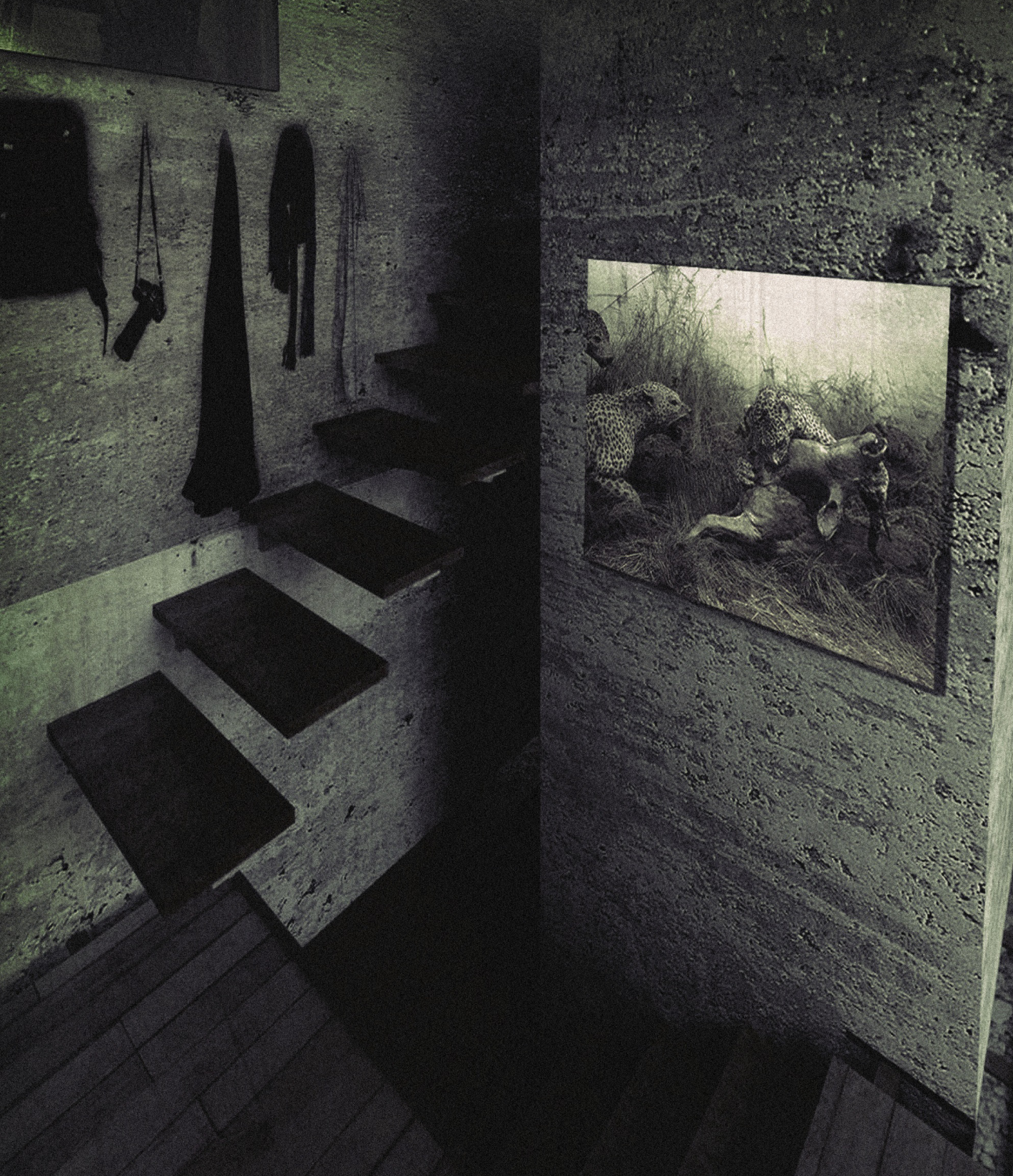
Haphazard, physical 'verb type' space is carried through to the interior proper; here taking on a distinctly labyrinthine quality. The rear of the building imbeds into the hill slope; darker less open spaces and passages contort about the Apolline elements.

There is here a compromise, which informs a significant decision. The Apolline elements dictate geometric regularity within the inhabitation proper, and something is lost in this; not only a stronger departure from regular form, but a deeper dis-clarity through the lack of logic vital to the labyrinth's aesthetic import. Due to this, the majority of the Apolline elements are separated proper from the inhabitation, becoming almost removed land scape fixtures, visual aspects, as in the Greek structure this is their nature in the first instance. Only two of these forms are placed where the building is intended to evolve, and these are therefore placed in recession; orientated in the depth and height dimensions relative to the site's natural frontal direction. While geometricaly regular, the passages are distinctly of depth and density.

While Clarity is lost in these elements, not only in terms of departing from height and width dimensions, but inevitably through their immersion within the inhabitation, Autonomy, as addressed, is to a degree retained: as observable, an accentuated recessed gap is placed between floor and concrete forms, a layer of glass lies across exposed joists, while sand - a formless composition - partially fills the spans between. 
Stairs are seperate and cantilevered, as opposed to more monolithic structures that would merge the Apolline elements. A subtle touch, the 'verb' character of space is emphasised through removable -less fixed -crates that complete the passage.

Through imbedding the in-situ concrete forms into the earth of the site, they inevitably loose clarity and autonomy. The ability to grasp there 'closedness', the proportional limits of their form, is weakened, i.e how deep they go. While their general proportionate relations internally and collectively give an intuit sense of their un-visble dimensions, one measure to affirm a sense of their 'closedness' was to cantilever one element (opposite) as a means to expose the extent of its vertical dimensions. Through its proportionate relations with the others, an impression is given of each forms limits. In actuality, of course, the depth of each form would be excessive in a practical sense, and they would be of a depth only necessary to insure their stability - this action then provides an impression to the contrary. (While this is one step of practicality, their is no illusions to the relative economic incongruity in such large structures; though the project is concerned here with matters separate to such consideration.) 


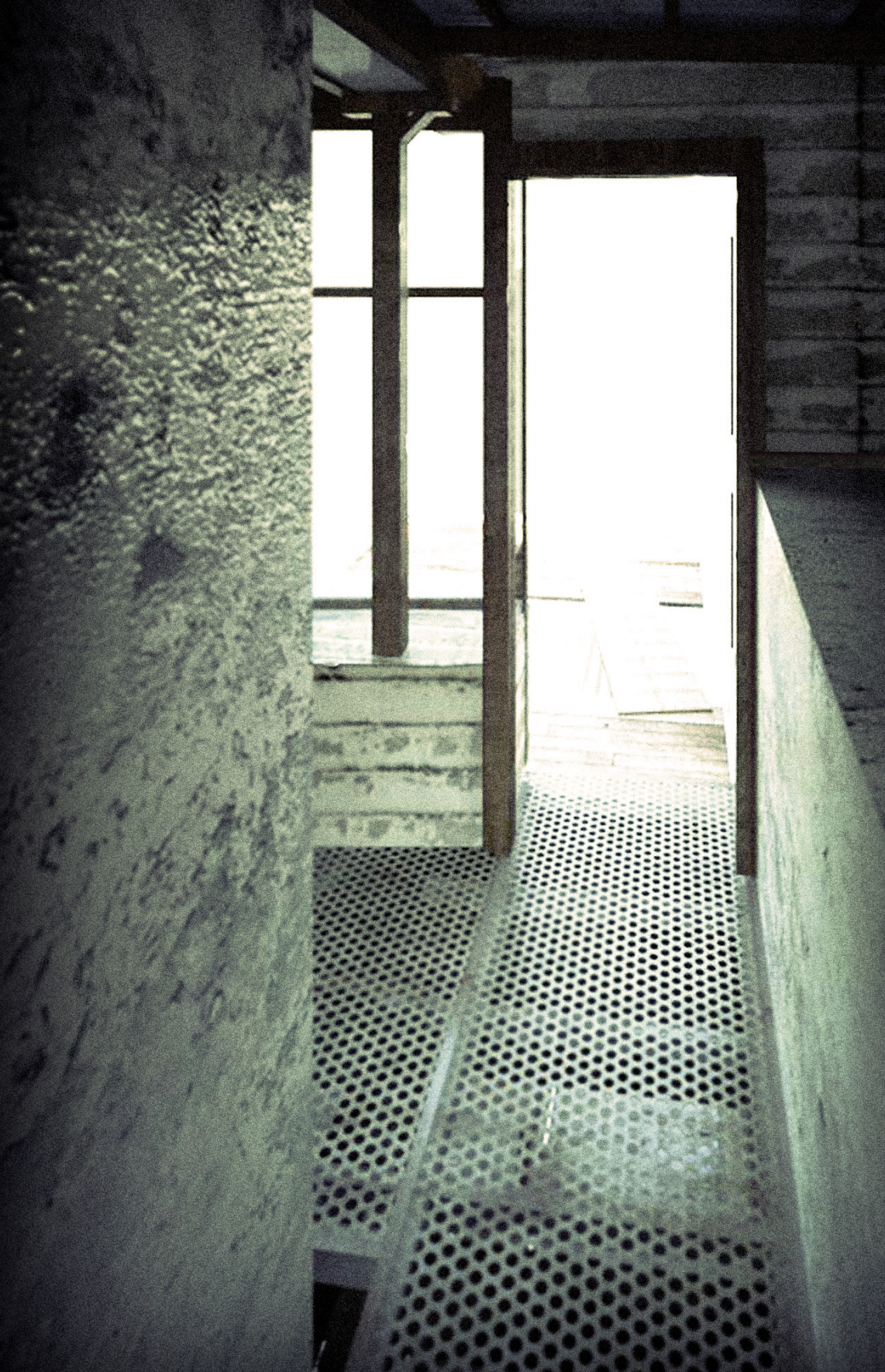


Perferated steel was used in an upper level passage between the Apolline elements as means to retain a degree of sepratness. Due to the width of the passage a negative detail was restricting.

Exterior weather boards recycled from a previous structure of the building, or else where, are reappropriated for an interior space. Past events are more merged.

A door leads to the corrugated roof of the main living area; an adhoc use of space, timber planks and a makeshift platform provide a casual area overlooking the sea. The formal and functional organisation is not completely resolved, - 'closed'/ finished - the inhabitants are then in a continual process of appropriating it - of changing it, and their use of it. 

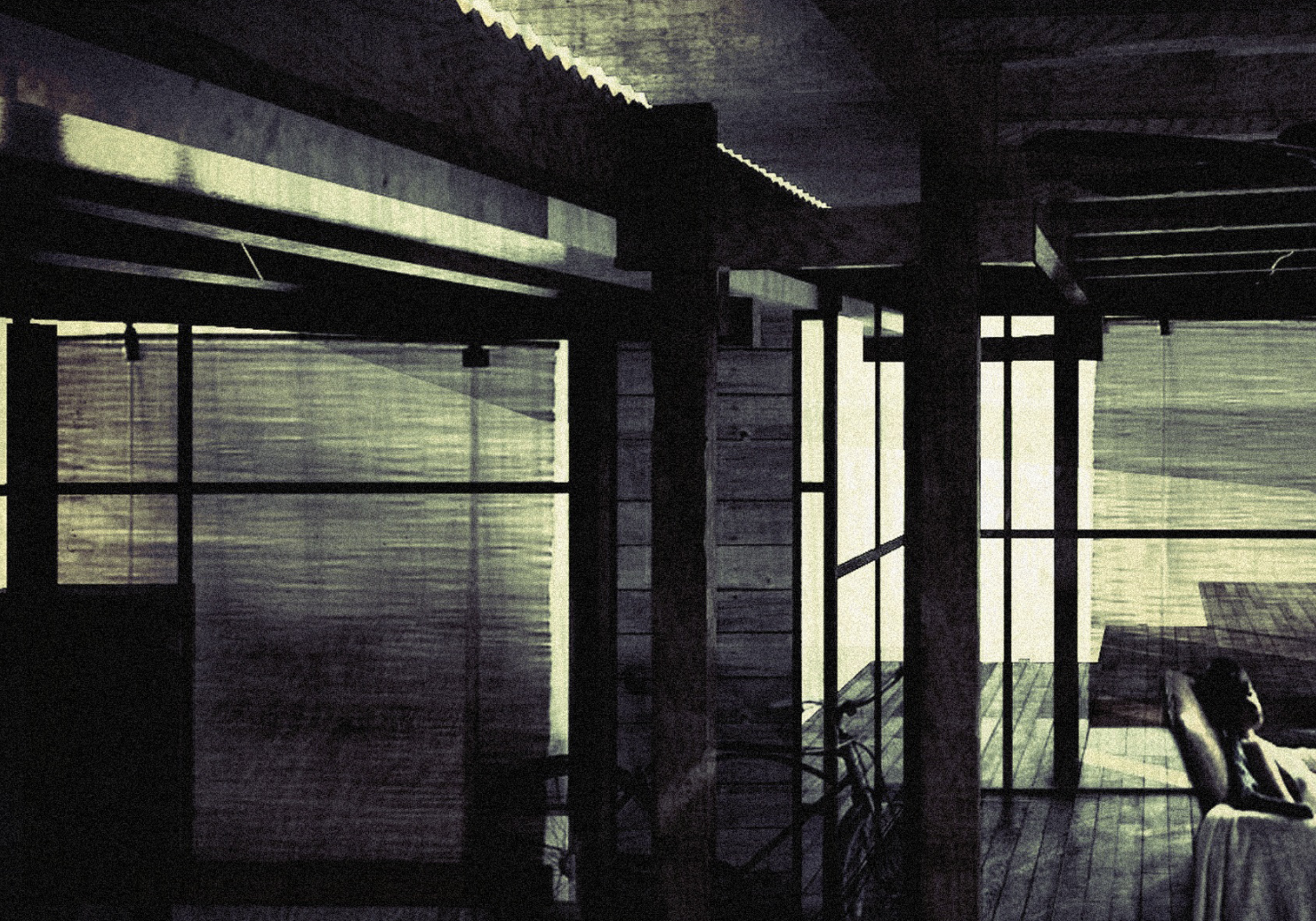
is
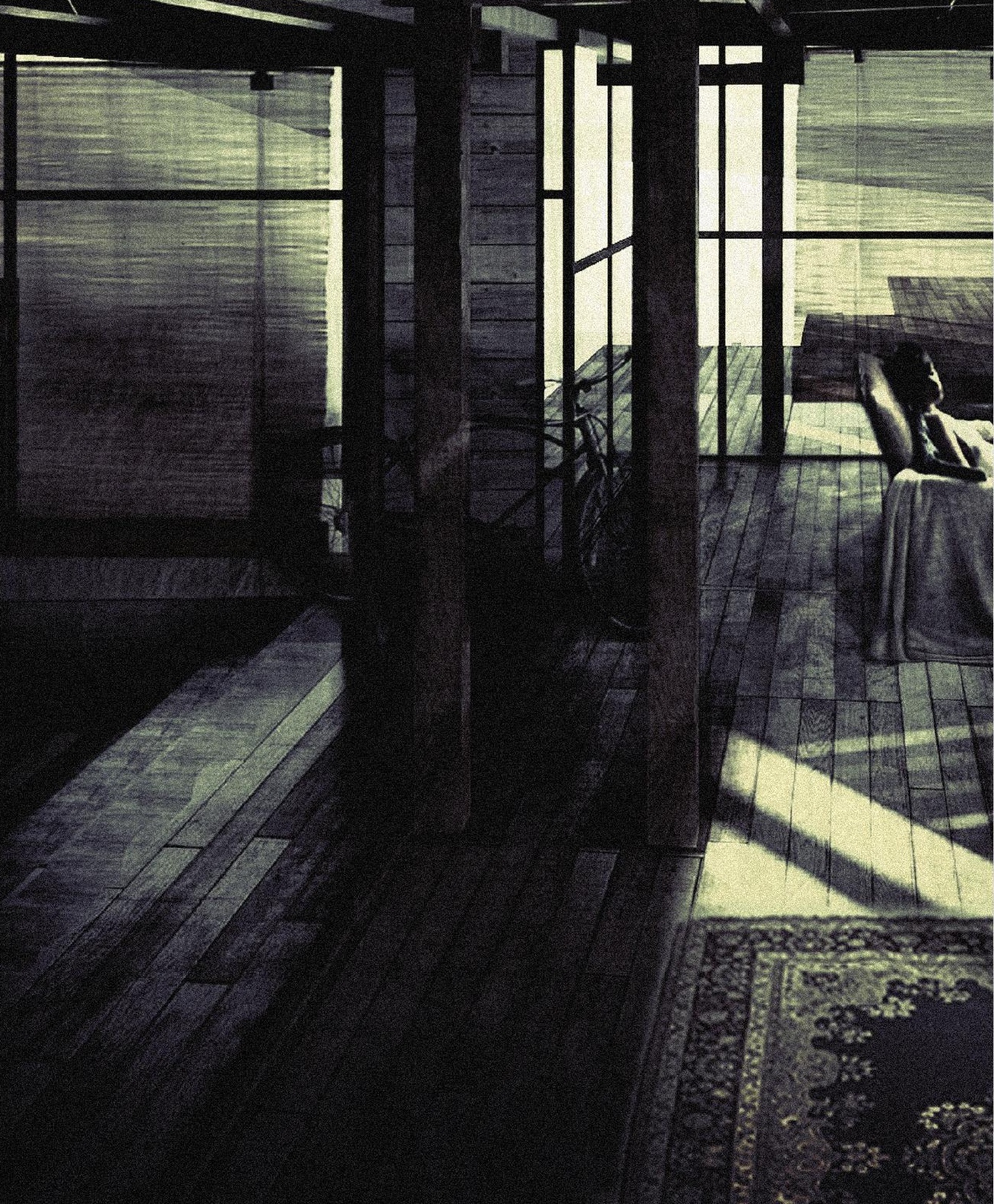
(Figure 36)
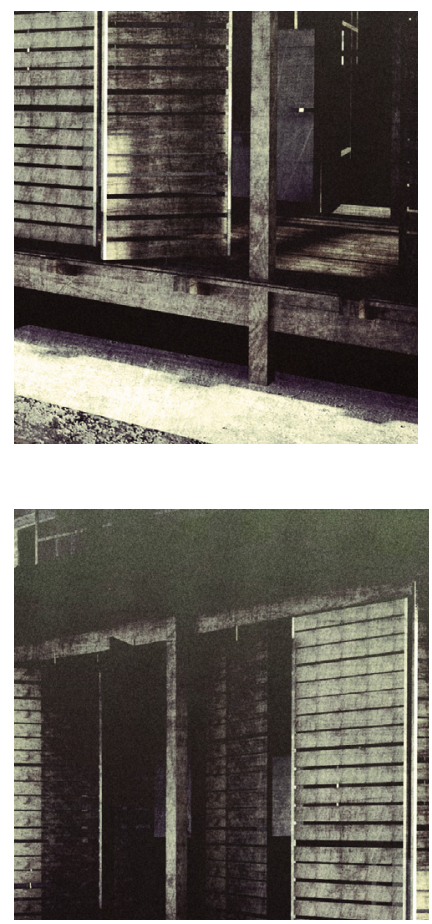

From the depth and sense of immersive unclarity achieved at the rear of the building, the interior unfolds into an open, less dense frontal space. The building affirms and reciprocates the horizontal Apolline elements as it aligns with them, taking on more structural regularity. 


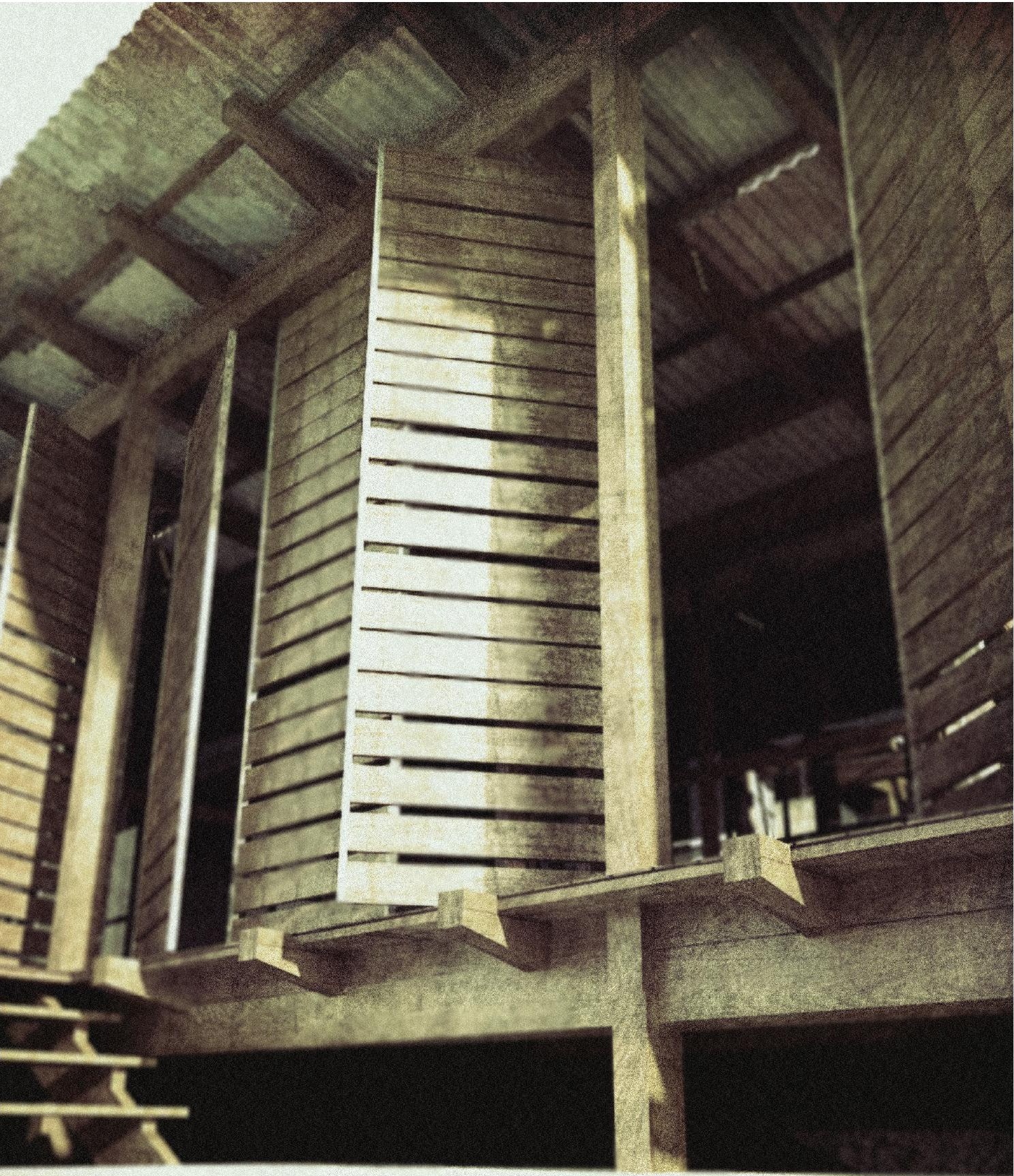

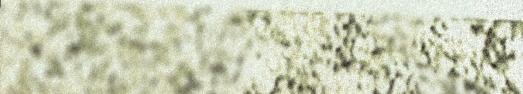

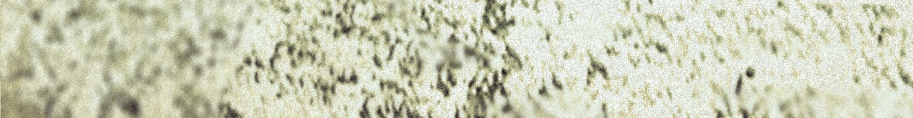

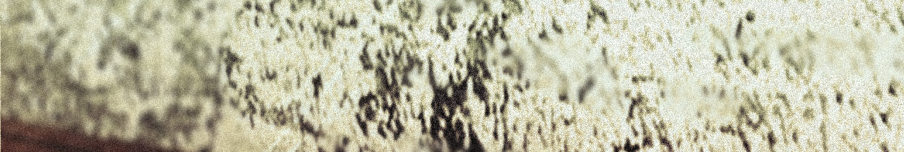

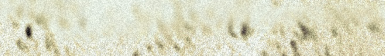


The frontality of this main space is not only intended as a juxtaposition with the more labrinthine-Favela quality of the rear of the building, but it performs the necessary function of pulling the two horizontal Apolline elements into distinctly 'picturesque' height and width dimension - and visa versa. Geomety becomes distinctly regular at the immediate front, while maintaining seperation, as it enroches onto the concete forms lightly with post foundations.

The pivoting, movable screens introduce an ephemeral element into the building composition, to offset the density and mass of the concrete structures.. Boxed within a steel frames the delicate wooden slots are left to weather and degrade. (Their is a second skin of removable glass and timber panels which inclose the living area proper, set back from this exterior, sheltered space).

Aged and incongruently coloured re-used corrugated iron breaks the general visual regularity of the space, retaining an open 'fragmented' aesthetic. An important element in that it offsets an adherence to uniformity, which inevitably closes off future possibilities of the building; limiting them within the confines of a set palette of design. Despite moments of regularity, differences and peculiarities become an integral part of the building's (vitally linked) aesthetic order - its 'fragmented unity'. 


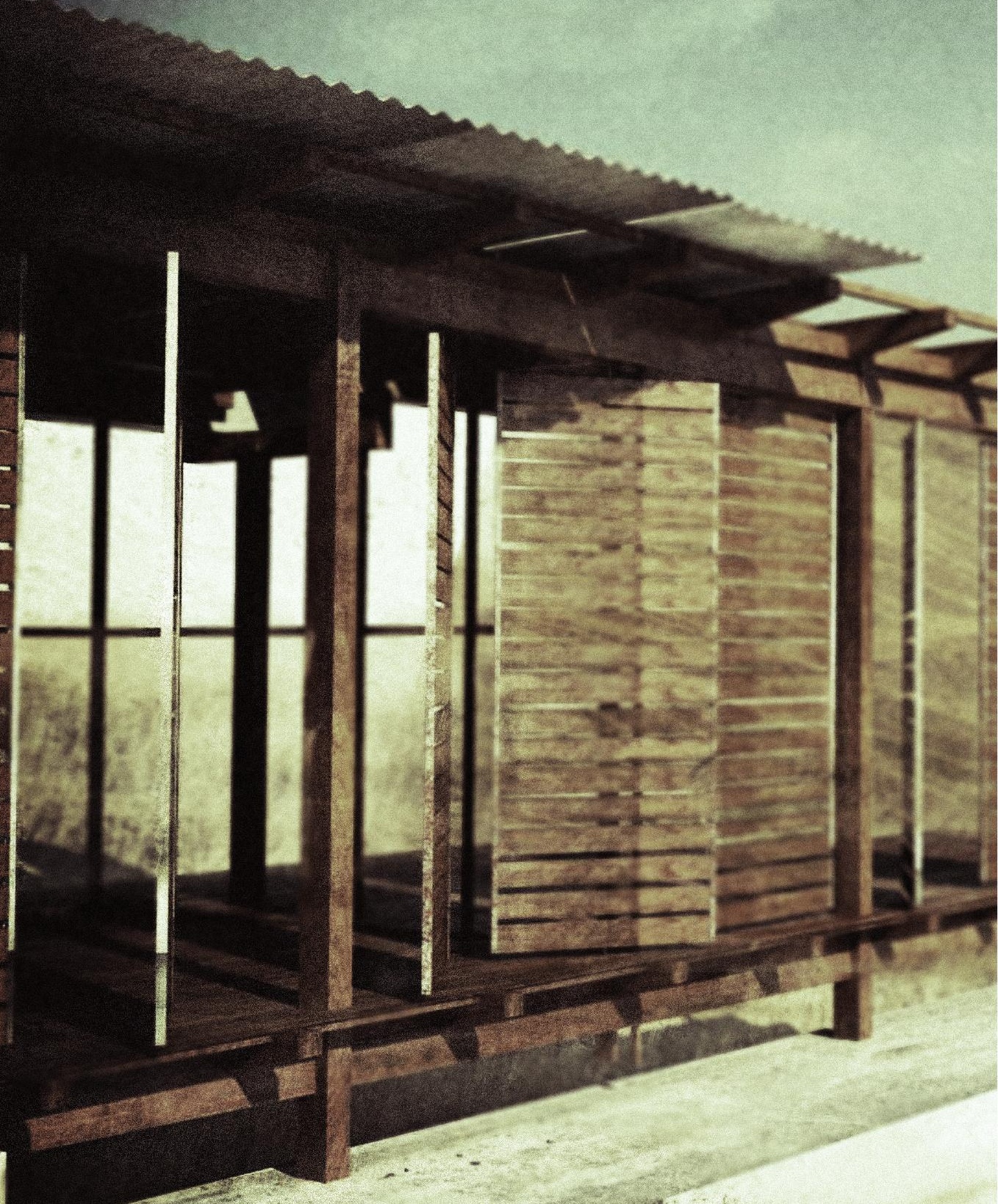


The frontal plane is placed in 'tension' with one of the few symbolic gestures of the building, an impression of growth, in depth, along its length.

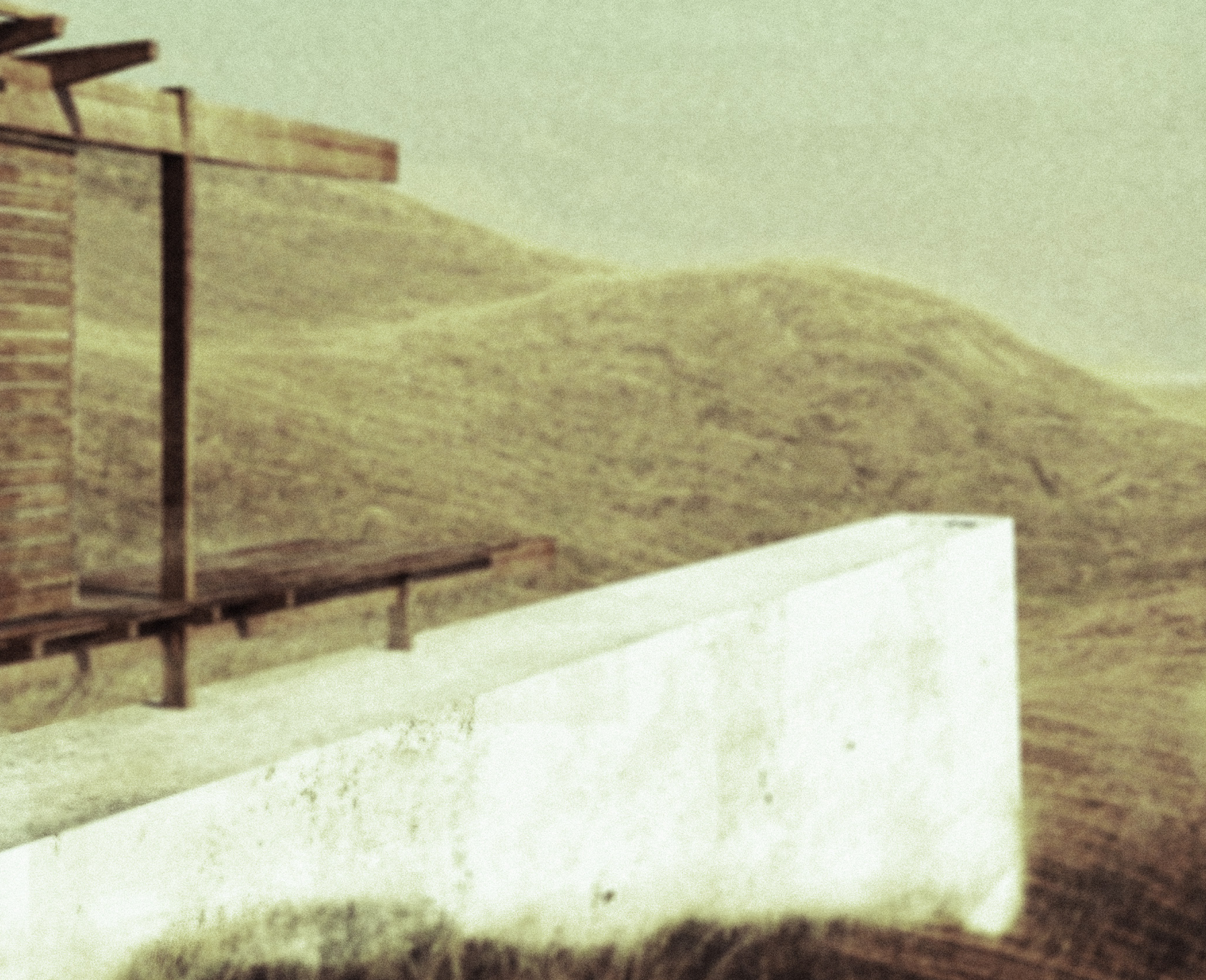




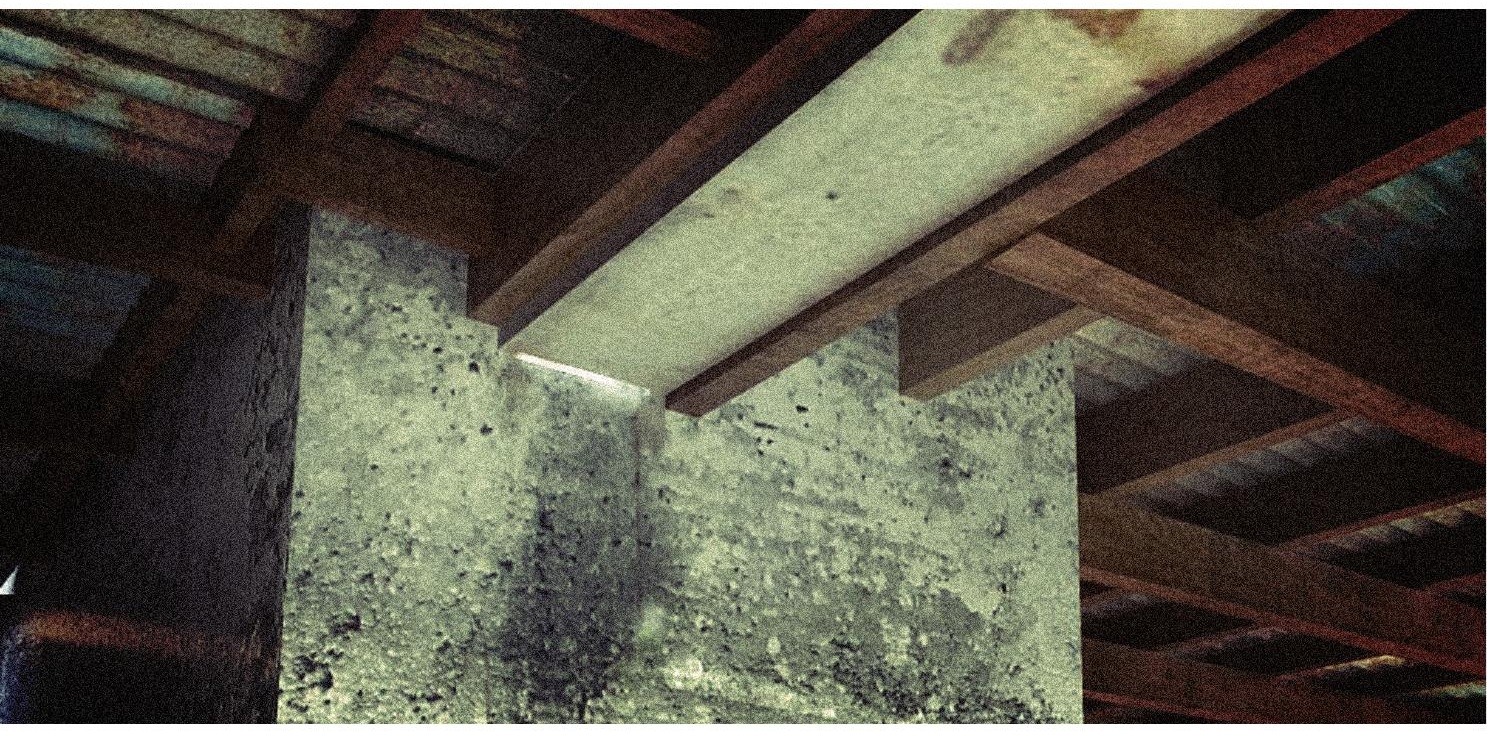

(Figure 40)
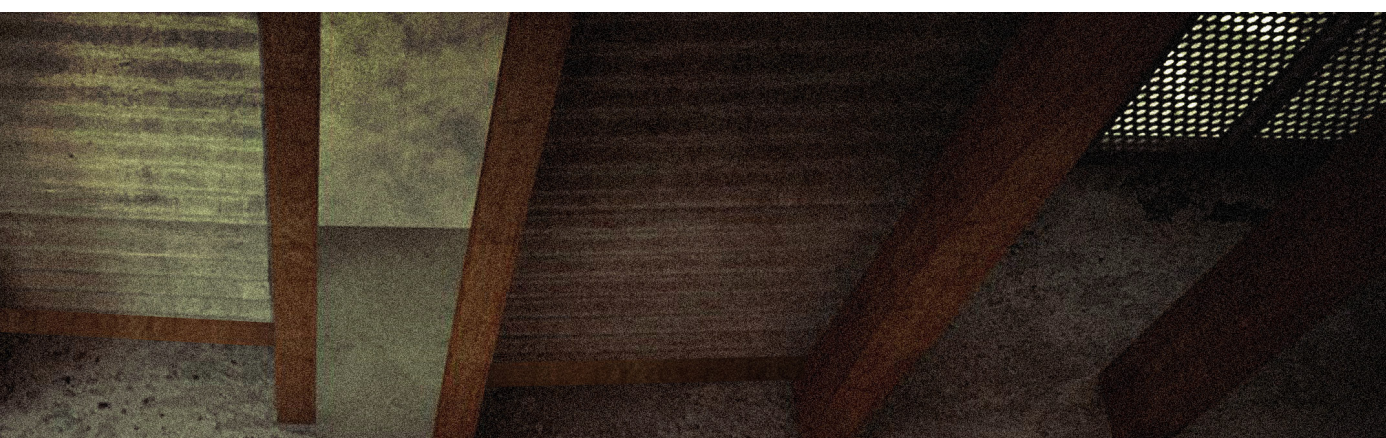
"The mouth kisses, the mouth spits; no one mistakes the saliva of the first for the second" (1993, p. 108).

Leatherburrows and Mostafavie use this phrase as a metaphor to capture the ambiguous relation we have with erosion, degradation, age and dirt. If such qualities are not intended, desired or welcomed, they easily take on a 'negative' value, as they deduct from an ideal state - consider for example a polished, immaculately white surface; any mark is likely to be seen as a 'subtraction' to its strong ideality as opposed to an 'addition' of depth or 'character' - traces of Time. The Apolline elements have an initial ideal state written in their constitution; perfection, timelessness, an absolute autonomy from the becoming of the material world-picture. Their subjection to a degree of ruination, and the building's generally, easily take on a negative value - that subtle shift from the grace of age, of weathering in Time, to filth and decay, as a subtraction or decline from the ideal state: 'eternalised' individuation. Through placing weathering and ruination within a frame work of intention - placing it on display - we have a chance to court and influence the balance of this sensibility.

The overflow from internal gutters becomes an essential detail by which the process of weathering - and the passage of Time it sediments and documents - is placed in a frame of appreciation; as something of intended value, with its own internal ends. 


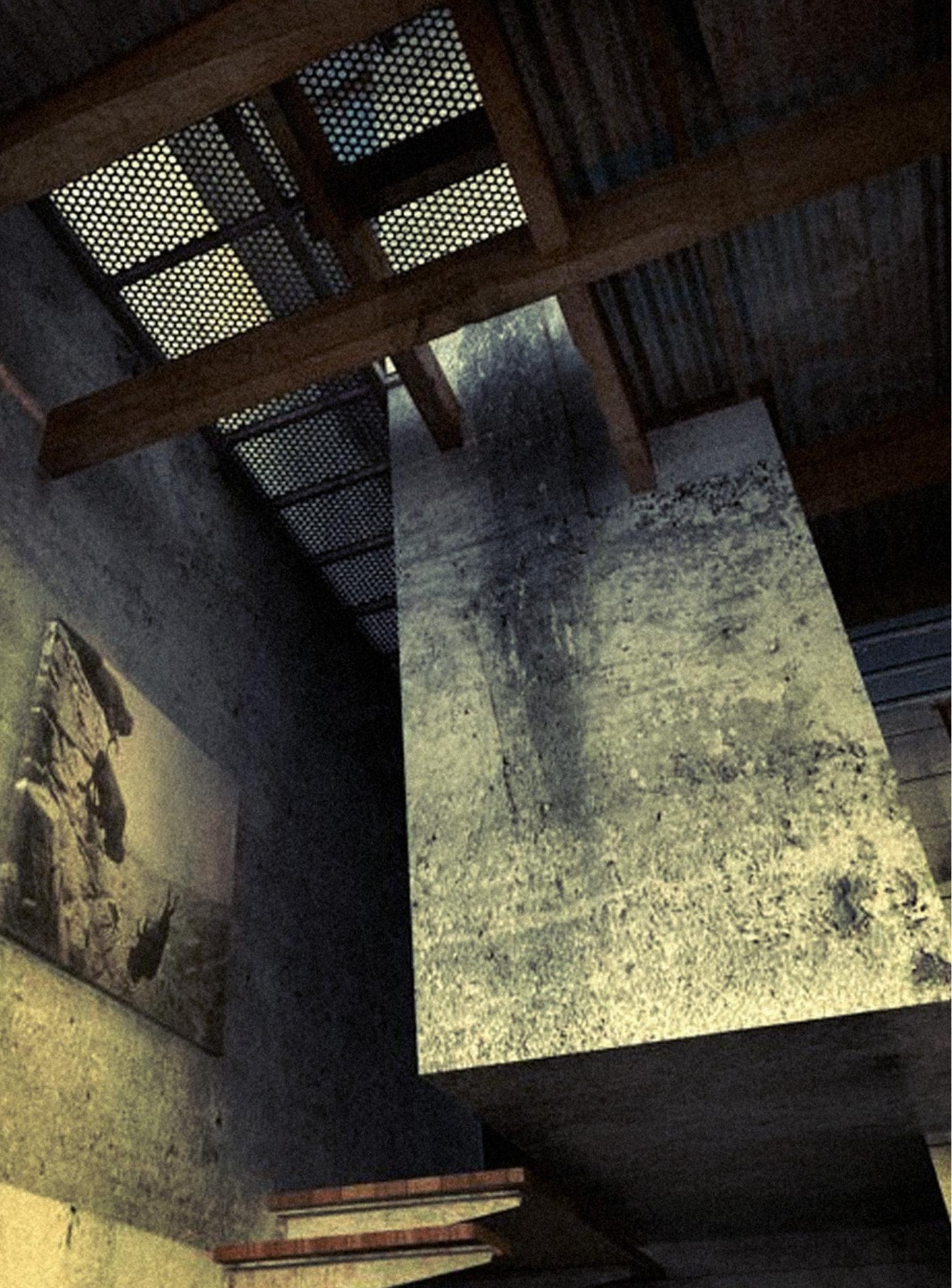


(Figure 42) 
The following two images attempt to capture a more unified, un-spatialised Time. Representationaly they consolidate phases of the building - or as Bergson writes of real Time it "prolongs a plurality of moments into each other, contracting them into a single intuition." (1911/1896, p. 292). A conceptual sketch outlining the intended future space, is overlain with a photo (a render); one which appears to capture an event long past. The future and past amalgamate into a more singular, connected present as they are brought together visually. It is this very layering, or sedimenting of 'times', which is, as has been viewed, at the core of such a building's capacity to draw or contract scattered events into a more intimate relation within present tense experience. 
1

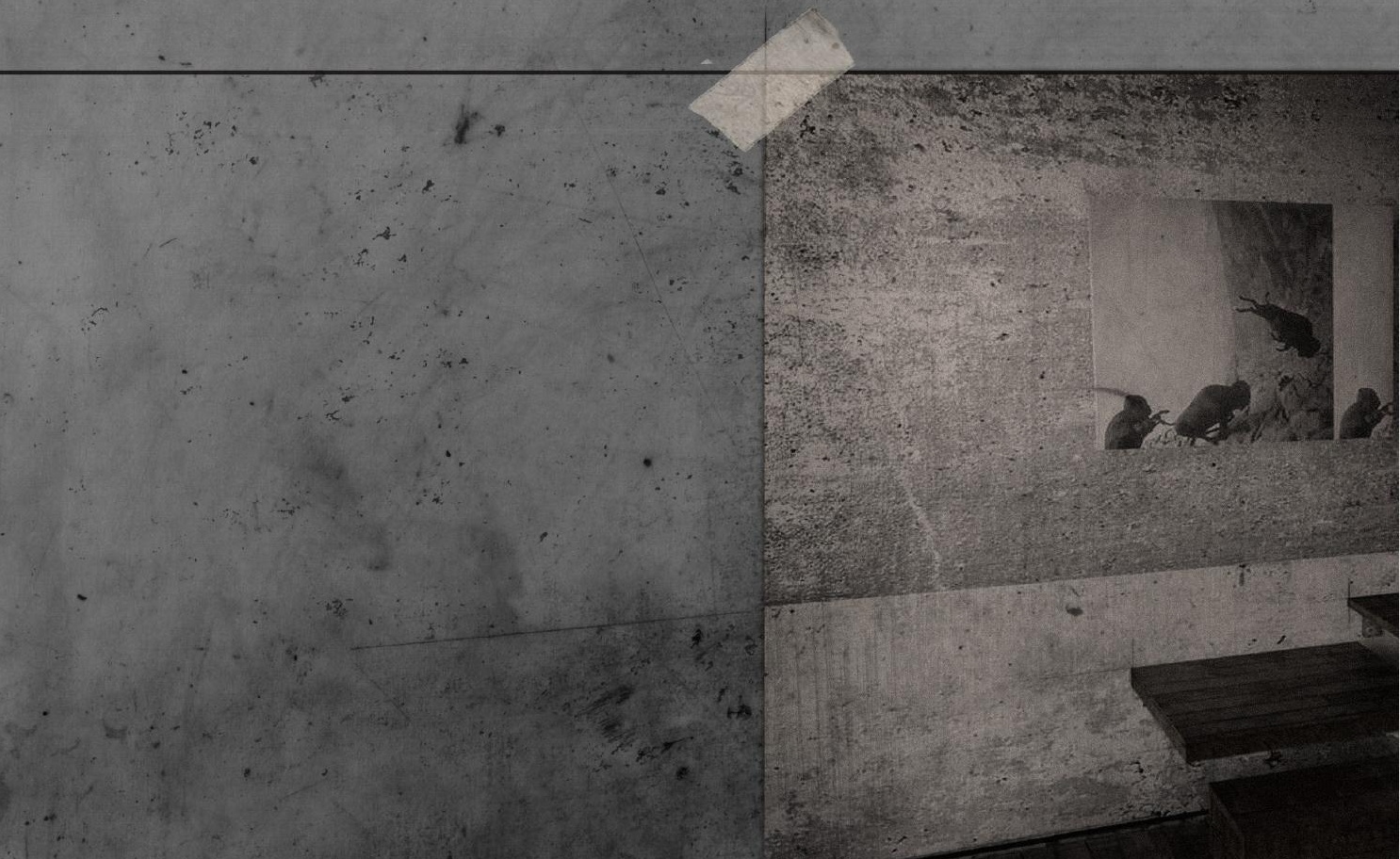


(Figure 44)

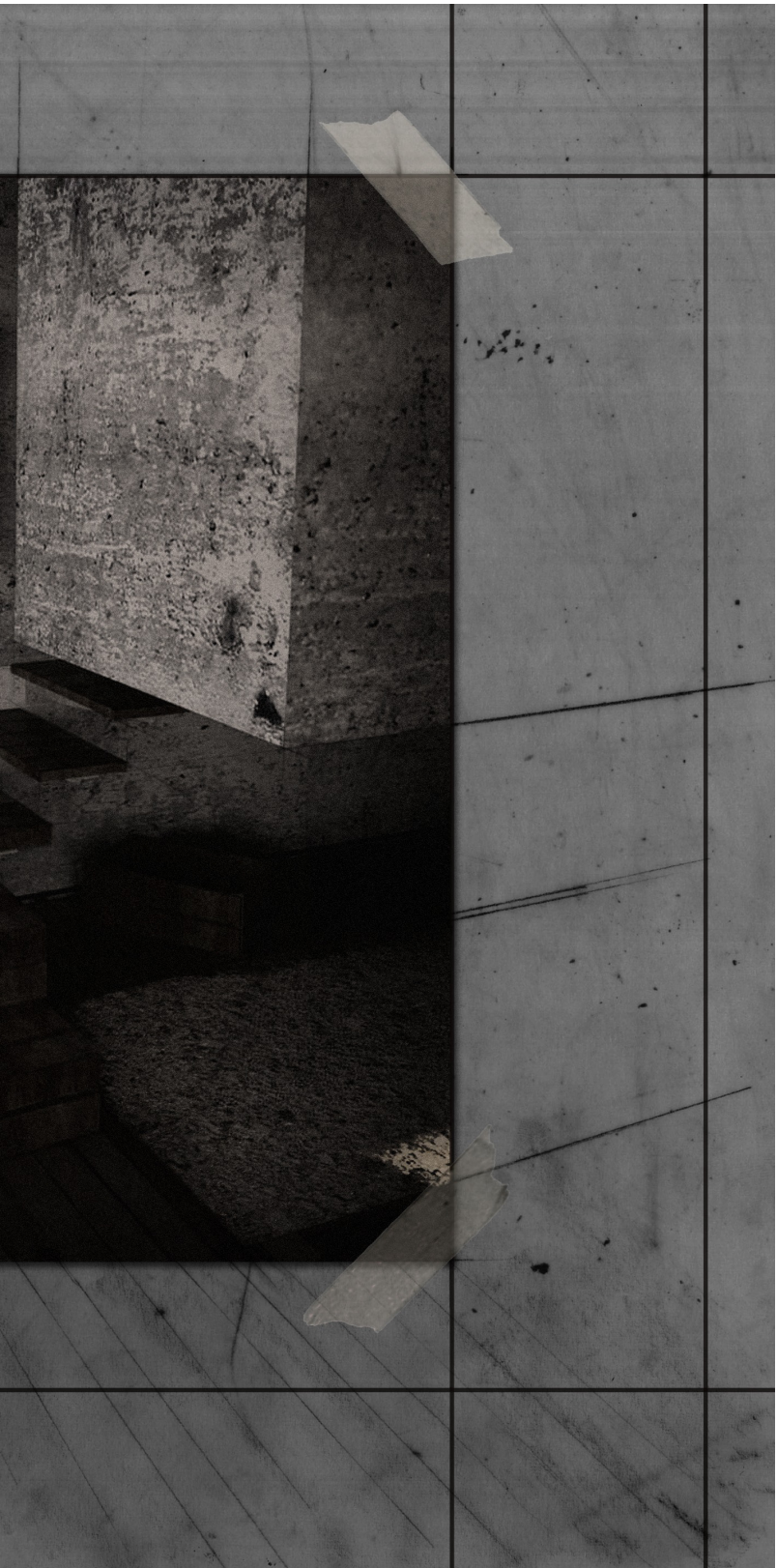




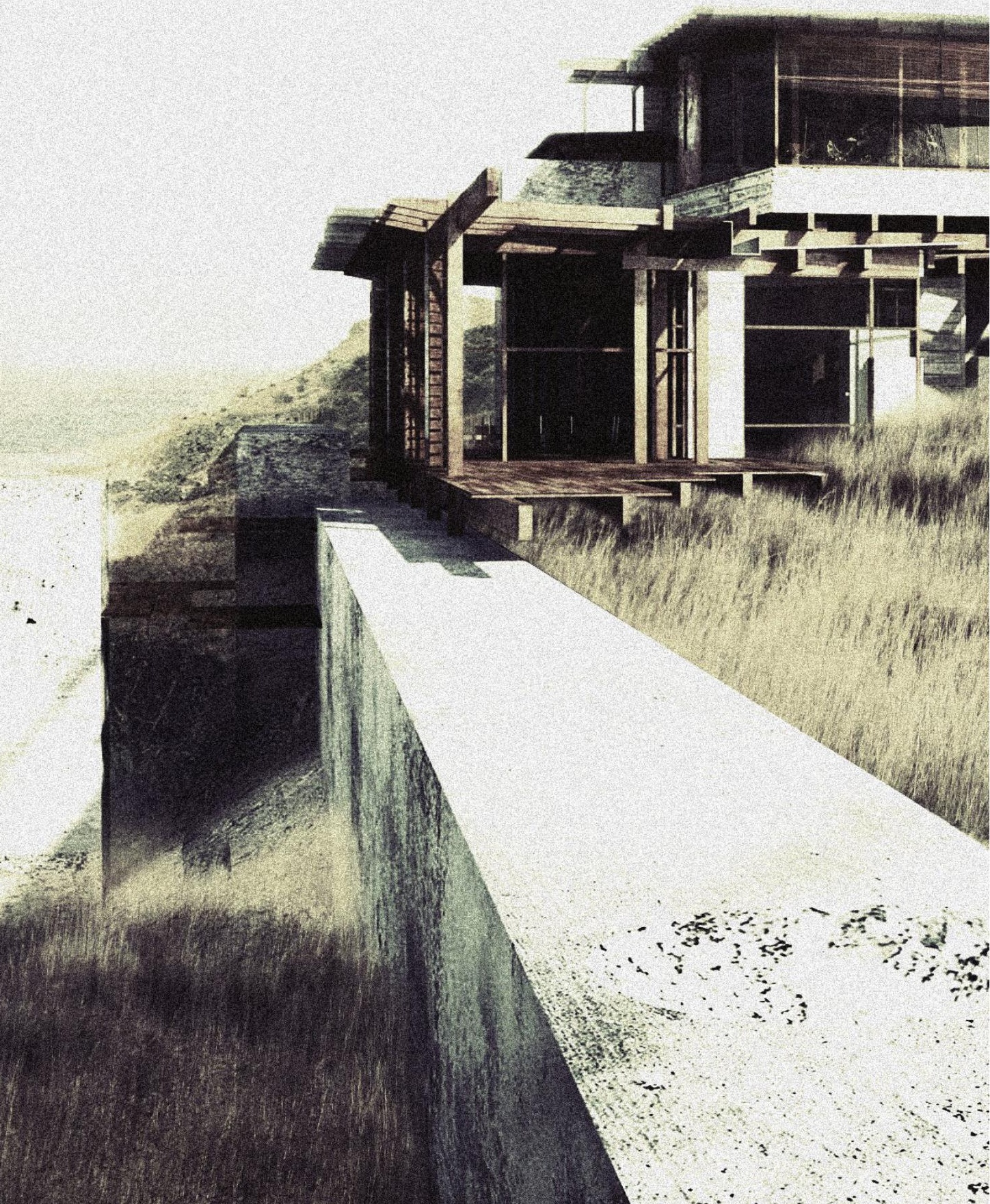




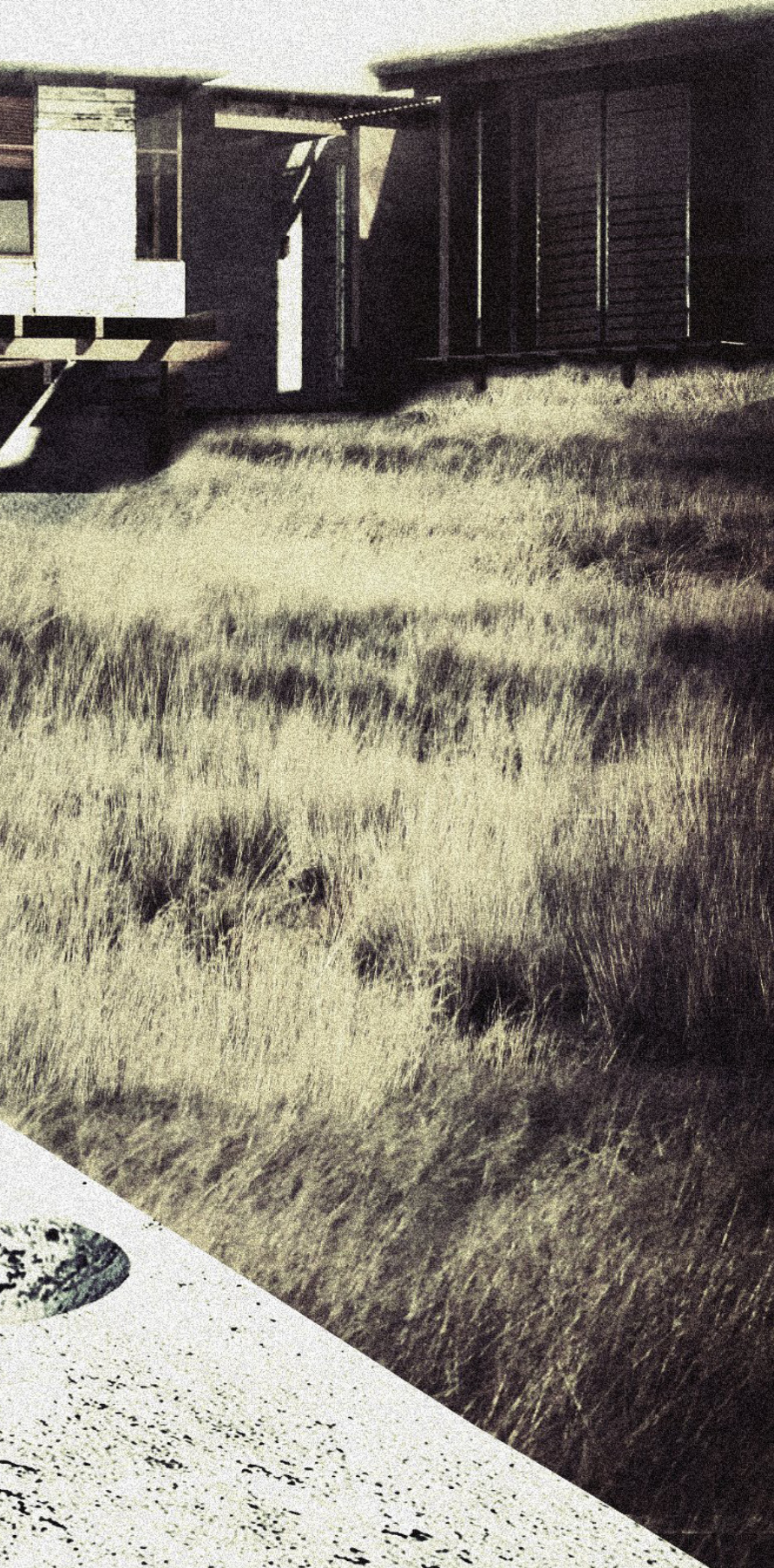

The shift from the entrance and rear of the building, and its unclarity, its concealing 'mystery', and that of the open more 'picturesque' front (this image depicts a side view of the front) find mutual intensification through their aesthetic juxtaposition. As in each aspect of the building's constitution, relative degrees of 'becoming' and 'being' collate; they mutually draw attention to each other, draw their presence to us - just as the darker shades of a painting only make the lighter tones more bright. 
Note: while standard APA reference formatting is used with respect to text, due to the size of reference details of many images, they could no appropriately fit as in work references, therefore standard APA text citation is used in the thesis, while full figure APA citations are presented here in line with other referencing formats.

Figure 1 \& Cover page: The Living Theatre's 1968 Paradise Now production. From: Beinecke Rare Book and Manuscript Library, Yale University; Living Theatre Records (1968).

Figure 2: Theatre of Dionysus, Athens. Adapted From: Lawrence, A. W. (1957). Greek Architecture (p. 78). Baltimore, USA: Penguin Books.

Figure 3: 'Blue World-Space' by C. Davies, 1985, Oil on canvas. Adapted From, Davies, C. (2004). Virtual Space (p. 74). In, Penz, F., Radick, G. \& Howell, R., (eds.), Space: In Science, Art and Society (pp. 69-104). Cambridge, England: Cambridge University Press.

Figure 4: 'Medicine' by Gustav Klimt, 1897-1898 (destroyed 1945), Oil on canvas. Photo: Galerie Welz. Adapted From: Hofmann, W. (1999). Poets Are Always Producing Chaos: Nietzsche, Klimt, and Turn-of-the-Century Vienna (p. 80). In Kosta, A., Wohlfarth, I. (eds.), (1999). Nietzsche and an Architecture of Our Minds. (pp. 67-90). Los Angeles: The Getty Research Institute for the History of Art and the Humanities.

Figure 5: Turner, J. M.W, Fishermen at Sea, 1796, Oil on canvas, 91.5 x 122.4 cm. London, The Tate Gallery. From: Bockemühl, M. (2000). J.M.W. Turner: 1775-1851: the world of light and colour (p. 24). (Claridge, M., Trans). Germany: Taschen.

Figure 6: Temple of Apollo, Antalya, From: Martin, R. (1998). Greek Architecture: History of world Arcitecture. New York: Rizzoli International Publications. p. 87. 
Figure 7: 'Eclipse of May 29, 1919'. From: F. W. Dyson, A. S. Eddington, and C. Davidson, (1920). A Determination of the Deflection of Light by the Sun's Gravitational Field, from Observations Made at the Total Eclipse of May 29, 1919 (p. 322). Philosophical Transactions of the Royal Society of London. Series A, Containing Papers of a Mathematical or Physical Character. pp. 291-333.

Figure 8: Capital and anta in south wing of Propylaea. 437-432. Athens. dapted from: Lawrence, A. W. (1957) Greek Architecture (p. 383/ plate 63). Baltimore, USA: Penguin Books Ltd. (Original photo by Picard, M.)

Figure 9: Palazzo Cancelleria. From: Wolffin, H. (1967). Renaissance and Baroque. USA: Cornell University Press

Figure 10: Paestum, temple of Hera 1 (basilica). Adapter from: Martin, R. (1998) Greek Arcbitecture: History of world Arcitecture (p. 89). New York: Rizzoli International Publications.

Figure 10: The Pyramids of el-Geezeh (Giza). Photograph ca. 1857. From Frith, F. (1862) Lower Egypt, Thebes and the Pyramids. London: Getty Research Institute, acc. no. 84-B8850. and Khafre. In, Papadopoulos, J. K., Leventhal, M. R. (2003). Theory and practice in Mediterranean archaeology: Old World and New World perspectives (p. 117). Los Angeles, USA: Cotsen Institute of Archaeology, University of California.

Figure 11: Arcade from internal courtyad of the Palazzo Cancelleria. Photo: Sklifas. S, (2008). Retrieved Frome, http://steven-sklifas.photoshelter. $\mathrm{com} /$ gallery-image/Rome-Historical-Center-images/G0000VVyZ5P2INU8/I00000ZGJ7Am1ck8

Figure 12: 'The mighty pyramidal block of stone'. Adapted From, Young, J. (2010). Friedrich Nietzsche: a philosophical biography (p.318). New York, Cambridge: Cambridge University press.

Figure 13: 'Temple 'C'. Early 6th centtury. Selinus.' Adapted from: Lawrence, 
A. W. (1957). Greek Architecture (p. 348/ plate 30). Baltimore, USA. Penguin Books Ltd. (orginal photo by France, A.)

Figure 14: 'Forest View'. Photo: Vaupel, H., (2008). From: personal portpholio: Retrieved from: http://www.flickr.com/photos/ tobi0406/2559841399/sizes/1/in/photostream/

Figure 15: Turner, J. M.W, Snow stoms: Hannibal and his army crossing the Alps, 1812, Oil on canvas, 146 x $237.5 \mathrm{~cm}$. London, The Tate Gallery. Sourse : Bockemühl. M. (2000). J.M.W. Turner: 1775-1851: the world of light and colour. (Claridge, M, Trans). Germany: Taschen. p. 21.

Figure 16: 'Less Demoiselles - colbot creek'. From: Hamelton, D. (1973). Less Demoiselles D Hamelton. Paris: Robert Laffont. p. 155.

Figure 17: '1968 protests in Paris'. Photo: (C) Hulton-Deutsch Collection/ CORBIS. From: Ragovin, H. (2008, December). The Year of Revolt. Tufts Journal. Retrieved from, http://tuftsjournal.tufts.edu/2008/12_1/features/02/

Figure 18: Pol bury's 'The Lectern'. 1963. Detail. From: Brett, G. (1968). Kinetic art: The language of movement. London, England: Studio-Vista. p. 53.

Figure 19: Mira Schendel's 'Another Droghinas'. 1966. Rice-paper. From: Guy Brett, (1968), Source: Brett, G. (1968). Kinetic art: The language of movement. London, England: Studio-Vista. p. 47.

Figure 20 'Morro Favela, 1920'. From: Vaz, L. F, \& Jacques, P. B. (2003), Pequeña historia de las Favelas de Rio de Janeiro. p. 263. In CIUDAD Y TERRITORIO Estudios Territoriales, XXXV (136-137), pp. 259-73 (Orginal photograph by, Malta, 1920. A.G.C.R.J.) Retrived form, http://dialnet.unirioja.es/servlet/articulo?codigo $=819538$

Figure 21: 'Top of Morro Favela', Photo: Sertich, A. N., (2010). Retrieved 
from, http-// favelaissues.files.wordpress.com/2010/04/top-of-morro. jpg.

Figure 22: 'Grand Nucleus', acrylic on wood, first designed in 1960, exhibited in Galerie G4, Rie de Janeiro, 1964. Source: Oiticica, H. (1992). Helio Oiticica: exhibition catalogue. Witte de With, Center for Contemporary Art, Rotterdam. p. 52

Figure 23: NewYorkaises Pentrable (\# 15) - Mauquette. New York City, 1971. From: Oiticica, H. (1992). Helio Oiticica: exhibition catalogue. Witte de With, Center for Contemporary Art, Rotterdam. p.143

Figure 24: 'Nests', made and installed at sussex University, Brighton, England, 1969. Sourse:Helio Oiticica: exhibition catalogue. Witte de With, Center for Contemporary Art, Rotterdam, p. 139.

Figure 25: 'Rocinha Favela'. Photo: C. Kelly, 2008. Retrieved from, http:/ / gallery.pastpanic.com/v/riofavela/IMG_7575.jpg.html

Figure 26: 'Alley in Rocinha Favela'. Photo: Saricie, 2006. Retrieved from: http://travel.saricie.com/SouthAmerica2006/Favela_en.htm.

Figure 27: 'The labyrinth'. From: Lucas. G, Rattray. E, Laxer. D (Producers), Henson. J (Director). (1986) The Labyrinth [motion picture]. Film still 00:19:25.

Figure 28: 'Robert Morris installation at Tate Gallery in 1971. Photo: Tate Gallery. Source: Higgins, C. (2009, April 6). Tate Modern's Turbine Hall recreates a 1971 art sensation: Bodyspacemotionthings allows audience to crawl, clamber balance and slide. The Guardian, Retrived from: http://www. guardian.co.uk/artanddesign/2009/apr/06/tate-modern-bodyspacemotionthings-turbine-hall.

Figures 29-45 are the work of the author. 
Alexander, S. (1966). Space, Time Deity: The Gifford Lectures at Glasgow Part One 1916-1918. London: Macmillan. (Orginaly published in 1920)

Anderson, B. (2009). Affective atmospheres. Emotion, Space and Society 2(2): $77-81$

Artaud, A. (1974). The Theatre of Cruelty: First manifesto. In Collected Works, vol. 4, (Corti. V, Trans.). pp. 68-76. London: Calder and Boyars. (Originally published in Nouvelle Revue Francaise (1932), 229, 1 October.)

Asbury, M., (2005) Neoconcretism and Minimalism: On Ferreira Gullar's Theory of the Non-Object'. In: Mercer, K. (ed.). Cosmopolitan Modernisms. London and Massachusetts: InIVA and MIT Press. pp.168-189.

Augustine, (1992). Confessions, cap, XI/14-15, (O’Doneel, J. J. ed) England: Oxford. Orginaly writen in 397 or 398 AD

Bataille, G. (1929). A Critical Dictionary: The Informe. In: Documents, 1(7), pp. 372-85. Reprinted in Stoekl, A. (ed.) (1985). Georges Bataille: Visions of Excess: Selected Writings 1927-1939. Minneapolis: University of Minnesota Press:

Ball, H. (1996). Flight Out of Time: A Dada Diary. (Elderfield, J. ed, Raimes, A. Trans.). Berkeley and London: University of California Press.

Bergson, H. L. (1946). The creative mind (Andison, M. L., Trans). New York: Philosopical Library. (Originally published, La pensée et le mouvant. Paris: Presses Universitaires de France, 1934.)

-. (1911). Matter and Memory (Paul, N. M. \& Palmer, W. S., Trans.) New York: Zone Books. (Originally published, Matière et mémoire. Paris: Presses Universitaires de France, 1896.) 
-. (1983). Creative Evolution (Mitchell, A. Trans). Lanham: University Press of America. (Originally published, L'évolution créatrice. Paris: Presses Universitaires de France, 1907.)

—. (1920). Mind-Energy, (Carr, H. W., Trans.). London: MacMillan. (Originally published, L'énergie spirituelle. Paris: Presses Universitaires de France, 1919.)

—. 1919. Time and Free Will, (Pogson, F. L., Trans). New York: MacMillan. (Originally published, Essai sur les données immédiates de la conscience. Paris: Presses Universitaires de France, 1889.)

Bishop, C. (ed.) (2006). Participation: Documents of Contemporary Art. London: Whitechapel; Boston Massachussets: MIT Press.

Bolton, R. (1975). Plato's Distinction between Being and Becoming. The Review of Metaphysics 29(1): 66-95.

Bostock, D. (1978). Plato on Change and Time in the Parmenides. Phronesis 23(3): 229-242.

Braga, P. P., (2001). Hélio Oiticica: Nietəssche's Übermensch in the Brąilian Slums. MA Thesis, University of Illinois. Retrieved from, http://gsd. ime.usp.br/ pbraga/thesis.pdf

Braga, P. P., (2003). Hélio Oiticica and the Parangolés. Third Text 17(1): $43-52$.

Braga, P. P., Ed. (2008). Fios Soltos: a arte de Hélio Oiticica (Loose Threads: The Art of Hélio Oiticica). Sao Paulo: Editora Perspectiva SA.

Brett, G. (1968). Kinetic art: The language of movement. London, England: Studio-Vista.

Carman, T. (1995). Heidegger's concept of presence. Inquiry: An Interdisci- 
plinary Journal of Philosophy 38(4): 431-453.

Corngold, S. (1990). Nietzsche's Moods: Studies in Romanticism. 29,(1), Nietzsche and Romanticism. Boston: Boston University, pp. 67-90.

Davies, C. (2003). Landscape, Earth, Body, Being, Space, and Time in the Immersive Virtual Environments Osmose and Ephémère: In: Malloy, J. (ed)(2003). Women, Art, and Technology. Cambridge, MA and London, England: MIT Press. pp. 322-337.

Davies, C. (2004). Virtual Space: In, Penz, F., Radick, G. \& Howell, R., (eds.) (2004), Space: in Science, Art and Society. Cambridge, England: Cambridge University Press. pp. 69-104.

Derrida, J. (1994). Given time: Counterfeit money. (Kamuf, P. ed \& trans). Chicago: University of Chicago Press. (Originally publised as Donner le temps, Editions Galilee, 1991).

Eliade, M. (1982). Ordeal by labyrinth: conversations with Claude-Henri Rocquet. Chicago : University of Chicago Press.

Etlin, R. A. (Winter, 1998). Aesthetics and the Spatial Sense of Self. The Journal of Aesthetics and Art Criticism, 56 (1): 1-19.

Faulkner, W. (1929). The Sound and the Fury. United states: Jonathan Cape \& Harrison Smith.

Figueiredo, L., Pape, L. \& Salomão, W., (eds.) (1986). Hélio Oiticica: Aspiro ao Grande Labirinto. Rio de Janeiro: Rocco.

Fink, E. (2003). Nietzsche's philosophy (Richter, G. Trans). New York; London: Continuum International Publishing Group.

Frazer, J. G. (1933). The golden bough: a study in magic and religion. $12 \mathrm{v}$. London: Macmillan. 
Frankl, P. (1968). Principles of Architectural History: The four Phases of Arcbitectural Style, 1420-1900 (O'Groman, J. F., Trans, \& ed.) Cambridge, Massechusetts., London, England: The MIT Press.

Fried. M. (1998). 'Art and Objecthood', in Art and Objecthood. Chicago and London: The University of Chicago Press. (originally published in Artforum, 5 (June 1967), pp.12-23

Gunter, P. A. Y. (1971). Bergson's Theory of Matter and Modern Cosmology. Journal of the History of Ideas 32(4): 525-542.

Gorgolewski, M. (2005, september). Ecological Building. Paper presented at Heritage Canada Foundation Annual Conference - Heritage and sustainability: Canadian Communities and Kyoto. Retreved from, http://www. heritagecanada.org/eng/news/archived/conference_proceedings/ Heritage5-En-final.pdf

Gunter, P. A. Y. (1982). Bergson and Jung. Journal of the History of Ideas 43(4): 635-652.

Guthrie, W. K. C. (1951). The Greeks and their gods. Boston: The. Beacon Press.

Hale, J. (2005). Gottfried Semper's primitive but as an act of self-creation. Arq: Architectural Research Quarterly. 9(1): 45-49.

Harries, K. (1982). Building and the Terror of Time. Perspecta 19, Yale School of Architecture: pp. 59-69.

Harries, K. (1997). The ethical function of architecture. Cambridge, Mass: MIT Press.

Hatab, L. J. (1978). Nietzsche and eternal recurrence: the redemption of time and becoming. Washington: University Press of America. 
Heidegger, M. (1979). Nietzsche: The will to power as art. (Krell. D. F, Trans) San Francisco: Harper \& Row.

Heidegger, M. and D. F. Krell (1981). Tragedy, Satyr-Play, and Telling Silence in Nietasche's Thought of Eternal Recurrence. Boundary 9(3): 25-39. Duke University Press.

Hodin, J. P. (1958). The Timeless and the Timebound in Art. The Journal of Aesthetics and Art Criticism 16(4): 497-502.

Hofmann, W. (1999). Poets Are Always Producing Chaos: Nietzsche, Klimt, and Turn-of-the-Century Vienna. In Kosta, A., Wohlfarth, I. eds. (1999) Nietzsche and an Architecture of Our Minds. (pp. 67-90). Los Angeles: The Getty Research Institute for the History of Art and the Humanities.

Holl, S., Pallsmaa, J. \& Perz-Gomez, A., (2006). Questions of Perception: Phenomenology of Architecture. San Francisco, USA: William Stout Publishers.

Innes, C. (1993). Avant Garde Theatre 1892-1992. London and New York, Routledge.

Jacques, P. (2003) Estética da ginga: a arquitetura das favelas através da obra de Hélio Oiticica. Rio de Janeiro: Casa da Palavra.

Jacques, P. B (2010). Lerning form the Favelas, In KoCAInn. (eds, Brasil, D. Dietl, T. Grau, C. Konig, B.) (Brasil, D., Trans). Berlin: Revolver Publishing. pp. 300-314.

Jones, R. (1882). Physics as Metaphor. Minneapolis, USA: University of Minnesota Press.

Jowett, B. (2009). Timaeus and Critias: Plato. Digireads publishing. ISBN 1420933914, 9781420933918. 
Kimmel, L. (2007). Notes on a poetics of Time. In Tumieniecka, A. T. (eds) (2007). Analecta Husserliana: The Yearbook of Phenomenological Reasearch; Temporality in Life as Seen Through Literature: Contributions to phenomenology of life. Vol, 86, pp. 257-269. Dordrecht, The Netherlands: Springer.

Kostelanetz, R. (1989). The Discovery of Alternative Theater: Notes on Art Performances in New York City in the 1960s and 1970s. Perspectives of New Music, 27(1): 128-172. Retrieved from, http://www.jstor.org/stable/833264

Lawrence, A. W. (1957). Greek Architecture. Baltimore, USA: Penguin Books.

Lipps, T. (1903). Ästhetik: Psychologie des Schönen und der Kunst [Aesthetics: Psycbology of beauty and art. Hamburg \& Leipzig: Voss.

Lorand, R. (1999). Bergson's Concept of Art. British Journal of Aesthetics, 39(4), 400-415. Retrieved from, http://bjaesthetics.oxfordjournals. org/

Lucas. G, Rattray. E, Laxer. D (Producers), Henson. J (Director). (1986) The Labyrinth [motion picture]. United Kingdon/United States: Henson Associates Lucasfilm.

Marcuse, H. (1971). Liberation from the Affuent Society. In Cooper, D. ed (1971). The Dialectics of Liberation. pp 175- 182. Harmondsworth, Enland: Perguin Books. (orgianaly published 1968)

Martienssen, R. D. (1965). The Idea of Space in Greek Architecture, 2nd ed. Johannesburg, South Africa.

Martin, R. (1998). Greek Architecture: History of world Arcitecture. New York, USA: Rizzoli International Publications, Inc. 
Martin, S. and Ruiz, (A eds.) (1999-2000) The experimental exercise of freedom: Lygia Clark, Gego, Mathias Goeritz, Hélio Oiticica and Mira Schendel. California, Los Angeles: Museum of Contemporary Art.

McMahon, A. P. (1935). Would Plato Find Artistic Beauty in Machines? Parnassus, $7(2), 6-8$.

Melzer, A. (1994). Dada and Surrealist Performance. Baltimore and London: John Hopkin's University Press.

Merleau-Ponty, M. (1962). The Phenomenology of Perception. London: Routledge \& Kegan Paul.

Merleau-Ponty, M. (1964). The Primacy of Perception: and other essays on phenomenolical psychology, the philosopy of art, history and politics. (Edie, J. M, ed).Illinois: Northwester University Press.

Milevska, S. (2006) Participatory art: A Paradigm Shift from Objects to Subjects. Available from: http://www.springerin.at/dyn/heft_text. php?textid $=1761$ \&lang $=$ en

Moore, K. Z. (1980). "The Beauty of the Beast: Presence/Absence and the Vicissitudes of the Sphinx in Sophocles' Oedipus Tyrannus and Oedipus at Colonus." boundary 28(3), pp. 1-18.

Morris, R. (1995). Continous Project Altered Daily: The Writings of Robert Morris. Cabridge, Massachusets; London, England: The MIT Press.

Morris, R. (2001). Threading the Labyrinth. October, Vol. 96, pp. 61-70; Published by: The MIT Press, Stable URL: http://www.jstor.org/stable/779117

Morris, R. (1966) Notes on Sculpture 1-3, Artforum 4:6 (1966): 42-4; 5:2 (1966): 20-3; 5:10 (1967). Rpt in, Harrison, C. \& Wood, P. (eds.)(2005). Art in Theory 1900-2000. Malden, MA: Blackwell Publishing, pp. 828-35. 
Mostafavi, M., Leatherbarrow, D. (1993) On Weathering: The Life of Buildings in Time. Cambridge, MA and London: MIT Press.

Neff, R. (1970). The Living Theatre: USA. Indianapolis and New York: The Bobbs-Merrill Company.

Nietzsche, F. W. (1872). The Birth of Tragedy. In Guess, R., \& Speirs, R. eds,. (1999). The Birth of Tragedy and Other Writings. Cambridge, UK: Cambridge University Press.

Nietzsche, F. W. (2005). Thus spoke Zarathustra: a book for everyone and nobody (Parkes. G., Trans). New York: Oxford University Press. (Orginal pubilication of 'thus spoke Zarthustra': 1883)

Nietzsche, F. W. (1967). Ecce Homo: How One Becomes What One Is (W. Kaufmann, ed \& Trans). New York: Vintage. (Original publication of Ecce Homo: 1888)

Nietzsche, F. W. (2006) On Moods. In The Nietzsche reader. (Ansell-Pearson, K., Largeb, D. eds). USA, MA; UK Oxford; Carltron; Australia: Blackwell publishing. (On moods was writen in 1864)

Oiticica, H. (1992). Helio Oiticica: exbibition catalogue (Brett, G. ed). Witte de With, Center for Contemporary Art, Rotterdam.

Pallasmaa, J. (2000). Hapticity and time: Notes on fragile architecture. In, Architectural Review, 207(1239), pp.78-84.

Perl, E. D. (1999). The Presence of the Paradigm: Immanence and Transcendence in Plato's Theory of Forms. The Review of Metaphysics 53(2): 339-362.

Perez-Gomez, A. (1983). Architecture and the Crisis of Modern Science. Cambridge and London: The MIT Press.

Patterson, R. (1998). On the eternality of Platonic Forms. In N. D. Smith 
(ed.), (1998) Plato: critical assessments (Vol. 2, pp. 142-160). London; New York: Routledge.

Pletsch, C. E. (1977). History and Friedrich Nietzsche's Philosophy of Time. History and Theory 16(1): 30-39.

Poteat, W. H, \& Nicell, J. M. (1993). The primacy of persons and the language of culture: essays. Missouri, USA: University of Missouri Press.

Psarra, S. (2003). The book and the labyrinth were one and the same' - narrative and architecture in Borges' fictions. The Journal of Architecture 8(3): 369 391.

Riegl, A. (1985). Late Roman art industry: Trnaslated from the orignal Vienesse edition with forword and annotations. (Winkes, R.., Trans, Bretschneider G., ed). Italy, Roma: Archaeologica.

Rohde, E. (1972). Psyche: The cult of souls and belief in immortality among the Greeks (Hillis, W. B, Trans from the 8th ed). Freeport, N.Y: Books for Libraries Press. (Originaly published 1920)

Romilly, J. d. (1968). Time in Greek tragedy. Ithaca, N.Y. : Cornell University Press. (Revised version published in French (Paris, 1971) under title: Le temps dans la tragedie grecque.)

Salomão, W. (1996). Helio Oiticica: qual e o Parangole. Rio de Janeiro: Relume Dumara.

Salzstein, S. (1994). Hélio Oiticica: Autonomy and the limits of subjectivity. Third Text 8(28): 117 - 128.

Satre, J. P. (1939). Time in Faulkener: The Sound and the Fury. In Hoffman, F. J., Vickery, O. W., eds. (1963). William Faulkner: Three Decades of Criticism. pp 225 -235. New York and Bulingame: Harcourt, Brace \& World, Inc. 
Sartre, J. P. (1971). Being and Nothingness: An Essay in Phenomenological Ontology. Barnes, H.., Trans. New York: Washington Square Press, . (Originally published as L'Etre et Néant, Essai d'ontologie phénoménologique. Paris: Gallimard, 1943.)

Scheiffele, E. (2001). Acting: an altered state of consciousness. Research in Drama Education: The Journal of Applied Theatre and Performance 6(2): 179-191. Doi: 10.1080/13569780120070722

Schober, A. (2004). Hélio Oiticica's Parangolés: Body-Events, Participation in the Anti-Doxa of the Avant-Garde and Struggling Free From It. Available from: http://homepage.univ i e.ac.at/anna.schober/Schober.pdf

Schopenhauer, A. (1969). The world as will and representation. (E. F. J. Payne Trans.). New York: Dover Publications. (Original work published 1819)

Shank, T. (2005). Beyond the boundaries: American alternative theatre. Ann Arbor: The University of Michigan Press.

Silva, R. R. D. (2005). Hélio Oiticica's Parangolé or the art of transgression. Third Text 19(3): 213 - 231.

Stedman, R. C. (2003). Is It Really Just a Social Construction?: The Contribution of the Physical Environment to Sense of Place. Society \& Natural Resources: An International Journal 16(8): 671 - 685.

Sorabji, R. (2006). Time, Creation and the Continuum: Theories in Antiquity and the Early Middle Ages. Chicago: University of Chicago Press. (Originally publisshed 1983)

Sorabji, R. (1972). Aristotle on memory. London: Duckworth.

Stambaugh, J. (1987). The problem of time in Nietssche. Lewisburg: Bucknell University Press. 
Thiboutot, C., Martinez, A., et al. (1999). Gaston Bachelard and phenomenology: Outline of a theory of the imagination. Journal of Phenomenological Psychology 30(1): 1.

Tiffany, Daniel, (2000). Toy Medium: Materialism and Modern Lyric. London: University of Califoria Press.

Titiev, M. (1970). Ethnology: The Tewa World: Space, Time, Being, and Becoming in a Pueblo Society. American Anthropologist 72(5): 1140-1141.

Tschumi, B. (1975). Questions of Space: The Architecture Paradox of the Pyramid and the Labyrinth. In Hays, K. M. (ed)(1998). Architecture Theory Since 1968, ed. K. M. Hays, (pp 219-242). Cambridge and London: The MIT Press.

Whittaker, J. (1968). The "Eternity" of the Platonic Forms. Phronesis, 13(2): 131-144

Wölfflin, H. (1886) Prolegomena to a Psycholog of Architecture. (ph.D.,) In Mallgrave, H. F., Ikonomou E., ed. \& trans., (1994). Empathy. Form, and Sace: Problems in German Aesthetics, $1973-1893$ (pp. 149-192). Santa Monica: Getty Center for the hisoty of Art and the Humanities.

- (1932). Principles of Art History: The Problem of the Development of Style in Later Art. (Hottinger, M. D., Trans). New York: Dover Pulications. (Originally published, 1915).

- (1952). Classic Art. An Introduction to the Italian Renaissance. Translated from the 8th German Edition (Benno Schwabe \& Co, Basle 1948) by Peter and Linda Murray (Phaidon Press, London 1952, 2nd Edn 1953).

- (1967). Renaissance and Baroque. USA: Cornell University Press (Originally published 1961)

Worringer, W. (1967). Abstraction and Empathy; A Contribution to the Psy- 
chology of Style (M. Bullock, Trans.). Cleveland: Meridian Books. (Originally published, 1901).

Yeager, K. L. (1998). Nietssche, Plato, Heraclitus and the pursuit of illuminate dwelling. History of Political Thought 19: 621-640.

Young, J. (2010). Friedrich Nietzsche: a philosophical biography. Cacbridge, england: Cambridge University Press.

Zelevansky, L. \& Hillings, V. L., (2004). Beyond geometry: experiments in form, 1940s-70s. Cambridge, MA: MIT Press.

Zumthor, P. (1998). Thinking Arcbitecture. (Oberli-Turner, M. Trans.). Baden, Switzerland: Lars Müller. 
Note: while standard APA reference formatting is used with respect to text, due to the size of reference details of many images, they could no appropriately fit as in work references, therefore standard APA text citation is used in the thesis, while full figure APA citations are presented here in line with other referencing formats.

Figure 1 \& Cover page: The Living Theatre's 1968 Paradise Now production. From: Beinecke Rare Book and Manuscript Library, Yale University; Living Theatre Records (1968).

Figure 2: Theatre of Dionysus, Athens. Adapted From: Lawrence, A. W. (1957). Greek Architecture (p. 78). Baltimore, USA: Penguin Books.

Figure 3: 'Blue World-Space' by C. Davies, 1985, Oil on canvas. Adapted From, Davies, C. (2004). Virtual Space (p. 74). In, Penz, F., Radick, G. \& Howell, R., (eds.), Space: In Science, Art and Society (pp. 69-104). Cambridge, England: Cambridge University Press.

Figure 4: 'Medicine' by Gustav Klimt, 1897-1898 (destroyed 1945), Oil on canvas. Photo: Galerie Welz. Adapted From: Hofmann, W. (1999). Poets Are Always Producing Chaos: Nietzsche, Klimt, and Turn-of-the-Century Vienna (p. 80). In Kosta, A., Wohlfarth, I. (eds.), (1999). Nietzsche and an Architecture of Our Minds. (pp. 67-90). Los Angeles: The Getty Research Institute for the History of Art and the Humanities.

Figure 5: Turner, J. M.W, Fishermen at Sea, 1796, Oil on canvas, 91.5 x 122.4 cm. London, The Tate Gallery. From: Bockemühl, M. (2000). J.M.W. Turner: 1775-1851: the world of light and colour (p. 24). (Claridge, M., Trans). Germany: Taschen.

Figure 6: Temple of Apollo, Antalya, From: Martin, R. (1998). Greek Architecture: History of world Arcitecture. New York: Rizzoli International Publications. p. 87. 
Figure 7: 'Eclipse of May 29, 1919'. From: F. W. Dyson, A. S. Eddington, and C. Davidson, (1920). A Determination of the Deflection of Light by the Sun's Gravitational Field, from Observations Made at the Total Eclipse of May 29, 1919 (p. 322). Philosophical Transactions of the Royal Society of London. Series A, Containing Papers of a Mathematical or Physical Character. pp. 291-333.

Figure 8: Capital and anta in south wing of Propylaea. 437-432. Athens. dapted from: Lawrence, A. W. (1957) Greek Architecture (p. 383/ plate 63). Baltimore, USA: Penguin Books Ltd. (Original photo by Picard, M.)

Figure 9: Palazzo Cancelleria. From: Wolffin, H. (1967). Renaissance and Baroque. USA: Cornell University Press

Figure 10: Paestum, temple of Hera 1 (basilica). Adapter from: Martin, R. (1998) Greek Arcbitecture: History of world Arcitecture (p. 89). New York: Rizzoli International Publications.

Figure 10: The Pyramids of el-Geezeh (Giza). Photograph ca. 1857. From Frith, F. (1862) Lower Egypt, Thebes and the Pyramids. London: Getty Research Institute, acc. no. 84-B8850. and Khafre. In, Papadopoulos, J. K., Leventhal, M. R. (2003). Theory and practice in Mediterranean archaeology: Old World and New World perspectives (p. 117). Los Angeles, USA: Cotsen Institute of Archaeology, University of California.

Figure 11: Arcade from internal courtyad of the Palazzo Cancelleria. Photo: Sklifas. S, (2008). Retrieved Frome, http://steven-sklifas.photoshelter. $\mathrm{com} /$ gallery-image/Rome-Historical-Center-images/G0000VVyZ5P2INU8/I00000ZGJ7Am1ck8

Figure 12: 'The mighty pyramidal block of stone'. Adapted From, Young, J. (2010). Friedrich Nietzsche: a philosophical biography (p.318). New York, Cambridge: Cambridge University press.

Figure 13: 'Temple 'C'. Early 6th centtury. Selinus.' Adapted from: Lawrence, 
A. W. (1957). Greek Architecture (p. 348/ plate 30). Baltimore, USA. Penguin Books Ltd. (orginal photo by France, A.)

Figure 14: 'Forest View'. Photo: Vaupel, H., (2008). From: personal portpholio: Retrieved from: http://www.flickr.com/photos/ tobi0406/2559841399/sizes/1/in/photostream/

Figure 15: Turner, J. M.W, Snow stoms: Hannibal and his army crossing the Alps, 1812, Oil on canvas, 146 x $237.5 \mathrm{~cm}$. London, The Tate Gallery. Sourse : Bockemühl. M. (2000). J.M.W. Turner: 1775-1851: the world of light and colour. (Claridge, M, Trans). Germany: Taschen. p. 21.

Figure 16: 'Less Demoiselles - colbot creek'. From: Hamelton, D. (1973). Less Demoiselles D Hamelton. Paris: Robert Laffont. p. 155.

Figure 17: '1968 protests in Paris'. Photo: (C) Hulton-Deutsch Collection/ CORBIS. From: Ragovin, H. (2008, December). The Year of Revolt. Tufts Journal. Retrieved from, http://tuftsjournal.tufts.edu/2008/12_1/features/02/

Figure 18: Pol bury's 'The Lectern'. 1963. Detail. From: Brett, G. (1968). Kinetic art: The language of movement. London, England: Studio-Vista. p. 53.

Figure 19: Mira Schendel's 'Another Droghinas'. 1966. Rice-paper. From: Guy Brett, (1968), Source: Brett, G. (1968). Kinetic art: The language of movement. London, England: Studio-Vista. p. 47.

Figure 20 'Morro Favela, 1920'. From: Vaz, L. F, \& Jacques, P. B. (2003), Pequeña historia de las Favelas de Rio de Janeiro. p. 263. In CIUDAD Y TERRITORIO Estudios Territoriales, XXXV (136-137), pp. 259-73 (Orginal photograph by, Malta, 1920. A.G.C.R.J.) Retrived form, http://dialnet.unirioja.es/servlet/articulo?codigo $=819538$

Figure 21: 'Top of Morro Favela', Photo: Sertich, A. N., (2010). Retrieved 
from, http-// favelaissues.files.wordpress.com/2010/04/top-of-morro. jpg.

Figure 22: 'Grand Nucleus', acrylic on wood, first designed in 1960, exhibited in Galerie G4, Rie de Janeiro, 1964. Source: Oiticica, H. (1992). Helio Oiticica: exhibition catalogue. Witte de With, Center for Contemporary Art, Rotterdam. p. 52

Figure 23: NewYorkaises Pentrable (\# 15) - Mauquette. New York City, 1971. From: Oiticica, H. (1992). Helio Oiticica: exhibition catalogue. Witte de With, Center for Contemporary Art, Rotterdam. p.143

Figure 24: 'Nests', made and installed at sussex University, Brighton, England, 1969. Sourse:Helio Oiticica: exhibition catalogue. Witte de With, Center for Contemporary Art, Rotterdam, p. 139.

Figure 25: 'Rocinha Favela'. Photo: C. Kelly, 2008. Retrieved from, http:/ / gallery.pastpanic.com/v/riofavela/IMG_7575.jpg.html

Figure 26: 'Alley in Rocinha Favela'. Photo: Saricie, 2006. Retrieved from: http://travel.saricie.com/SouthAmerica2006/Favela_en.htm.

Figure 27: 'The labyrinth'. From: Lucas. G, Rattray. E, Laxer. D (Producers), Henson. J (Director). (1986) The Labyrinth [motion picture]. Film still 00:19:25.

Figure 28: 'Robert Morris installation at Tate Gallery in 1971. Photo: Tate Gallery. Source: Higgins, C. (2009, April 6). Tate Modern's Turbine Hall recreates a 1971 art sensation: Bodyspacemotionthings allows audience to crawl, clamber balance and slide. The Guardian, Retrived from: http://www. guardian.co.uk/artanddesign/2009/apr/06/tate-modern-bodyspacemotionthings-turbine-hall.

Figures 29-45 are the work of the author. 
Alexander, S. (1966). Space, Time Deity: The Gifford Lectures at Glasgow Part One 1916-1918. London: Macmillan. (Orginaly published in 1920)

Anderson, B. (2009). Affective atmospheres. Emotion, Space and Society 2(2): $77-81$

Artaud, A. (1974). The Theatre of Cruelty: First manifesto. In Collected Works, vol. 4, (Corti. V, Trans.). pp. 68-76. London: Calder and Boyars. (Originally published in Nouvelle Revue Francaise (1932), 229, 1 October.)

Asbury, M., (2005) Neoconcretism and Minimalism: On Ferreira Gullar's Theory of the Non-Object'. In: Mercer, K. (ed.). Cosmopolitan Modernisms. London and Massachusetts: InIVA and MIT Press. pp.168-189.

Augustine, (1992). Confessions, cap, XI/14-15, (O’Doneel, J. J. ed) England: Oxford. Orginaly writen in 397 or 398 AD

Bataille, G. (1929). A Critical Dictionary: The Informe. In: Documents, 1(7), pp. 372-85. Reprinted in Stoekl, A. (ed.) (1985). Georges Bataille: Visions of Excess: Selected Writings 1927-1939. Minneapolis: University of Minnesota Press:

Ball, H. (1996). Flight Out of Time: A Dada Diary. (Elderfield, J. ed, Raimes, A. Trans.). Berkeley and London: University of California Press.

Bergson, H. L. (1946). The creative mind (Andison, M. L., Trans). New York: Philosopical Library. (Originally published, La pensée et le mouvant. Paris: Presses Universitaires de France, 1934.)

-. (1911). Matter and Memory (Paul, N. M. \& Palmer, W. S., Trans.) New York: Zone Books. (Originally published, Matière et mémoire. Paris: Presses Universitaires de France, 1896.) 
-. (1983). Creative Evolution (Mitchell, A. Trans). Lanham: University Press of America. (Originally published, $L \quad$ c a $c$ ce. Paris: Presses Universitaires de France, 1907.)

-. (1920). Mind-Energy, (Carr, H. W., Trans.). London: MacMillan. (Originally published, $L$ e ge e e. Paris: Presses Universitaires de France, 1919.)

- 1919. Time and Free Will, (Pogson, F. L., Trans). New York: MacMillan. (Originally published, $E$ a $e d \quad e \quad d a e$ de ac ce ce. Paris: Presses Universitaires de France, 1889.)

Bishop, C. (ed.) (2006). Participation: Documents of Contemporary Art. London: Whitechapel; Boston Massachussets: MIT Press.

Bolton, R. (1975). Pa D $\quad$ a be ee Be gad Bec $g$. The Review of Metaphysics 29(1): 66-95.

Bostock, D. (1978). Plato on Change and Time in the Parmenides. Phronesis 23(3): 229-242.

Braga, P. P., (2001). H O cca: Ne ce be e c e B a a Slums. MA Thesis, University of Illinois. Retrieved from, http://gsd. ime.usp.br/ p pbraga/thesis.pdf

Braga, P. P., (2003). H O cca a d e Pa a g . Third Text 17(1): $43-52$.

Braga, P. P., Ed. (2008). F $S \quad$ : a a e de H O c ca (Loose Threads: The Art of Hélio Oiticica). Sao Paulo: Editora Perspectiva SA.

Brett, G. (1968). Kinetic art: The language of movement. London, England: Studio-Vista.

Carman, T. (1995). Heidegger's concept of presence. Inquiry: An Interdisci- 
plinary Journal of Philosophy 38(4): 431-453.

Corngold, S. (1990). Nietzsche's Moods: Studies in Romanticism. 29,(1), Nietzsche and Romanticism. Boston: Boston University, pp. 67-90.

Davies, C. (2003). Landscape, Earth, Body, Being, Space, and Time in the Immersive Virtual Environments Osmose and Ephémère: In: Malloy, J. (ed)(2003). Women, Art, and Technology. Cambridge, MA and London, England: MIT Press. pp. 322-337.

Davies, C. (2004). Virtual Space: In, Penz, F., Radick, G. \& Howell, R., (eds.) (2004), Space: in Science, Art and Society. Cambridge, England: Cambridge University Press. pp. 69-104.

Derrida, J. (1994). Given time: Counterfeit money. (Kamuf, P. ed \& trans). Chicago: University of Chicago Press. (Originally publised as Donner le temps, Editions Galilee, 1991).

Eliade, M. (1982). Ordeal by labyrinth: conversations with Claude-Henri Rocquet. Chicago : University of Chicago Press.

Etlin, R. A. (Winter, 1998). Aesthetics and the Spatial Sense of Self. The Journal of Aesthetics and Art Criticism, 56 (1): 1-19.

Faulkner, W. (1929). The Sound and the Fury. United states: Jonathan Cape \& Harrison Smith.

Figueiredo, L., Pape, L. \& Salomão, W., (eds.) (1986). Hélio Oiticica: Aspiro ao Grande Labirinto. Rio de Janeiro: Rocco.

Fink, E. (2003). Nietzsche's philosophy (Richter, G. Trans). New York; London: Continuum International Publishing Group.

Frazer, J. G. (1933). The golden bough: a study in magic and religion. $12 \mathrm{v}$. London: Macmillan. 
Frankl, P. (1968). Principles of Architectural History: The four Phases of Arcbitectural Style, 1420-1900 (O'Groman, J. F., Trans, \& ed.) Cambridge, Massechusetts., London, England: The MIT Press.

Fried. M. (1998). 'Art and Objecthood', in Art and Objecthood. Chicago and London: The University of Chicago Press. (originally published in Artforum, 5 (June 1967), pp.12-23

Gunter, P. A. Y. (1971). Bergson's Theory of Matter and Modern Cosmology. Journal of the History of Ideas 32(4): 525-542.

Gorgolewski, M. (2005, september). Ecological Building. Paper presented at Heritage Canada Foundation Annual Conference - Heritage and sustainability: Canadian Communities and Kyoto. Retreved from, http://www. heritagecanada.org/eng/news/archived/conference_proceedings/ Heritage5-En-final.pdf

Gunter, P. A. Y. (1982). Bergson and Jung. Journal of the History of Ideas 43(4): 635-652.

Guthrie, W. K. C. (1951). The Greeks and their gods. Boston: The. Beacon Press.

Hale, J. (2005). Gottfried Semper's primitive but as an act of self-creation. Arq: Architectural Research Quarterly. 9(1): 45-49.

Harries, K. (1982). Building and the Terror of Time. Perspecta 19, Yale School of Architecture: pp. 59-69.

Harries, K. (1997). The ethical function of architecture. Cambridge, Mass: MIT Press.

Hatab, L. J. (1978). Nietzsche and eternal recurrence: the redemption of time and becoming. Washington: University Press of America. 
Heidegger, M. (1979). Nietzsche: The will to power as art. (Krell. D. F, Trans) San Francisco: Harper \& Row.

Heidegger, M. and D. F. Krell (1981). Tragedy, Satyr-Play, and Telling Silence in Nietasche's Thought of Eternal Recurrence. Boundary 9(3): 25-39. Duke University Press.

Hodin, J. P. (1958). The Timeless and the Timebound in Art. The Journal of Aesthetics and Art Criticism 16(4): 497-502.

Hofmann, W. (1999). Poets Are Always Producing Chaos: Nietzsche, Klimt, and Turn-of-the-Century Vienna. In Kosta, A., Wohlfarth, I. eds. (1999) Nietzsche and an Architecture of Our Minds. (pp. 67-90). Los Angeles: The Getty Research Institute for the History of Art and the Humanities.

Holl, S., Pallsmaa, J. \& Perz-Gomez, A., (2006). Questions of Perception: Phenomenology of Architecture. San Francisco, USA: William Stout Publishers.

Innes, C. (1993). Avant Garde Theatre 1892-1992. London and New York, Routledge.

Jacques, P. (2003) Estética da ginga: a arquitetura das favelas através da obra de Hélio Oiticica. Rio de Janeiro: Casa da Palavra.

Jacques, P. B (2010). Lerning form the Favelas, In KoCAInn. (eds, Brasil, D. Dietl, T. Grau, C. Konig, B.) (Brasil, D., Trans). Berlin: Revolver Publishing. pp. 300-314.

Jones, R. (1882). Physics as Metaphor. Minneapolis, USA: University of Minnesota Press.

Jowett, B. (2009). Timaeus and Critias: Plato. Digireads publishing. ISBN 1420933914, 9781420933918. 
Kimmel, L. (2007). Notes on a poetics of Time. In Tumieniecka, A. T. (eds) (2007). Analecta Husserliana: The Yearbook of Phenomenological Reasearch; Temporality in Life as Seen Through Literature: Contributions to phenomenology of life. Vol, 86, pp. 257-269. Dordrecht, The Netherlands: Springer.

Kostelanetz, R. (1989). The Discovery of Alternative Theater: Notes on Art Performances in New York City in the 1960s and 1970s. Perspectives of New Music, 27(1): 128-172. Retrieved from, http://www.jstor.org/stable/833264

Lawrence, A. W. (1957). Greek Architecture. Baltimore, USA: Penguin Books.

Lipps, T. (1903). Ästhetik: Psychologie des Schönen und der Kunst [Aesthetics: Psycbology of beauty and art. Hamburg \& Leipzig: Voss.

Lorand, R. (1999). Bergson's Concept of Art. British Journal of Aesthetics, 39(4), 400-415. Retrieved from, http://bjaesthetics.oxfordjournals. org/

Lucas. G, Rattray. E, Laxer. D (Producers), Henson. J (Director). (1986) The Labyrinth [motion picture]. United Kingdon/United States: Henson Associates Lucasfilm.

Marcuse, H. (1971). Liberation from the Affuent Society. In Cooper, D. ed (1971). The Dialectics of Liberation. pp 175- 182. Harmondsworth, Enland: Perguin Books. (orgianaly published 1968)

Martienssen, R. D. (1965). The Idea of Space in Greek Architecture, 2nd ed. Johannesburg, South Africa.

Martin, R. (1998). Greek Architecture: History of world Arcitecture. New York, USA: Rizzoli International Publications, Inc. 
Martin, S. and Ruiz, (A eds.) (1999-2000) The experimental exercise of freedom: Lygia Clark, Gego, Mathias Goeritz, Hélio Oiticica and Mira Schendel. California, Los Angeles: Museum of Contemporary Art.

McMahon, A. P. (1935). Would Plato Find Artistic Beauty in Machines? Parnassus, $7(2), 6-8$.

Melzer, A. (1994). Dada and Surrealist Performance. Baltimore and London: John Hopkin's University Press.

Merleau-Ponty, M. (1962). The Phenomenology of Perception. London: Routledge \& Kegan Paul.

Merleau-Ponty, M. (1964). The Primacy of Perception: and other essays on phenomenolical psychology, the philosopy of art, history and politics. (Edie, J. M, ed).Illinois: Northwester University Press.

Milevska, S. (2006) Participatory art: A Paradigm Shift from Objects to Subjects. Available from: http://www.springerin.at/dyn/heft_text. php?textid $=1761$ \&lang $=$ en

Moore, K. Z. (1980). "The Beauty of the Beast: Presence/Absence and the Vicissitudes of the Sphinx in Sophocles' Oedipus Tyrannus and Oedipus at Colonus." boundary 28(3), pp. 1-18.

Morris, R. (1995). Continous Project Altered Daily: The Writings of Robert Morris. Cabridge, Massachusets; London, England: The MIT Press.

Morris, R. (2001). Threading the Labyrinth. October, Vol. 96, pp. 61-70; Published by: The MIT Press, Stable URL: http://www.jstor.org/stable/779117

Morris, R. (1966) Notes on Sculpture 1-3, Artforum 4:6 (1966): 42-4; 5:2 (1966): 20-3; 5:10 (1967). Rpt in, Harrison, C. \& Wood, P. (eds.)(2005). Art in Theory 1900-2000. Malden, MA: Blackwell Publishing, pp. 828-35. 
Mostafavi, M., Leatherbarrow, D. (1993) On Weathering: The Life of Buildings in Time. Cambridge, MA and London: MIT Press.

Neff, R. (1970). The Living Theatre: USA. Indianapolis and New York: The Bobbs-Merrill Company.

Nietzsche, F. W. (1872). The Birth of Tragedy. In Guess, R., \& Speirs, R. eds,. (1999). The Birth of Tragedy and Other Writings. Cambridge, UK: Cambridge University Press.

Nietzsche, F. W. (2005). Thus spoke Zarathustra: a book for everyone and nobody (Parkes. G., Trans). New York: Oxford University Press. (Orginal pubilication of 'thus spoke Zarthustra': 1883)

Nietzsche, F. W. (1967). Ecce Homo: How One Becomes What One Is (W. Kaufmann, ed \& Trans). New York: Vintage. (Original publication of Ecce Homo: 1888)

Nietzsche, F. W. (2006) On Moods. In The Nietzsche reader. (Ansell-Pearson, K., Largeb, D. eds). USA, MA; UK Oxford; Carltron; Australia: Blackwell publishing. (On moods was writen in 1864)

Oiticica, H. (1992). Helio Oiticica: exbibition catalogue (Brett, G. ed). Witte de With, Center for Contemporary Art, Rotterdam.

Pallasmaa, J. (2000). Hapticity and time: Notes on fragile architecture. In, Architectural Review, 207(1239), pp.78-84.

Perl, E. D. (1999). The Presence of the Paradigm: Immanence and Transcendence in Plato's Theory of Forms. The Review of Metaphysics 53(2): 339-362.

Perez-Gomez, A. (1983). Architecture and the Crisis of Modern Science. Cambridge and London: The MIT Press.

Patterson, R. (1998). On the eternality of Platonic Forms. In N. D. Smith 
(ed.), (1998) Plato: critical assessments (Vol. 2, pp. 142-160). London; New York: Routledge.

Pletsch, C. E. (1977). History and Friedrich Nietzsche's Philosophy of Time. History and Theory 16(1): 30-39.

Poteat, W. H, \& Nicell, J. M. (1993). The primacy of persons and the language of culture: essays. Missouri, USA: University of Missouri Press.

Psarra, S. (2003). The book and the labyrinth were one and the same' - narrative and architecture in Borges' fictions. The Journal of Architecture 8(3): 369 391.

Riegl, A. (1985). Late Roman art industry: Trnaslated from the orignal Vienesse edition with forword and annotations. (Winkes, R.., Trans, Bretschneider G., ed). Italy, Roma: Archaeologica.

Rohde, E. (1972). Psyche: The cult of souls and belief in immortality among the Greeks (Hillis, W. B, Trans from the 8th ed). Freeport, N.Y: Books for Libraries Press. (Originaly published 1920)

Romilly, J. d. (1968). Time in Greek tragedy. Ithaca, N.Y. : Cornell University Press. (Revised version published in French (Paris, 1971) under title: Le temps dans la tragedie grecque.)

Salomão, W. (1996). Helio Oiticica: qual e o Parangole. Rio de Janeiro: Relume Dumara.

Salzstein, S. (1994). Hélio Oiticica: Autonomy and the limits of subjectivity. Third Text 8(28): 117 - 128.

Satre, J. P. (1939). Time in Faulkener: The Sound and the Fury. In Hoffman, F. J., Vickery, O. W., eds. (1963). William Faulkner: Three Decades of Criticism. pp 225 -235. New York and Bulingame: Harcourt, Brace \& World, Inc. 
Sartre, J. P. (1971). Being and Nothingness: An Essay in Phenomenological Ontology. Barnes, H.., Trans. New York: Washington Square Press, . (Originally published as L'Etre et Néant, Essai d'ontologie phénoménologique. Paris: Gallimard, 1943.)

Scheiffele, E. (2001). Acting: an altered state of consciousness. Research in Drama Education: The Journal of Applied Theatre and Performance 6(2): 179-191. Doi: 10.1080/13569780120070722

Schober, A. (2004). Hélio Oiticica's Parangolés: Body-Events, Participation in the Anti-Doxa of the Avant-Garde and Struggling Free From It. Available from: http://homepage.univ i e.ac.at/anna.schober/Schober.pdf

Schopenhauer, A. (1969). The world as will and representation. (E. F. J. Payne Trans.). New York: Dover Publications. (Original work published 1819)

Shank, T. (2005). Beyond the boundaries: American alternative theatre. Ann Arbor: The University of Michigan Press.

Silva, R. R. D. (2005). Hélio Oiticica's Parangolé or the art of transgression. Third Text 19(3): 213 - 231.

Stedman, R. C. (2003). Is It Really Just a Social Construction?: The Contribution of the Physical Environment to Sense of Place. Society \& Natural Resources: An International Journal 16(8): 671 - 685.

Sorabji, R. (2006). Time, Creation and the Continuum: Theories in Antiquity and the Early Middle Ages. Chicago: University of Chicago Press. (Originally publisshed 1983)

Sorabji, R. (1972). Aristotle on memory. London: Duckworth.

Stambaugh, J. (1987). The problem of time in Nietssche. Lewisburg: Bucknell University Press. 
Thiboutot, C., Martinez, A., et al. (1999). Gaston Bachelard and phenomenology: Outline of a theory of the imagination. Journal of Phenomenological Psychology 30(1): 1.

Tiffany, Daniel, (2000). Toy Medium: Materialism and Modern Lyric. London: University of Califoria Press.

Titiev, M. (1970). Ethnology: The Tewa World: Space, Time, Being, and Becoming in a Pueblo Society. American Anthropologist 72(5): 1140-1141.

Tschumi, B. (1975). Questions of Space: The Architecture Paradox of the Pyramid and the Labyrinth. In Hays, K. M. (ed)(1998). Architecture Theory Since 1968, ed. K. M. Hays, (pp 219-242). Cambridge and London: The MIT Press.

Whittaker, J. (1968). The "Eternity" of the Platonic Forms. Phronesis, 13(2): 131-144

Wölfflin, H. (1886) Prolegomena to a Psycholog of Architecture. (ph.D.,) In Mallgrave, H. F., Ikonomou E., ed. \& trans., (1994). Empathy. Form, and Sace: Problems in German Aesthetics, $1973-1893$ (pp. 149-192). Santa Monica: Getty Center for the hisoty of Art and the Humanities.

- (1932). Principles of Art History: The Problem of the Development of Style in Later Art. (Hottinger, M. D., Trans). New York: Dover Pulications. (Originally published, 1915).

- (1952). Classic Art. An Introduction to the Italian Renaissance. Translated from the 8th German Edition (Benno Schwabe \& Co, Basle 1948) by Peter and Linda Murray (Phaidon Press, London 1952, 2nd Edn 1953).

- (1967). Renaissance and Baroque. USA: Cornell University Press (Originally published 1961)

Worringer, W. (1967). Abstraction and Empathy; A Contribution to the Psy- 
chology of Style (M. Bullock, Trans.). Cleveland: Meridian Books. (Originally published, 1901).

Yeager, K. L. (1998). Nietssche, Plato, Heraclitus and the pursuit of illuminate dwelling. History of Political Thought 19: 621-640.

Young, J. (2010). Friedrich Nietzsche: a philosophical biography. Cacbridge, england: Cambridge University Press.

Zelevansky, L. \& Hillings, V. L., (2004). Beyond geometry: experiments in form, 1940s-70s. Cambridge, MA: MIT Press.

Zumthor, P. (1998). Thinking Arcbitecture. (Oberli-Turner, M. Trans.). Baden, Switzerland: Lars Müller. 